\title{
LANDSLIDE INDUCED GRAVITATIVE DEBRIS FLOW IN
}

\section{NATURAL TERRAIN}

\author{
Submitted by \\ Bhuwani Prasad Paudel, B. Eng. \\ University of Roorkee, India
}

A thesis submitted to the Faculty of Graduate Studies and Research in partial fulfillment of the requirement for the degree of Master of Applied Science

\author{
Department of Civil and Environmental Engineering \\ Carleton University \\ Ottawa, Ontario
}

(C) Bhuwani Paudel, 2004

The Master of Applied Science in Civil Engineering is a joint program with the University of Ottawa, administrated by the Ottawa-Carleton Institute of Civil Engineering 


$\begin{array}{ll}\begin{array}{l}\text { Library and } \\ \text { Archives Canada }\end{array} & \begin{array}{l}\text { Bibliothèque et } \\ \text { Archives Canada }\end{array} \\ \begin{array}{l}\text { Published Heritage } \\ \text { Branch }\end{array} & \begin{array}{l}\text { Direction du } \\ \text { Patrimoine de l'édition }\end{array} \\ \begin{array}{l}\text { 395 Wellington Street } \\ \text { Ottawa ON K1A 0N4 } \\ \text { Canada }\end{array} & \begin{array}{l}\text { 395, rue Wellington } \\ \text { Ottawa ON K1A ON4 } \\ \text { Canada }\end{array}\end{array}$

Your file Votre référence ISBN: 0-612-97435-9 Our file Notre référence ISBN: 0-612-97435-9

The author has granted a nonexclusive license allowing the Library and Archives Canada to reproduce, loan, distribute or sell copies of this thesis in microform, paper or electronic formats.

The author retains ownership of the copyright in this thesis. Neither the thesis nor substantial extracts from it may be printed or otherwise reproduced without the author's permission.
L'auteur a accordé une licence non exclusive permettant à la Bibliothèque et Archives Canada de reproduire, prêter, distribuer ou vendre des copies de cette thèse sous la forme de microfiche/film, de reproduction sur papier ou sur format électronique.

L'auteur conserve la propriété du droit d'auteur qui protège cette thèse. $\mathrm{Ni}$ la thèse ni des extraits substantiels de celle-ci ne doivent être imprimés ou aturement reproduits sans son autorisation.
In compliance with the Canadian Privacy Act some supporting forms may have been removed from this thesis.

While these forms may be included in the document page count, their removal does not represent any loss of content from the thesis.
Conformément à la loi canadienne sur la protection de la vie privée, quelques formulaires secondaires ont été enlevés de cette thèse.

Bien que ces formulaires aient inclus dans la pagination, il n'y aura aucun contenu manquant. 
Dedicated to

my father Tirtha Prasad and mother Chet Maya 


\begin{abstract}
A gravitative debris flow is formed by an initial landslide that turns into a debris flow. During a wet season, the water content in the loose material at high elevation in a sloping terrain causes the material to decrease in strength such that an initial slide occurs. As the landslide mass slides down the valley, it experiences mechanical disturbance that leads to softening or liquefaction of the material. Consequently, further downslope movement of the softened or liquefied material is characterized with high mobility known as a debris flow. The high mobility leads to large runout distance over which destruction will occur.
\end{abstract}

The study in this thesis consists of two case studies of landslides in natural slope. The first landslide transformed into a debris flow while the second one did not. Several numerical models (Slope/W, FLAC, DAN and FLO-2D) have been applied for the analysis of these case records. Based on the findings of the case records, a parametric study has been conducted to investigate the effects of the soil parameters and the natural terrain inclination on the runout distance of a debris flow. The study leads to the following conclusions. (1) The friction model of the dynamic analysis of Hungr (1995) gives the most satisfactory result for this type of debris flow. (2) The runout distance increases with the decrease of the angle of friction mobilized after the initial landslide or with the increase in the natural terrain inclination. (3) The results of the parametric study have been compared to the observed runout distance of 28 debris flows and reasonable agreement has been obtained. 


\section{ACKNOWLEDGEMENT}

The author would like to express his sincere gratitude to people who have made direct or indirect contribution during the period of his research and studies. Of all, the single individual that has influenced the author the most is his supervisor Prof Dr. K. T. Law, whose tireless efforts in keeping the author in proper research track and showing proper angles to attack complex research problems at difficult and crucial times deserve great respect.

Great appreciation goes to Geotechnical Engineering Office in Hong Kong for field observation reports of Lai Pui Street landslide and also granting permission to use the DAN simulation program for this research. The author wants to extend many thanks to Department of Roads, Nepal; especially Mr. Shiva Raj Adhikari for taking personal efforts for providing valuable report on the Barabensi landslide.

The author would like to express his sincere thanks to Prof S. Sivathayalan, Professor E. Evgin, and Prof. V. K. Garga, of Ottawa Carleton Institute of Civil Engineering for their contributions in providing valuable knowledge in various fields that are important to the author.

Special thanks go to his friends Pramod Dhakal, Prashanta Dhakal and Ram Acharya for helping him on an ongoing basis during the completion of his studies. My many thanks go to the members of Nepalese Community in Ottawa whose help, support and encouragements have made Ottawa a great home away from home. Special thanks go to Anup Pradhananga in lending his computer expertise to the author. 


\section{CONTENTS}

Abstract

$\begin{array}{ll}\text { Acknowledgement } & \text { ii }\end{array}$

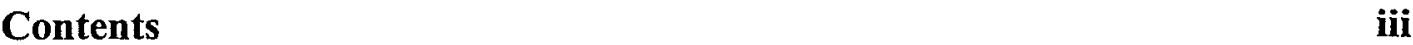

List of Figures $\quad$ ix

List of Tables $\quad$ xiii

1 Introduction 1

$\begin{array}{ll}1.1 & \text { Landslides and debris flow }\end{array}$

1.2 Scope and objective 3

$\begin{array}{lll}1.3 & \text { Methodology of study } & 4\end{array}$

1.4 Thesis organization 4

2 Literature Review 6

$\begin{array}{lll}2.1 & \text { Landslides } & 6\end{array}$

$\begin{array}{ll}\text { 2.1.1 Definition } & 6\end{array}$

$\begin{array}{ll}\text { 2.1.2 Types of landslides } & 7\end{array}$

$\begin{array}{lll}2.1 .3 & \text { Triggers of landslides } & 11\end{array}$

$\begin{array}{lll}2.2 & \text { Mechanism of slope failure } & 13\end{array}$

$\begin{array}{ll}2.3 & \text { Analysis of slope failure and landslides } \\ \end{array}$ 
$\begin{array}{lll}2.4 .1 & \text { Definition } & 17\end{array}$

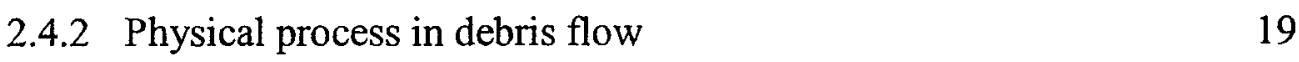

$\begin{array}{ll}2.4 .3 & \text { Types of debris flow }\end{array}$

2.4.4 Triggering of debris flow 24

2.4.5 Debris flow triggered from landslide 28

2.4.6 Influence of other factors for debris flow formation 29

2.4.7 Runout distance and travel angle 34

2.4.8 Runout distance of debris flow 35

3 Modeling of Landslide and Debris flow 36

$\begin{array}{lll}3.1 & \text { Introduction } & 36\end{array}$

$\begin{array}{lll}3.2 & \text { Slope/W } & 36\end{array}$

$\begin{array}{lll}3.3 & \text { FLAC } & 37\end{array}$

$\begin{array}{lll}3.4 & \text { DAN } & 39\end{array}$

3.4.1. Rheology used in the model 41

$\begin{array}{lll}3.5 & \text { FLO-2D } & 44\end{array}$

$\begin{array}{lll}\text { 3.5.1 Debris flow simulation } & 48\end{array}$

3.5.2 Assumptions and limitations of the model 54

$\begin{array}{lll}3.6 & \text { Summary } & 57\end{array}$ 
$\begin{array}{lll}4.1 & \text { Site description } & 60\end{array}$

$\begin{array}{lll}4.1 .1 & \text { Location } & 60\end{array}$

$\begin{array}{lll}4.1 .2 & \text { History } & 60\end{array}$

$\begin{array}{lll}\text { 4.1.3 Topography } & 64\end{array}$

4.1.4 Morphology $\quad 66$

$\begin{array}{lll}\text { 4.1.5 Geomorphology } & 69\end{array}$

$\begin{array}{lll}4.1 .6 & \text { Geology } & 72\end{array}$

$\begin{array}{lll}4.1 .7 & \text { Rainfall } & 74\end{array}$

$\begin{array}{lll}4.1 .8 & \text { Hydrology } & 75\end{array}$

$\begin{array}{lll}4.1 .9 & \text { Failure events } & 76\end{array}$

$\begin{array}{ll}\text { 4.1.10 Laboratory observation } & 77\end{array}$

$\begin{array}{lll}4.2 & \text { Analysis } & 77\end{array}$

4.2.1 Using Slope/W for landslide initiation 78

4.2.2 Using FLAC for landslide initiation $\quad 82$

$\begin{array}{lll}\text { 4.2.3 Dynamic analysis } & 85\end{array}$

$\begin{array}{ll}\text { 4.2.4 Analysis from FLO-2D } & 97\end{array}$

$\begin{array}{lll}4.3 & \text { Summary } & 104\end{array}$ 
5.1 Site description

5.1.1 Location

5.1.2 History of the landslide

5.1.3 Topography

5.1.4 Morphology

5.1.5 Geomorphology

5.1.6 Geotechnical investigation

5.1.7 Resistivity sounding and profiling

5.1.8 Hydrology

5.1.9 Climate

5.1.11 Soil index properties 
6.1 Introduction

6.2 General description

6.2.1 Definition of terms

6.2.2 Pore pressure and Cohesion

6.2.3 Friction

6.2.4 Sets of parameters

$6.3 \quad$ Results

6.3.1 Constant height and varying slope

6.3.2 Constant horizontal distance and changing natural terrain inclination

6.3.3 Friction in different terrain inclination

6.3.4 Pore pressure

6.3.5 Different combinations of pore pressure and cohesion

6.3.6 Natural terrain inclination and friction angle for long slope

6.4 Comparison with field observation

6.4.1 Comparison chart

6.4.2 Discussion 
7 Summary, Conclusions and Recommendations

7.1 Summary

7.2 Conclusions

173

7.3 Recommendations

174

References

Appendix

186

viii 


\section{LIST OF FIGURES}

Figure 2. 1 Typical landslide and its various components (Figure adopted from Lara 2000, after IAEG Commission on Landslide (1990)) 8

$\begin{array}{lr}\text { Figure 2. } 2 \text { Single- slip surface failure } & 9\end{array}$

$\begin{array}{ll}\text { Figure 2. } 3 \text { Multi-slip surface failures } & 9\end{array}$

Figure 2. 4 Classification of debris flow (Takahashi 2000) 24

Figure 3. 1 Slope model in FLAC for stability analysis 38

Figure 4. 1 Location of the landslide source (Maunsell, 2002) 62

Figure 4. 2 Aerial photograph of landslide area (Maunsell, 2002) 63

Figure 4. 3 Aerial photograph before the landslide (Maunsell, 2002) 64

Figure 4. 4 Longitudinal profile of landslide source and debris trail (Maunsell, 2002

Figure 4. 5 Geomorphology of the landslide area (Maunsell, 2002)

Figure 4. 6 Scarp of the landslide (Maunsell, 2002)

Figure 4. 7 Rainfall intensity in 15 minute duration (Maunsell, 2002)

Figure 4. 8 Cross-section of Lai Pui Street landslide for Slope/ W analysis

Figure 4. 9 Lai Pui Street landslide grid discrete model 
Figure 4. 11 Landslide mass is divided into blocks

Figure 4. 12 Polynomial fitting for width of debris flow trail

Figure 4. 13 Longitudinal Profile of Lai Pui Street landslide for analysis

Figure 4. 14 Debris flow velocity and runout distance from friction rheology 94

Figure 4. 15 Velocity and runout distance from Voellmy rheology in DAN 94

Figure 4. 16 The debris flow runout distance for a turbulent factor of

$500 \mathrm{~m} / \mathrm{s} 2$

96

Figure 4. 17 Grid of $10 \mathrm{mx} 10 \mathrm{~m}$ size for topography simulation

Figure 4. 18 Grid element maximum velocity 106

Figure 4. 19 Grid system maximum flow depth

Figure 4. 20 final flood plain flow depth

Figure 5. 1 Barabensi landslide location in Nepal

Figure 5. 2 Landslide areas above the bank of Sun Koshi River

(NEPECON 2002)

Figure 5. 3 Physical feature of the Barabensi landslide (NEPECON 2000)

Figure 5. 4 Barabensi landside Profile A (NEPECON 2000)

Figure 5. 5 Barabensi landslide Profile B

Figure 5. 6 Profile A for slope stability analysis 
Figure 5. 7 Stability analysis of slope profile A of Barabensi

landslide with Morgenstern Price Method

Figure 5. 8 Stability analysis of Profile A from Morgenstern Price Method

$$
(\mathrm{ru}=0.07)
$$

Figure 5. 9 Slope model for Profile B, Barabensi landslide

Figure 5. 10 Slope stability using Morgenstern and Price method at $r u=0.0$

Figure 5. 11 Stability analysis for slope Profile B using Morgenstern and Price method with $\mathrm{ru}=0.12$

Figure 5. 12 Slope model for Profile A, Barabensi Landslide

Figure 5. 13 Displacement at failure of Profile A, Barabensi Landslide

Figure 5. 14 Discretized slope model for Profile B of Barabensi Landslide

Figure 5. 15 Displacement at failure of Profile A, Barabensi Landslide

Figure 5. 16 Profile A of Barabensi landslide

Figure 5. 17 The landslide movement of profile B Barabensi landslide

Figure 5. 18 Profile B of Barabensi landslide

Figure 5. 19 The landslide movement of Profile B, Barabensi landslide

Figure 6. 1 Natural terrain inclination and runout distance definition

Figure 6. 2 Modified runout distance of debris flow vs natural

terrain inclination 
Figure 6. 3 Modified runout distance vs terrain inclination for long slope of horizontal distance of $2000 \mathrm{~m}$

Figure 6. 4 Modified runout distance vs mobilized friction angle for different terrain inclination

Figure 6. 5 Runout distance vs pore pressure at terrain inclination $=30^{\circ}$

Figure 6. 6 Modified runout distance vs pore pressure ratio at terrain

$$
\text { inclination }=41^{\circ}
$$

Figure 6. 7 Runout distance vs natural terrain inclination at different mobilized friction angles

Figure 6. 8 Runout distance comparison of observed and estimated runout distance of the November 1993 debris flow on Lantau Island

Figure 6.9 Lantau Island area B (Wong et al. 1996)

Figure 6. 10 Lantau Island area A (Wong et al.1996) 


\section{LIST OF TABLES}

Table 2. 1 Terms for different parts of landslides

Table 2. 2 Classification of terms for mass movement (Varnes 1978) 21

Table 2. 3 Classification of debris flow according to Hungr et al. (2001) 22

Table 3. 1 Observed value for momentum equation term

(after Henderson1996) (FLO-2D Manual 2001)

Table 3. 2 Topography and selection of the momentum equation terms

(O'Brien and Julin 2003)

Table 3. 3 Surface roughness and coefficient $K$

(FLO -2D Manual, Woolhiser, 1975)

Table 3. 4 Yield stress and viscosity as a function of sediment concentration 55

Table 3. 5 The mudflow behavior as a function of sediment concentration

(FLO-2D manual 2001)

Table 4. 1 Input parameters for Slope/W

Table 4. 2 Input parameters for FLAC

Table 4. 3 Division of the landslide in blocks

Table 4. 4 Longitudinal profile (Maunsell 2002)

Table 4. 5 Polynomial coefficients 
Table 4. 6 Distance and elevation from source

Table 4. 7 Input parameters for DAN

Table 4. 8 Rainfall incident

Table 4. 9 Concentration in different saturation condition with

up stream runoff

102

Table 4. 10 Input Hydrograph

103

Table 5. 1 Soil parameters

Table 5. 2 Input parameters in Slope /W

Table 5. 3 Input parameters in FLAC

Table 5. 4 Result from FLAC

Table 6. 1 Sets of study

Table 6. 2 Runout distance for different cohesion and pore pressure

Table 6. 3 Different combination of cohesion and friction for runout distance 157

Table 6. 4 Debris flow with gravitational mode

Table 6. 5 Debris flows with hydraulic mode

Table 6. 6 Debris flows with mixed mode 


\section{CHAPTER 1}

\section{INTRODUCTION}

Landslides are one of the most devastating natural calamities humans have been encountering ever since their existence on earth. Landslides cause loss of lives and properties every year around the world, and they are particularly devastating in hilly regions of the world. Even in developed countries like the United States and Canada, landslides cause losses. In the United States, on an average 50 people lose their lives from landslides every year (Paul and Elliot 2001). In Canada, between 1840 to 1999, 570 people lost their lives due to landslides (Evans 2000). The impact on poor and hilly countries is more acute. For example, in the monsoon of 2002, landslides killed 244 persons, displaced 9,063 families, destroyed or damaged 3,359 houses, and forced thousands of people to be displaced in Nepal. The total loss could have been much higher than reported as many cases go unnoticed due to difficulties in reaching and getting information from the affected areas (Nepal Red Cross Society 2003). One of the most hazardous forms of landslides is debris flow. Hence, an ability to predict the initiation of debris flow and its runout distance in natural terrain is crucial for saving lives and infrastructures. This chapter introduces the problems associated with debris flows and outlines the scope and objectives of the research work reported in this thesis. 


\subsection{Landslides and debris flow}

The movements of soil mass from the upper reach to the lower reach caused by gravity force as a result of instabilities of the slope material is called landslide. Landslides are divided in three main categories: slides, flows, and falls (Bromhead 1986). Slides move in a discrete boundary shear force, and sliding mass remains in contact with underlying parental rock or soil. In flows, soil moves without concentration of boundary shear, and the mass becomes an aggregate; flows may remain in contact with the parent rock or soil mass. Falls are droppings of material that are separated from the parental rock or soil.

The failure soil mass may change into different types of landslide along its path due to various factors. For example, a fall may change into a flow or a slide after impact on the base, depending on the dynamic strength, enclosed air and water, and height above the base or available potential energy of the soil mass (Bromhead 1986, Iverson 1997). A fall after impact can be divided into a primary slide and a secondary slide. A primary slide involves new materials from erosion, and a secondary slide involves mixing of existing slide mass and water.

The shape of movement of a landslide depends on the type, moisture content, and pore pressure of the soil mass. In soft soil, the sliding surface takes the shape of nearly an arc of a circle. A landslide flowing on a stratified deposit, however, generally takes a flat shape. All other shapes are combinations of these two extremes.

Among all landslides, the debris flow is the most devastating. A debris flow is a flow of fluid and solid-soil and transfer of momentum between each other. Landslides 
change into debris flow in special circumstances. Research on identifying the conditions that change a landslide into a debris flow is still a very promising area because of the complexity in nature and destructive power of the process.

\subsection{Scope and objective}

As mentioned earlier, a debris flow is highly hazardous compared to a simple landslide. Hence, it is worthwhile to conduct research so that the result could be used to save the potential loss that debris flows would bring. Against this background, the objective of this thesis is to study the various consequences of landslides changing into a debris flow and its runout distance. The study also includes the role of different parameters such as friction, cohesion, and natural terrain inclination that cause an initial failure mass to change into a debris flow and travel large distance.

The scope of this research is to study two specific cases and a cluster of cases of landslides. One case record and a cluster of landslides are taken from Hong Kong and another case record is taken from Nepal. All the records are in the hilly regions of the world. Information available for the case records is reviewed. Using computer software, back analysis of the landslide mass is conducted and the prevailing parameters for debris flow formation have been identified. Furthermore, parametric studies of the factors influencing the formation of the debris flow and runout distance from a landslide have been carried out. Besides, the effects of the parameters have been compared with observation from a number of landslides.

The objectives of this study are to evaluate various parameters that changes a landslide into a debris flow, to determine the role of different parameters for runout 
distance of the debris flow, to make some recommendations on the most appropriate mathematical model for analyzing the runout distance of debris flows, and to develop a relationship of the influence of various parameters on the runout distance.

\subsection{Methodology of study}

The methodology of study consists of the following:

- Review of research work related to landslide and debris flow.

- Review of field and laboratory reports for two drastically different landslides, one from Nepal and the other from Hong Kong.

- Back analysis of landside and debris flow in order to ascertain parameters of landslide and debris formation.

- Study of different strength parameters of soil and natural terrain inclination of the debris flow path that influence debris flow movement.

\subsection{Thesis organization}

The thesis is organized into seven chapters. Chapter 2 elaborates and reviews research on landslides and landslide-induced debris flows.

Chapter 3 describes modeling techniques of landslide in different stages. Application of different computer software Slope/W and FLAC for stability analysis and DAN, and FLO- 2D for runout and inundation characteristics of landslide induced debris flow is discussed. 
Chapter 4 focuses on detailed study of the Lai Pui Street landslide in Hong Kong, which includes field report review and the landslide incident. It also presents a review on the rainfall and ground saturation condition in the study area and, slope stability analysis from Slope/W and FLAC, and back-analysis of debris flow from DAN and FLO-2D. Factors affecting stability of landslide and debris flow formation are identified. Use of numerical models for estimating similar types of debris flow initiation from the available rainfall and saturation condition is given.

Chapter 5 presents a case study on a landslide of different nature, Barabensi Landslide in Nepal. The field report of the landslide has been reviewed. Back analysis of the slope based on Slope/W and FLAC computer software has been conducted and DAN based analysis of the movement of the soil mass after failure from its initial position is provided.

In Chapter 6, the results of a parametric study on runout distance of debris flow are described. The influence of natural terrain inclination and soil characteristics on the runout distance is also described. A chart of runout distance related to natural terrain inclination, and soil characteristics are developed. A case history of Lantau Island Hong Kong is reviewed and compared with the developed chart.

In Chapter 7, the summary and conclusions are given. Recommendations for further research are also given in this chapter of the thesis. 


\section{CHAPTER 2}

\section{LITERATURE REVIEW}

In this chapter, research done in landslides and debris flows from different researchers is reviewed and presented. Various models for stability and runout distance of landslide are focused.

\subsection{Landslides}

\subsubsection{Definition}

Landslide is a natural process of soil movement. In a natural or a man-made slope, when the shearing resistance is insufficient to counter balance the forces causing movement along any surface within it, the soil starts moving along that surface. A natural slope, which is initially stable, can be disturbed by alteration of the slope geometry through cutting or filling of the slope and by alteration of the resisting force. In addition, several other internal and external factors can also lead to the weakening of the soil to the state that the load can no longer be resisted. The external forces disturbing the slope may result from seismic activity, pore water pressure, deforestation, valley filling, rainfall, and construction of water retaining structures. These external agents may cause both short-term and long-term effects on the shear strength of the soil material. Weathering, groundwater conditions, and other stress factors can change the internal condition of the soil. Thus, a natural slope may fail because of one or many of the 
internal and external factors (Chowdhury1978). Figure 2.1 shows a typical type of landslide and Table 2.1 gives the terms for its various parts.

\subsubsection{Types of landslides}

\subsubsection{Types of landslides according to slip surface}

Landslides are classified into rotational, translational, and compound types according to movements from the initial position. The movement of landslide from the initial position depends on in situ soil conditions.

A rotational type of landslide occurs both in drained and undrained conditions and in uniform fills or natural strata. Rotational failure occurs specifically in clay or shale and sometimes in silt (Terzaghi and Peck 1948). The movement of the soil can become very fast in this type of landslide such as several meters per second in clay or shale, but in rock the may be a few centimeters a year to several meters per month (Buma and Van Asch 1996). Rotational movement may trap air and water into the sliding mass to produce a high fluidizing effect.

Figure 2.2 and Figure 2.3 shows the mode of the failure of rotational slides in single and multiple rotational slips. 


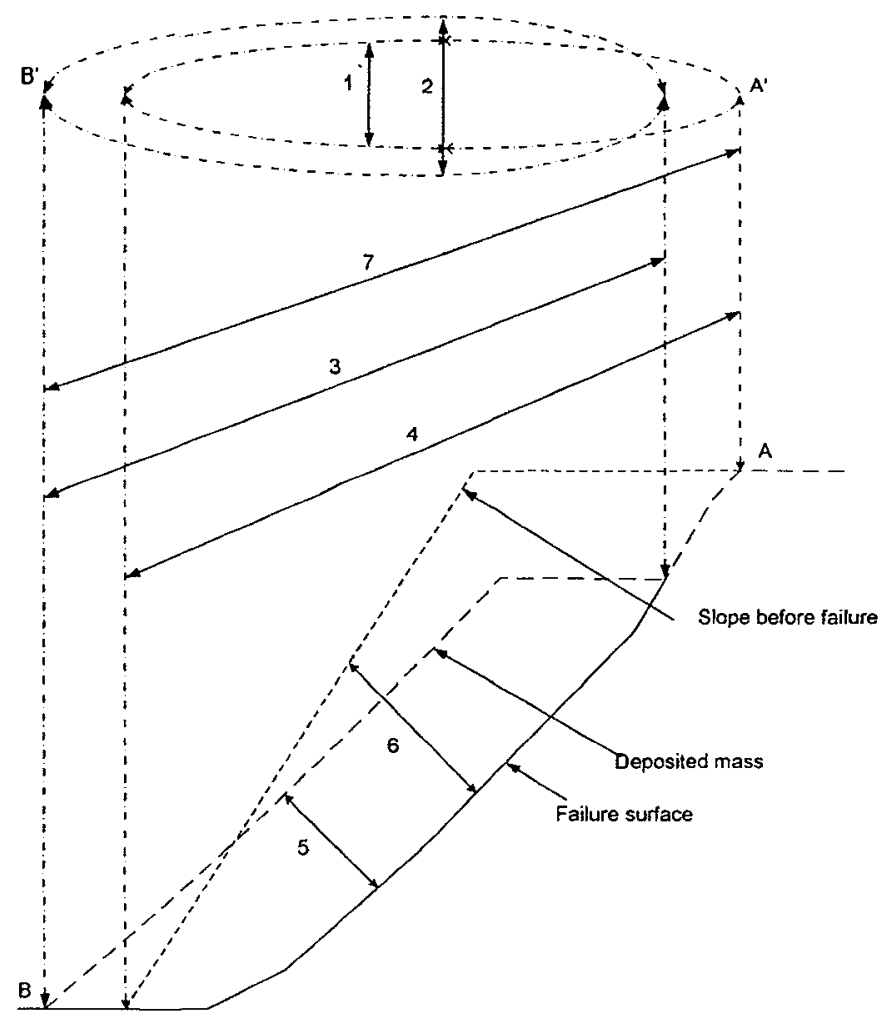

Figure 2. 1 Typical landslide and its various components (Figure adopted from Lara 2000, after IAEG Commission on Landslide (1990))

Table 2. 1 Terms for different parts of landslides

\begin{tabular}{|c|l|c|}
\hline Number & Term & Notation \\
\hline 1 & Width of displaced mass & $\mathrm{W}_{\mathrm{d}}$ \\
2 & Width of surface of rapture & $\mathrm{W}_{\mathrm{f}}$ \\
3 & Length of displaced mass & $\mathrm{L}_{\mathrm{d}}$ \\
4 & Length of surface of rapture & $\mathrm{L}_{\mathrm{f}}$ \\
5 & Depth of displaced mass & $\mathrm{D}_{\mathrm{d}}$ \\
6 & Depth of surface of rapture & $\mathrm{D}_{\mathrm{f}}$ \\
7 & Total length & $\mathrm{L}$ \\
\hline
\end{tabular}




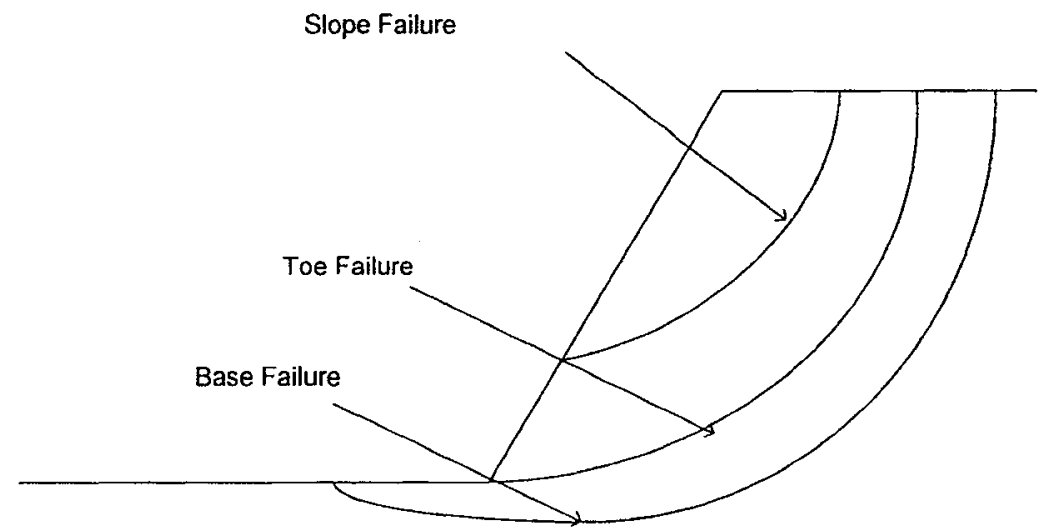

Figure 2. 2 Single- slip surface failure (Buma and Van Asch 1996)

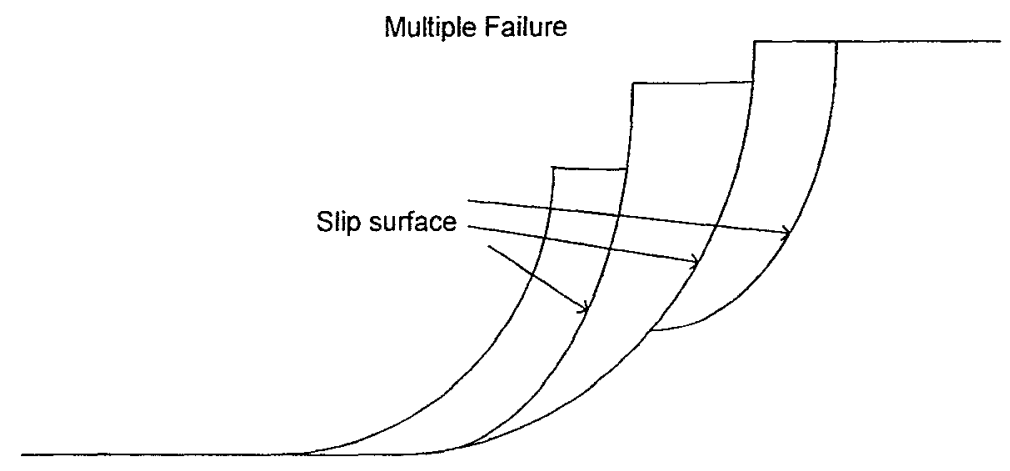

Figure 2. 3 Multi-slip surface failures( Buma and Van Asch 1996)

A translational slide moves along a planar slip surface mostly controlled by a weakness plane of unstable soil mass structure (Skempton and Hutchinson 1969). The weakness plane can form on the impervious bedrock interface as a result of seepage or high pore pressure. If there is strong bedrock along or near the slip surface such as the Barabensi landslide in Nepal and the Lai Pui Street landslide in Hong Kong (both being studied in this thesis), translational types of landslide will be formed. Sometimes the 
weak layer may liquefy such as with the quick clay landslide in Furrer, Norway (Skempton and Hutchinson 1969).

A compound slide is intermediate between a rotational and a translational slide. The slip surface may be a combination of a circular and a planar slip surface. As described by (Hutchinson 1988), the slip surface of this type of landslide is typical of slides consisting of curved or planar rearward part.

The speed of movement of a landslide is dependent on the brittleness index of the soil. Brittleness index is defined as the ratio of the difference of the peak strength and the residual strength to the peak strength Bishop (1967). If the brittleness index is low, landslide speed is moderate and if the brittleness index is high, the slide speed is high. In the Barabensi landslide, Nepal, the slipping layer is in clayey silt with low brittleness. On the other hand, the Lei Pui Street landslide in Hong Kong, the slip surface is in silty colluvium, which has a high brittleness index. Therefore, the Barabensi landslide moved slowly while the Lei Pui Street landslide moved rapidly.

\subsubsection{Types of landslide according to dispersion of slide mass}

According to slide mass dispersion, landslide is classified into sudden spread failure, earth flow, and flow slides (Lara 2000). This classification is based on the movement of the mass from its initial condition.

Sudden spread failure is a type of translational failures, which has dominant movement of lateral extension, influenced by shear and tensile fractures (Varnes 1978). This type of failure occurs in sensitive soil (Crawford and Eden 1967). Earthquakes can also trigger landslides of this type. 
An earth flow is a movement of already failed soil mass. The speed and thickness of the flow depends on the particle constituents in the moving mass. The speed of the mass may be as small as $0.1 \mathrm{~m} / \mathrm{s}$ and the failure mass can move even in a flat slope. A further classification is given in the debris section of this Chapter.

A flow slide has a rapid extensive runout in very gentle to horizontal ground. This type of movement takes place in highly porous and structurally weak bond materials under high pore pressure. The failure of the soil mass structure due to shear failure abruptly changes the mass into a semi-fluid. Highly porous silt and weak rock mass are prone to this type of soil movement. The Lei Pui Street landslide in Hong Kong can be categorized within this type of landslide after it moved some distance down slope. The distance traveled by the flow depends on brittleness index, geometry, slipping volume of the moving mass, and the topography of the sliding areas. This type of movement mostly occurs under high pore pressure in slide prone areas. In this category, the total mass of the slide liquefies and flows as a fluid.

\subsubsection{Triggers of landslides}

Landslides are triggered by many factors. Most landslide-triggering factors can be divided into four main categories. These are geological factors, hydrological factors, topography, and loading conditions. Geological factors include the past formation of cracks, creeping of underlying soil, glacial loading, and movement of subduction zone. Hydrological factors include rainfall, runoff, infiltration, permeability, and groundwater table. Topographical factors are slope geometry, vegetation, catchment area and drainage 
condition. Loading factors are direction, size, and types of loading such as earthquake load.

Landslide triggering factors are also grouped on the basis of long-term and shortterm instability conditions. Immediate disturbances like excavation and construction of structures, river cutting, earthquake, and rainfall erosion are factors for short-term instability and the natural phenomenon of slope changing morphology is a case of longterm instability. A short-term unstable slope may stem from man-made construction or natural process. Man-made unstable processes include excavations, embankment construction, earth dams, and spoil heaps. Natural conditions for unstable slope are topography, geology, material properties, and natural events like earthquake and rainfall.

Load increases from rainfall, moisture, man-made structures, or vegetation in the ground may trigger a landslide.

The time factor may reduce the stability of slopes. There are some time dependent factors, which affect slope stability (Bjerrum and Jorstad 1968). Such factors include presence of valley joints along which rock mass detached during previous landslides, rock joints formed during the formation of the valley in the past, and overburden pressure from geological processes. Joints on the surface and subsurface of rock play a vital role in erosion. More erosion takes place in deep joints, because of greater depth and long flow surface. Joints may release strain energy during the formation of joint in the rock, causing landslides (Ferguson 1974, Matheson 1972). The process of strain energy release during the formation of the joint in the rock also causes landslides. The presence of water in the joint and pore water pressure are major causes for the rock mass to detach at the joint. 
Earthquakes in marginally stable slopes may also trigger landslides. Earthquake load is a major landslide-triggering factor, due to the presence of periodic horizontal loading during earthquakes.

\subsection{Mechanism of slope failure}

The Coulomb failure criterion is commonly used for analysing slope failure as represented in Equation (2.1)

$$
\tau=c^{\prime}+\sigma^{\prime} \tan \phi^{\prime}
$$

where $\tau=$ mean shear stress acting on the failure surface, $\phi^{\prime}=$ angle of internal friction, $c^{\prime}=$ cohesion of soil, $\sigma^{\prime}=$ mean effective normal stress. The product of $\sigma^{\prime} \tan \phi^{\prime}$ is the frictional resistance along the failure plane of the soil. The cohesion c' is the resistance of soil particle dependent on various factors such as electrostatic, mechanical cementing of secondary minerals, matric suction and negative pore pressure or capillary action in the soil. Sometimes roots of vegetation and trees may also increase the cohesion. The cohesion tends to be destroyed if large soil displacements occur. Once the cohesion is destroyed, it is not easy to regain.

Pore pressure also changes the soil strength as it affects the effective stress. The effective pressure is given by $\sigma^{\prime}=\sigma-p$ where $p$ is the pore pressure given by $p=\gamma_{w} h$, where $\gamma_{w}$ is the unit weight of water and $h$ is height of water at the failure surface measured in $\mathrm{x}, \mathrm{y}$ and $\mathrm{z}$ coordinates.

Increase of pore pressure decreases the shear strength of the soil. The condition of pore pressure and normal stress as given in Equation 2.2 is known as liquefaction 
condition. Liquefaction is defined as the transformation of a granular material from a solid state into to a liquefied state due to pore pressure development within the soil mass (Youd 1993). In this condition, the normal stress gradient at any depth $\mathrm{z}$ is equal to the unit weight of the soil or the pressure gradient in the soil mass at that depth. In liquefaction, the vertical pore-pressure gradient equals the vertical gradient of the total normal stress $\sigma$, which equals to the unit weight of soil. In this case, the relation of pore pressure and normal stress rate and unit weight of the soil mass $\left(\gamma_{t}\right)$ is as given in Equation (2.2) (Iverson et al. 1997).

$$
\frac{\partial p}{\partial z}=\frac{\partial \sigma}{\partial z}=\gamma_{t}
$$

At this condition, $\sigma^{\prime}$ and $\mathrm{c}$ are equal to zero (cohesion strength is zero only for granular soil), and the soil behaves like a liquid. For example, during an earthquake or landslide, transient stressing may disrupt soil structure and cohesive bonds, elevate pore pressures, and partially or completely liquefy the soil (Holzer et al. 1989, Iverson and Lahusen 1989, Eckersley 1990).

Soil grains in the shearing zone start rearranging their position after liquefaction. If the shear strain rate is very low, the soil grains rearrange and the density of the soil will approach the critical state density. In this process, the soil reaches the critical state density regardless of its previous stress history, whether the soil be over-consolidated or normally consolidated. Dense soil dilates to reach the critical state and critical state density. Loose soil will contract to reach the critical state. If the undrained condition exists, excess pore pressure will be generated. This excess pore pressure plays a vital 
role to form debris flow from a landslide. This will be discussed in the subsequent section.

The ratio of strength to disturbing stress is known as the Factor of Safety (FS). FS can be written as the sum of the three dimensionless ratios $T_{f}, T_{w}, T_{c}$ in an infinite slope (Iverson 1992). The relation of FS and these dimensional ratios is given in Equation (2.3), (2.4), and (2.5)

$$
F S=T_{f}+T_{w}+T_{c}
$$

Where, $T_{f}=\tan \phi^{\prime} / \tan \theta$, ratio of frictional resisting strength to gravitational driving stress.

$$
T_{w}=\frac{\left[\frac{d}{y}-1\right] \frac{\partial p}{\partial y} \tan \phi^{\prime}}{\gamma_{t} \tan \theta}
$$

where, $T_{w}$ is the ratio of strength modification by groundwater to the gravitational driving stress.

$$
T_{c}=\frac{c^{\prime}}{\gamma_{t} Y \sin \theta}
$$

Where, $T_{c}$ is the ratio of cohesive strength to the gravitational driving stress, $\theta$ the angle of slope, $\phi^{\prime}$ the angle of internal friction, $Y$ the total height of the moving mass from failure surface, $d$ the height from surface to groundwater level in the $y$ direction. The watertable is assumed parallel to the slope surface so that along the surfaces above the failure surfaces with constant $p$ in an infinite slope represent the depth averaged total unit 
weight of saturated and unsaturated soil. If the resisting forces exceed the driving forces, FS $>1$ and the slope remains stable. For $\leq 1$, the slope is not stable and starts failing.

\subsection{Analysis of slope failure and landslides}

There are many methods to analyse slope stability. All the methods make some assumptions. For stability analysis of homogenous soil with circular rotational slip surface, Bishop's limit equilibrium method is the best choice. For non-homogenous soils or non-circular slip surfaces condition, Janbu's and Morgenstern and Price methods of stability analysis are more appropriate (Chowdhury 1978). Again, for a specified circular or non-circular slip surface, Janbu's method also provides reliable results (Chowdhury1978).

The strength reduction method is also used to analyse the factor of safety. This strength reduction method is still under study for its appropriateness for application (Dawson et al. 1999). In this model, landslide mass is placed back into its previous position and the consequence of landslide movement is studied, by reducing the strength of the sloping soil.

The probable failure incident of the slope can be analysed using failure consequences observed from similar slopes that previously failed. Back analysis enables the study of the condition of failure initiation of the previously failed slope. Such studies provide guidelines for further identification of the stability situation of existing natural and man-made slopes. 


\subsection{Debris flow}

\subsubsection{Definition}

Debris flow is a very rapid to extremely rapid flow of saturated non-plastic mass of debris (Hungr et al. 2001). Rickmers (1913) defined debris flow as:

"When a gentle slope of grit and shingle has been soaked like a sponge by rain or melting snows there may come a time when it bulges out and slides off in the manner of a bog-burst on Irish Moors. Slipping into channels and gullies, this mass is mixed with more water, attains a higher speed, and carries away soft material as well as rocks which it finds on its way. It is during this descent that the mud-spate generally acquires its characteristic composition, for only by movement can an even mixture of liquids and solids be maintained... a mud-spate may also be caused by the sudden bursting of a reservoir of water in the bed of a torrent (or the glacier above) which may thus be enabled to charge itself, for a short time, with an inordinate amount of loose material from the higher banks beyond the reach of normal floods."

“..... Operating with a minimum of water the mud-spate liquefies itself automatically when, during its descent, it has become too thick. Stopping for a while it dams up the water runlet in the gully and then proceeds again, repeating if needs be the process several times".

United State Geological Survey (1995) defines debris flow as follows:

"Some landslides move slowly and cause damage gradually, whereas others move so rapidly that they can destroy property and take lives suddenly and unexpectedly. 
Debris flows, sometimes referred to as mudslides, mudflows, lahars, or debris avalanches, are common types of fast-moving landslides. These flows generally occur during periods of intense rainfall or rapid snowmelt. They usually start on steep hillsides as shallow landslides that liquefy and accelerate to speeds that are typically about 10 mph, but can exceed $35 \mathrm{mph}$. The consistency of debris flow ranges from watery mud to thick, rocky mud that can carry large items such as boulders, trees, and cars. Debris flows from many different sources can combine in channels where their destructive power may be greatly increased. They continue flowing down hills and through channels, growing in volume with the addition of water, sand, mud, boulders, trees, and other materials. When the flows reach canyon mouths or flatter ground, the debris spreads over a broad area, sometimes accumulating in thick deposits that can wreak havoc in developed areas."

The above definitions show that debris flow is a severely destructive form of moving soil mass that could cause loss of lives and damage man-made structures.

Debris flow is a flow, which is a combination of solid and fluid sharing and transforming momentum from each other. Debris flow is different from other types of flow such as sediment flows, floods, turbidity currents, and rock avalanches. Sediment flow consists of sediment concentration in the flowing water. Rock avalanches consist of solid grains transferring momentum from each other. Flood and turbidity currents consist of fluid turbulence motion transferring momentum. Various flows are defined in different ways based on different considerations but debris flow is the mobility of solid and liquid flow simultaneously (Iverson et al. 1986, 1997). Particles involved in the flow 
may be of any size and shape that have completely lost their cohesion, but still maintain some inter-particle friction dependent on the concentration of solid particles.

\subsubsection{Physical process in debris flow}

Debris flow initiates in different ways but it exhibits the same physical character after full mobilization. Some debris flows are formed from bed erosion by water flowing with high velocity on a sloping land, and some of the debris flows originate from landslide mass mobilized with surface runoff. After initiation of a landslide, the debris is being remolded and diluted with water and is capable of flowing in a narrow channel. Debris flow may move large distances even in a confined channel if the slope is sufficiently steep.

Debris flow formation from landslides without external water and debris flow formation from bed erosion are two different phenomena and require different mathematical model for analysis (Takahashi 2000). A debris flow from external water from bed erosion is due to water flowing with high velocity on a sloping land. A debris flow from in situ moisture content requires sufficiently steep and long slope to mobilize.

\subsubsection{Types of debris flow}

The classification of debris flows is based on various parameters: speed, moisture content, material matrix, geometry, and physical settings. Varnes (1978) classified debris flows into two categories: "rapid" for velocity $>1.5 \mathrm{~m} /$ day and "less then rapid," for

velocity $<1.5 \mathrm{~m} /$ day. Table 2.2 shows the classification of movement mechanism of sliding mass proposed by Varnes (1978). 
Cruden and Varnes (1996) classified landslides according to the velocity of the movement. They provide seven categories starting from extremely rapid to extremely slow. Extremely rapid debris flows move at $5 \mathrm{~m} / \mathrm{sec}$, very rapid at $3 \mathrm{~m} / \mathrm{min}$, rapid at $1.8 \mathrm{~m} /$ month, moderate at $13 \mathrm{~m} /$ month, slow at $1.6 \mathrm{~m} /$ year, very slow at $16 \mathrm{~mm} /$ year, and extremely slow at $<16 \mathrm{~mm} /$ year.

Kang et al. (2003) classified debris flows into two broad categories based on the initiating forces on the sliding mass. These are gravitative and hydraulic debris flows. A debris flow mobilized by soil sliding and rock falling is categorized into the gravitative debris flow. Hydraulic debris flows develop in creeks or water flowing surfaces where large amount of sediment are formed from scouring and erosion. Hydraulic debris flow usually occurs in dilute form. This type of debris flow is commonly found in Japan and Russia (Kang et al. (2003)

Wong et al. (1997) further classified gravitative debris flows into three categories based on movement of the debris. These are gravitational movement, hydraulic movement, and mixed movement. Gravitational movement is the movement of the debris mass with self-weight, which includes sliding, disintegration, collision, bouncing, and rolling of the soil mass. Erosion and deposition are also included in this type of landslide. Large landslide failures in planar sloping surfaces associated with small catchments fall under this category. Hydraulic movement is developed as a result of landslide mass mixing with surface running water. This movement occurs when a landslide mass encounters a large amount of surface running water. Debris concentration has been very low in this type of movement. Mixed movement is the contribution of debris flow movement from both hydraulic and gravitational movement. If it is difficult 
to identify whether a debris flow is gravitational or hydraulic, it falls into the mixed movement category.

Table 2. 2 Classification of terms for mass movement (Varnes 1978)

\begin{tabular}{|c|c|c|c|}
\hline Rate of Movement & Rock & Debris & Earth \\
\hline $\begin{array}{l}\text { Rapid and higher } \\
(>1.5 \mathrm{~m} / \text { day })\end{array}$ & $\begin{array}{l}\text { Rock flow } \\
\text { (creep, slope } \\
\text { sagging) }\end{array}$ & $\begin{array}{l}\text { Debris flow } \\
\text { debris } \\
\text { avalanche }\end{array}$ & $\begin{array}{l}\text { Wet sand and silt } \\
\text { flow rapid earth flow } \\
\text { loess flow dry sand } \\
\text { flow }\end{array}$ \\
\hline $\begin{array}{l}\text { Less then rapid } \\
(<1.5 \mathrm{~m} / \text { day })\end{array}$ & & $\begin{array}{l}\text { Solifluction } \\
\text { Soil creep } \\
\text { Block } \\
\text { stream }\end{array}$ & Earth flow \\
\hline
\end{tabular}

Hungr et al. (2001) classify landslide flow types according to material content in the landslides mass. Table 2.3 shows the classification of debris flow by Hungr et al. (2001). 
Table 2. 3 Classification of debris flow according to Hungr et al. (2001)

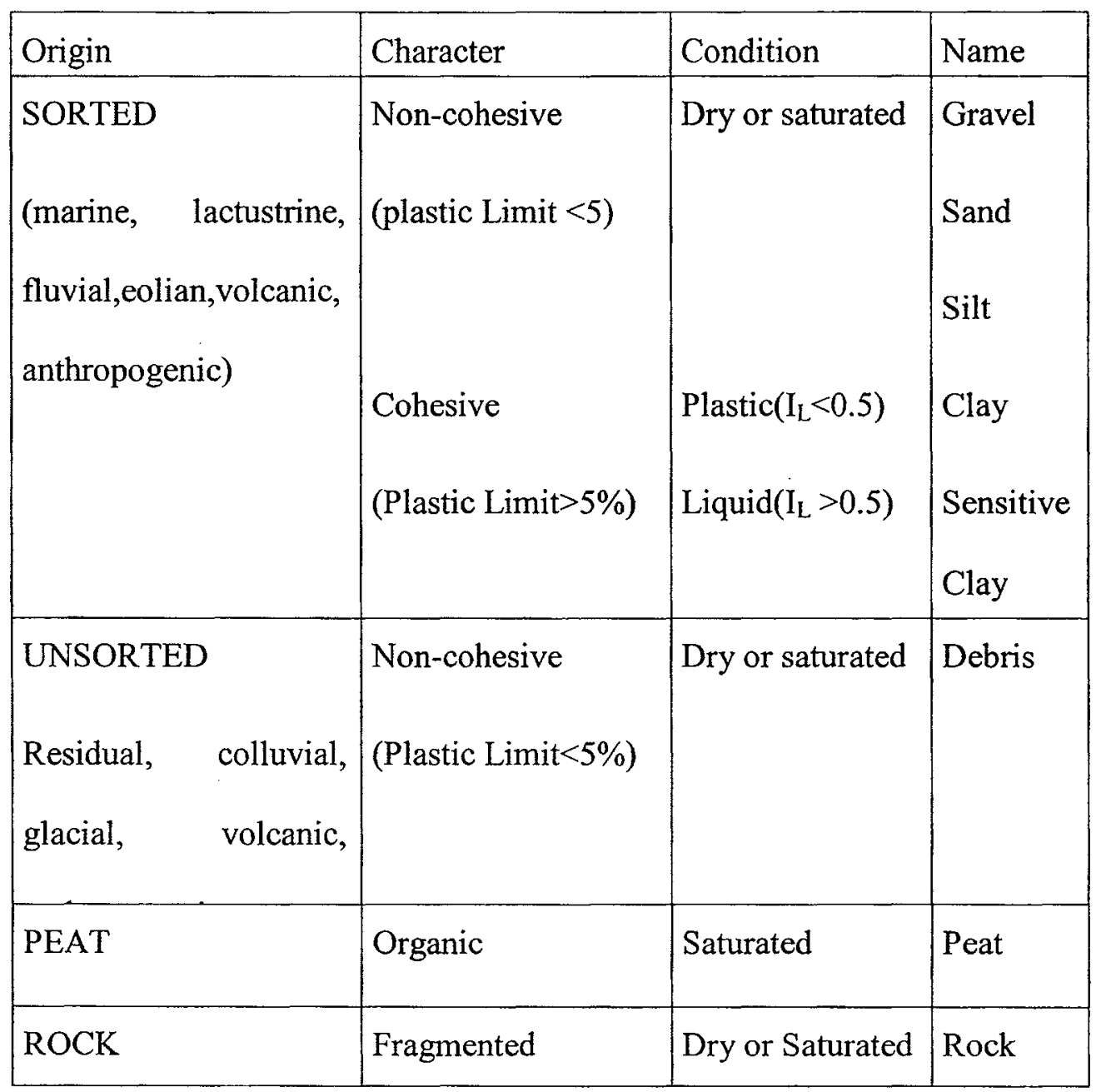

Takahashi (2000) classified debris flows into three different categories according to flow behavior. The Bagnold number, the Reynolds number and the sediment concentration are used for classifying into stony, viscous and muddy debris flows (Figure 2.4). The debris flow behavior depends on sediment concentration, particle size composition, depth of flow, and slope geometry of the flow path.

A stony type of debris flow is characterized by high concentration of large particles and low concentration of fine particles. The relative depth is small but the 
Bagnold number is large for this type of debris flow, and the stress is developed mainly from particle collision.

For a viscous debris flow, both the Reynolds number and the Bagnold number are small. In viscous debris flow, slurry of fine particle fills up the voids of the very coarse particles. A number of intermittent bores are formed in the flow path. The flow becomes mostly laminar and only the head of every surge is turbulent. There is no accumulation of large stones as in the case of stony types of debris flow. An example of this type of debris flow is the debris flow that occurs in Jiangjia area, China.

In the case of muddy type of debris flow, both the Reynolds number and the relative depth are large. This condition is satisfied when the sediment particles are in between large and small. There is no evidence of accumulation of large stones at the head of this type of debris flow.

Figure 2.4 shows the classification of debris flow with volumetric concentration 0.3 to 0.5 by (Takahashi 2000 ). He also suggests that if the coarse particle concentration is larger than 0.5 it becomes the dominant moving particle with enduring contact with each other. If the coarse particle concentration is smaller than 0.3 , stony and viscous types debris flows cannot occur. Large particles of debris cannot disperse in the entire depth of such dilute flow. In such a low concentration, stress produced by particle collision or by the squeezing flow of viscous interstitial fluid is insufficient to make large enough spaces to disperse the particle in the entire depth. In this condition, debris flow is separated into two layers, a lower particle concentration layer and an upper low concentration or clear water layer. Takahashi (2000) calls this type of debris flow as immature debris flow. 


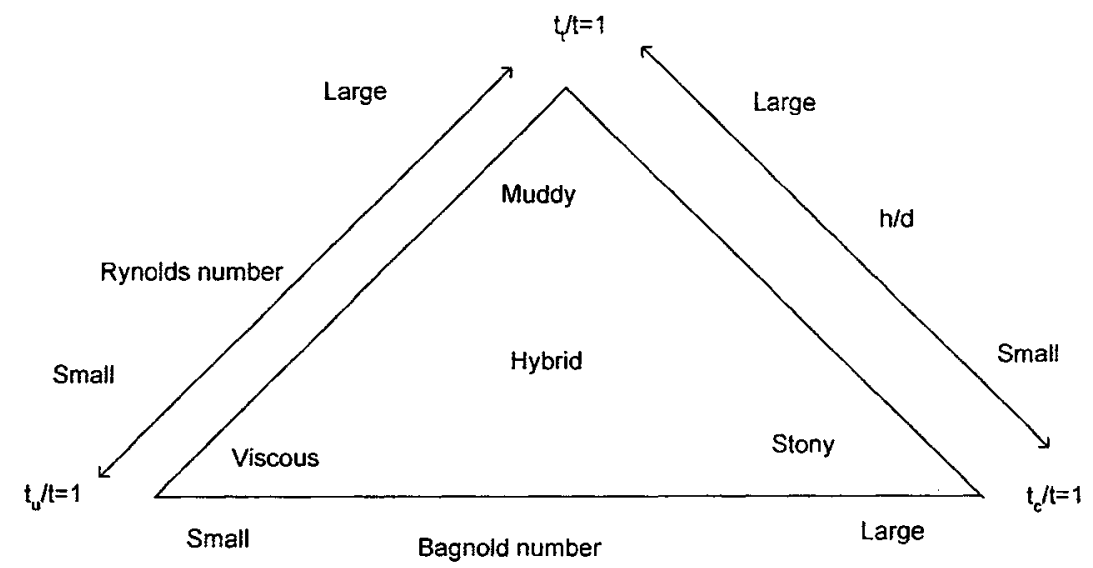

Figure 2. 4 Classification of debris flow (Takahashi et al. 2000)

\subsubsection{Triggering of debris flow}

The formation of debris flow is a complex phenomenon. Blackwelder (1928) listed some favorable conditions for debris flow formation. These are: abundant water, unconsolidated materials that become slippery when wet, slopes steep enough to induce mobility in the materials, and insufficient ground protection by forest. Insufficient protection of the ground by forest may not be a major factor for debris formation. There is evidence of debris flow formation even in dense forest while some landslides do not change into debris flows even when they initiate in bare ground. Pain (1972) studied landslides changing into debris flows in New Zealand and observed that out of 25 landslides in each of two topographies, 22 changed into debris flows in forest and 16 changed into debris flows in grassland. 
A debris flow may also be initiated from pyroclastic flows and flood erosion. Pierson et al. (1990) observed that debris can be formed from pyroclastic flows caused by melting snow and ice. O'Connor et al. (1997) observed that debris flow initiation from abrupt floods of water undermines and incorporates with ample amount of sediment. Johnson and Rodine(1984) observed that debris flows formed predominately from mobilization of landslides.

Water content and grain size distribution are taken as the major factors of debris formation by some researchers. The amount of water content in the soil mass influences the soil properties. Pore pressure and bulk density are changed in different water content in the soil mass. Water content influences cohesive strength, friction angle, and density in the soil. If these parameters decrease to the threshold value in a natural terrain, the soil mass changes into debris flow. Many researchers studied the influence of grainsize distribution for debris flow formation from landslides and found that poor sorting of the particles is considered one of the factors for formation of debris flow (Rodine and Johnson 1976).

Johnson and Rodine (1984) proposed a mobility index for predicting debris flow from in situ saturation condition of the sliding mass. The mobility index $M$ proposed by Rodiune (1984) is defined as in Equation (2.6)

$$
M=W_{f c} / W
$$

where, $W_{f c}$ is field capacity, and $W$ is in situ water content for mobilization. Field capacity $W_{f c}$ is the weight of water in the in situ soil divided by the saturated weight of soil. Johnson and Rodine (1984) also show that increase in water content decreases the 
cohesion, friction angle and unit weight of the in situ soil. The field capacity of clay rich soil is higher than that of sand rich soil. Clay rich soil has a higher mobility index about 1.03 compared to sand rich soil of 0.88 . The higher the mobility indexes the higher is the potential for formation of debris flow.

The mobility index only is not sufficient to explain debris flow from erosion and landslide transformation. Various factors are required to consider for debris flow formation. Due to the influence of different factors for formation of debris flow, a debris flow can easily form in sandy soil but sometimes does not form even in clayey soil. Slope geometry and other favorable conditions for mobilization of in situ moisture content are equally important for initiation of debris flow.

Mathewson et al. (1990) and Reid et al. (1997) observed that soil moisture, and pore water pressure responses from localized groundwater flow from adjacent bedrock are favorable conditions for the formation of debris flow. Cannon and Ellen (1988) studied the effect of prolonged moderate intensity rainfall on the formation of debris flow. This prolonged rainfall reduces the matric suction and destroyed cohesion ( $\mathrm{Li}$ et al. 2004). Campbell (1975) studied how bursts of high intensity rainfall cause debris flows. They found that high intensity rainfall develops a transient perched watertable that mobilizes the soil mass to form a debris flow. Prolonged intense rainfall and localized groundwater flow from adjacent bedrock cause immediate debris flow after sliding. This phenomenon arises from the positive pore pressure resulting from the mobilization of debris from the landslide (Iverson et al. 1997).

Johnson and Rodine (1984) pointed out that landslides of shallow depth are easily changed into debris flows due to the high mobility index. Landslides of greater depth 
have more consolidation, and lower mobility index, and less chance of transformation into a debris flow. Ayotte (1999) made the same observation after studying landslides in Hong Kong and Iverson et al. (1997) after studying landslides in US. This observation also supports the Lei Pui Street landslide changing into a debris flow, which had maximum depth of $1.5 \mathrm{~m}$. The Barabensi landslide did not change into a debris flow because the maximum depth is approximately $8 \mathrm{~m}$. The higher the depth of landslide, the lower is the chance of debris flow formation.

The transformation of landslide into a debris flow is highly influenced by the slope geometry of the flow path. The steeper the natural terrain, the more is the energy for the slide mass to transform into a debris flow. The combination of the terrain inclination of the debris flow path and the sliding soil characteristics may be helpful for predicting the runout distance of a debris flow. The influences of these parameters are studied in Chapter 6.

One method of predicting debris flow formation is from historical records. This method may not be realistic due to changing physical features of the catchment area over the course of time. Nevertheless, it can clearly show whether the area is prone to debris flow formation (Johnson and Rodine 1984).

\subsubsection{Debris flow triggered from landslide}

Some debris flows are initiated from landslides. This gives rise to gravitative debris flows as defined by Kang et al. (2003). Three processes are involved in the phenomenon (Iverson et al 1997). They are: (1) widespread failure of all soil mass in the initial landside; (2) partial or complete liquefaction of soil mass by high pore fluid 
pressure; and (3) conversion of landslide translational energy into internal vibrational energy within the sliding mass. The first process is the consequence of failure initiation and the latter two are internal and external factors for debris flow formation. A debris flow may be initiated from any one or a combination of all the three processes.

In the first process, widespread failure of all the soil mass in the initial landslide may occur if high pore pressure exists throughout the failure mass that can be caused by heavy infiltration of rainwater. Earthquake loading may also generate failure in the whole soil mass of the initial landslide. A landslide, which killed around 600 people in a single event in El Salvador, is an example of wide spreading failure caused by an earthquake.

In the second process, partial or complete liquefaction may be formed by redistribution of excess pore water pressure (Iverson et al. 1997, Sassa 1985, Ellen and Fleming 1987).

In the third process, the downward movement of the failure mass suffers a loss of potential energy, which is partly turned into kinetic energy for the mass motion and partly dissipated in overcoming internal resistance. This in turn leads to relative displacement between the soil grains. Consequently, grain vibration is generated and the cohesion destroyed.

A steep and sufficiently long slope is required for the third process to take place. For a long and steep slope, there is sufficient energy to transfer to the moving mass to reduce the granular contact and the friction between grains and granular material starts flowing. This is a condition for a landslide transforming into a debris flow. In this process, energy translates from friction of the slope to the grain and grain-to-grain 
contacts. The transformation process is defined as the mobilization of landslide into debris flow.

The slide mass, which loses its strength due to liquefaction, possesses high mobility. Fully mobilized debris flow can enter through a small opening without displacing other portion of the structure. Therefore, debris flow can enter through doors and windows of houses and fill the whole house without disturbance of wall and foundation.

Debris flow may be formed from combinations of pore pressure, grain vibration, and wide spread failure. A detailed study of these factors is necessary to understand the formation and movement of a debris flow. The contribution of these factors for the formation of a debris flow from a landslide has been studied individually in the literature. The transformation and runout distance of the landslide induced debris flow in different particle friction, pore pressure, slope geometry, is therefore studied together in Chapter 6 of this thesis.

\subsubsection{Influence of other factors for debris flow formation}

\subsubsection{Saturated thickness of sliding mass}

Saturated soil mass in an infinite slope with particular water content must exceed a critical thickness to mobilize as a debris flow (Johnson and Rodine 1984, Ellen and Fleming 1987). When the critical thickness is exceeded, the shear stresses at the base of the soil exceed the Bingham yield strength. For as long as soil inter-particle stress is larger than the yield strength of the soil, the soil mass remains in motion. 
Johnson and Rodine (1984) provide a relation of critical thickness for initiation of debris flow. The critical thickness $\left(T_{c}\right)$ for debris beginning to flow on an infinite slope is given as:

$$
T_{c}=(C / \gamma \sin \delta) /(1-\tan \phi / \tan \delta)
$$

where, $c$ is the cohesive strength, $\gamma$ the unit weight of the debris, $\delta$ the slope angle of the surface base of the debris flow, $\phi$ the angle of internal friction.

In this relation, there is no consideration of pore pressure, liquefaction, and viscosity of the fluid. These parameters are equally important for the formation of debris flow. Therefore, it is necessary to consider yield strength as a function of soil properties such as pore pressure, viscosity, and friction angle rather than a function of depth of the slope only (Iverson 1997).

\subsubsection{Pore pressure}

Generation and redistribution of pore pressure is important for pore pressure influence in debris flow formation. The rate of pore pressure generation and redistribution develop three conditions within soil mass. These are undrained, drained, and in-between conditions. In the undrained condition, total stress transfers to nonequilibrium pore pressure. In the drained condition, solid stress transfer without development of non-equilibrium pore pressure. Slope failure conditions generally fall between these extremes.

The generation of pore pressure in a soil mass moving down the slope can be analysed using deformation rate and volume change in the soil mass. If the down slope 
motion exceeds $1 \mathrm{~m} / \mathrm{s}$, even coarse soils may show undrained behavior, and high pore pressures may develop as a result of soil contraction (Iverson and La Husen 1989). In other words, fine-grained soils may exhibit drained behavior without significant porepressure change if the landslide motion is sufficiently slow.

Pore pressure redistribution and grain vibration develop simultaneously during sliding soil mass due to gravity. Chances of all factors being involved in the debris flow formation are higher than the involvement of one or two factors individually. In the above study, pore water pressure and grain vibration relation with the in situ soil strength for debris flow formation have not been explained. The energy required to transform a landslide into a debris flow can be equated with the soil strength and available gravitational force. The relation between the required energy to transform landslide into a debris flow $\left(E_{t}\right)$ is a function of potential energy available $\left(P_{e}\right)$, pore pressure $(P)$, cohesion of the soil $(C)$, and the internal angle of friction $(\phi)$. Detailed field observation and laboratory tests are required for understanding the relation between them. The relation of $E_{t}$ with other factors is given in Equation 2.9. Detail studies are necessary to draw the contribution of each factor simultaneously.

$$
E_{t}=f\left(P_{e}, P, C, \phi\right)
$$

\subsubsection{Hydrologic factor for debris flow}

There are several empirical relations between rainfall and debris flow occurrence. These relations may be deterministic or probabilistic. Empirical relations are developed based on the study of a particular catchment, and these relations are suitable for that catchment. Such empirical relations for the prediction of debris flows have been 
developed based on the Alphas region in Europe, Jiangjia and other parts of China and many catchments in Japan. United States Geological Survey (USGS) has calibrated rainfall and debris flow relations within various catchment areas in Colorado. Some empirical studies account for uncertainty parameters of soil such as transmissibility, rainfall depth, and ground water head. However, the use of these relations is limited to the study area. For the development of relation in any catchment a long history of rainfall records, topography and other soil parameters are necessary.

The saturation process decreases the matric suction, increases the load, and reduces cohesion as well. Shallow slope failures may be triggered under fully saturated conditions by infiltration, which increases the soil weight and reduces the ambient soil moisture suction (Brand 1981, Li et al. 2004). Studies also indicate that a debris flow can result from the development of positive pore pressure mostly associated with saturation. This process was involved in Lai Pui Street landslide.

\subsubsection{Water content}

The water content in the soil mass influences the stability of slope and mobilization of landslide into the debris flow. Soils mobilized to form debris flows were saturated or nearly saturated prior to failure (Sidle and Swanston 1982, Johnson and Sitar 1990).

A cohesionless sub-aerial slope standing at the angle of repose, can sustain no positive pore pressure without failing. This is the condition similar to the case study in Chapter 4, Lei Pui Street Landslide. Some amount of water content may be present in the soil before pressures cause anticipatory failure of the slope. In other words, slope may 
remain stable long enough to become nearly saturated. A steep slope of cohesionless soil will fail before the slope is saturated. For partially saturated cohesionless soil, other factors also support transformation into debris flow, in addition to partial saturation condition.

When downward flux of groundwater discharge from rainfall equals the saturated hydraulic conductivity $(K)$ of the soil, a steady state develops. With prolonged rainfall at intensities greater than or equal to $K$, a saturated zone will start at the soil surface, and propagate downwards. Sometimes a perched watertable may be formed within which positive pore pressure develops (Li et al. 2004).

Li et a1. (2004) observed that, a transient perched or positive water pressure developed in the heaviest rainfall (194.5mm per day) and volumetric water content also increased in saturated state in one study in Hong Kong. After rainfall ceases, the soil remains in tension-saturated state even as gravity drainage occurs and negative pore pressures or matric suction develop. A subsequent burst of high-intensity rainfall can cause the tension-saturated zone to develop positive pore pressures almost instantaneously, provided there is a watertable or stratum of low permeability beneath it. This condition was satisfied in case study 1 , in Chapter 4 , the Lei Pui Street landslide, Hong Kong, which was initiated after 15 minutes of heavy rainfall of about $30 \mathrm{~mm}$ that followed a prolonged rainfall. Such a rapid response mechanism was also observed by $\mathrm{Li}$ et al. (2004) in a capillary fringe above a watertable. A mechanism of this type may have initiated debris flows in the hill slope studied by Iverson (1990). This mechanism may be involved in the transformation of the Lei Pui Street Landslide into a debris flow as described in Chapter 4. 
At the time of slope failure, the possibility is that the soil-water contents in a significant fraction of the soil may remain less than the saturated condition. When positive pore pressures trigger failure, water contents in the unsaturated zone rise to saturated or near-saturated levels as a consequence of soil contraction, which originates on the slip surface. This slip surface spreads to adjacent soil by conduction of granular vibration. This process may be a probable cause of many landslides changing into debris flows in Lantau Island and Lei Pui Street landslide, Hong Kong.

\subsubsection{Runout distance and travel angle}

Some researchers proposed that the runout distance of debris flows can relate to the travel angle. The travel angle is the angle of inclination of a line drawn from crown to the front of the debris. This angle ranges from $30^{\circ}$ to $40^{\circ}$ with an average of $35^{\circ}$ for gravitational movement, $20^{\circ}$ to $30^{\circ}$ for hydraulic movement, and $25^{\circ}$ to $35^{\circ}$ for mixed movement in Lantau Island. Wong et al. (1997) suggest that the relation between the travel angle and debris flow runout distance could be applicable for estimation of runout distance in similar conditions. However, there are various factors influencing the travel angle, such as amount of water mixing in the moving mass, which is not reflected in the travel angle. In addition, the location of debris flow initiation is difficult to understand from travel angle, the location is important to predict debris flow initiation. In this study, friction angle is used for comparison of the debris flow runout, which entirely depends on the characteristics of the debris flow. 


\subsubsection{Runout distance of debris flow}

Travel distance is an indicator of the transformation process of a landslide mass into a debris flow. If the travel distance of a landslide is very small (less than the initial length of landslide), it does not transform to a debris flow. If the travel distance is large, a landslide mass behaves as a debris flow.

The prediction of travel distance of a debris flow has been studied by many researchers. Voellmy (1955) and Salm (1966) proposed that the runout distance might be calculated from energy and momentum conservation principles, as for snow avalanches. This model assumes that the friction of the avalanche along the slope during runout remains a constant, or a function of velocity. Takahashi and Yoshida (1979) proposed the momentum conservation equation for analysis of debris flow runout.

One of the most appropriate and tested model over many case study records is the model proposed by Hungr (1995). The model has been tested in several case studies in Hong Kong. The selection of the rheology of the debris flow in the model depends on the experience of the user and back analysis of the previous records. Details of the model are given in Chapter 3.

This model is used in the two case records in this thesis. The model is also used for parametric study on the runout distance of debris flow in Chapter 6. 


\section{CHAPTER 3}

\section{MODELING OF LANDSLIDES AND DEBRIS FLOWS}

\subsection{Introduction}

Landslides and debris flows are complex natural phenomena but they can be simulated with mathematical models. In this chapter, I provide notes on computer software Slope/W, Fast Lagrangian Analysis of Continua (FLAC), dynamic analysis (DAN) and FLO-2D that are used in this thesis for modeling the various stages of a landslide. The assumptions, limitations, and modeling procedures of software are discussed in this Chapter.

\subsection{Slope/W}

Slope/W is computer software, which provides efficient slope stability analysis from limit equilibrium methods. The program can model heterogeneous soil types, complex stratigraphy and slip surface geometry, with variable pore-water pressure conditions. Slope/W provides a choice of deterministic and probabilistic inputs for soil parameters. It can analyze simple as well as complex problems of slope stability. Different methods can be used for calculation of the factor of safety. Slope/W is capable of modeling complex slope geometry, external line loads, reinforcement anchors, pore pressure ratio or ground water level line and different properties of soil layers. 
Various methods of slope stability analysis are available in the software, including Ordinary or Fellenius, Janbu's simplified and Janbu's generalized, Spencer's, Mogenstern and Price, GLE, Corps of Engineere's, Lowe-Karafiath.

The slip surface or block slip can be defined in the software. The topography of the slope before failure and the scarp surface of the slide after failure can be modeled. By applying different soil strength parameters, one can analyse the limiting instability of the failure slope.

Back analysis of landslides helps for studying parameters such as pore pressure, cohesion, and friction during initiation of failure. The factor of safety of the failure mass is taken as one, and soil parameters can be adjusted for finding soil strength parameters from Slope/W. This software can be used for case histories like Barabensi landslide in Nepal and Lei Pui Street landslide in Hong Kong these are studying in this research.

\subsection{FLAC}

The strength reduction method is applied for slope stability analysis in FLAC. The slope can be modeled in a finite difference program and large cohesion and tension strengths are applied at the beginning. The strength of the slope gradually reduces to the failure condition in the successive calculations. The ratio between initial strength of the slope to the failure strength is the factor of safety of the slope. This method was initially used by Zienkiewich et al. (1975) and later by Nayler (1982), Donald and Giam(1988), Matsui and San(1982), Ugai(1989), Ugai and Leshchinsky (1995), Pokharel (1996) and others. 
In this study, FLAC is used to determine the failure surface and initial factor of safety from back analysis of the failure slope. The failure surface in this method is found automatically after reduction of strength of the soil in the slope. A typical slope stability model is shown in Figure 3.1

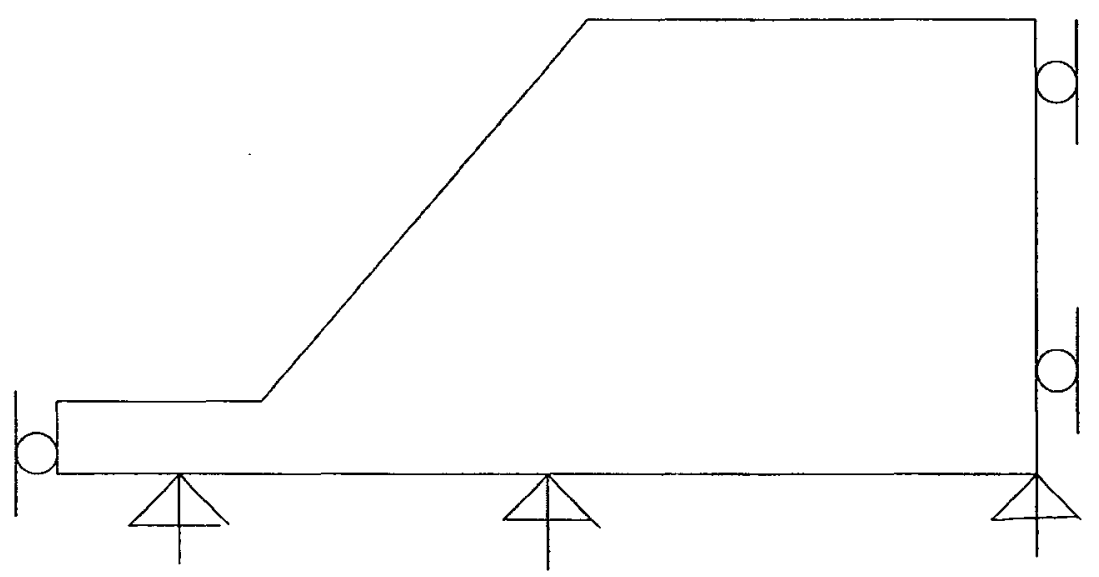

Figure 3. 1 Slope model in FLAC for stability analysis

Different soil strength parameters and groundwater condition can be applied in the model for analysis. Soil characteristics like modulus of elasticity and Poisson's ratio are necessary for deformation analysis. The program gives the factor of safety, initial displacement, and velocity of the failure soil mass from its original condition.

In this study, FLAC is used for back figuring the soil parameters of a failed slope at the time of failure. The results obtained from FLAC are compared to those from other methods of slope stability analyses. 


\subsection{DAN}

The dynamic analysis, DAN, is an analysis of rapid flow slides, debris flows, and avalanches proposed by Hungr (1995). In this model, the debris flow is considered as a saturated mass flow, and its velocity profiles are assumed similar to the flow of fluids.

This method of analysis gives the following quantities: runout distance covered by debris flow or maximum distance covered by debris mass, thickness of the debris mass, and flow velocities.

In the dynamic model, an equivalent fluid, whose properties approximate the behavior of the prototype, replaces the moving mass, which is heterogonous and complex. The dynamic analysis takes into consideration of the lateral confinement of the flow surface. The model is easy to use as it is two dimensional in nature, and efficient. It facilitates rapid and comprehensive matching of parameters to observe prototype results such as deposition and velocity (Hungr 1995).

This model is based on Lagrangian finite difference solution of the hydrodynamic equation. It uses vertically integrated momentum equation, curvilinear coordinates, and a moving mesh. For modeling, the moving mass is divided into different blocks and the boundary block was numbered $(i=1$ to $n)$. The continuity equation was applied in the fixed volume of blocks $(j=1$ to $n-1)$, separating the boundary blocks.

The assumption in this analysis is that the flow surface path is reasonably smooth. The explicit solution occurs in the given time steps and the error is redistributed iteratively. Block height $H_{i}$ and width $B$ are measured perpendicular to the flow direction. The force $(F)$ acting on the block is given by Equation (3.1). 


$$
F=\gamma \mathrm{H}_{i} \mathrm{~B}_{i} d s \sin \alpha+P-T
$$

where, $\gamma$ is the bulk unit weight of the boundary block, $P$ is the internal pressure resultant, $T$ is basal layer resisting force, $\alpha$ is slope angle of the bed from the horizontal, $d s$ the length of the block $i, B_{i}$ the width of Block $i, H_{i}$ the height of the Block $i$.

The blocks move from one position to another and the final velocity of the block $\left(v_{i}\right)$ change from the old velocity $\left(v_{i}{ }^{\prime}\right)$, which is given by Equation (3.2). Consequently, blocks move from the initial position $\left(S_{i}{ }^{\prime}\right)$ to the final position $\left(S_{i}\right)$ in curvilinear displacement, which is given by Equation (3.3).

$$
\begin{aligned}
& v_{i}=v_{i}{ }^{\prime}+\frac{g(F \Delta t-M)}{\gamma H_{i} B_{i} d s} \\
& S_{i}=S_{i}{ }^{\prime}+\frac{\Delta t\left(v_{i}+v_{i}{ }^{\prime}\right)}{2}
\end{aligned}
$$

where, $\Delta t=$ time step interval, and $g$ is acceleration due to gravity, $M$ is momentum flux resulting from erosion or entrainment of material. The new height of the boundary block $\left(h_{j}\right)$ can be computed from the constant volume of the flow as given in Equation (3.4)

$$
h_{j}=\frac{2 V_{j}}{\left(S_{i+1}-S_{i}\right)\left(B_{i+1}+B_{i}\right)}
$$

where, $h_{j}=$ height of the mass Block $j$. The subscripts $i$ and $j$ are used for boundary blocks and mass blocks respectively. The height of each boundary block is calculated from the mean depth of adjacent mass blocks as given in Equation (3.5). 


$$
H_{i}=\frac{h_{j-1}+h_{j}}{2}
$$

The block at the end is assumed triangular so that the area of the end mass is the area of the triangle. The lateral pressure coefficient, $k$, is defined as the ratio between the tangential and normal stress in the flowing mass. Equation (3.6) provides the relationship between $\mathrm{k}$ with the new position.

$$
k_{i} \frac{d H}{d s}=\frac{1}{2}\left[\frac{k_{j}\left(h_{j}-H_{i}\right)}{S_{j}-S_{i}}+\frac{k_{j-1}\left(H_{j}-h_{j-1}\right)}{S_{i}-S_{j-1}}\right]
$$

The incremental tangential strain in each mass block is calculated from the displacement of the adjacent boundary blocks, where $\Delta$ signifies the change in time steps. Equation (3.7) provides the final strain in each step.

$$
\Delta \varepsilon_{j}=\frac{\left(S_{i+1}-S_{i}\right)-\left(S_{i+1}^{\prime}-S_{i}{ }^{\prime}\right)}{\left(S^{\prime}{ }_{i+1}-S_{i}{ }^{\prime}\right)}
$$

\subsubsection{Rheology used in the model}

The term $T$ used by Hungr (1995) is a flow resistance term at the bottom of the layer. This term depends on the various parameters and rheology of the material. The assumption is that the shear stress of the tangential plane of curvilinear path linearly increases with the normal depth. The different rheologies proposed by Hungr (1995) in the model are Plastic flow, Friction flow, Newtonian laminar flow, Turbulent flow, 
Bingham flow, Coulomb viscous flow, Voellmy fluid flow. The details of two rheologies used in this research are presented here.

1. Friction flow rheology:

In this rheology, $T$ is a function of the effective normal stress, $\phi$, the friction angle, $r_{u}$, the pore pressure ratio, $a_{c}$, the centrifugal acceleration, $\alpha$, the slope angle $A_{i}$ the base area $\left(d_{s} B_{i}\right)$ as given in Equation (3.8)

$$
T=A_{i} \gamma \mathrm{H}_{i}\left(\cos \alpha+\frac{a_{c}}{g}\right)\left(1-r_{u}\right) \tan \phi
$$

Here, the centrifugal acceleration, $a_{c}$, is $v^{2} / r$, which depends on the vertical curvature radius of the path $R$, and $r_{u}$ is the pore pressure ratio. The friction angle is assumed to be a function of displacement to simulate strength from the peak to the residual stage. The pore pressure may be a function of location or elapse of time.

2. Voellmy rheology:

Given in Equation (3.9), the Voellmy model uses a friction term $(T)$ for snow avalanches.

$$
T=A_{i}\left[\gamma H_{i}\left(\cos \alpha+\frac{a_{c}}{g}\right) \tan \phi+\gamma \frac{v_{i}^{2}}{\xi}\right]
$$

The turbulent coefficient $\xi$ has the dimension of acceleration. This model provides a satisfactory result for rockslide avalanches (Koerner 1976, Kaiser 1984).

For the analysis of the pressure term, the model assumes that the pressure increases $(P)$ linearly with depth in the debris mass. Equation (3.10) provides the 
relationship of the pressure in term of slope acceleration, acceleration due to gravity and earth pressure coefficient.

$$
P=-k \gamma \frac{d h}{d s}\left(1+\frac{a_{c}}{g}\right) H_{i} B_{i} \cos \alpha d s
$$

The pressure gradient $k\left(\frac{d h}{d s}\right)$ is obtained from Equation (3.6), and $k_{j}$ is updated from Equation (3.11).

$$
k_{j}=k_{j}{ }^{\prime}+S_{c} \Delta \varepsilon_{j}
$$

where, $S_{C}=$ stiffness coefficient taken as $\left(k_{p}-k_{a}\right) / 0.5$ for compression or $S_{u}=\left(k_{p}-k_{a}\right) / 0.025$ for unloading.

The DAN model is a useful tool for studying a hazard analysis in the hilly terrain, where landslide-induced debris flows are frequent. In this study, this model is used for two different purposes. These are (1) verification of rheology with case histories of recently observed landslides in Hong Kong and Nepal, and (2) parametric study of the effect of soil characteristics such as friction, pore pressure, initial landslide slope, and slope of natural terrain inclination on debris flow runout distance. In addition to this, the model is used for the preparation of a chart for the estimation of debris flow hazard territory around the landslide initiation source. The chart can be used for debris flow risk assessment in any particular place in the natural terrain, where the characteristics of landslide soil and natural terrain inclination are known. 


\subsection{FLO-2D}

FLO-2D is a volume conservation model, which distributes a mass of flood and debris into a given area of grid elements. It is a good tool for predicting flow wave attenuation in a complex flood plain. The program can simulate overland flow using topographic data files, which can be produced from digitized base map or developed from a digital terrain model (DTM). A Grid Developer System (GDS) is also available in the program, which can develop a square grid system on a set of random digital terrain mapping. The program provides maximum flow depth and velocity in each grid system. The area of debris flow hazard can be predicted from the model.

In FLO-2D simulation, flood routing in two dimensions is accomplished through a numerical integration of the equation of the motion and the conservation of debris flow. The constitutive fluid equation includes the continuity equation, and the two-dimensional equations of motion, which are given by Equations (3.12), (3.13) and (3.14)( FLO-2D manual 2003).

$$
\begin{aligned}
& \frac{\partial h}{\partial t}+\frac{\partial h V_{x}}{\partial x}+\frac{\partial h V_{y}}{\partial y}=i \\
& S_{f x}=S_{o x}-\frac{\partial h}{\partial x}-\frac{V_{x}}{g} \frac{\partial V_{x}}{\partial x}-\frac{V_{y}}{g} \frac{\partial V_{x}}{\partial y}-\frac{1}{g} \frac{V_{x}}{\partial t} \\
& S_{f y}=S_{o y}-\frac{\partial h}{\partial y}-\frac{V_{y}}{g} \frac{\partial V_{y}}{\partial y}-\frac{V_{x}}{g} \frac{\partial V_{y}}{\partial x}-\frac{1}{g} \frac{\partial V_{y}}{\partial t}
\end{aligned}
$$

where, $V_{x}$ and $V_{y}$ are the depth average velocity components along $x$ and $y$ coordinates. The term $i$, on the right hand side in Equation (3.12), is the excess rainfall intensity. 
Friction slope components, $S_{f x}$ and $S_{f y}$ are written as a function of bed slope $S_{o x}$ and $S_{o y}$, pressure gradient and convective and local acceleration terms. The model has options for diffusive wave and full dynamic representation of the momentum equation. The diffusive wave approximation does not consider the last acceleration terms, convective and local acceleration. In the full dynamic wave version, all the terms are considered in the momentum equation.

The equation of motion is solved by computing the average velocity between two grid elements at a time. The flow direction is considered in eight directions, four in compass direction, and four corner of the grid. The velocity is computed independently and is one dimension in nature. All the terms related to the momentum equation, pressure, convective and local acceleration components in the momentum equation are updated and maintained.

Table 3. 1 Observed value for momentum equation term (after Henderson 1996) (FLO-2D Manual 2001)

\begin{tabular}{|l|c|c|l|l|}
\hline & Bed Slope & Pressure Gradient & $\begin{array}{l}\text { Convective } \\
\text { Acceleration }\end{array}$ & $\begin{array}{l}\text { Local } \\
\text { Acceleration }\end{array}$ \\
\hline $\begin{array}{l}\text { Momentum } \\
\text { Equation }\end{array}$ & $S_{o}$ & $\frac{\partial y}{\partial x}$ & $\frac{v}{g} \frac{\partial \nu}{\partial x}$ & $\frac{1}{g} \frac{\partial v}{\partial t}$ \\
\hline $\begin{array}{l}\text { Magnitude } \\
(\mathrm{ft} / \mathrm{mi})\end{array}$ & 26 & 0.5 & $0.12-0.25$ & 0.05 \\
\hline
\end{tabular}

The relative magnitude of all terms used in the computation of the momentum equation is important for the output result and its accuracy. For a steep alluvial channel 
and fast rising hydrograph, Henderson (1996) computed all the terms as given in Table 3.1

The computed values in Table 3.1 show that for $26 \mathrm{ft} / \mathrm{mile}$ slopes, the convective acceleration and the local acceleration terms are very small as compared to the bed slope. Pressure gradient is important in the complex topography. For numerical stability, flat slope requires small time steps. Diffusive wave is required generally to have a mild slope for numerical stability. For very steep slopes, adverse slopes, and flat slope the local and convective acceleration terms can play a vital role.

The full dynamic wave equation is recommended for FLO-2D model except for simple overland flow simulation on a mild or a steep slope (FLO-2D Manual 2001). In Table 3.2, guidelines for selection of flood routine method for different topographical condition are given.

In FLO-2D model, the continuity and momentum equations are solved by central finite difference numerical integration. The non-linear partial differential equation is solved in a discrete uniform square grid domain. The discharge is estimated by assuming a linear trial function (central average) of related parameters (depth, roughness, area) of two adjacent grids. The solution of the momentum equation gives the flow velocity across the boundary of the grid. The product of velocity and each time step yields the discharge across the grid elements. These values are taken from the average of two grid elements. The model allows that each grid discharge flows in eight directions. The sum of the discharge across the grid is the sum of the flow in each individual grid. 
Table 3. 2 Topography and selection of the momentum equation terms $\left(O^{\prime}\right.$ Brien and Julin 2003)

\begin{tabular}{|c|c|c|}
\hline 1 & $\begin{array}{l}\text { Steep alluvial; fans, watersheds or } \\
\text { floodplains }\end{array}$ & $\begin{array}{l}\text { Diffusive wave, Kinematics } \\
\text { wave }\end{array}$ \\
\hline 2 & $\begin{array}{l}\text { Mildslope floodplains, backwater } \\
\text { areas which influence hydrograph, } \\
\text { overbank flows }\end{array}$ & Dynamic wave, diffusive wave \\
\hline 3 & Bed slope $>10 \mathrm{ft} / \mathrm{mile}$ and $\mathrm{TS} \mathrm{v} / \mathrm{d}>171$ & $\begin{array}{l}\text { Dynamic wave, Diffusive } \\
\text { wave, kinematic wave }\end{array}$ \\
\hline 4 & $\begin{array}{l}\text { Bed slop 2 to to } 10 \mathrm{ft} / \text { mile } \\
\text { andTSv } /<171\end{array}$. & $\begin{array}{l}\text { Dynamic wave, Diffusive } \\
\text { wave }\end{array}$ \\
\hline 5 & Bed slope $<2 \mathrm{ft} / \mathrm{mile}$ and $\mathrm{TS}(\mathrm{g} / \mathrm{d})^{0.5}>30$ & $\begin{array}{l}\text { Dynamic wave, Diffusive } \\
\text { wave }\end{array}$ \\
\hline 6 & Bed slope $<2 \mathrm{ft} / \mathrm{mile}$ and $\mathrm{TS}(\mathrm{g} / \mathrm{d})<30$ & Dynamic wave \\
\hline
\end{tabular}

The sum of the bed slope and pressure head gradient are used to calculate flow velocity with the diffusive wave equation. This velocity is used as a seed for the full dynamic wave equation (FLO-2D Manual 2003). The previous time step velocities are used in the solution of convective acceleration and local acceleration velocities. If the dynamic wave equation fails to converge within numerical calculation in five successive iterations, the algorithm defaults to the diffusive wave solution. The steps of the calculation are given for the grid element of single roughness value, elevation and flow depth. The local acceleration term can be calculated from the difference of the velocity 
in a given time step $\Delta t$. Similarly, the convective acceleration term is the difference of velocity in the previous time step. If $V_{t}$ and $V_{t-l}$ are velocity in $t$ and $t-l$ time steps then the local acceleration term $\left((1 / g)^{*} \partial V / \partial t\right)$ will be $\left(\Delta\left(V_{t}-V_{t-l}\right) / g\right)^{*} \Delta t$. Once the velocity is known then the velocity times the cross section of the flow gives the discharge. When the discharge is known, the discharge and time step provide the total volume crossing the grid. The net volume divided by surface area of the grid gives the change in the flow depth for that time step. For numerical stability of the analysis sufficiently small time steps are required (FLO-2D manual 2003).

\subsubsection{Debris flow simulation}

A debris flow is formed from the mobilization of kinetic energy after change from potential energy. The motion of the debris flow is governed by the concentration of sediment. A quadratic rheologic model is used for predicting the viscous and yield stress as a function of sediment concentration. The sediment concentration is recorded in the system during computation. In each grid system, dilution effect, mudflow cessation, and the remobilization of the deposit can be simulated.

When the required mobilization exists, the mass behaves as a fluid. Mudflow with high concentrations of fine sediment in the fluid matrix behaves as Bingham fluids with low shear rate (O'Brien and Julien 1987, Julien and Lan 1991). In the low sediment concentration, turbulent stresses dominate in the flow. Similarly, low concentration of fine particles and high concentration of coarse particles are required to generate dispersive stresses. O'Brien and Julien (1985) proposed the continuum of flow regimes from viscous to turbulent or dispersive flow in their quadratic shear stress model. 
Debris flow involves interaction of solid mass and fluid, and transfer of energy and momentum between each other in the process. The debris flow process involves turbulence, viscous shear, exchange of fluid and sediment particle momentum, particle drag, and sediment particle collision. Along the way of movement, particles collide, grind, and rotate. Fluid matrix exhibits non-Newtonian behavior, from the concentration of fine sediment, which possesses some cohesion.

In the steep alluvial fans, large shear rates (from $10 \mathrm{~s}^{-1}$ to $50 \mathrm{~s}^{-1}$ ) and turbulent stress may be generated in the debris flow from landslides. When turbulence is formed, the collision of sediment particles under large rate of flow deformation increases and a dispersive stress may develop. As mentioned above, when large sediment particles are dominant compared to the cohesive fine sediment particles like silt and clay, it is easy to develop the dispersive stress. Flow will approach laminar condition when concentration of fine sediment increases, and fluid turbulence as well as particle impact is reduced. In debris movement, sediment concentration varies with location and time. Both influence viscous and turbulent stresses, which dominate each other and also produce flow surges (FLO-2D manual 2003)

The shear stress in debris flow involves summation of five shear stresses (FLO2D manual 2003). These are cohesive yield stress $\tau_{c}$, Mohr-Coulomb shear stress $\tau_{m c}$, viscous shear stress $\tau_{v}$, turbulent shear stress $\tau_{t}$, dispersive shear stress $\tau_{d}$ as given in equation (3.15).

$$
\tau=\tau_{c}+\tau_{m c}+\tau_{v}+\tau_{t}+\tau_{d}
$$


The viscous shear stress $\tau_{\nu}$ can be written as $\eta d v / d y$, where $d v / d y=$ strain rate, and $\eta$ is viscosity of the debris matrix. Equation (3.15) can be changed to the Equation no (3.16) (O’Brein and Julien, 1985)

$$
\tau=\tau_{y}+\eta\left(\frac{d v}{d y}\right)+C\left(\frac{d v}{d y}\right)^{2}
$$

where, $\tau_{y}=\tau_{c}+\tau_{m c}, C=\rho_{m} l^{2}+\mathrm{f}\left(\rho_{m}, C_{v}\right) d_{s}^{2}$ where $C$ denotes the inertial shear stress coefficient, which depends on the mass density of the mixture $\rho_{m}$, the Prandtl mixing length 1 , the sediment size $d_{s}$, and volumetric sediment concentration $C_{v}$. Initially Bagnold (1954) defined the functional relationship $f\left(\rho_{m}, C_{v}\right)$ as given by Equation (3.17).

$$
f\left(\rho_{m}, C_{v}\right)=a_{i} \rho_{m}\left[\left(C^{*} / C_{v}\right)^{\wedge}(1 / 3)-1\right]
$$

where, $C^{*}$ is the maximum static volume concentration for the sediment particles. The value of $a_{i}$ is approximately .01 and is an empirical constant. Later Takahashi (1979) found that the coefficient $a_{i}$ may vary over several orders of magnitude. Bagnold (1954) function was revised by Egashira et al. (1989) as follows:

$$
f\left(\rho_{s}, C_{v}\right)=\frac{\pi}{12}\left(\frac{6}{\pi}\right)^{1 / 3} \sin ^{2} \alpha_{1} \rho_{s}\left(1-e_{n}^{2}\right) C_{v}^{1 / 3}
$$

where, the energy restitution coefficient $e_{n}$ after impact ranges from 0.7 to 0.85 for sands, $\alpha_{l}$ is the average particle impact angle and $\rho_{s}$ is the mass density of sediment particles. The first two terms of the shear stress equation (Equation 3.16) are referred to as Bingham shear stress, which represents the internal resistance of the fluid. The sum of the yield and viscous stress represents the stress of cohesive, hyper concentrated sediment 
fluid in a viscous flow regime. The third term of the stress equation represents the sum of dispersive and turbulent shear stresses, which depends on the square of the velocity gradient.

For simulation of debris flows, all the stresses are involved ( $O^{\prime}$ Brien et al. 1993) in different proportion. Viscosity and yield stresses for high sediment concentration are relatively small compared to the turbulent stresses associated with high velocity, which depends on the fluid matrix concentration. The velocity will be lower in higher viscous stress and higher in turbulent stresses; turbulence will dominate in small yield stress and viscosity.

The model uses dimensionless slope relation as shown in Equation (3.19).

$$
s_{f}=s_{y}+s_{v}+s_{t d}
$$

Here the total frictional slope $S_{f}$ is the sum of turbulent slope $S_{t d}$, viscous slope $S_{\nu}$, and yield slope $S_{y}$. Furthermore, $S_{v}$ and $S_{t d}$ can be written in terms of depth average velocity $V$. Again, $S_{v}$ is given by Equation (3.20).

$$
S_{v}=\frac{K \eta}{8 \gamma_{m}} \frac{V}{h^{2}}
$$

where $y_{m}$ is the specific weight of the sediment mixture. The resistance parameter $K$ for laminar flow ranges from 24 to 5000 according to the roughness and irregularity shape of the flowing channel. The value of $K$ is important in laminar and transitional flow but not important in turbulence flow. Resistance parameters are given in Table 3.3, which is taken form FLO-2D manual (2003). 
For turbulence and dispersive shear stress, the non-dimensional stress relationship is given by Equation (3.21).

$$
S_{t d}=\frac{n_{t d}{ }^{2} V^{2}}{h^{4 / 3}}
$$

where $n_{t d}$ is equivalent Manning's roughness factor $n$ of combination of both turbulent and dispersive shear stress component. In high sediment concentration, particle contact increases cause development of turbulent and dispersive shear stress. This process increases the flow resistance $n_{t d}$, The Equation 3.19 can be written as in Equation (3.22).

$$
S_{f}=\frac{\tau y}{\gamma_{m} h}+\frac{K \eta V}{8 \gamma_{m} h^{2}}+\frac{n_{f d}^{2} V^{2}}{h^{3 / 4}}
$$

The model estimates the velocity in the momentum equation. The flow velocity is computed across each grid element boundary using the average flow depth between two elements. For overland flow such as debris flow from a landslide, reasonable values of $K$ and Manning's $n$ can be assumed. Values of $K$ for laminar flow are given in Table 3.3. The specific weight of the fluid matrix $\gamma_{\mathrm{m}}$ increases with sediment concentration. Sediment concentration also influences yield stress $\tau_{\mathrm{y}}$ and viscosity $\eta$.

When rheological analysis is not available the following rheological relationships, given in Equations (3.23) and (3:24), are recommended by previous research to compute the yield stress and viscosity in this model (FLO-2D manual 2001).

$$
\begin{aligned}
& \eta=\alpha_{1} e^{\beta 1 C v} \\
& \tau_{y}=\alpha_{2} e^{\beta 2 C v}
\end{aligned}
$$


where $\alpha$ and $\beta$ are empirical coefficients which can be determined from laboratory tests. Table 3.4 shows the experimental value of $\alpha$ and $\beta$ by different researchers. In this study, related values from the previous experiment will be taken. The values of these empirical parameters are given in Table 3.4 .

Here $C_{v}$ is the volume of sediment to the volume of water and sediment. $C_{\nu}$ can be written in terms of $C_{w}$, sediment concentration by weight. The relationship of $C_{v}$ and $C_{w}$ is given as:

$$
C_{\nu}=C_{w} \gamma /\left\{\gamma_{s}-C_{w}\left(\gamma_{s}-\gamma\right)\right\}
$$

where, $\gamma=$ specific weight of water and $\gamma_{s}=$ specific weight of the sediment. The specific weight of the mudflow mixture $\gamma_{m}$ is a function of the sediment concentration by volume. These relationships are given by Equations 3.26, 3.27, 3.28.

$$
\begin{aligned}
& \gamma_{m}=\gamma+C_{\nu}\left(\gamma_{s}-\gamma\right) \\
& \rho_{m}=\rho+C_{\nu}\left(\rho_{s}-\rho\right) \\
& \rho_{m}=Y_{m} / g
\end{aligned}
$$

In the simulation, a bulking factor $(B F)$ is required. The bulking factor can be written as $B F=1 /\left(1-C_{v}\right)$.

As mentioned before, a debris flow is a very viscous and hyper-concentrated sediment flow. It is non-homogenous and non-Newtonian. It has transient properties, which change with time, location, and position of the mass. The flow behavior of debris is highly influenced from fluid matrix properties, channel geometry, slope, and roughness. The fluid matrix consists of water and sediment. 
Table 3. 3 Surface roughness and Coefficient K(FLO -2D Manual, Woolhiser, 1975)

\begin{tabular}{|l|l|}
\hline Surface Type & Range of $K$ \\
\hline Concrete/ asphalt & $24-108$ \\
\hline Bare sand & $30-20$ \\
\hline Graded Surface & $90-400$ \\
\hline Bare clay-loamsoil, eroded & $100-500$ \\
\hline Sparse vegetation & $1,000-4,000$ \\
\hline Short praire grass & $3,000-10,000$ \\
\hline Blue grass sod & $7,000-50,000$ \\
\hline
\end{tabular}

The viscosity of the hyper-concentrated flow depends on the sediment concentration percentage, types of clay and silt content, and temperature of the matrix. High viscosity and yield stresses result in a laminar type of debris flow. If the matrix is less viscous, it will yield turbulent types of flow. Table 3.5 presents the debris flow behavior as a function of sediment concentration.

FLO-2D considers the continuity of water and sediment together in the flow plain. The model updates change in sediment and water volumes in each grid in a given time step. After the end of simulation, the model shows the amount of sediment and water removed or deposited in the study area.

\subsubsection{Assumptions and limitations of the model}

In the FLO-2D model, some of the assumptions are: the flow within the duration of a time step is considered as a steady flow; pressure distribution is hydro-static; hydraulic roughness is based on steady flow resistance; channel elements represent uniform channel geometry and roughness within a channel section; the model is 
simulating temporarily and spatially the average flow conditions in between grid elements; and the base of the grid is considered rigid so that scour and deposition are not considered.

Table 3. 4 Yield stress and Viscosity as a function of sediment concentration (FLO -2D Manual, Woolhiser, 1975)

\begin{tabular}{|c|c|c|c|c|}
\hline \multirow[t]{2}{*}{ Source } & \multicolumn{2}{|r|}{$\eta=\alpha e^{\beta C \nu}$} & \multicolumn{2}{|c|}{$\tau=\alpha e^{\beta C v}$} \\
\hline & $A$ & $\beta$ & $A$ & $\beta$ \\
\hline \multicolumn{5}{|l|}{ Field Data } \\
\hline Aspen Pit 1 & 0.181 & 25.7 & 0.0360 & 22.1 \\
\hline Aspen Pit 2 & 2.72 & 10.4 & 0.0538 & 14.5 \\
\hline Aspen Natural Soil & 0.152 & 18.7 & 0.00136 & 28.4 \\
\hline Aspen Mine Fill & 0.0473 & 21.1 & 0.128 & 12.0 \\
\hline Aspen Watershed & 0.0383 & 19.6 & 0.000495 & 27.1 \\
\hline Aspen Mine Source & 0.291 & 14.3 & 0.000201 & 33.1 \\
\hline Glenwood 1 & 0.0345 & 20.1 & 0.00283 & 23.0 \\
\hline Glenwood 2 & 0.0765 & 16.9 & 0.648 & 6.20 \\
\hline Glenwood 3 & 0.000707 & 29.8 & 0.00632 & 19.9 \\
\hline Glenwood 4 & 0.00172 & 29.5 & 0.0000602 & 33.1 \\
\hline \multicolumn{5}{|c|}{ Relationship available from the Literature } \\
\hline Ida (1938) & - & - & 0.0000373 & 36.6 \\
\hline Dai et al(1980) & 2.6 & 17.48 & 0.00750 & 14.39 \\
\hline Kang and Zhang(1980) & 1.75 & 7.82 & 0.0405 & 8.29 \\
\hline \multirow[t]{2}{*}{ Qian et al. (1980) } & 0.00136 & 21.2 & - & - \\
\hline & 0.05 & 15.48 & - & - \\
\hline Chien and $\mathrm{Ma}(1958)$ & 0.0588 & $19.1-32.7$ & - & - \\
\hline \multirow[t]{2}{*}{ Fei(1981) } & 0.16 & 25.6 & - & - \\
\hline & 0.00470 & 22.2 & - & - \\
\hline
\end{tabular}


Table 3. 5 The mudflow behavior as a function of sediment concentration (FLO2D manual 2001)

\begin{tabular}{|c|c|c|c|}
\hline & \multicolumn{2}{|c|}{ Sediment Concentration } & \multirow[t]{2}{*}{ Flow Characteristics } \\
\hline & By volume & By weight & \\
\hline \multirow[t]{2}{*}{ Landslide } & $0.65-0.8$ & $0.83-0.91$ & Will not flow; failure by block sliding \\
\hline & $0.55-0.65$ & $0.76-0.83$ & $\begin{array}{l}\text { Block sliding failure with internal deformation } \\
\text { during the slide; slow creep prior to failure }\end{array}$ \\
\hline \multirow[t]{2}{*}{ Mud flow } & $0.48-0.55$ & $0.72-0.76$ & $\begin{array}{l}\text { Flow evident; slow creep sustained mudflow; } \\
\text { plastic deformation under its own weight; } \\
\text { cohesive flow; some mixing }\end{array}$ \\
\hline & $0.45-0.48$ & $0.69-0.72$ & $\begin{array}{l}\text { Flow spreading on level surface; cohesive flow; } \\
\text { some mixing }\end{array}$ \\
\hline \multirow[t]{3}{*}{$\begin{array}{l}\text { Mud } \\
\text { Flood }\end{array}$} & $0.40-0.45$ & $0.65-0.69$ & $\begin{array}{l}\text { Flow mixes easily; shows fluid properties in } \\
\text { deformation; spreads on horizontal surface; } \\
\text { liquid surface with two fluid phase appears }\end{array}$ \\
\hline & $0.3-0.35$ & $0.54-0.59$ & $\begin{array}{l}\text { Separation of water on surface; wave travels } \\
\text { easily; most sand and gravel have settled out } \\
\text { and move as bed load }\end{array}$ \\
\hline & $0.20-0.3$ & $0.41-0.54$ & $\begin{array}{l}\text { Distinct wave action; fluid surface; all particles } \\
\text { resting on bed in quiescent fluid condition }\end{array}$ \\
\hline Water & $<0.2$ & $<0.41$ & $\begin{array}{l}\text { Water flood with conventional suspended load } \\
\text { and bed load }\end{array}$ \\
\hline
\end{tabular}

FLO-2D is a volume conservation model for two-dimensional overland and channel flow. The program uses the finite difference routing algorithms. The flow moves around the given domain consisting of a system of grids. FLO-2D provides the distribution of a flow mass in a given area and time. The model does not consider fluid particle dynamics, which involves streamlines and the movement of fluid blocks around the grid system. This is limited due to numerical stability of the model (FLO-2D manual 2002). The spatial and temporal resolution of the FLO-2D model is dependent on the 
size of the grid elements and the rate of in-flow discharge fluids. In a given time, discharge is distributed in the grid system and the model shows the incremental increase and decrease of flow depth.

Each grid element represents a single elevation and roughness factor. Therefore, variations of these factors within the grid element are not allowed. Mounds and depression within the grid element cannot be simulated.

In an abruptly changing geometry of the flow plain, a small time step is required for stable and smooth transition from one shape to another. The simulated flow uses the steepest path even flow direction changes by $90^{\circ}$ angle are allowed. Due to debris flow along eight directions, the flow between two grid elements may crisscross each other during computation, but the total volume will be the same. Supercritical and sub-critical flow transitions are incorporate between two grids

The model cannot simulate shock waves, rapidly flowing flow, or hydraulic jumps, and these abrupt changes in the flow profile are smoothed out in the model's calculations.

\subsection{Summary}

The initiation of the landslide in any slope can be analysed from the slope stability of the existing slope with the help of Slope/W and FLAC software. Both of these methods are reasonable for prediction. However, parameters used in FLAC are difficult to obtain as compared to Slope/W.

The DAN model is appropriate for runout distance analysis for different types of debris flow. The options of different rheologies are available in the model for simulation 
of different debris flows. Small time steps are recommended for smooth calculation of debris flow progress. This model is useful for the prediction of debris flow runout distance so this model is extensively used in this thesis.

FLO-2D model is a good tool for the assessment of debris flow inundation in a debris flow prone area. In this study, debris flow assessment of a case history of Lei Pui Street Landslide is carried out. The depth and velocity of the debris flow at any point of the flow surface can be determined in the analysis. The amount of external water mixing into the debris can be simulated. The sum of total mass of water and debris mass can be placed at the source point and the model will show the area covered by the debris mass on the flood plain. In the simulation, the total volume of debris is placed in the source point.

The flow rheology of the debris mass can be selected from the previously obtained rheological analysis of similar types of soil. This model is useful for inundation observation of the fully mobilized debris mass.

FLO-2D model is useful for velocity and debris flow depth prediction for a given topography and debris volume. Therefore, this model is used for velocity and debris flow analysis for a case study in Chapter 4 . 


\section{CHAPTER 4}

\section{LEI PUI STREET LANDSLIDE, HONG KONG}

A case study of a devastating landslide that occurred in Hong Kong in 2001 is presented in this Chapter. Although landslides occur every year and all over the world, it is difficult to find sites such as this, where comprehensive geotechnical data are recorded. The purpose of this case study is to simulate different stages of the landslide using computer software and comparison with field observation. In addition, this case study helps identify the important parameters that trigger a landslide and transform it into a debris flow. The review and reporting of field and laboratory investigation is based on the draft report prepared by Maunsell Geotechnical Services Ltd (2002) for the Government of Hong Kong Special Administration Region (SAR), China. Analysis of the initial failure to the inundation of debris in the flood plain is carried out with the help of different computer software.

The location of the landslide is on a natural hillside above Lei Pui Street, Shek Lei Estate, Kwai Chung, Hong Kong. The landslide occurred on September 01, 2001 at 10:50 p.m. The slide mass spilled over a $25 \mathrm{~m}$ high steep cliff, impacted on the flat portion of the hillside, and mixed with the surface runoff in natural drainage. The debris volume in the source area was $250 \mathrm{~m}^{3}$. The landslide was small but it developed into a debris flow. The road below the initial landslide was blocked for three days. 


\subsection{Site description}

\subsubsection{Location}

Lei Pui Street Landslide is located above the Lei Pui Street, Shek Lei Estate, Kwai Chung, Hong Kong. The location of the landslide is shown in Figure 4.1 and the aerial view of the landslide is shown in Figure 4.2. The landslide incident source is at $135 \mathrm{~m}$ above Lei Pui Street. This is at $220 \mathrm{mPD}$ on the northwest facing hillside and is at an angle of $41^{\circ}$ from the horizontal. Below the toe of the initial landslide, bedrock outcrop is laying on the surface at an inclination ranging from $52^{\circ}$ to $58^{\circ}$ to the horizontal. Lei Pui Street is a two lane road with a gradient of 1 in 10 and is connected to a major road, Shek Pai Street that has a gradient about 1 in 20.

\subsubsection{History}

The landslide site and its vicinity were undeveloped until 1949 , based on aerial photograph taken in 1949. Some terrace was formed and squatter homes were built in 1963. The construction of Shek Pai Street and a few blocks of Shek Lei Estate were completed in 1967. Some part of the hill slope soil was unstable and moved in 1967. Some developments together with Lei Pui Street were completed in 1973. A power transmission station on the ridgeline above the landslide was completed in 1973. A new settlement was established between 1973 and 1981. During the period from 1982 to 1987, some recreational and services buildings were constructed. An aerial photograph of the landslide area before the landslide taken in 1993 is shown in Figure 4-3. 
As a result of heavy human intervention, some locations of the new settlement was considered unsafe so that Housing Department (HD) started house clearing from 1984 and continued till 1988 by the request of Geotechnical Engineering Office (GEO) Hong Kong, SAR Government. Major grading of slope and other strengthening work were carried out; residence houses removed; and the hand-over process conducted till December 2000.

Before the Lei Pui Street landslide incident, seven landslides were recorded since settlement in the area within the catchment area with debris flowing up to Lei Pui Street. This shows that the area was prone to landslide. These landslides were small with width of less than $20 \mathrm{~m}$ at the widest point. There was no record of large landslides in the area. The hillside looks like a scarp of the previous landslides. Human intervention through new construction has given rise to more disturbances to the stability of the slope. Therefore, more landslides have been observed recently in the area. 


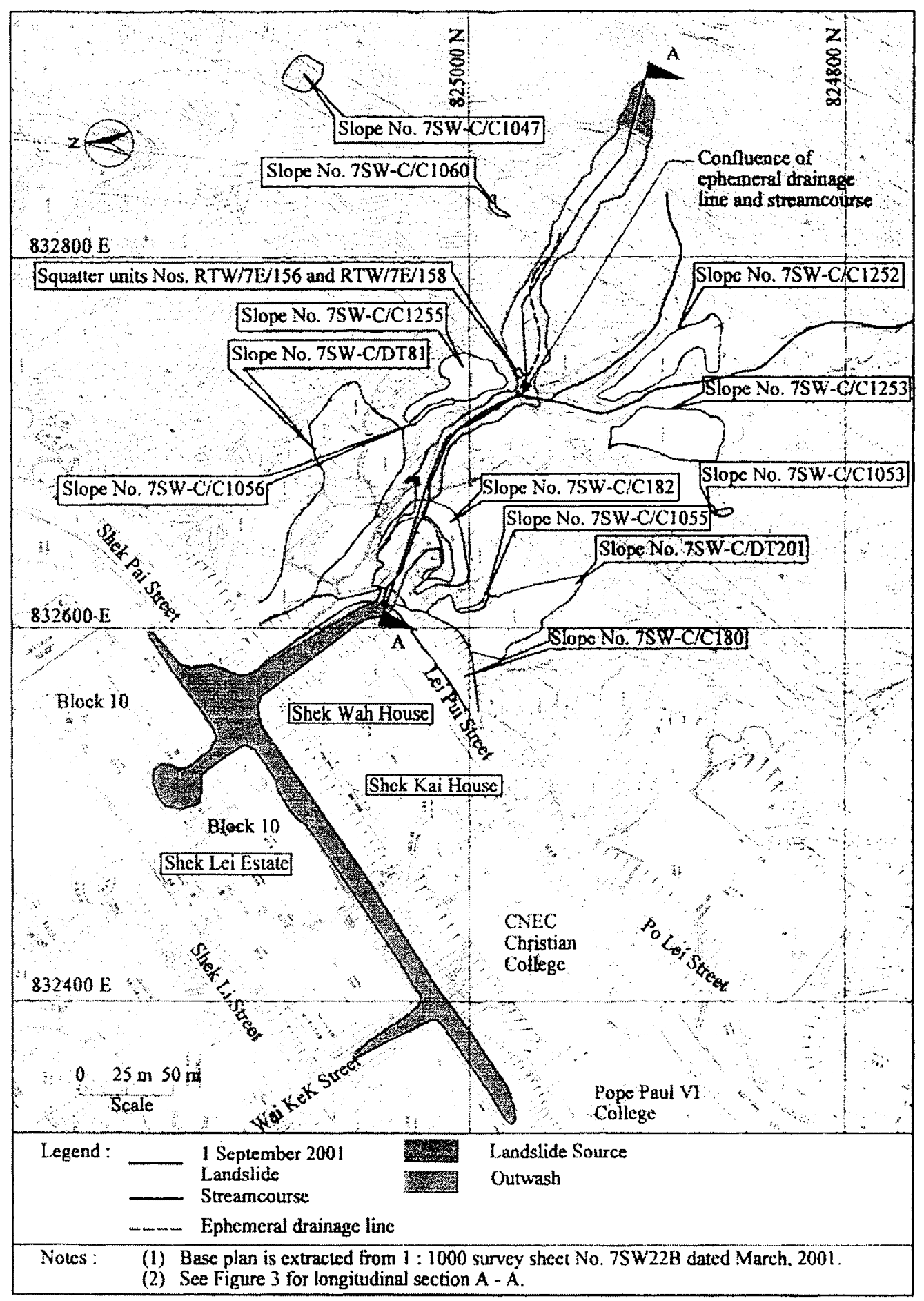

Figure 4. 1 Location of the landslide source (Maunsell, 2002) 


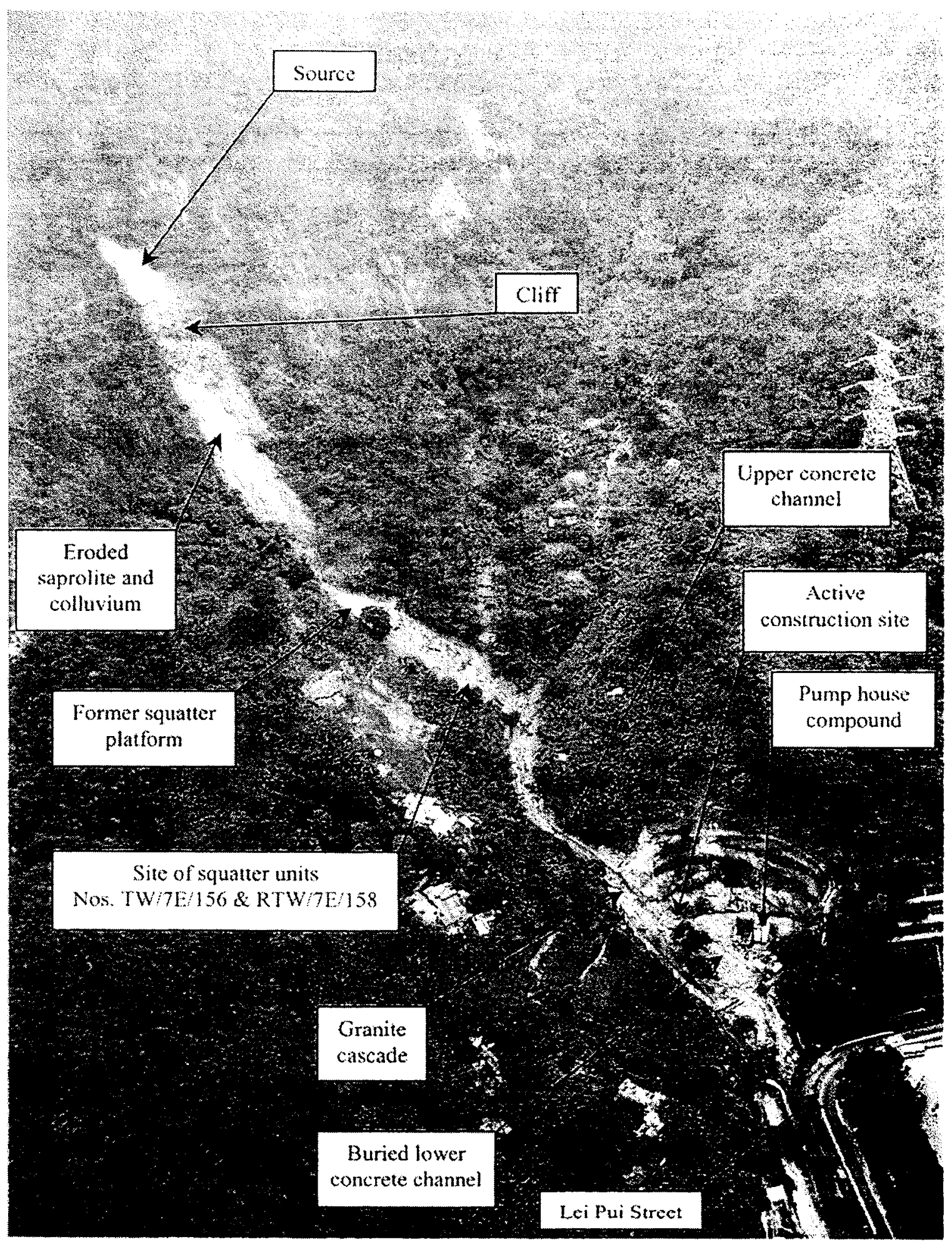

Figure 4. 2 Aerial photograph of landslide area (Maunsell, 2002) 


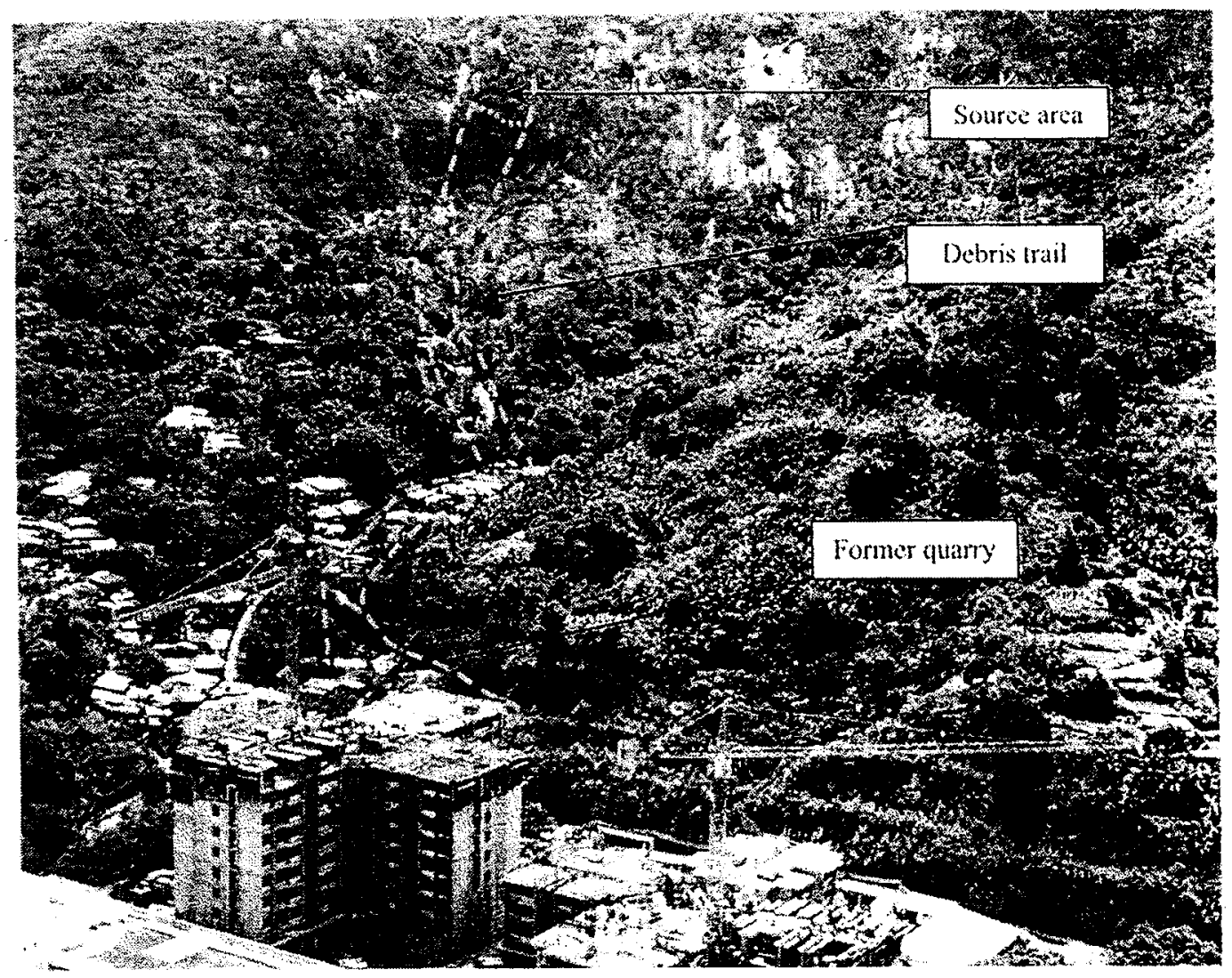

Figure 4. 3 Aerial photograph before the landslide (Maunsell, 2002)

\subsubsection{Topography}

The landslide occurred on a steep hill slope with an angle approximately $40^{\circ}$ from the horizontal. Immediately below the landslide source is a rock outcrop with a steep slope angle ranging from $52^{\circ}$ to $58^{\circ}$. The detailed features of the longitudinal section of the landslide area and the debris trail are shown in Figure 4.4. The gradient of the Shek Pai Street and Lei Pui Street is about 1 in 20 and 1 in 10, respectively. Lei Pui Street is a two-lane, two-way carriageway. The landslide is above the junction of the two streets. About $50 \mathrm{~m}^{3}$ outwash material from the landslide reached a sharp bend of Lei Pui street and flowed further for some distance. 


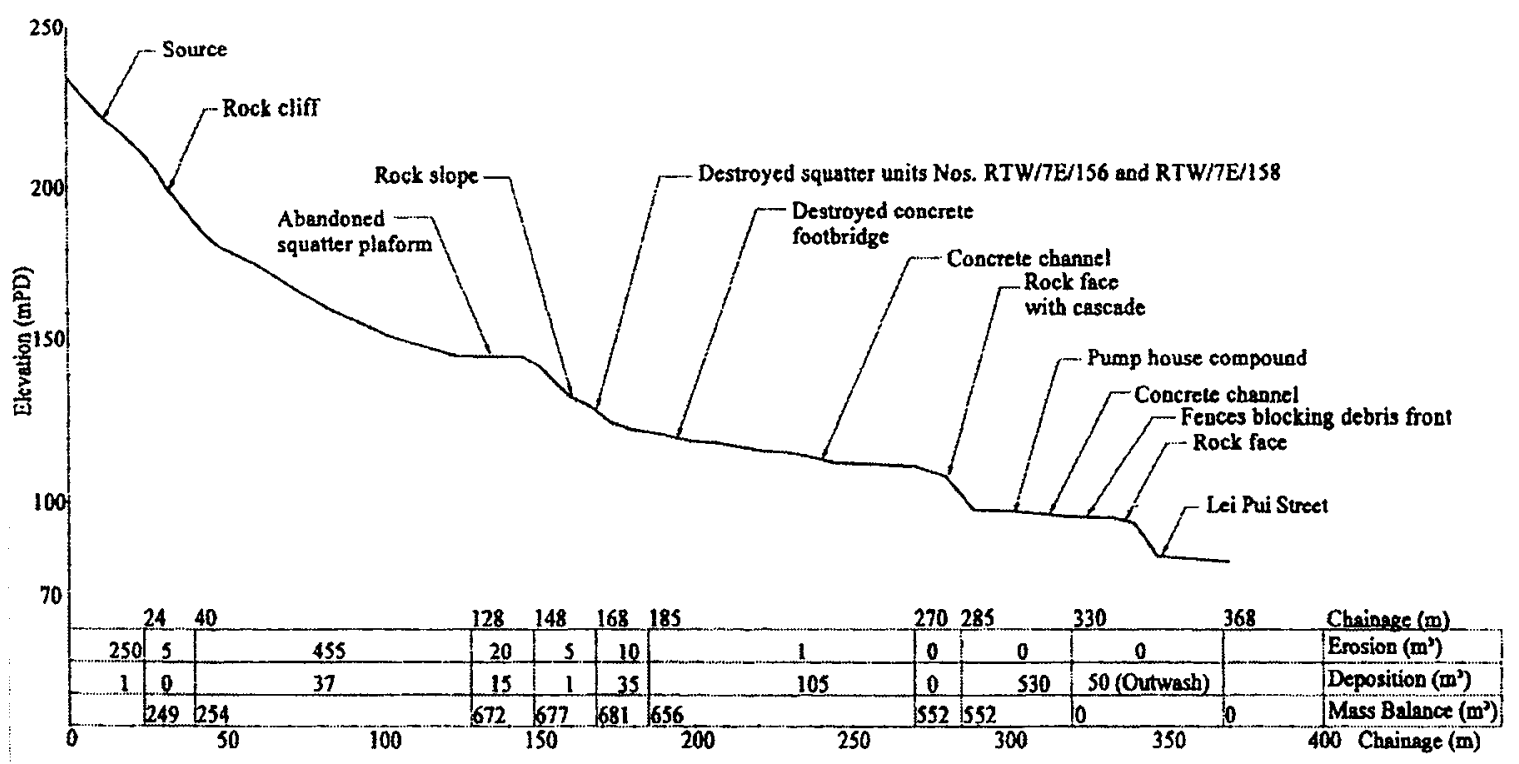

Figure 4. 4 Longitudinal profile of landslide source and debris trail (Maunsell, 2002

The terrain inclination above the landslide area is about $45^{\circ}$. Dense vegetation, shrubs, and small trees cover the surface area of the landslide source location. The vegetation is thinning out along the crest of the ridgeline up to $80 \mathrm{~m}$ above the source mass. The lower part of the landslide area is sparsely vegetated granite rock outcrop. The rest of the hill slope below the rock outcrop up to Lei Pui Street is at an average angle of about $30^{\circ}$. This part of the hillside has dense woodland except for local cultivated areas and former squatter platforms.

There is a confluence point of drainage line and stream course at $190 \mathrm{~m}$ below the landslide source. A footbridge deck of $3.5 \mathrm{~m}$ span was provided above the stream just 10 $\mathrm{m}$ downstream from the confluence. The landslide destroyed the footbridge. The gradient of the stream course from the bridge to $15 \mathrm{~m}$ above the slope side is 1 in 7 . A 
drainage channel of $2 \mathrm{~m}$ wide and $1.2 \mathrm{~m}$ deep with concrete sidewall of $250 \mathrm{~mm}$ thick was constructed after Chainage $240 \mathrm{~m}$ from the landslide source. Upper to the lower drainage portion, a cascade is constructed down to Lei Pui Street. There was an active construction site near the water supply department pump house. A temporary fence has been erected around the new construction site.

\subsubsection{Morphology}

Figure 4.4 shows the longitudinal section of the landslide and debris trail with the chainage started from the crest of the landslide. Chainage 0 to 25 is the landslide source area. This area is located at $233 \mathrm{mPD}$ inclined at an angle of $41^{\circ}$ from the horizontal within the area of granite bedrock with a thin colluvial cover. The aerial photograph of this area shows that this source area was also heavily vegetated with shrubs and small trees before the landslide. The source was $26 \mathrm{~m}$ long and $15 \mathrm{~m}$ wide at the base. The volume of the detached materials is estimated as $250 \mathrm{~m}^{3}$.

The deepest exposed profile contained approximately $0.5 \mathrm{~m}$ of colluvium, overlying $1.0 \mathrm{~m}$ of moderately to slightly decomposed granite outcrop. The detached material is reduced to zero depth at the lower portion of the landslide.

Between Chainage 25 and Chainage 128 the profile is steep. Chainage 25 to 50 is a $25 \mathrm{~m}$ long rock cliff at an angle of $52^{\circ}$ to $58^{\circ}$ from the horizontal. Abrasion and stripping of the rock surface and tree branches and bark was due to the landslide incident in that portion of the profile. Approximately $5 \mathrm{~m}^{3}$ of soil was eroded from small ledges on the face of the cliff. The slope of the hillside decreases to $40^{\circ}$ beyond the base of rock surface. This portion of the slope had colluvial deposit overlying completely 
decomposed (CDG) and highly decomposed granite (HDG). The upper layer of the colluvium was less then $0.3 \mathrm{~m}$ thick and overlay decomposed granite. The composition of colluvium was clast (talus) supported with nearly equal proportions of angular cobbles and boulders of moderately decomposed granite. This colluvium contained up to $25 \%$ of silty sand and gravel.

Chainage 40 to 70 is at the base of the rock surface, where maximum erosion took place. At the north side, the depth of erosion was up to $1 \mathrm{~m}$. The eroded mass was colluvium and completely decomposed granite. On the other hand, at the south side of the area, material depletion of zero to $0.3 \mathrm{~m}$ thick was observed. The different erosion was due to the impact of the wedge shaped landslide debris. The volume of eroded material between Chainage 40 and 70 was $125 \mathrm{~m}^{3}$.

Chainage 70 to 115 has a drainage line gradient of 1 in 1.7 , which is approximately $30^{\circ}$ from the horizontal. Due to this flatter slope, the deposition of colluvium increases. In this region, the debris trail bifurcates into a main channel on the north and a minor one on the south. Bedrock is exposed due to erosion of the main channel from the debris flow. A loose boulder of $2.2 \mathrm{~m}$ was deposited in the north side of the channel. Chainage 77 to Chainage 102 is recently deposited colluvium lobe. In this section, debris was transported over the lobe with some erosion and flattening of vegetation, and subsequent deposition was started in a thin layer. The volume of debris eroded in this section was approximately $260 \mathrm{~m}^{3}$.

In Chainage 102 to 128 , approximately $70 \mathrm{~m}^{3}$ recently deposited colluvium is eroded. In Chainage 128 to 325 , the debris trail is narrowed to $10 \mathrm{~m}$. At Chainage 137 , due to smooth bends, a supperelevation of $3^{\circ}$ was estimated from the marks along the 
sides of the debris trail. A thin layer of $100 \mathrm{~mm}$ debris was deposited on the side. The debris looks like a fine remolded material. After Chainage 148, the debris flowed on cascade steps on rock slab with a slope angle ranging from $35^{\circ}$ to $45^{\circ}$. A thin layer of about $200 \mathrm{~mm}$ topsoil and colluvium was removed and boulders of $300 \mathrm{~mm}$ in size were accumulated. The deposited material was found fully saturated and in a soft condition in the evening of September 03, 2001, 2 days after the landslide event.

At Chainage 190, the debris flow trail is much flatter and wider with deposition on the west bank of this having $3.0 \mathrm{~m}$ thick and on the east bank $1.3 \mathrm{~m}$ thick. In this Chainage, the debris trail enters into the mainstream course.

In Chainage 200 to 243 , the debris trail was approximately $10 \mathrm{~m}$ in width. A footbridge of $3.5 \mathrm{~m}$ span was damaged by the debris flow. The deck of the footbridge was $3 \mathrm{~m}$ wide and $3.5 \mathrm{~m}$ in span. In Chainage 207 , a large boulder, about $1.8 \mathrm{~m}$ by $1.4 \mathrm{~m}$, was deposited. Between chainage 200 to $243,25 \mathrm{~m}^{3}$ fine and coarse remoulded and reworked debris was deposited.

At chainage 243 , boulders up to about $1 \mathrm{~m}$ in size were deposited. The deposition volume of debris in this section was approximately $80 \mathrm{~m}^{3}$.

The debris front consisted of approximately 60 to $70 \%$ boulders and cobbles, $15 \%$ tree fragments and construction debris and 15 to $25 \%$ sandy gravel and organic material. In the trial pits excavated within a nearby quarry site, the deposited debris was $600 \mathrm{~mm}$ thick and $65 \%$ was cobbles, and boulders. A trial pit excavated behind the debris front showed that the material consisted of $25 \%$ cobbles and boulders, and less than $25 \%$ fine sand and silt with a thickness of $300 \mathrm{~mm}$. The total volume of debris deposited was 530 $\mathrm{m}^{3}$. 


\subsubsection{Geomorphology}

The catchment area including the landslide portion is shown in Figure 4.5. The catchment area of the hillside immediately above the landslide is $3,500 \mathrm{~m}^{2}$. Subcatchment $A$, which contains the landslide source, has an area of about $26,000 \mathrm{~m}^{2}$. In addition, the catchment area measured at Chainage 190 is approximately $84,000 \mathrm{~m}^{2}$. The catchment area increased from 110,000 to $133,000 \mathrm{~m}^{2}$ between Chainage 190 and Lei Pui Street.

The geographical area under study was subdivided into five different terrains in order to study the effect of instability of a slope for landslides formation. These terrains are shown in Figure 4.5, where the upper slopes are identified as Terrain 1, middle rock outcrops and lower slopes as Terrain 2, west-facing hillside as Terrain 3, smooth rounded and north to northeast facing slopes with a few rock outcrops as Terrain 4, and rounded south-facing slopes with rock outcrops as Terrain 5.

The upper portion of Terrain 1 has a slope angle of $30^{\circ}$ to $40^{\circ}$ and contains 13 inferred old landslides and 1 recent landslide. The topography shows that the rock head is relatively deep compared to nearby areas. The underlying coarse grain rock, which is more susceptible to weathering as compared to fine-grained rocks, is decomposed up to significant depth. This area shows a zone of depletion, and has released many landslides in the past geological time. 


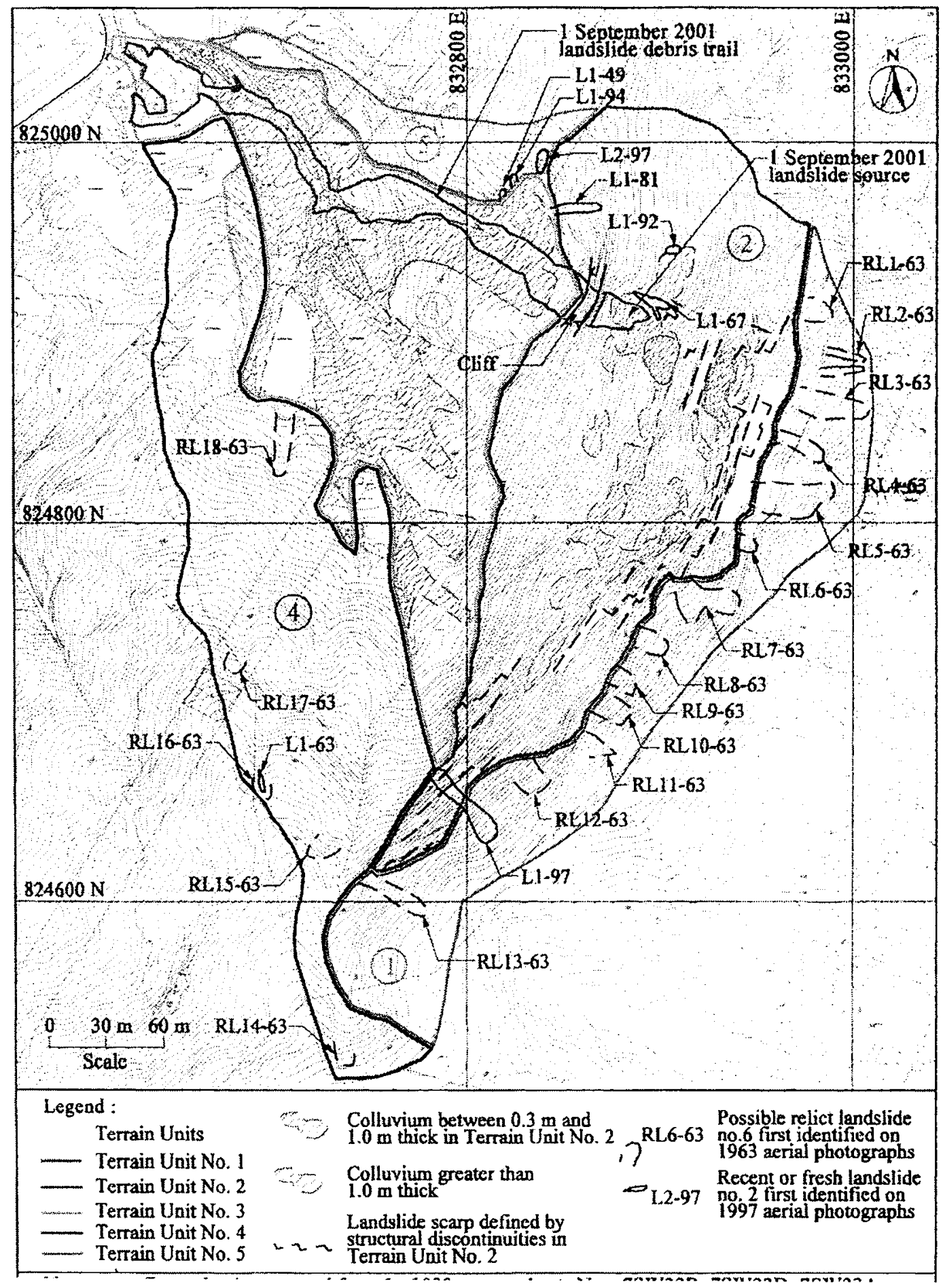

Figure 4. 5 Geomorphology of the landslide area (Maunsell, 2002)

The middle slope terrain, Terrain 2, consists of fine-grained granite rock outcrops at inclinations of $40^{\circ}$ to $50^{\circ}$. These rocks have prominent sheeting joints with weak fill. 
The stability of this terrain is heavily influenced by the underlying rock structure. There are four sets of joints on the rock surface in the source vicinity and scarps portion. Set 1 joints are oriented to planar sliding and Set 2 joints are oriented to toppling. Both sets form release surfaces and potential cracks, which allow plane sliding. Set 3 and Set 4 joints strike at a high angle to the Set 1 and Set 2 joints. This specific combinations form lateral release surfaces and also allow the rocks to detach. Set 2 types of joints may have contributed largely to the landslide under study. On the photograph, many blocks are detached from Set 2 types of joint. Many of the cliffs in the hillslope show scarp structures that have failed by a combination of toppling and sliding. In addition, many remaining scarps can be regarded as being potentially unstable.

A thin layer of colluvium lies above the slide and it is mildly sloped along the Set 2 terrain. Colluvium is found resting on overhung sheeting joint directly beneath the source. Colluvium is exposed during erosion from the slide, revealing loose, clastsupported, angular cobbles, boulder, gravels, and silty sand.

Three small landslides of about $20 \mathrm{~m}^{3}$ or less in the volume and shallow depth occurred in 1967,1981 , and 1992. Some portion of this terrain has erosion along the temporary drainage line. Terrain 2 is primarily a zone of active depletion and transportation.

Terrain 3 lies at the lower side of the Terrain 2, that has a colluvium layer thickness greater than $1 \mathrm{~m}$. The rock head is relatively deep and exposed in the temporary drainage line. There is colluvium on the foot of the cliff, containing slightly to moderately decomposed clasts with little saprolite development between the colluvium and bedrock. From this, it is inferred that the process of frequent erosion by rock 
avalanches probably occurred near the foot of the cliff in recent geological time. Terrain 3 is a zone of deposition containing the depleted material from Terrain 1 and Terrain 2. The depleted material from the upper terrain was transported in the form of debris and hypo-concentrated flow. The activity of the zone of depletion in the upper terrain enters the bank of many of the temporary drainage lines.

Terrain 4 was found to be more unstable than the other terrains. Mostly, the exposed portion of the temporary drainage line was unstable. Consequently, six landslides were recorded in this terrain in the past due to instability. The instability may be due to weak structural orientation, i.e. oblique orientation of strike of the main rock structure.

\subsubsection{Geology}

The detail of the landslide scarp is given in Figure 4.6. The stress relief joints Set 1 are roughly undulating with the dip typically ranging from $31^{\circ}$ to $50^{\circ}$. The average dip is about $41^{\circ}$ and the dip directions range from $270^{\circ}$ to $298^{\circ}$. The depth of $5 \mathrm{~mm}$ to $80 \mathrm{~mm}$ of the surfaces of joints are moderately to highly decomposed rocks and loose sand infilling of up to $100 \mathrm{~mm}$ thickness, and occasional sandy silt infilling of up to $40 \mathrm{~mm}$

thickness. The maximum length of a single, continuous, joint is about $18 \mathrm{~m}$. The spacing of the joints varies from $0.2 \mathrm{~m}$ to $1.0 \mathrm{~m}$ with an average of $0.3 \mathrm{~m}$. 


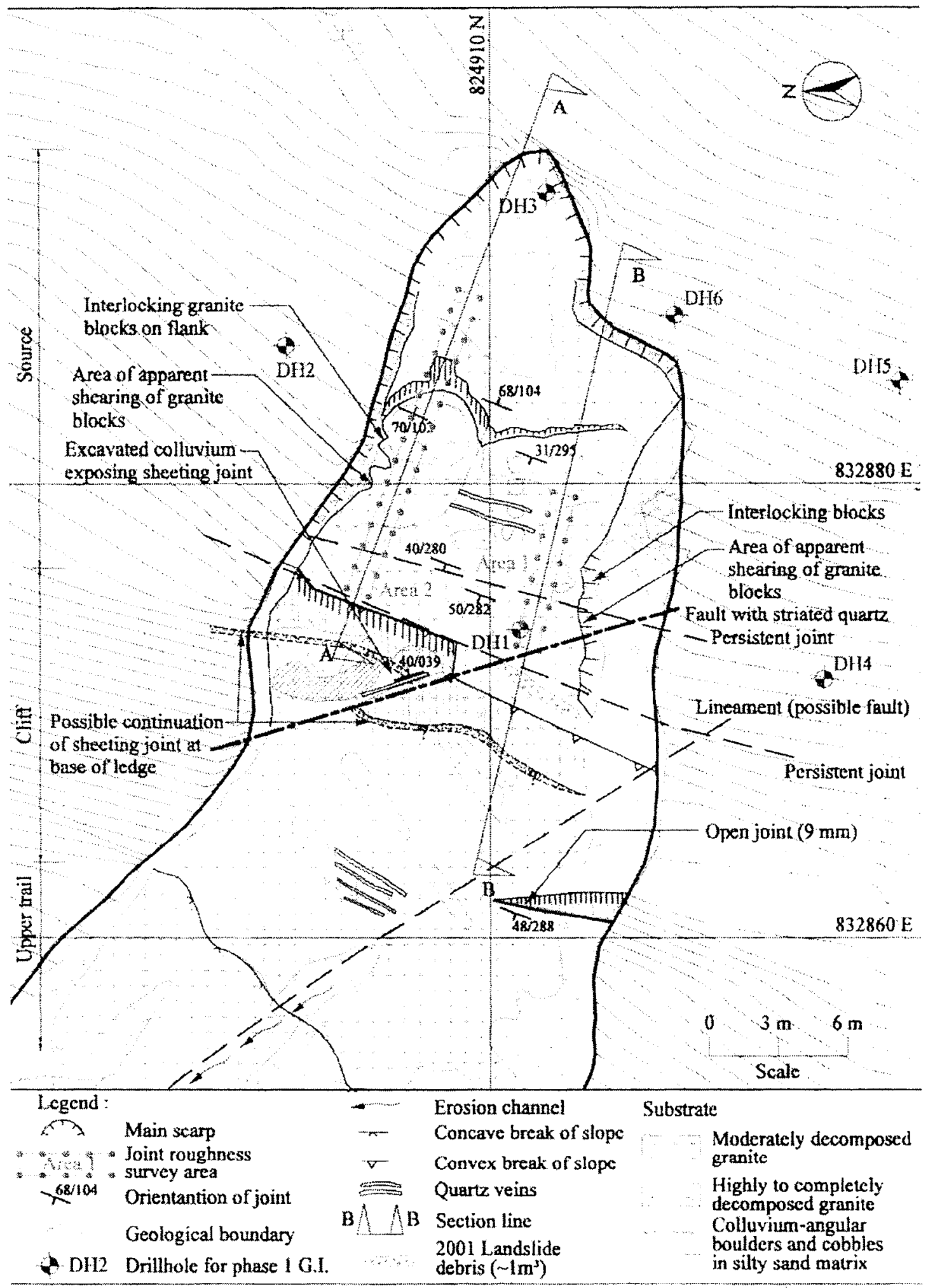

Figure 4. 6 Scarp of the landslide (Maunsell, 2002) 
Set 2 type of joints are roughly planar with the dip typically ranging from $60^{\circ}$ to $70^{\circ}$ and dip direction ranging from $100^{\circ}$ to $110^{\circ}$. Joints are moderately decomposed within $5 \mathrm{~mm}$ to $20 \mathrm{~mm}$ of the joint surfaces, and in some places are filled with very loose silty sand, up to $30 \mathrm{~mm}$ thick. The spacing of the joints varies between $0.2 \mathrm{~m}$ to $6.0 \mathrm{~m}$.

\subsubsection{Rainfall}

A rain gauge station was located about $500 \mathrm{~m}$ west of the incident. The rainfall was recorded daily from July 31 to September 01, 2001. Hourly rainfall was also recorded at the same station from August 30, 2001 to September 02, 2001. In addition to recording rainfall from the nearest rain gauge station, GEO automatic rain gauge stations were also used. The pattern of the rainfall record from automatic rain gauge is similar to the rainfall record obtained in the nearest rain gauge station.

Heavy rainfall was recorded during the landslide incident. Rainfall was heavy between 9:30 PM. to 11:00 PM. The rainfall within the preceding 24 hours was $202.5 \mathrm{~mm}$, and within 12 hours was $181.5 \mathrm{~mm}$. The maximum one hour rolling rainfall was recorded to be $97 \mathrm{~mm}$ between 9:50 PM to 10.50 PM on Sept. 01, 2001. The black rainstorm warning and landslip warning were announced at 10:45 PM on September 1, 2001. The black rainstorm warning and the landslip warning were cancelled at 03:15 AM and 10:00 AM on Sept 02, 2001.

Lam and Leung (1994) suggests that the 2-hour rainfall with a corresponding return period of 14 years is the most severe slope instability. The rainfall observed at 10:50 PM. was comparable with that of the most severe rainstorms previously recorded from the same station for the duration between 2 hours and 3 hours. Figure 4.7 shows the 
15 minutes highest intensities in Sep 01, 2001, which was $30 \mathrm{~mm}$ after 8:30 PM and 28 mm between 10:30 PM to 10:45 PM.

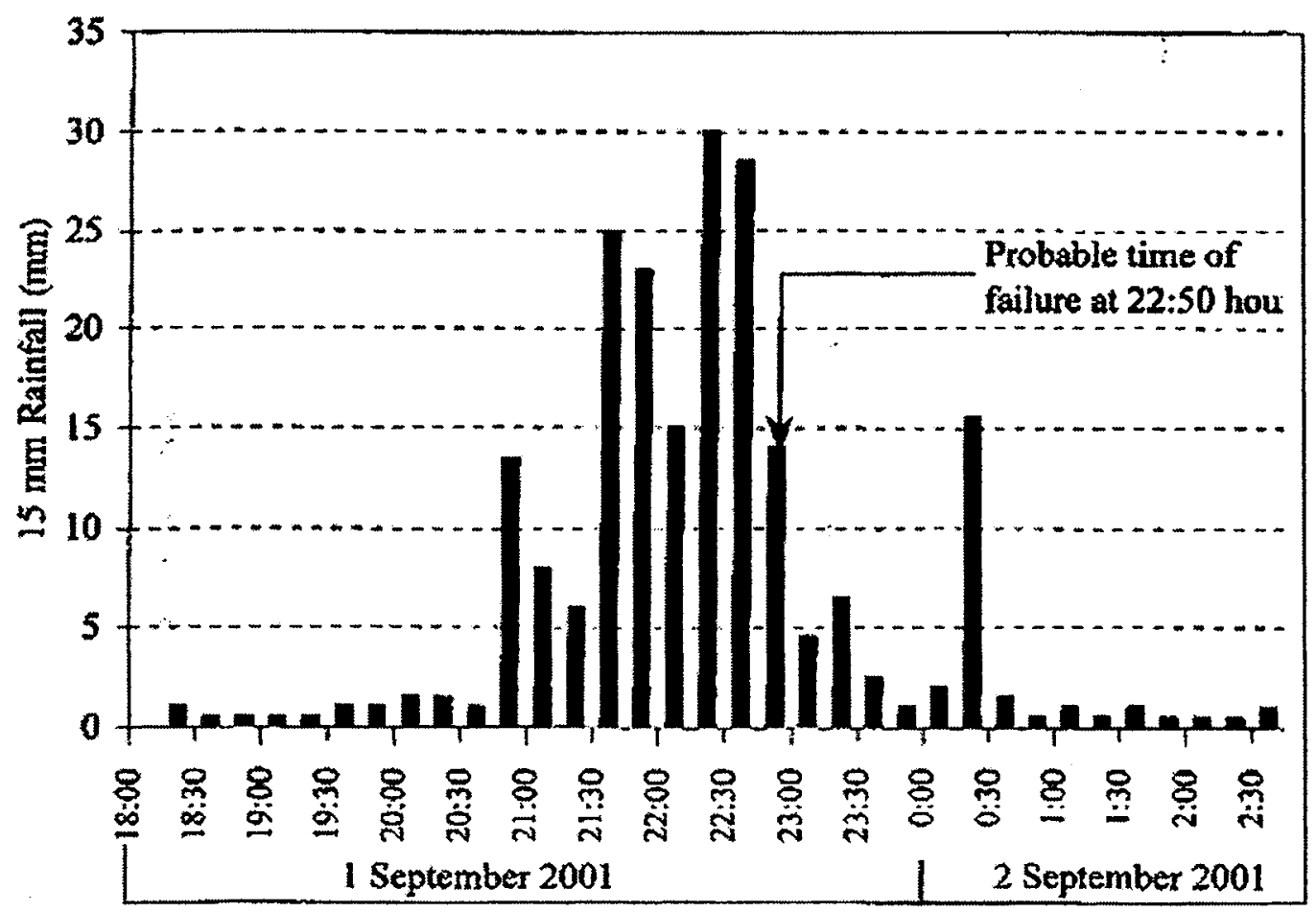

Date \& Time

Figure 4. 7 Rainfall intensity in 15 minute duration (Maunsell, 2002)

\subsubsection{Hydrology}

The catchment area above the landslide source involved in seepage is $3500 \mathrm{~m}^{2}$. The seepage was not detected in the scarp location three days after the landslide incident. However, abundant seepage was observed within the rock slabs adjacent and above the landslide even in the weeks following the rainstorm and the landslide incident. Therefore, the failure may have been caused by generation of instant pore pressure through seepage. The undulating slope geometry and different thickness of the 
permeable colluvium overlaying the less permeable CDG was the main contributing factor for the seepage.

The groundwater level recorded near the source area early in the next morning after the landslide was within $2.5 \mathrm{~m}$ to $4 \mathrm{~m}$ below the ground surface. The depth of the groundwater level influenced the depth of the dilated and decomposed sheeting joints. These may be because the filling fluid escaped via the sheeting joints.

\subsubsection{Failure events}

The landslide event was recorded by the police force with the help of witnesses. At the beginning, dogs were barking at 8:30 PM. and subsequently flow of muddy water started in the temporary drainage line. Four occupants of the squatter units, which were later destroyed by the debris flow, decided to depart shortly afterwards and ran down the steps in front of the squatter units and crossed the concrete bridge, which also was demolished by the debris later.

The main debris flow occurred at about 10:50 PM according to the Hong Kong Police Force report. The incident was first reported to the police emergency unit at 10:55 PM. Further reports were subsequently made four times between 10:58 PM and 11:05 PM. A minibus driver, who was proceeding along Lei Pui Street from Shek Pai StreetLei Pui Street junction, saw the debris on the road with torrential water flow. The driver also observed a large quantity of soil with water, vegetation, rubbish, kitchen utensils, and a cooking gas cylinder being swept toward his vehicle. The Police observed at 10:58 PM that both lanes of Lei Pui Street were blocked by debris. A huge sound was heard before the debris flow. Intense rainfall was recorded between 10:15 PM and 10:45 PM, 
shortly before the landslide. The landslide most probably occurred at 10:50 PM (Maunsell 2002).

\subsubsection{Laboratory observation}

Bulk soil samples were taken from the various test pits from the landslide scarp and were observed by Maunsell (2002). The soil matrix was composed predominantly of sand and gravel, about 64 to 95 percent. The particle size distribution of the landslide debris contained sand and gravel was from 49 to 55 percent. Silt contents ranged from about 25 to 30 percent, sand contents ranged from 15 to 19 percent, clay contents were from 0 to 22 percent, and silt contents were from 5 to 15 percent, respectively. The soil strength parameters, cohesion and friction, for deposited debris were $0.0 \mathrm{kPa}$ and $26^{\circ}$ respectively. The infill sediment, which has low strength, was predominantly silt and sand mix, with sand ranging from 20 to 65 percent, and clay ranging from 8 to 32 percent. Natural joint surfaces have friction angle of $42^{\circ}$, which were obtained from the shear box test. The failure surface is within the natural joint so that operational range of angle of friction is less than $42^{\circ}$. Therefore, operational angle of friction is taken as $41^{\circ}$ and zero cohesion in this study.

\subsection{Analysis}

The initial landslide is back-analyzed with the use of different pore pressures and strength parameters pertinent to the completely to moderately decomposed granite and the overlying colluvium in the sloping terrain of Hong Kong area. Slope/W and FLAC are used for analyses. FLAC is used to compute the factor of safety of failure mass. This factor of safety was then compared with that obtained from Slope/W. 
The movement of debris after the initial landslide is analysed using DAN and FLO-2D. The analyses provide velocity and depth of debris at different locations and the runout distance.

\subsubsection{Using Slope/W for landslide initiation}

The initial landslide mass is modeled as shown in Figure 4.8 (dimensions shown in figure are reduced to 1:300 scale). The failure slope is drawn from the topographic map, taken before the landslide incident. The landslide scarp line is drawn from the information available in Maunsell (2002).

The parameter selection for analysis is based on the observation and laboratory test results documented in Maunsell (2002). The slope of the landslide area is approximately $41^{\circ}$. The failure surface of the landslide is in the decomposed saprolite and colluvium. The cohesion is taken as zero. The angle of internal friction of the sliding mass is taken as $41^{\circ}$. The unit weight of the sliding mass is taken as $19.5 \mathrm{kN} / \mathrm{m}^{3}$. The list of input parameters used in Slope/W analysis is given in Table 4.1. In Table 4.1, listed pore pressure ratio $\left(r_{u}\right)$ is the ratio of water pressure to the normal stress on the failure surface. 
Table 4. 1 Input parameter for Slope/W

\begin{tabular}{|l|l|}
\hline Parameter & Value \\
\hline Friction angle & $41^{\circ}$ \\
\hline Cohesion & $0.0 \mathrm{kPa}$ \\
\hline Pore pressure ratio $\left(\mathrm{r}_{\mathrm{u}}\right)$ & 0.0 \\
\hline Unit weight & $19.5 \mathrm{kN} / \mathrm{m}^{3}$ \\
\hline
\end{tabular}

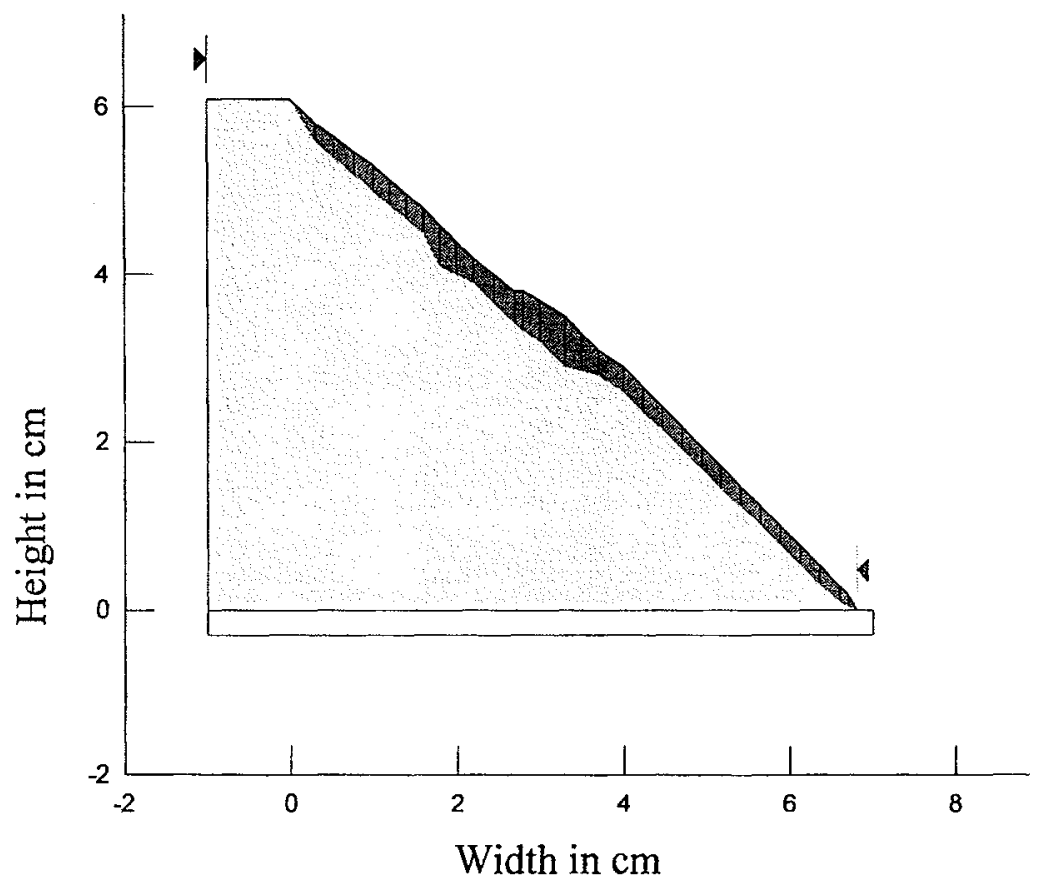

Figure 4. 8 Cross-section of Lei Pui Street Landslide for Slope/ W analysis

There was heavy rainfall during the landslide incident. The infiltration rate was $70 \%$ of rainfall intensity during heavy rainfall. Rainfall intensity greater than $10.0 \mathrm{~mm}$ for 15 minutes may generate transient pore pressure because the saturated transmissibility of the soil mass observed by $\mathrm{Li}$ et al. (2004) was $7.8 \times 10^{-6} \mathrm{~m} / \mathrm{s}$ in similar soil condition. 
The rainfall intensity rate during the heavy rainfall $(30 \mathrm{~mm}$ in 15 minutes) was greater than the saturated transmissibility of the soil down to $2 \mathrm{~m}$ depth of colluvium ( $\mathrm{Li}$ et al. 2004). Figure 4.7 shows that since 2 hours before the landslide incident, rainfall intensity was greater than $10 \mathrm{~mm}$ per 15 minutes. An apparent positive pore pressure may be generated due to higher infiltration rate but the duration of rainfall for intensity greater than transmissibility was short ( 2 hours). In this short period, the depth of permeation was less than $50 \mathrm{~mm}$. Therefore, transient pore pressure generated by the heavy rainfall was less significant to the landslide initiation.

The degree of saturation of the landslide mass down to $1 \mathrm{~m}$ depth during the failure was $90 \%$ (Li et al. 2004). The depth of failure surface of the landslide varied from zero to $1.45 \mathrm{~m}$ from the ground surface with the average depth being less then $1 \mathrm{~m}$. Therefore, the slide mass was in near saturation condition before failure. The failure surface was along the interface between the CDG and the colluvium. For depth of colluvium greater then $1.0 \mathrm{~m}$, the soil may not have been saturated and suction may still have existed. The most part of the landslide depth is less than $1 \mathrm{~m}$ and the soil mass within that depth was saturated. This soil mass was the cause of generation of pore pressure.

In the back analysis, the slope was modeled to its physical form that existed before the landslide. The slip surface was taken from the field data, which was measured along the scarp of the landslide.

The modeling techniques described in Chapter 3 have been used to calculate the ratio of resisting force to the disturbing force as an indicator of stability of a slope. When the ratio falls below 1.0, the slope is unstable. 
The computation of factor of safety reported in this analysis assumes that a slope has its maximum stability when the pore pressure is zero in the soil mass. Such a condition is fulfilled in the absence of water head due to rain or groundwater.

The calculated factor of safety for the landslide was found to be 1.06 from the Ordinary method, and 1.08 from Bishop's method and Janbu's simplified method. The simplified Janbu's method is more applicable for a planar slip surface as found in this case.

The calculated factor of safety of the slope at zero pore pressure being marginally greater than 1.0 indicates that the slope was near limit equilibrium.

The landslide occurred immediately after the heaviest 15 minutes of rainfall that was preceded by continuous rain for two months. This caused piping and seepage in the interface of CDG and colluvium. Piping was seen in the scarp of the landslide the morning after the incident.

Pore pressure in a slope can be generated in many ways. It can be generated from infiltration at the upper part of the slope where the colluvium is thin. It can be easily saturated during small rainfalls and start seepage along colluvium and impervious layer interface. Pore pressure is also formed when the infiltration rate is higher than the saturated transmissibility of the soil, which can occur temporarily during heavy rainfall.

When the pore pressure ratio $\left(r_{u}\right)$ was raised from 0.0 to 0.04 in the model, the factor of safety dropped from 1.08 to 1.0 . Assuming the failure soil depth of $1.0 \mathrm{~m}$, this pore pressure ratio of 0.04 was equivalent to $11 \mathrm{~cm}$ of water head at the slip surface. 
The cohesion of soil played a vital role in the stability of the slope. The factor of safety increased from 1.08 to 1.44 when the cohesion was increased from 0.0 to $1.0 \mathrm{kPa}$. When the cohesion was $1.0 \mathrm{kPa}$, the pore pressure ratio $r_{u}$ required to reduce the factor of safety from 1.44 to 1.0 was 0.24 , which is equivalent to $48 \mathrm{~cm}$ water head in $1.0 \mathrm{~m}$ thick soil. Similarly, when the cohesion increased to $2.0 \mathrm{kPa}$, the factor of safety of the slope increased to 1.8 , and the $r_{u}$ necessary to reduce the factor of safety to 1.0 was 0.43 , which is equivalent to $85 \mathrm{~cm}$ water head in $1.0 \mathrm{~m}$ thick soil.

The laboratory measurements showed zero cohesion for the soil under the saturated condition. However, the stability analysis showed that the slope was already in limit equilibrium with friction angle of $41^{\circ}$. If the soil had only frictional strength, it could have started sliding before a heavy rainfall. If the soil had an apparent cohesion due to suction, the cohesion would be reduced gradually because of infiltration and saturation. This indicated that some cohesion did exist in the soil prior to the failure. After some time, suction gradually decreased and reduced the apparent cohesion to cause the slope to fail.

\subsubsection{Using FLAC for landslide initiation}

The FLAC software simulation technique has been described in Chapter 3. The use of FLAC in the modeling of a slope and safety factor calculation is given in this section. The factor of safety calculated from FLAC is compared to the factor of safety calculated from SLOPE/ W.

The analysis in the FLAC is based on the strength reduction method, where a slope is divided in a grid system and soil characteristics data collected from the field are 
given as input to the modeling program. A grid system of 36 by 18 is selected for modeling the slope of the Lei Pui Street Landslide. Figure 4.9 shows the model and dimensions of the slope. The slope angle is approximately $41^{\circ}$ from the horizontal. The Mohr Coulomb failure criterion is used in the analysis. Input parameters of soil are selected from the field report and literature as listed in Table 4.2

Table 4. 2 Input parameters for FLAC

\begin{tabular}{|l|l|}
\hline Parameter & Value \\
\hline Friction angle & $41^{\circ}$ \\
\hline Cohesion & $0.0 \mathrm{kPa}$ \\
\hline Unit weight & $19.5 \mathrm{kN} / \mathrm{m}^{3}$ \\
\hline Bulk modulus & $66.7 \mathrm{MPa}$ \\
\hline Shear modulus & $40.0 \mathrm{MPa}$ \\
\hline
\end{tabular}

Figure 4.9 shows the model of the slope for FLAC analysis. The right vertical face and left vertical face of the slope are prevented from moving along the horizontal direction and are allowed to move only along the vertical direction. The bottom of the slope is bedrock. Therefore, both horizontal and vertical movements are fixed at the bottom of the model. The boundary condition selected in this manner was found to introduce no significant error in the computation of the factor of safety of the slope. In addition, the marginal distance kept on the model is sufficient to nullify the boundary effect on factor of safety analysis. 
Initially, a large tensile strength of $10,000 \mathrm{kPa}$ is added to the soil strength for stability of the model before the gravity and other loads are applied. The tensile strength is gradually reduced to zero and the field gravitational load is gradually increased.

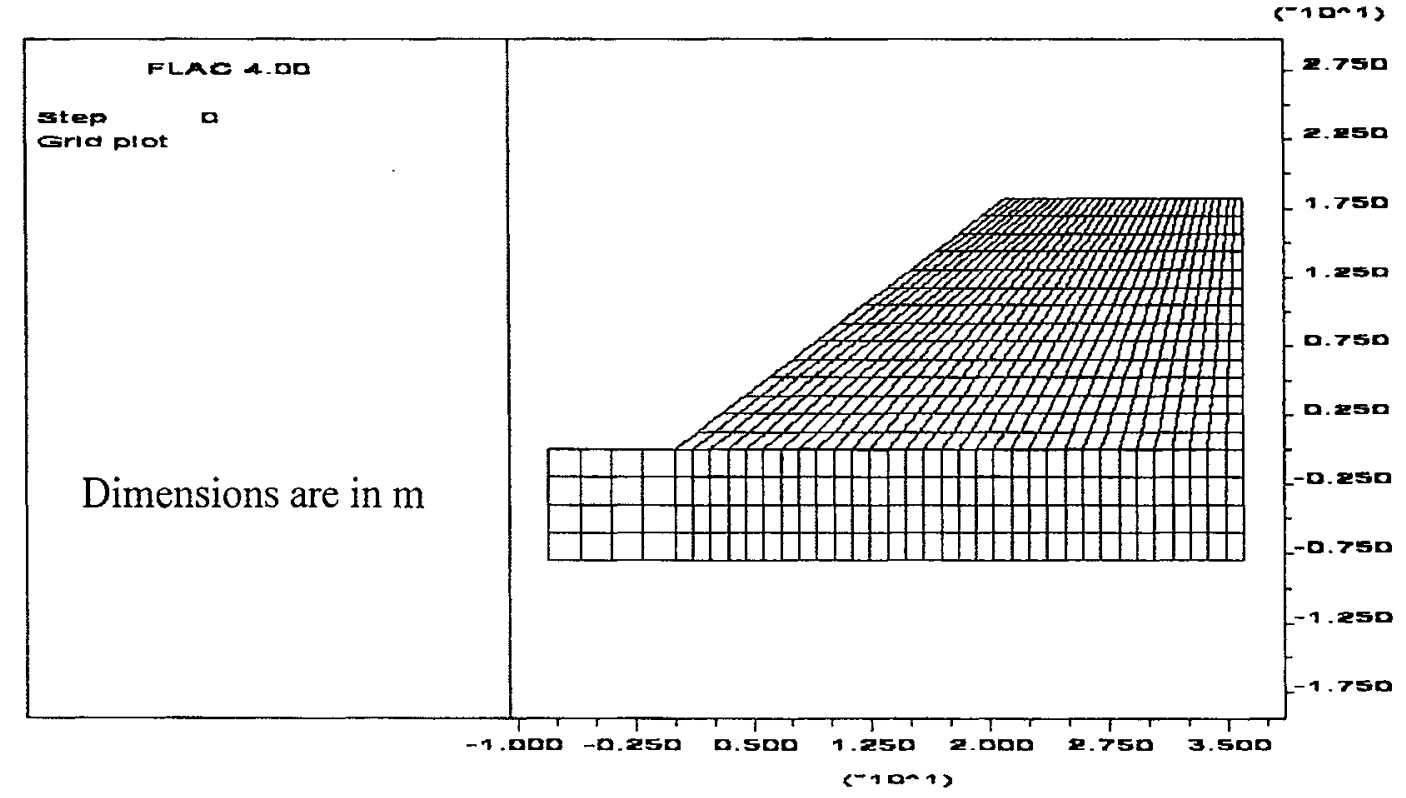

Figure 4. 9 Lei Pui Street Landslide grid discrete model

The factor of safety calculated using FLAC with zero cohesion is 0.9 , which is lower than the factor of safety calculated from SLOPE/W (1.08). Similarly, the factor of safety for cohesive strength of $1 \mathrm{kPa}$ and $2 \mathrm{kPa}$ is 1.0 and 1.12 respectively. It is seen that small value of cohesion influences significantly the stability of the slope. Figure 4.10 shows the failure mode of the slope as defined in FLAC. 


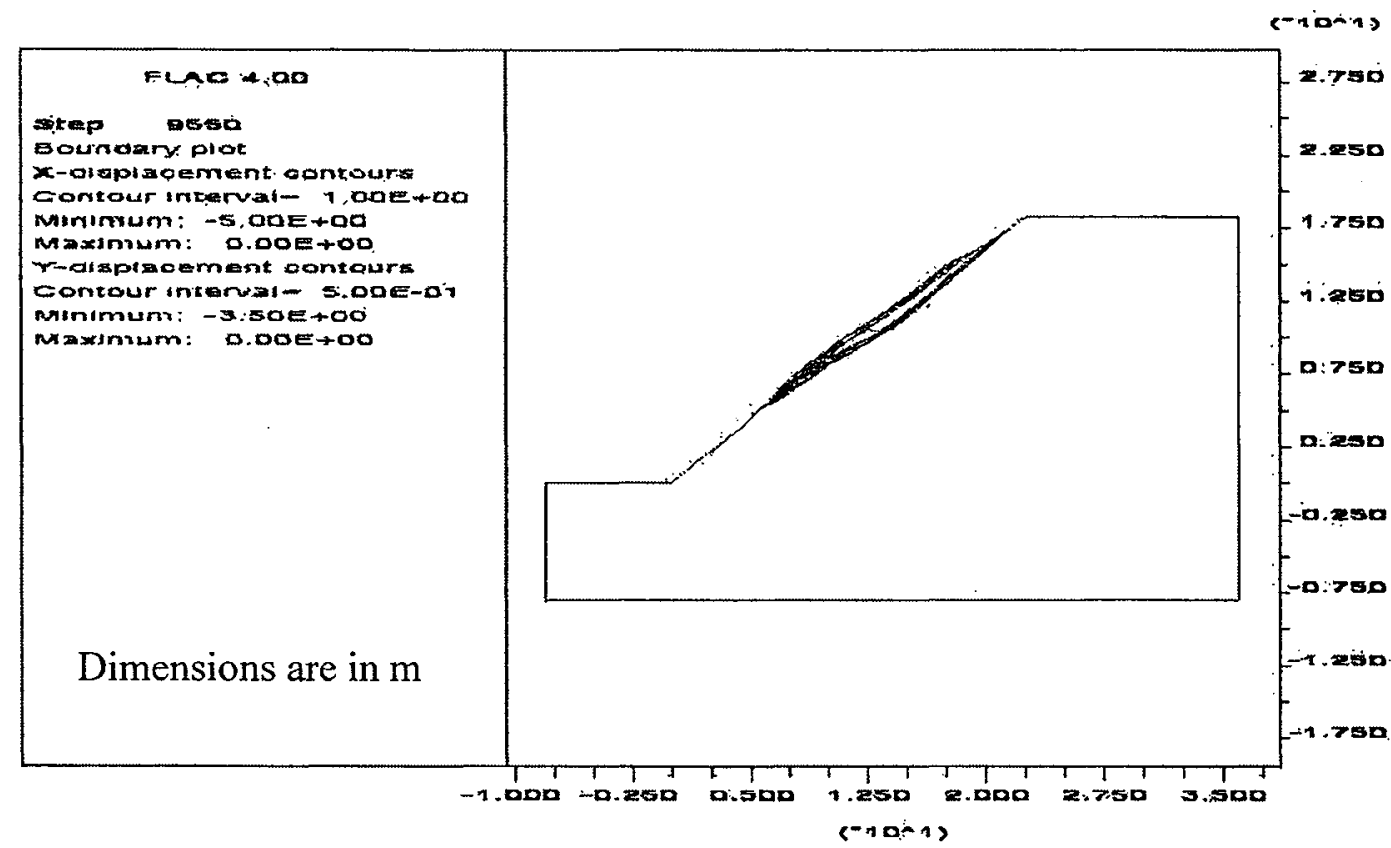

Figure 4. 10 Deformation in Lei Pui Street Landslide

Analysis shows that factor of safety is less than 1.0 in zero cohesion. This result also supports the existence of apparent cohesion before failure of the soil mass as mentioned in the factor of safety analysis in Slope/W.

\subsubsection{Dynamic analysis}

The previous section describes the initial failure of the slope. After the initial failure, the movement of the landslide varies significantly for different soil characteristics and flow surface. In some condition of soil characteristics and flow surface, the landslide mass transforms into debris flow. Debris flows generally move large distances compared 
to landslides that do not transform into debris flow. They are also more devastating. This section is dedicated to the analysis of velocity and runout distance of a debris flow, as it is important for designing safety measures for devastating landslides.

Debris flow width is known along the debris flow surface so that the discharge and the depth of the flow can be computed from the velocity obtained from the DAN analysis. Once these terms are known, counter measure structures for debris flow hazard protection can be designed.

The dynamic analysis (DAN) proposed by Hungr (1995) is useful for velocity and runout distance analysis of the debris flow. DAN, which is described in Chapter 3 , is conducted for the study of runout distance for this case record.

The landslide mass is divided in ten mass blocks for the DAN analysis as shown in Figure 4.11 . These 10 mass blocks are separated by 11 boundary blocks. The position and height of the boundary blocks are shown in Table 4.3, where $H_{i}$ represents the height of the boundary blocks, $P$ the initial pressure resultant, and $T$ the basal resistance force. Initially, the landslide mass is sliding at the slope angle of $41^{\circ}$.

The landslide mass is a mixture of soil and water with a volume of $282 \mathrm{~m}^{3}$ in the source location and that is divided in 10 mass blocks for modeling. It is assumed that the mass changes its rheology as it moves along.

The model is based on earth pressure theory. It assumes that the earth pressure increases linearly with depth. The resistance is calculated from the selected rheological model. The possible rheological models for the landslide debris flow are Newtonian 
laminar flow, Bhingham flow, Coulomb viscous flow, Voellmy rheology and friction rheology (Ayotte et al. 1999). The choice of an appropriate rheology and corresponding input parameters are based on trial and error and on previous experience (Hungr 1998). In this case, two models are used: frictional rheology and Voellmy rheology. According to (Ayotte et al. 1999), at the beginning of the slide on the steep slope, the friction model is appropriate and after some movement down the slope in a fixed channel, Voellmy model is suitable.

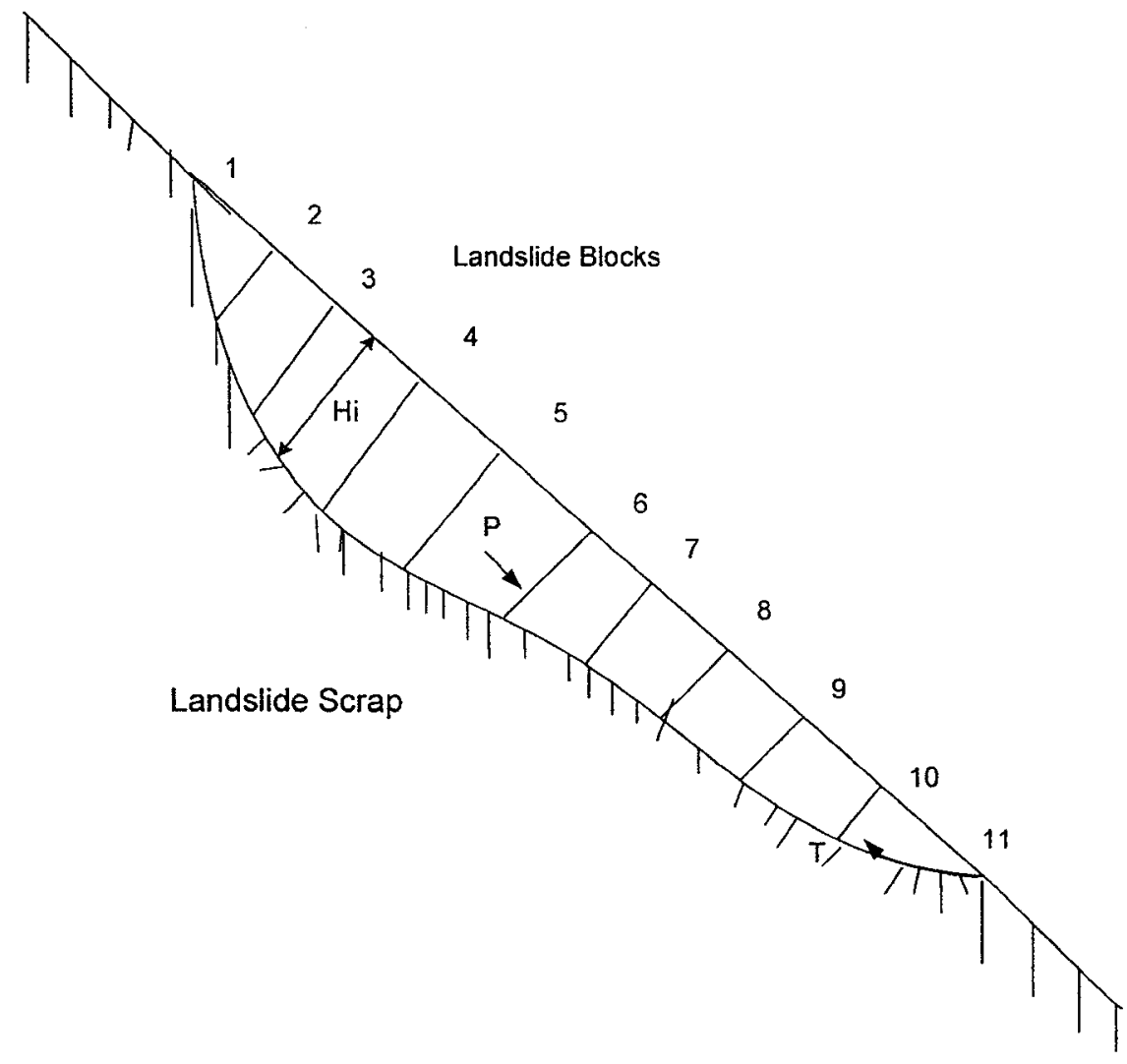

Figure 4. 11 Landslide mass is divided into blocks 
Reliable representation of the rheology of the debris mass is important to analyse the debris flow movement. Appropriate rheology of flow is necessary to chose for simulation. The debris flow surface is not a defined channel but lying along deepest profile of the natural terrain so that both friction and Voellmy rheology are used for initial observation.

Table 4.4 shows the longitudinal profile of the flow surface. Coordinates are taken from the available topographical map in 1:250 scale (Maunsell 2002).

Table 4. 3 Division of the landslide in blocks

\begin{tabular}{|c|c|}
\hline Distance from the top, $\mathrm{m}$ & Depth of the block, $\mathrm{m}$ \\
\hline 0 & 0.03 \\
\hline 2 & 0.20 \\
\hline 4 & 0.55 \\
\hline 5 & 0.80 \\
\hline 7 & 1.20 \\
\hline 9 & 1.45 \\
\hline 11 & 1.25 \\
\hline 12 & 0.55 \\
\hline 16 & 0.25 \\
\hline 18 & 0.20 \\
\hline 20 & 0.03 \\
\hline
\end{tabular}

The debris flow profile is simulated with sixth order polynomials. The mathematical relation of the sixth order profile is given by Equation (4.1)

$$
Y=a_{0} X^{0}+a_{1} X^{1}+a_{2} X^{2}+a_{3} X^{3}+a_{4} X^{4}+a_{5} X^{5}+a_{6} X^{6}
$$


where, $a_{0}, a_{1}, a_{2}, a_{3}, a_{4}, a_{5}, a_{6}$ are the polynomial constants, $Y$ is the profile elevation and $\mathrm{X}$ is the horizontal distance. Table 4.5 gives the $\mathrm{X}, \mathrm{Y}$ values using the sixth order of polynomial and the profile is shown in Figure 4.13.

Table 4. 4 Longitudinal profile (Maunsell 2002)

\begin{tabular}{|c|c|c|c|}
\hline Chainage from toe & Elevation & X (distance) & Y (height) \\
\hline 350.0 & 82.58 & 350.0 & 0 \\
\hline 340.0 & 94.88 & 340.0 & 12.3 \\
\hline 330.0 & 96.14 & 330.0 & 13.5 \\
\hline 310.0 & 96.99 & 310.0 & 14.4 \\
\hline 280.0 & 109.34 & 280.0 & 26.7 \\
\hline 260.0 & 112.28 & 260.0 & 29.7 \\
\hline 210.0 & 118.19 & 210.0 & 35.6 \\
\hline 180.0 & 123.74 & 180.0 & 41.1 \\
\hline 130.0 & 145.91 & 130.0 & 63.3 \\
\hline 100.0 & 155.50 & 100.0 & 72.9 \\
\hline 70.0 & 168.0 & 70.0 & 85.4 \\
\hline 60.0 & 175.95 & 60.0 & 93.3 \\
\hline 40.0 & 185.00 & 40.0 & 102. \\
\hline 20.0 & 215.20 & 20.0 & 132. \\
\hline 0.0 & 230 & 0.0 & 147. \\
\hline
\end{tabular}

Table 4.7 shows the various parameters used for the friction and Voellmy models in DAN. The DAN analysis provides velocity and depth of the flow along the debris flow trail. The landslide mass has a friction angle of $41^{\circ}$ for the initial slide. It is assumed that in the debris flow stage, the angle of internal friction that can be mobilized is reduced to $26^{\circ}$. This value was obtained from testing the debris deposited within 24 hours of the incident. This material has been subjected to the flowing stage and any original soil structure would have been destroyed. The strength obtained from this 
material therefore should be equal to the steady state or residual value that is close to the value mobilized during the flowing stage. The surface width of the debris trail is taken as $15 \mathrm{~m}$, which is approximated from Figure 4.12.

Table 4. 5 Polynomials coefficient

\begin{tabular}{|l|l|}
\hline Coefficients & Value \\
\hline $\mathrm{a}_{0}$ & 149.68 \\
\hline $\mathrm{a}_{1}$ & -1.39 \\
\hline $\mathrm{a}_{2}$ & 0.009424 \\
\hline $\mathrm{a}_{3}$ & $-4.2985 \mathrm{e}^{-5}$ \\
\hline $\mathrm{a}_{4}$ & $7.4556 \mathrm{e}^{-8}$ \\
\hline $\mathrm{a}_{5}$ & $9.9465 \mathrm{e}^{-11}$ \\
\hline $\mathrm{a}_{6}$ & $-3.3896 \mathrm{e}^{-13}$ \\
\hline
\end{tabular}

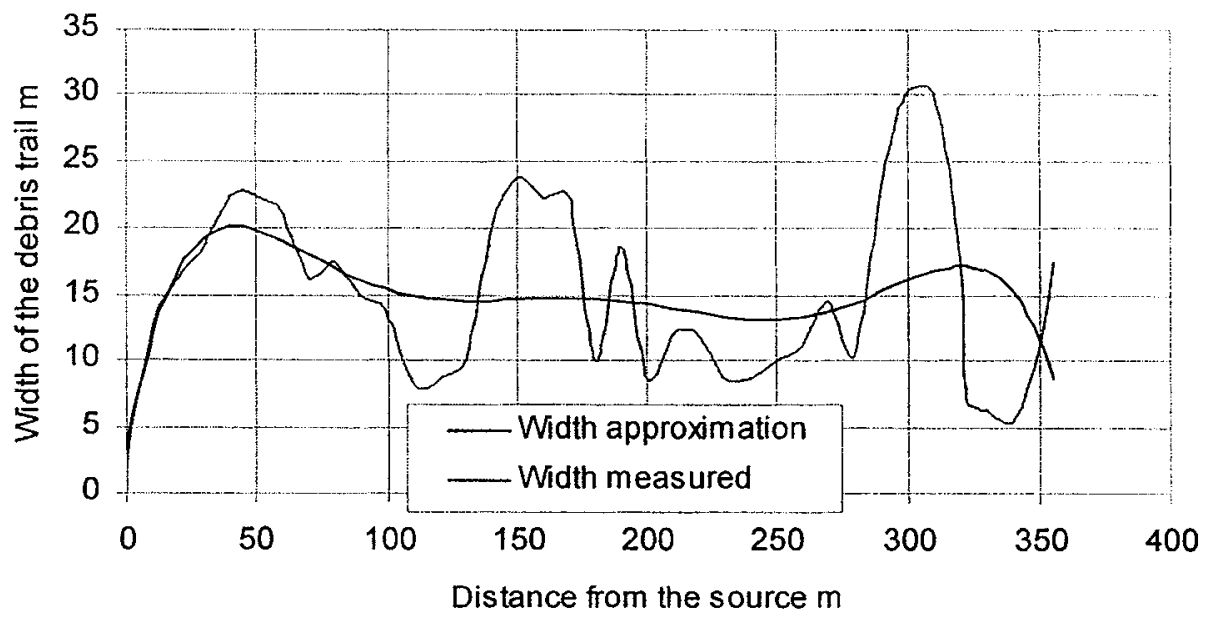

Figure 4. 12 Polynomial fitting for width of debris flow trail 


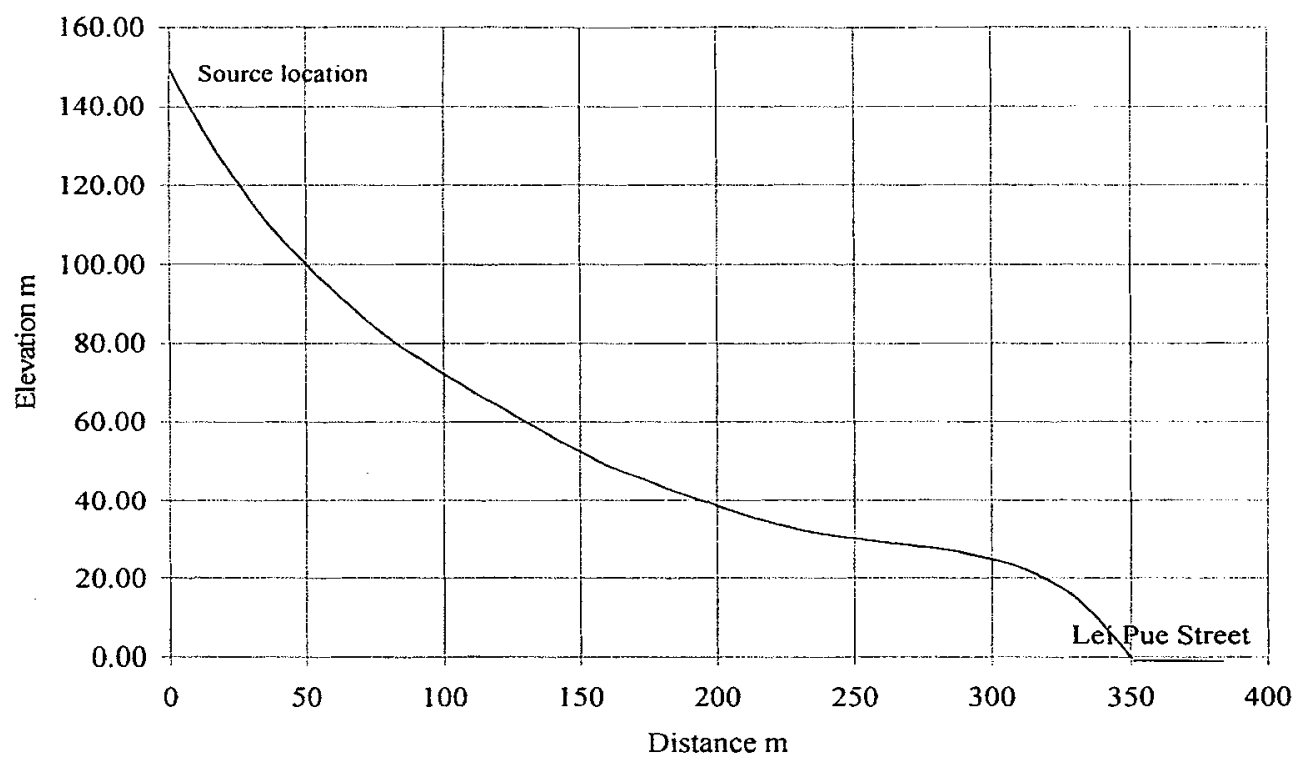

Figure 4. 13 Longitudinal Profile of Lei Pui Street Landslide for analysis

The elevation and chainage for the Lei Pui Street landslide using polynomial fitting are given in Table 4.6.

In DAN, it is possible to see the progress of a landslide at different time steps. In this simulation, the progress of the landslide was observed at a time interval, for updating velocity and runout distance of 0.01 second using friction rheology. The runout distance and velocity of the debris flow calculated by DAN in friction rheology are shown in Figure 4.14, which also shows the velocity along the debris flow trail.

DAN showed that the landslide simulation lasted for 45 seconds. The runout distance obtained from the analysis was $235 \mathrm{~m}$. This analysis also provided debris velocity along the debris flow path. It showed $20 \mathrm{~m} / \mathrm{s}$ as the maximum debris flow velocity at $90.0 \mathrm{~m}$ runout distance. 
Table 4. 6 Distance and elevation from source

\begin{tabular}{|c|c|}
\hline Chainage from Source in $\mathrm{m}$ & Elevation in $\mathrm{m}$ \\
\hline 0 & 149.68 \\
\hline 10 & 136.89 \\
\hline 20 & 125.74 \\
\hline 40 & 107.44 \\
\hline 70 & 87.19 \\
\hline 90 & 76.78 \\
\hline 140 & 56.20 \\
\hline 170 & 46.31 \\
\hline 220 & 34.38 \\
\hline 250 & 30.38 \\
\hline 280 & 27.67 \\
\hline 290 & 26.55 \\
\hline 310 & 22.81 \\
\hline 330 & 15.08 \\
\hline 350 & 0.0 \\
\hline
\end{tabular}

Both the frictional rheology and the Voellmy rheology are used for comparison of model results with the observed landslide behavior in the field. The frictional rheology yields high velocity, which gradually increases in the beginning, and makes a semicircular profile with runout distance.

Table 4. 7 Input parameters for DAN

\begin{tabular}{|l|l|l|}
\hline Model & \multicolumn{2}{|c|}{ DAN } \\
\hline Parameters & Friction rheology & Voellmy rheology \\
\hline Initial friction angle & $41^{\circ}$ & $41^{\circ}$ \\
\hline Mobilized friction angle & $26^{\circ}$ & $26^{\circ}$ \\
\hline Turbulence factor & - & 200 and 500 \\
\hline
\end{tabular}


In the field, side drainages are mixing with the debris flow at Chainage 190, a confluence point of a natural drainage. The influence of drainage is significant after confluence point $(190 \mathrm{~m})$. The landslide mass may be mobilized with the drainage water beyond the drainage confluence. Field observation shows that debris is deposited starting from $220 \mathrm{~m}$, which is beyond Chainage 190 . However, the runout distance calculated using DAN gives a value similar to the field condition $(235 \mathrm{~m})$. Therefore, drainage water influence is insignificant for the movement of sliding mass in this observation.

The friction rheological model provides a more reasonable runout distance than the Voellmy rheology in DAN. Therefore, the friction model is recommended for analyzing steep landslide like this case record, the Lei Pui Street landslide.

The maximum velocity computed in friction rheology is higher than that in the Voellmy rheology. From the friction rheology model the maximum velocity is $18 \mathrm{~m} / \mathrm{s}$ at $100 \mathrm{~m}$ and from the Voellmy model, the maximum velocity is $9 \mathrm{~m} / \mathrm{s}$ at $40 \mathrm{~m}$.

A comparison of velocity with field record is not possible because there is no information of the debris flow velocity during the landslide incident. From the angle of runout distance, the friction rheology provides more appropriate result for the Lei Pui Street landslide.

The results calculated using the friction rheology and the Voellmy rheology have been compared. The parameters for the Voellmy model are the same as for the friction model except that the turbulence coefficient $\xi$ is taken as $200 \mathrm{~m} / \mathrm{s}^{2}$ (difference between to rheology is given in Chapter 3). The runout distance and velocity with Voellmy rheology is given in the Figure 4.15. The runout distance and the maximum velocity obtained from this model are $120 \mathrm{~m}$ and $9 \mathrm{~m} / \mathrm{s}^{2}$, respectively. 


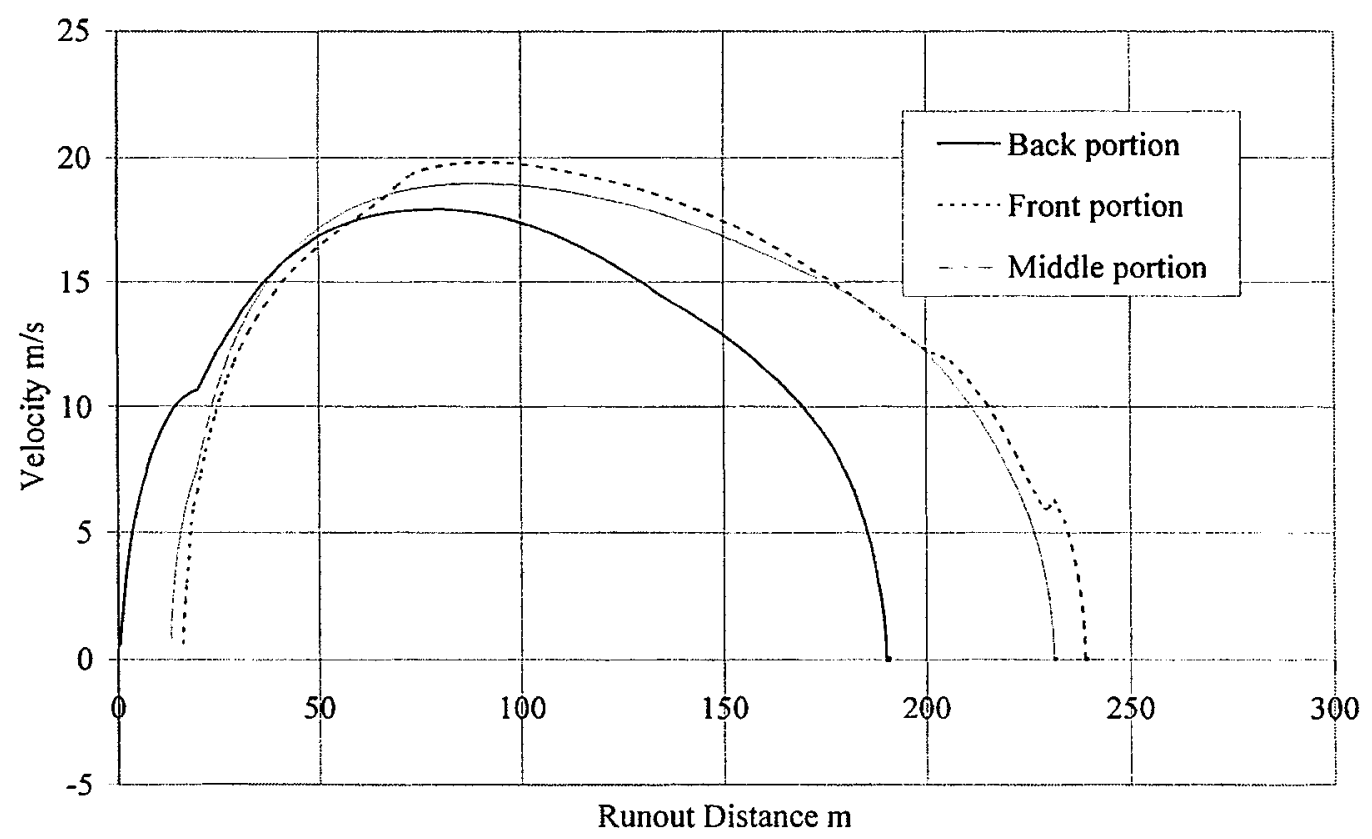

Figure 4. 14 Debris flow velocity and runout distance from friction rheology

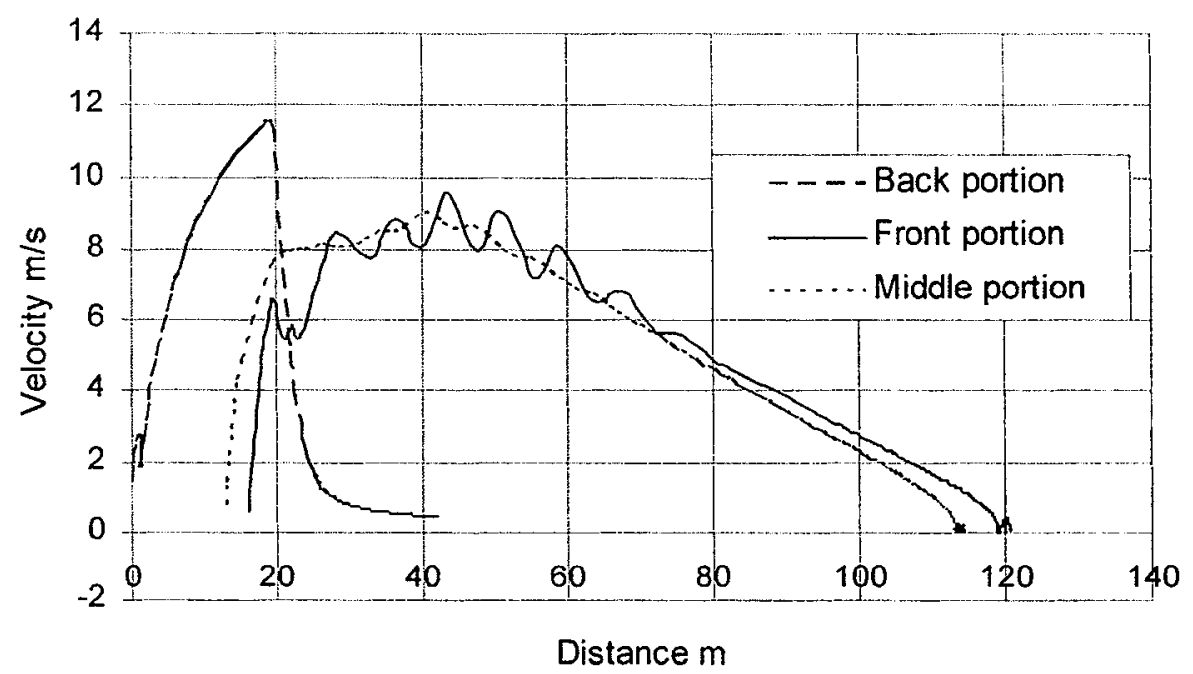

Figure 4. 15 Velocity and runout distance from Voellmy rheology in DAN 
The mobility of debris after Chainage 190m changed due to additional dilution and mixing of debris introduced by the runoff of a natural drainage. These considerations are not accounted for the analysis. However, the analysis carried out with initial debris condition will produce smaller runout distance as compared to the field observation. The analysis shows that the debris mobility from the initial soil characteristics is agreement with field comparison.

A study of different turbulent factors in Voellmy rheology is carried out in DAN. Figure 4.16 shows the runout distance with a larger turbulent factor of $500 \mathrm{~m} / \mathrm{s}^{2}$. For the turbulent factor increases from 200 to $500 \mathrm{~m} / \mathrm{s}^{2}$, the resulting runout distance changes from $120 \mathrm{~m}$ to $130 \mathrm{~m}$ and the maximum velocity from 9 to $11 \mathrm{~m} / \mathrm{s}$. The maximum recommended turbulent factor is $500 \mathrm{~m} / \mathrm{s}^{2}$ according to Hunger (1995). It shows that significant increase in turbulent factor only slightly increase in runout distance. Although for the higher value of turbulent factor, the runout distance computed with the Voellmy rheology is still smaller than the runout distance in the field. 


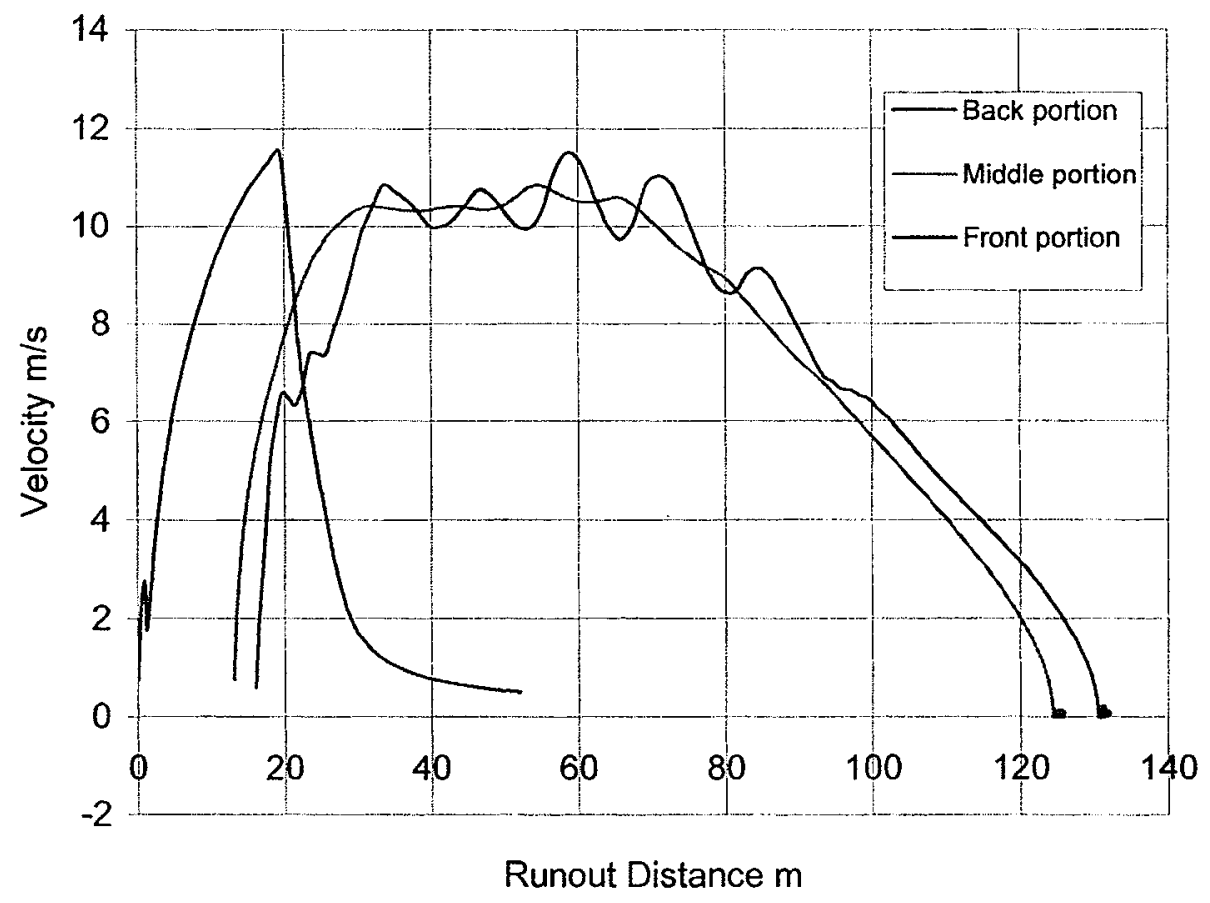

Figure 4. 16 The debris flow runout distance for a turbulent factor of $500 \mathrm{~m} / \mathrm{s}^{2}$

Between these two models (frictional and Voellmy), the friction model provides a runout distance closer to the field record than the Voellmy model. 


\subsubsection{Analysis from FLO-2D}

In this section, the simulation of the debris movement after landslide initiation is carried out using the FLO -2D computer software. The use of FLO-2D in modeling debris flow has been described in Chapter 3. The simulation of debris mass using the model for this case record is discussed here.

Field and laboratory test data are collected to obtain input parameters for the model in order to simulate the debris flow. The topography of the flow surface, its roughness and physical features such as buildings, roads and other man-made structures are pertinent input information. These are taken from Maunsell (2002). The laboratory test analysis consists of rheology of debris, viscosity, and yield stress. The relation of viscosity and yield stress with sediment concentration is taken from the literature and laboratory analysis reports proposed by O'Brien (FLO-2D manual 2003). The information of laboratory test is obtained from similar soil tests conducted by other Kang and Zhang (1980).

The moving mass of the landslide and immediate surface runoff above the landslide source is to be considered as a total volume of the debris. The landslide mass of $250 \mathrm{~m}^{3}$ and surface runoff water of $32 \mathrm{~m}^{3}$ is considered together for the total debris volume of $282 \mathrm{~m}^{3}$

Debris concentration, slope geometry, roughness of flow surface and surface area for debris movement are parameters required for input in the program. The slope geometry, flow surface area, and roughness factors are taken from a 1:250 map prepared 
by Maunsell (2002). The debris concentration was calculated based on catchment area, rainfall and volume of slide mass.

A mesh of $10 \mathrm{~m} \times 10 \mathrm{~m}$ grids is formed for simulation of the topography of the flow area as shown in Figure 4.17. The elevation and roughness factor of each grid are obtained from field data and were fed manually as input parameters to the digitized grid system. Higher elevation starts from the north and the elevation lowers along the south. The elevation of the northernmost grids is $230 \mathrm{~m}$, which is the highest in the flood plain. The Manning's roughness coefficient is selected from the field roughness condition, where the flow area has less vegetation than its bank. Therefore, the Manning's roughness coefficient is taken as 0.03 for the flow course and 0.05 for the course outside the deepest drain. The whole surface of grids is not available for the debris flow so that area reduction factor is applied in some grids.

The laboratory tests for the specific determination of the rheological factors needed for the debris flow analysis were not carried out. Instead, the pertinent information available in the literature for rheological factors is used. Kang and Zang (1980) proposed a rheological relation between the yield stress and the viscosity of the debris flow as a function of debris concentration. Among the proposed different rheological relations between yield stress and viscosity with debris concentration given in the literature, Kang and Zang's relation is more appropriate because their observation field was closer to the study field in this case study, Lei Pui Street landslide. The empirical coefficients $\alpha$ and $\beta$, which are taken from Kang and Zang (1980) are 1.75, 7.82 and $0.0405,8.29$ for viscosity $(\eta)$ and yield stress $(\tau)$ respectively. 
The inflow of the debris in the flood plain is simulated in the design grid from the highest elevation at the north. Evaporation and infiltration are neglected due to the small surface area of flow and the short duration of the event. The Froude number for flow is taken as 1.0 for initiation and is updated with the flow progress in subsequent levels. For shallow flows, Manning's $\mathrm{n}$ value is given as 0.2 and the $\mathrm{n}$ value adjustment is 0.01 for every update in Manning's n value.

The fully dynamic wave equation, explained in Chapter 3, was used for the analysis. The time interval of 0.01 second was chosen for the successive computation so as to obtain more stable simulation. The flow depth was taken as $0.2 \mathrm{~m}$ for change in flood plain depth. The specific gravity of the debris was taken as 2.7 . The laminar flow resistance was taken as 2000 .

\subsubsection{Debris concentration by volume}

Debris concentration is the most important part for the analysis of debris mobilization. Different debris concentration influences the viscosity and the shear stress of the debris flow. The shear stress and viscosity of the debris are also function of fines content together with volumetric concentration of the debris matrix. In this study, the debris concentration is assessed from the saturation condition and surface runoff in the landslide source area. Therefore, the total volume of water will be the sum of water contents initially and surface runoff.

Li et al. (2004) carried out detailed rainfall and infiltration study during the period of the landslide incident on September 01, 2001. Investigation was conducted from June 
2001 to December 2002. The Lai Pui Street landslide incident occurred within the observation period. The following observation of rainfall was recorded (Table 4.8).

Table 4. 8 Rainfall incident ( $\mathrm{Li}$ et al. 2004)

\begin{tabular}{|l|l|l|l|l|l|l|}
\hline Duration & 31 days & 15 days & 24 hours & 12 hours & 1 hour & 15 Min \\
\hline Rainfall $(\mathrm{mm})$ & 506.5 & 406 & 202.5 & 181.5 & 97 & 30 \\
\hline
\end{tabular}

The consequences of the different rainfall duration for landslide have been studied by many researchers in Hong Kong. Lumb (1975) suggested that 24-hour rainfall exceeding $100 \mathrm{~mm}$ and the 15-day antecedent rainfall exceeding $350 \mathrm{~mm}$ are more disastrous. It is reliable to take the 24 hours rainfall which is more effective in shallow depth landslides in Hong Kong. Brand et al. (1984) shows that in Hong Kong, the antecedent rainfall is not a major factor to landslides and the vast majority of landslides were induced by localized short duration rainfalls of high intensity such as greater than $70 \mathrm{~mm}$ per hour. Finlay et al. (1997) suggested that the number of landslides was best predicted using the 3-hour rainfall data. Dai et al (2001) showed that the 12-hour rolling rainfall was of the most importance in predicting the number of landslides. Among the conditions suggested above, the September 1st, 2001 was the worst condition for all rainfall intensity and duration for landslide.

If we consider the 24 hours rainfall for analysis, the amount of rainfall for 24 hours is $202.5 \mathrm{~mm}$. The infiltration of rainfall to the ground is approximately $70 \%$ in the Saprolite firm ground in Hong Kong (Li et al. 2004). 
The void ratio of soil at the scarp is 0.93 . The specific gravity is 2.7 . The soil porosity of landslide source mass is 0.48 . The total landslide mobilized volume is 250 $\mathrm{m}^{3}$. Daily rainfall and water content observation were carried out by Li et al. (2004) who suggested that saturation was approximately $90 \%$ and $95 \%$ for depth of $1.45 \mathrm{~m}$ and $1.0 \mathrm{~m}$ respectively. The soil mass was not fully saturated to the depth of $1.45 \mathrm{~m}$ even in 24 hour rainfall; it was only $90 \%$ of the slide mass was fully saturated. In this void ratio and saturated condition of the soil mass water volume contains approximately $108.3 \mathrm{~m}^{3}$.

The surface runoff from the immediate upper part of the landslide source area enters into the landslide mass. The landslide occurred immediately after 15 minute of heavy rainfall of $30 \mathrm{~mm}$. As described by Li et al. (2004), the infiltration rate is $70 \%$ of total rainfall in recorded period Sep 01,2001 . Thus, the surface runoff is $30 \%$ of the total rainfall. The surface runoff from the catchment area $3500 \mathrm{~m}^{2}$ is considered $31.5 \mathrm{~m}^{3}$, which inflow in the landslide mass. The total volume of the slide matrix, soil and water is 269.5 or approximately $270 \mathrm{~m}^{3}$.

From the above observations, soil concentration in the landslide soil matrix is approximately $48 \%$. Viscosity $\eta$ and yield stress $\tau_{\text {y }}$ of sliding debris are functions of sediment concentration, as given in Equation (4.2) and Equation (4.3) (FLO-2D Manual, 2003)

$$
\begin{aligned}
& \eta=\alpha^{1} e^{\beta_{1} C_{\nu}} \\
& \tau_{y}=\alpha_{2} e^{\beta_{2} C_{\nu}}
\end{aligned}
$$

where, $\alpha$ and $\beta$ are the empirical coefficients, and $C_{v}$ is the volumetric concentration. As mentioned previously, these coefficients are not analyzed from the 
laboratory for this specific reason; therefore, values given in the literature are taken for analysis.

The coefficient values suggested by Kang and Zhang (1980) are used in the analysis. The coefficient values in various conditions are given in the FLO-2D Manual (2000). The slide volume and other relevant information are given in Table 4.9. The input hydrograph for simulation is given in Table 4.10

Table 4. 9 Concentration in different saturation condition with up stream runoff

\begin{tabular}{|l|l|l|l|l|l|l|l|}
\hline \multicolumn{7}{|c|}{ Consideration of runoff from upper catchment } \\
\hline Total & Depth & Saturation & surface & Volume & Volume of & Total & Concentration \\
$\mathrm{m}^{3}$ & $\mathrm{~m}$ & percentage & $\mathrm{m}^{3}$ & $\mathrm{~m}^{3}$ & $\mathrm{~m}^{3}$ & $\mathrm{~m}^{3}$ & ratio \\
\hline 250 & 1.0 & 90 & 31.5 & 108.3 & 129.7 & 269.5 & 0.48 \\
250 & 2.0 & 85 & 31.5 & 100.08 & 132.25 & 263.84 & 0.50 \\
250 & 2.0 & 78 & 31.5 & 91.845 & 132.25 & 255.60 & 0.52 \\
250 & 3.0 & 68 & 31.5 & 80.07 & 132.25 & 243.82 & 0.54 \\
250 & 3.0 & 55 & 31.5 & 64.7625 & 132.25 & 228.51 & 0.58 \\
250 & 4.0 & 35 & 31.5 & 41.2125 & 132.25 & 204.96 & 0.65 \\
\hline
\end{tabular}

The landslide mass enters within very short period into the debris flow trail. The landslide volume of $270 \mathrm{~m}^{3}$ with debris concentration of 0.48 by volume enters in the FLO-2D simulation. The software simulates debris flow movement within 15 minutes. 
The debris flow surface in the grid system is shown in Figure 4.17. The velocity and depth of the flow along the debris flow surface are shown in Figures 4.18, 4.19 and 4.20.

At Chainage $190 \mathrm{~m}$, the maximum flow depth mark of debris flow was approximately $1.3 \mathrm{~m}$. The computed flood depth was, however, $1.0 \mathrm{~m}$, as shown in Figure 4.20. The difference in depth may be due to involvement of eroded material during flowing, which is not considered in the simulation. The velocity obtained from the simulation in different location is minimum $0.03 \mathrm{~m} / \mathrm{s}$ to maximum $0.35 \mathrm{~m} / \mathrm{s}$. As the velocity was not recorded in the field, it is difficult to assess with the computed result. The computation shows the velocity of $0.2 \mathrm{~m} / \mathrm{s}$ at the point where the maximum depth is $1.0 \mathrm{~m}$.

Table 4. 10 Input Hydrograph

\begin{tabular}{|r|r|r|r|r|r|}
\hline \multicolumn{2}{|c|}{ Input Hydrograph concentration=0.48 Total volume $270 \mathrm{~m}^{3}$} \\
\hline Time in hour & Time in sec & Time increment sec & Ordinates $\mathrm{m}^{3}$ & Volume & Concentratio \\
\hline 0.000 & 0.0000 & 0.0000 & 0.000 & 0 & 0.480 \\
0.000 & 0.3600 & 0.3600 & 31.00 & 2 & 0.480 \\
0.000 & 0.7200 & 0.3600 & 60.00 & 16 & 0.480 \\
0.000 & 1.0800 & 0.3600 & 90.00 & 27 & 0.480 \\
0.000 & 1.4400 & 0.3600 & 100.0 & 35 & 0.480 \\
0.000 & 1.8000 & 0.3600 & 220.0 & 55 & 0.480 \\
0.000 & 2.1600 & 0.3600 & 100.0 & 55 & 0.480 \\
0.000 & 2.5200 & 0.3600 & 90.00 & 35 & 0.480 \\
0.000 & 2.8800 & 0.3600 & 60.00 & 27 & 0.480 \\
0.000 & 3.2400 & 0.3600 & 31.00 & 16 & 0.480 \\
0.001 & 3.6000 & 0.3600 & 0.00 & 2 & 0.480 \\
\hline
\end{tabular}


The simulated volume of the landslide mass moves continuously on the given topography. The final deposition is not significant within the simulation region. Therefore, the runout distance of debris flow is difficult to predict in this study. The reason behind the dissimilar result may be due to discrepancies in rheological relation of yield stress and viscosity chosen for the simulation. It is noticed that DAN Voellmy rheology and FLO-2D give similar velocity of debris flow in lower portion of trail. The information obtained from the FLO-2D simulation did not closely match with the field information. Therefore, the friction rheology in DAN model was considered an appropriate rheology for the parametric studies reported in Chapter 6 .

\subsection{Summary}

This case record has been studied from initiation to the debris flow runout with the help of different computer software. Slope/W and FLAC have been used to calculate the factor of safety in the initiation. DAN and FLO-2D have been used to calculate the runout distance.

The factor of safety calculated using Slope/W is 1.08 , which indicates that the slope was at just limit equilibrium. The pore pressure ratio of 0.04 reduces the factor of safety to 1 . The factor of safety calculated using FLAC is 0.9 .

The runout distance is calculated using friction and Voellmy rheology in DAN. The debris flow runout distance in the field and the results obtained using friction rheology in DAN are in reasonable agreement. However, the runout distance computed from Voellmy rheology in DAN is significantly shorter than the runout distance observed in the field. Therefore, the friction model is considered appropriate for this case study. 
The debris mass is modeled in the FLO-2D software, where the maximum flood depth and the velocity in the flood plain are computed. The flood depth obtained from the analysis is slightly smaller than the depth marked in the field. In FLO-2D, the velocity of the debris flow is very small as compared to the velocity calculated from DAN. It is noticed that DAN Voellmy rheology and FLO-2D both give similar velocity of debris flow in the lower portion of the trail. Due to the lack of field data, the velocity of debris flow comparison could not be made.

The results from the FLO-2D simulation do not closely match the field observations. Therefore, the friction model in DAN is recommended for further study.

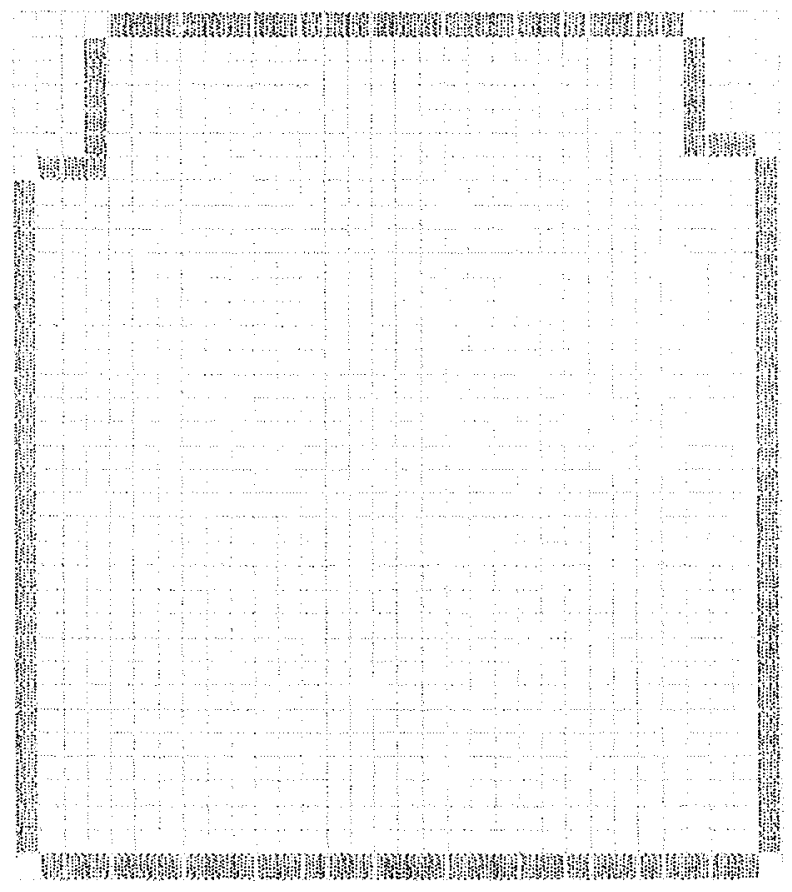

Figure 4. 17 Grid of $10 \mathrm{~m} \times 10 \mathrm{~m}$ size for topography simulation 
Grid Element Maximum. Velocity

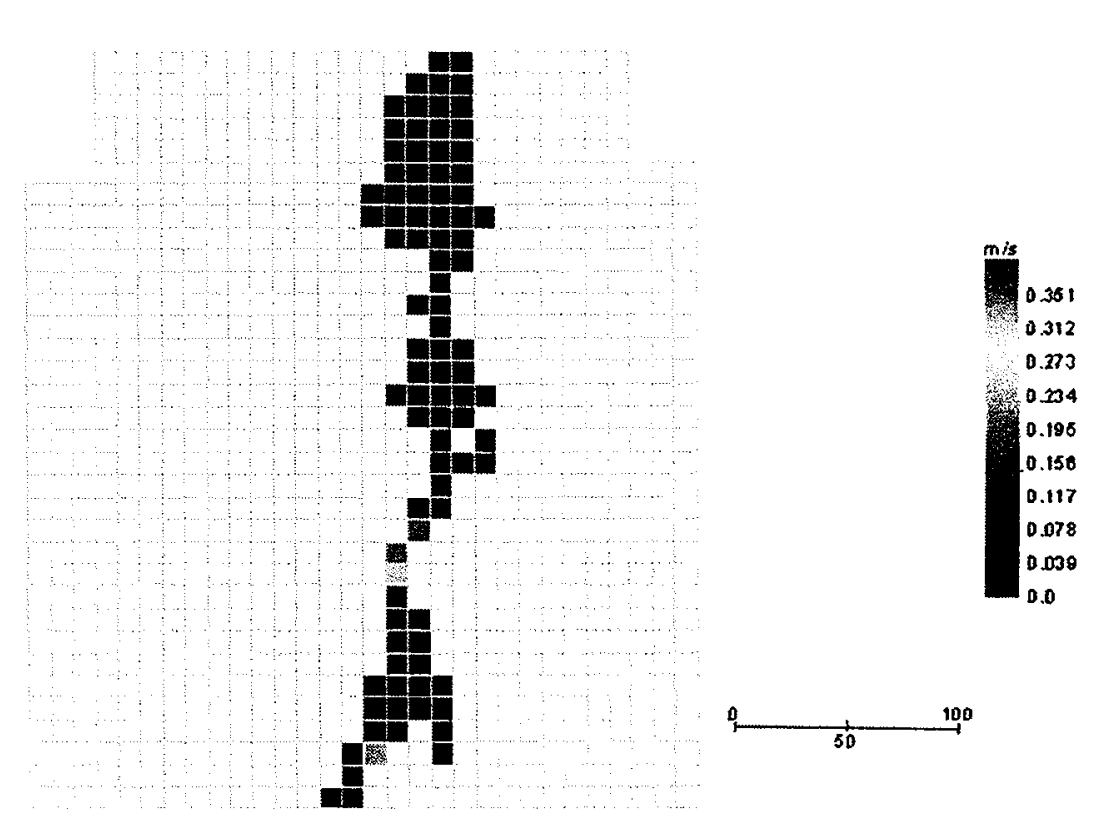

Figure 4. 18 Grid element maximum velocity 


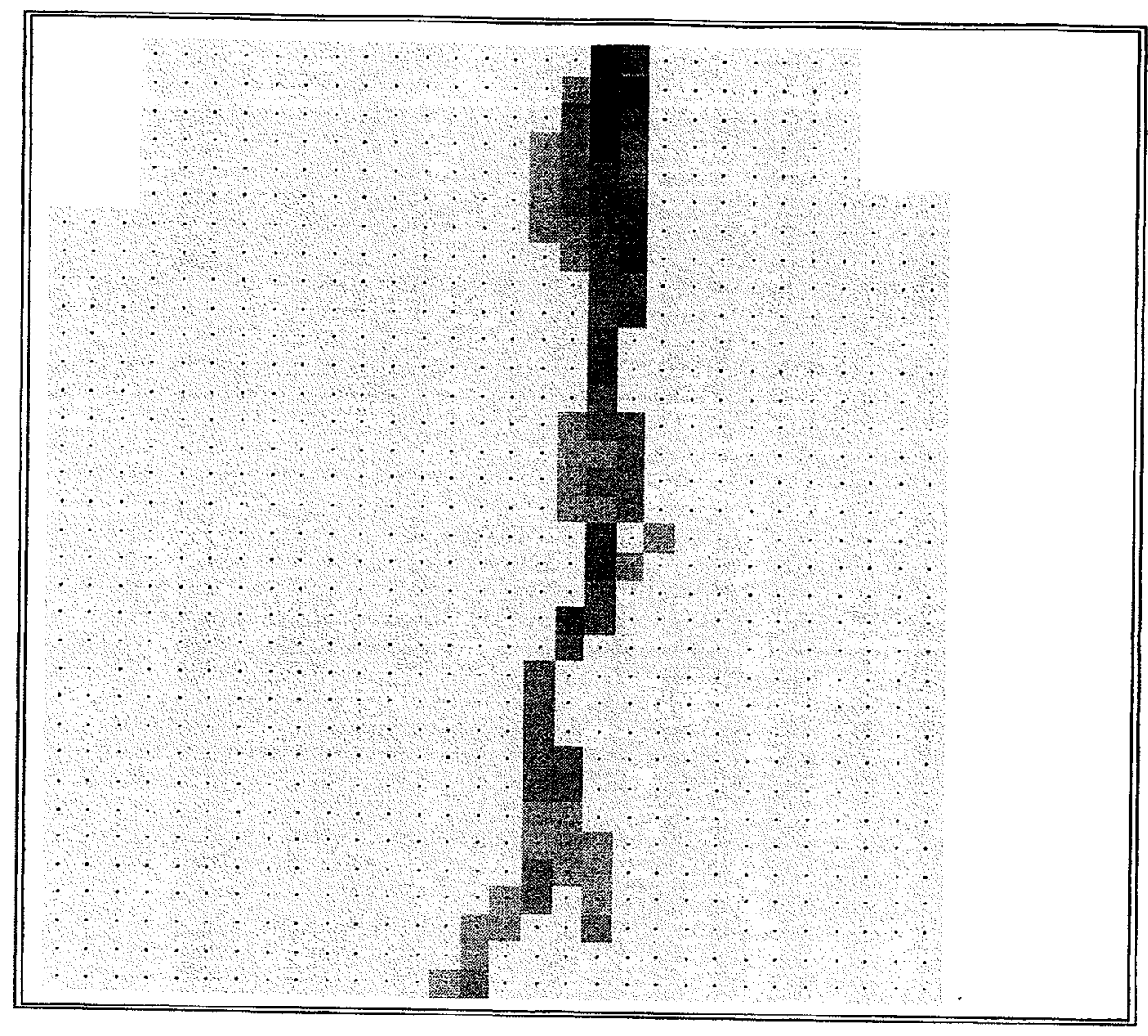

$7.5<$ OPEYH $<$ B. 0 $7.0<$ DEPTH $<7.5=$ 6.5 \& DBPYH \& $7.0 \mathrm{~m}$ $6.0<$ ORPIH $<6.5=$ $5.5<$ OXPIH $<6.0=$ $5.0<$ ABPIH $<5.5=$ $6.5<$ OEPIH $<5.0-$ 6. I $<$ OBP3H $<4.5=$ $3.5<$ ORPIH $<0.0=$ $3.0<$ QBPIH $3.5-$ $2.5<$ OBPIA $<3.0-$ $2.0<$ ORPIH $<2.5$ 1.5 5 ORPIH $<2.0=$ $1.0<0$ ORTH $<1.5=$ $0.5<$ DEPIH $<1.0-$ IOI 5 OBRIH $<0.5$ \% DEPIH $<$ IOL

Figure 4. 19 Grid system maximum flow depth 


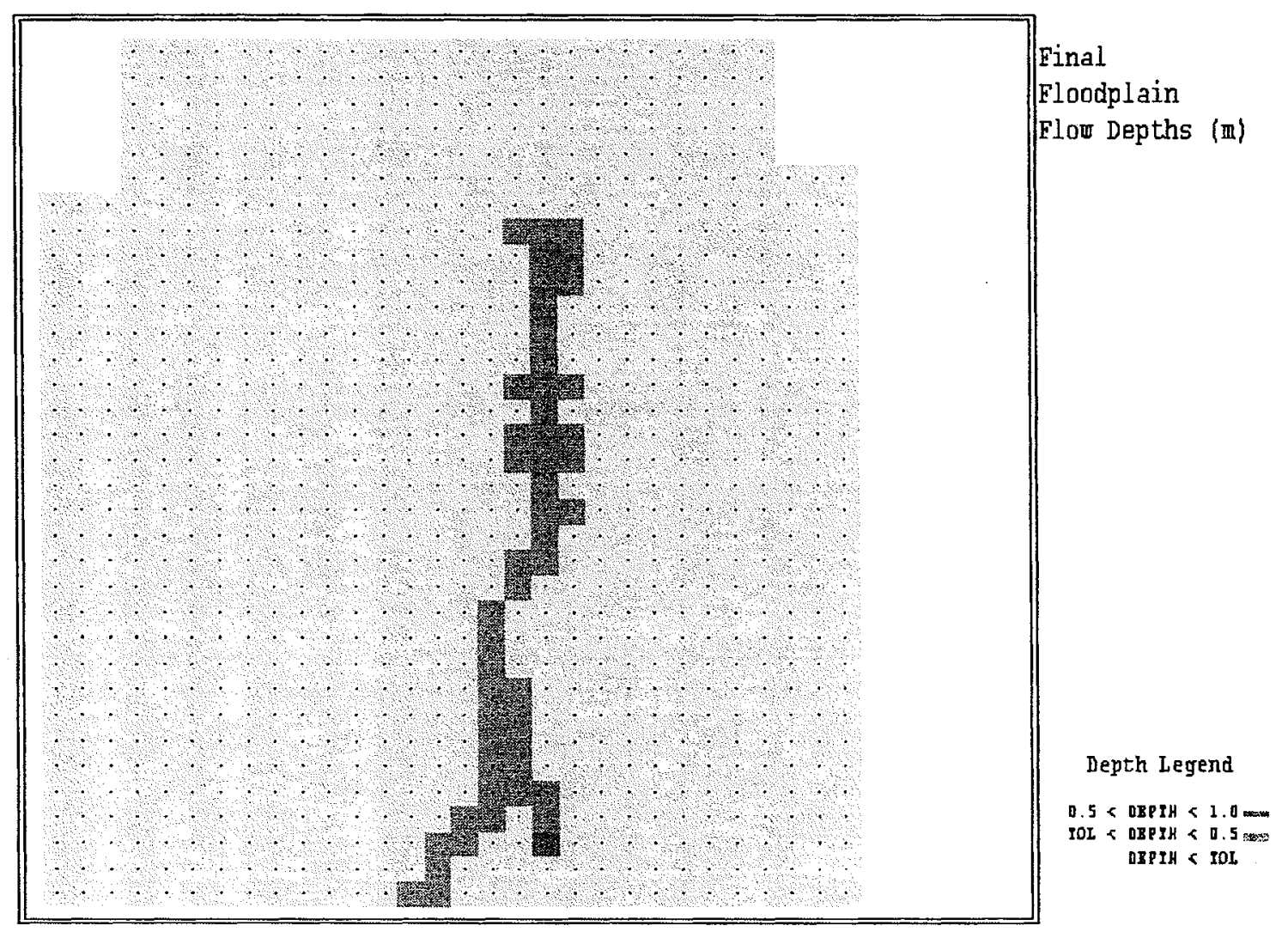

Figure 4. 20 final flood plain flow depth 


\section{CHAPTER 5}

\section{BARABENSI LANDSLIDE, NEPAL}

The Barabensi landslide in Nepal has been used as another case study because of its slow movement and the drastic difference in the nature of its movement compared to the Lei Pui Street landslide described in Chapter 4. Again, this study focuses on field observations, simulation, and back-analysis. This Chapter will re-emphasize the importance of the parametric studies reported in the next chapter.

The Barabensi Landslide is located at $84 \mathrm{~km}$ of Arniko Highway, north east from Kathmandu, Nepal. The Highway is sinking within the landslide reach $(84-85 \mathrm{~km}$ chainage) every year.

The landslide consists of four separate blocks, which are moving independently. The Sun Koshi River, the largest tributary of Sapta Koshi River, flows at the toe of the landslide. A detailed field report (2002) prepared by Department of Roads, Ministry of Transport, His Majesty's Government of Nepal for remedial measures of the landslide is

reviewed here. Remedial measures carried out by the department have not been effective and the landslide is still active. This study analyses the prevailing problem of the landslide. The field report submitted to the Department of Roads by Nepal Engineering Consultancy Services Centre Ltd (2002) is used for basic information and the review. 
The slope stability analysis from Slope/W and FLAC, landslide movement analysis from DAN and the factors governing the movement of the landslide mass are presented.

\subsection{Site description}

\subsubsection{Location}

The landslide area is located at $84 \mathrm{~km}$ northeast of Kathmandu, Nepal. The landslide location is near Barabensi, a small town along Arniko Highway. Close to the confluence of Bhote Koshi River and Sun Koshi River, the landslide is located $500 \mathrm{~m}$ downstream on the right side of the Sun Koshi River. The latitude and longitude of the landslide area are $27^{\circ} 46^{\prime} 26^{\prime \prime} \mathrm{N}$ and $85^{\circ} 53^{\prime} 25^{\prime \prime} \mathrm{E}$, respectively. The location of the landslide area is shown in Figure 5.1. At the beginning of the landslide incident $100 \mathrm{~m}$ length of the road was subsided.

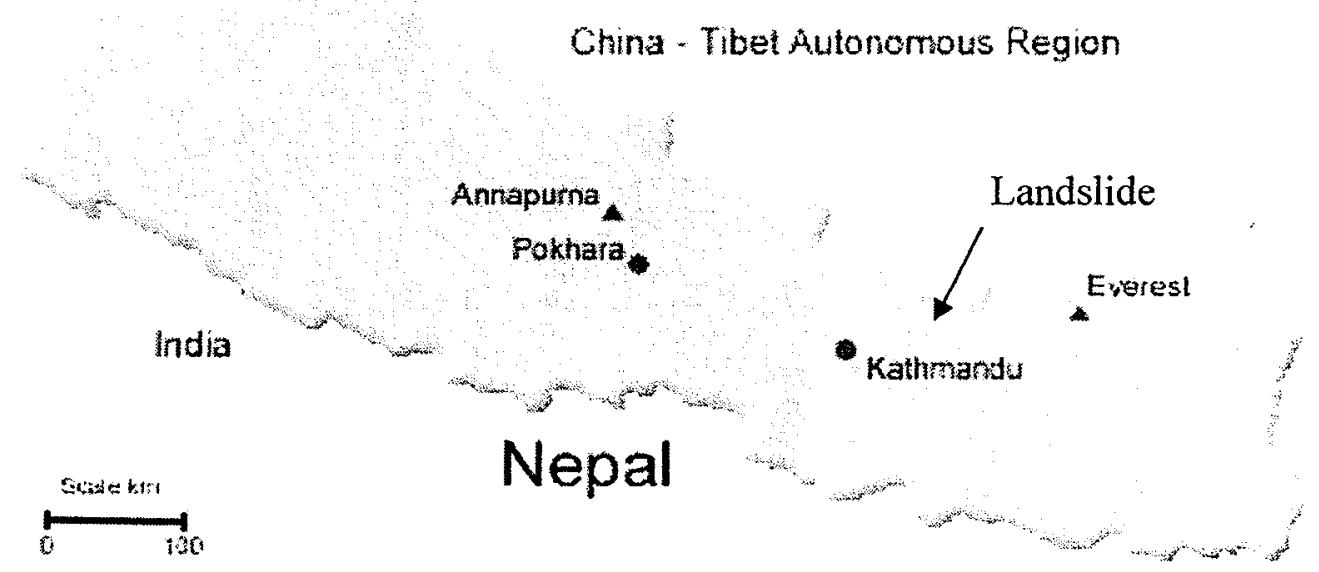

Figure 5. 1 Barabensi landslide location in Nepal (Travel information network) 


\subsubsection{History of the landslide}

This section of the road was washed out from a glacier lake outburst in 1983. The washout portion of the road was constructed again in 1984. Before the glacier outburst, the road was along the bank of the river. After the washout, it was shifted to the new position towards the hillside. The new position is sinking in every monsoon season during which the river cuts the toe of the landslide. The hill slope is made up of compacted and moderately compacted soil, which loses strength and starts moving during a rainfall.

\subsubsection{Topography}

A topographic map of 1:500 scale is available, which shows the prominent slide features such as tension cracks, scarps, seepage, slide mass, rock outcrops, sliding face, tilted trees, subsiding areas, and boulders. Bedrock of quartzite and phyllite are found at the toe of the hill on the bank of the river. Figure 5.2 and Figure 5.3 show the physical features of the landslide area, including tension cracks and scarp of individual moving mass of the landslide. Bushes cover most of the landslide area, though some portion is cultivated land. Bedrock outcrop is seen above the road in some scarp portion. Some civil and bioengineering measures like gabion walls, check dams, drains, house etc., are shown in the map. The surface is covered mostly by colluvium.

The centre lines of the longitudinal profiles of the landslide are shown in the topographic map. Longitudinal profiles along Sections A and B of the landslide are shown in Figures 5.4 and 5.5 respectively. All the features like scarps, outcrops, road longitudinal section, and cracks are recorded. 


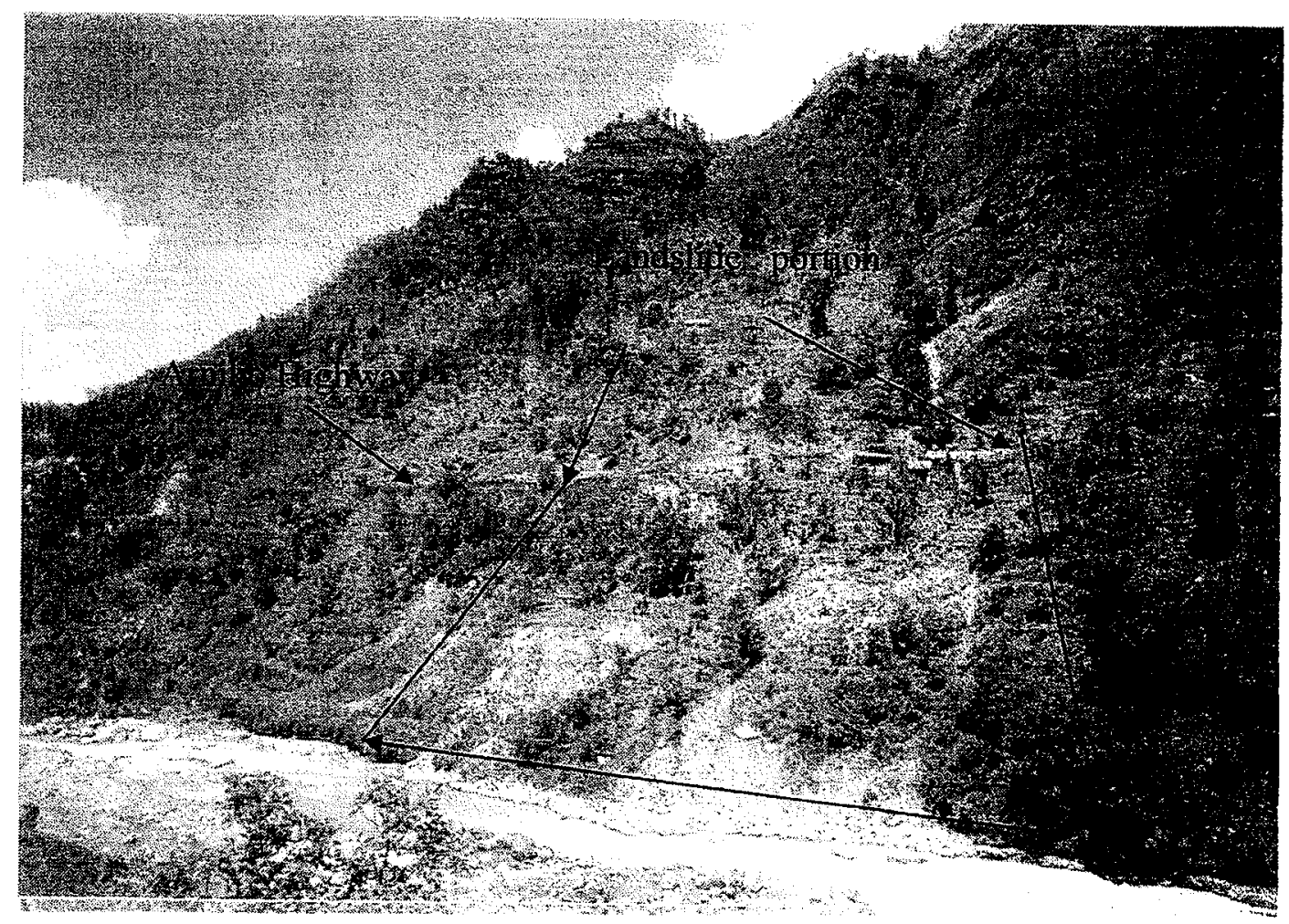

Figure 5. 2 Landslide areas above the bank of Sun Koshi River (NEPECON 2002) 


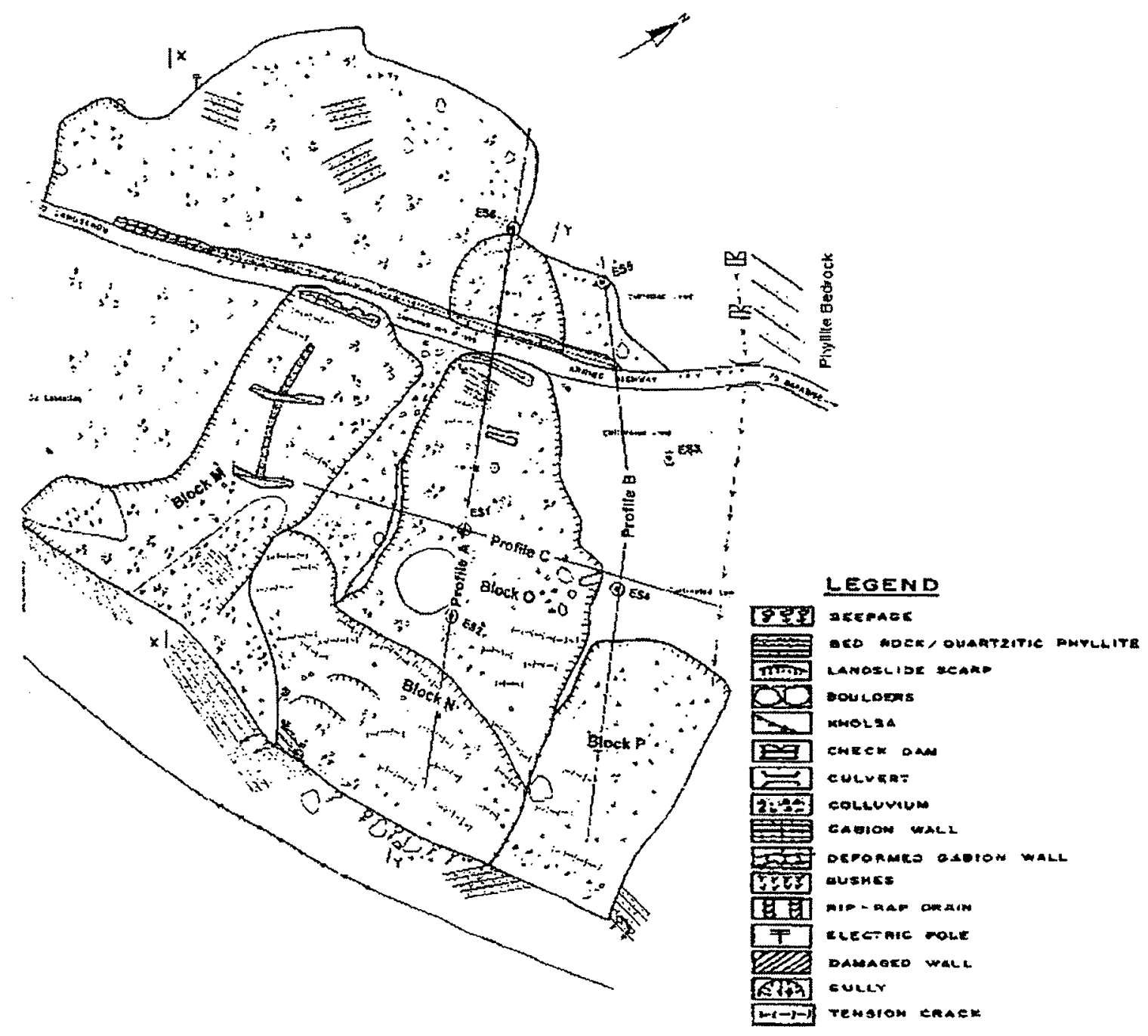

Figure 5. 3 Physical feature of the Barabensi landslide (NEPECON 2000) 


\section{Barabensi Landslide Zone A}

\section{Profile X-X}

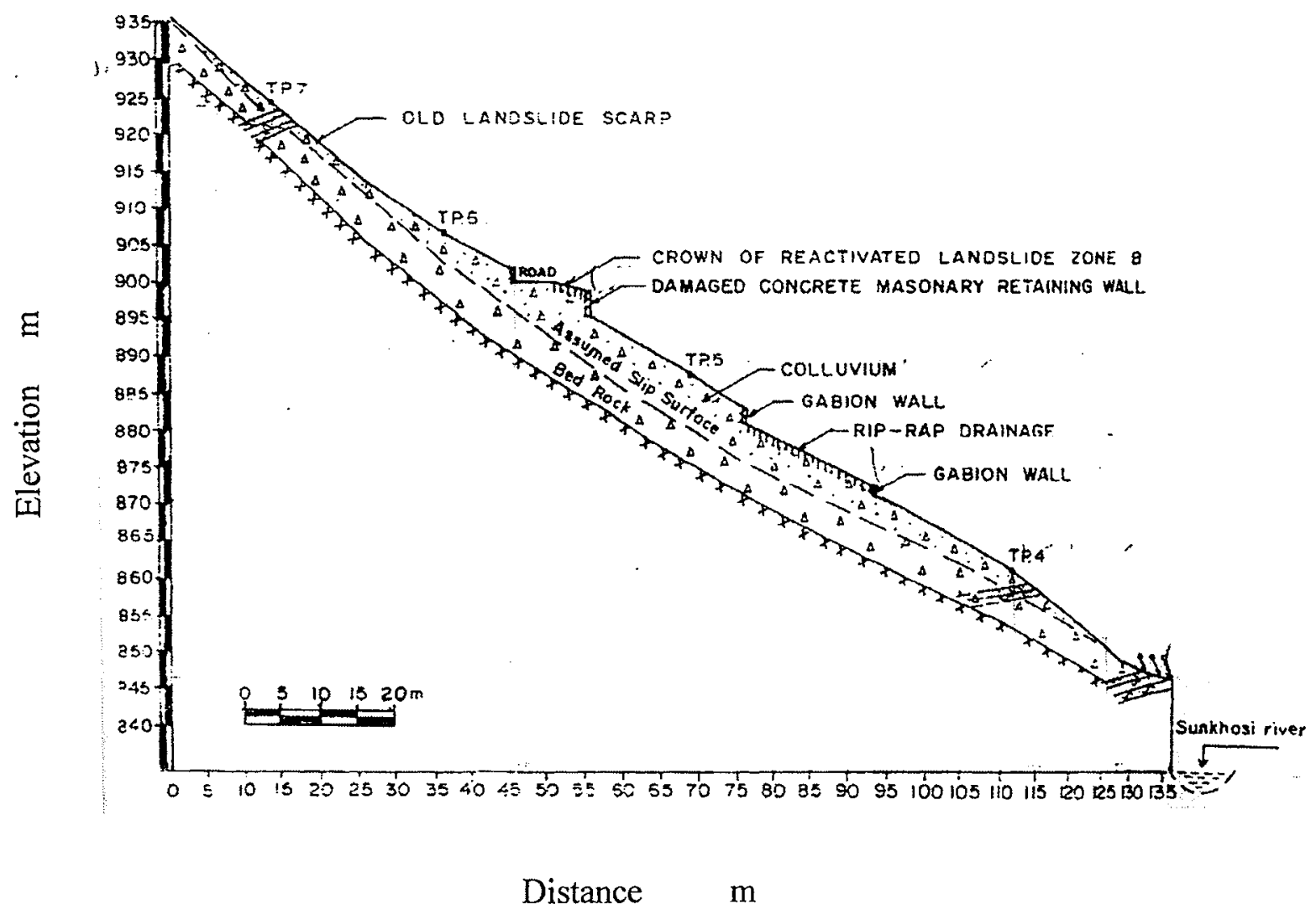

Figure 5. 4 Barabensi landside Profile A (NEPECON 2000) 


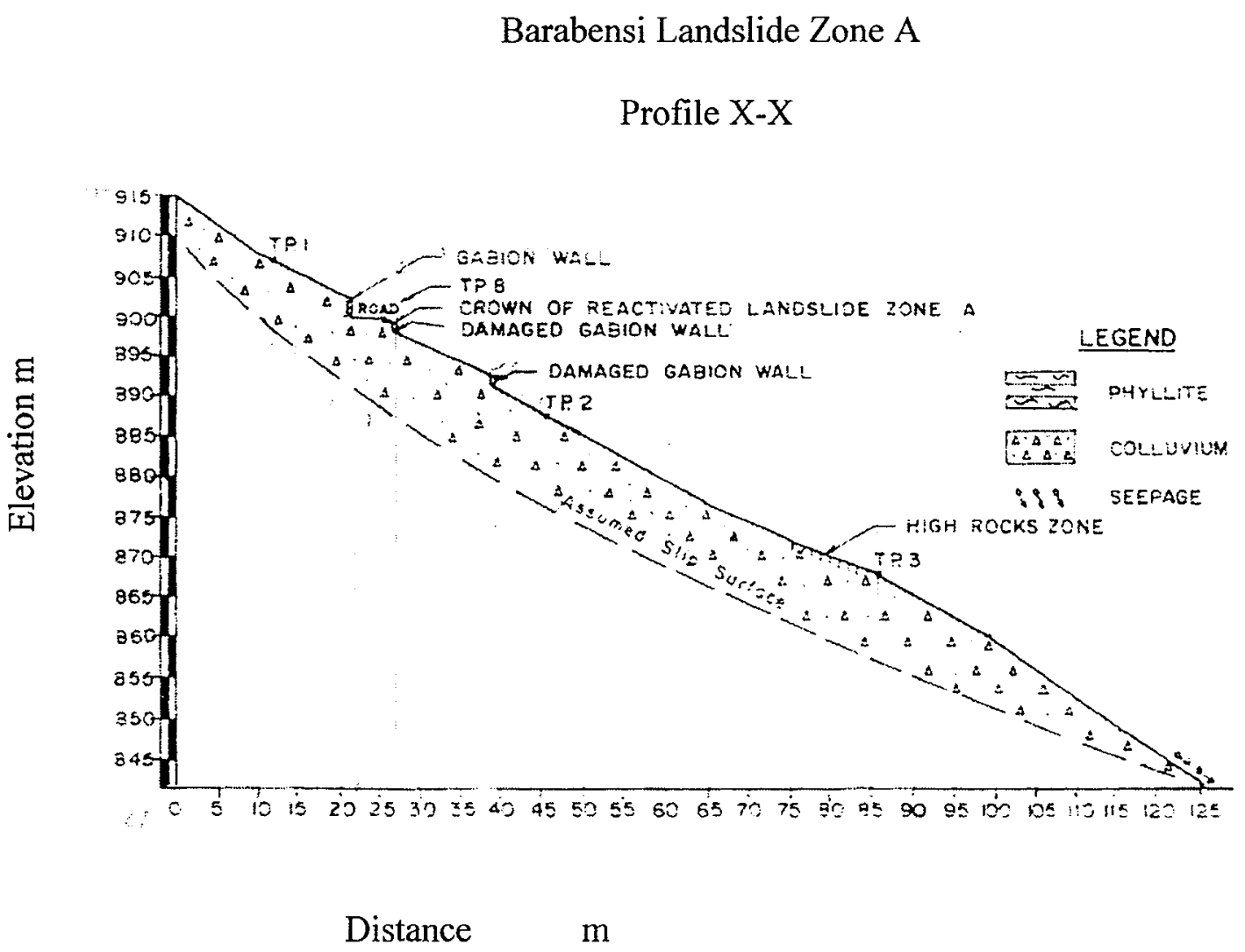

Figure 5. 5 Barabensi landslide Profile B (NEPECON 2002)

\subsubsection{Morphology}

The landslide area is along the bank of Sun Koshi River. The river cuts the toe of the hill slope and renders the hillside unstable. The landslide mass slowly moves every rainy season. There are tension cracks in the sliding mass, seepage water at the toe of the landslide and rock outcrops at some scarp portion of the landslide. Man-made structures and vegetation are disturbed in the slope. Vertical rock cliff and some boulders are at the toe of the hillside so that any loose mass reaching in that portion of the hillside easily 
falls into Sun Koshi River. Rock cliff is quite stable but boulder deposited in the toe is loose so that Sun Koshi River erodes the boulder portion every rainy season.

\subsubsection{Geomorphology}

The regional setting of the area is in the middle mountain range of central Nepal with rugged mountainous and valley river terrain. The landslide area is composed of lower grade metamorphic rocks of mid-land group. It contains grey phyllite and quartzite of Ranimata formation. The Phyllite is the predominating rock unit, which is fractured and jointed. Rock bedding is in the NW-NE direction.

The landslide area is located just downstream of the confluence of Bhote Koshi and Sun Koshi River with negligible catchment area above it. There is no catchment area beyond the landslide surface, which might influence the landslide. Therefore, additional flow from other catchments does not enter into the landslide mass. Small temporary drains are developed to drain off the surface runoff.

The outer surface of the slide area is covered by colluvial cone, which is bounded by a wedge-shaped rocky cliff. The main slide mass is colluvium, which is boulder mixed with low plastic silty clay soil. Colluvium consists of phyllite boulder, mica particles, and grey color low plastic silt. The colluvium layer is quite thick and large boulders exist in the landslide mass.

There are different geological terrains in the landslide. The left flank consists of a colluvial cone with rocky cliff. There is a temporary creek originating from open deep and sub-vertical joints in the rocky cliff. Runoff erodes colluvium and develops sediment 
that flows along the temporary drainage and deposited on the flat slope such as in the road portion during rainfall.

The landslide mass was moved about $1.5 \mathrm{~m}$ to $8 \mathrm{~m}$ in different location at the time of observation, which is the total movement accumulated since the landslide started to move. The roadside drain is cracked and tilted. The whole mass of the landslide has moved, but a house below the road does not have remarkable cracks.

The surface of the landslide mass is relatively barren, but is partly covered with elephant grass and small bushes. The surface of the sliding mass is a combination of bushes, grass, cultivation, and residence areas. From the mid-slope to the road level, there are trees, thick vegetation like elephant grasses and bushes. The general slope of the sliding area is about $34^{\circ}$. On the left portion of the slide, there is a house and farmland. The slope is gentle and is about angle of $30^{\circ}$ in this portion. The upper slope area above the road level has mostly grass with some trees, bushes, and cultivated land. The cut slope for the road is steep at an angle of $41^{\circ}$ from the horizontal. Fractured bedrock is found at this portion and toe of the landslide.

\subsubsection{Movement of landslide block}

The landslide movement at different location is different. The landslide zone is divided into four blocks based on their movement. The four blocks are described as Blocks $\mathrm{M}, \mathrm{N}, \mathrm{O}$, and $\mathrm{P}$. The physical features and movement of each block are described in the following with the aid of Figure 5.3. 
Block M: This slide block is on the south side of the whole landslide area. This block is inactive now because remedial measures such as a gabion retaining wall and vegetation cover with small trees and grass have been applied.

Block N: This portion of slide is directly above Sun Koshi River. Arc shaped tension cracks exist in this area. The slope surface is covered with grass. Water springs are also present along the toe of the slide mass. The head scarp of 2 to $5 \mathrm{~m}$ height extends almost parallel to the river. The scarp of this portion of landslide shows that angular phyllite is mixed with boulders, and the colluvium is mixed with some soapy low plasticity silty soil matrixes.

Block O: This block is located immediately above block N. This is the weakest block as evidenced by the presence of large tension cracks and fresh scarps. Part of the surface is covered by trees. The subsoil strata along the landslide profile A are shown in Figure 5.4 .

Block P: This block extends from Sun Koshi River to the cultivated farmland. Only the lower portion of this block is moving.

\subsubsection{Geotechnical investigation}

Sub-surface investigation was carried using test pits and hand augering up to the possible depth in different locations. Soil stratification, physical properties, and groundwater condition were determined. Field density and shear strength of the soil were evaluated. Soil samples were tested in the laboratory to determine the grain size distribution, shear strength, and natural water content. Detailed investigations are given in Table A1 in Appendix. 


\subsubsection{Resistivity sounding and profiling}

Seismic refraction survey and resistivity surveys (sounding/profiling) were carried out for the soil strata deeper than $3 \mathrm{~m}$. Vertical electrical sounding and profiling was conducted. The results of vertical electrical sounding are given in Table A2 in Appendix.

\subsubsection{Hydrology}

The Department of Metrology and Hydrology (DHM), Nepal has recorded rainfall in the area since 1968. The average annual rainfall ranges from $1200 \mathrm{~mm}$ to $1600 \mathrm{~mm}$, occurring mainly in the monsoon season (July-September). The maximum 24 hour rainfall intensity was observed to be $400 \mathrm{~mm}$ in 1987 . The rainfall data from Station No 1027 (Latitude $27^{\circ} 47^{\prime} \mathrm{N}$ and Longitude $85^{\circ} 54^{\prime} \mathrm{E}$ ) of Department of Metrology and Hydrology are given in Table A3 in Appendix.

There is a river confluence approximately one $\mathrm{km}$ upstream from the slide area. Immerging river Bhote Koshi originates from the snow fed glacier lakes of the inner high Himalayas. Both Rivers Bhote Koshi and Sun Koshi originate from inner Himalayas (High Mountain). River flooded from the glacier lake has bursted in the past. Major glacier lake bursts were observed in the years 1983 and 1987. The landslide toe is directly above the bank of the river so that during every monsoon season, the river level touches the toe of the landslide.

The geo-hydrological condition of the area is mostly localized between colluvium and bedrock of the landslide area. The colluvium of the area underlies by bedrock. Some part of rainfall infiltrates and some part passes through the surface runoff. The 
infiltration water passes along the bedrock and some location along impervious clay layer. At the toe of the slide, perennial seepage and springs exist. The ground water table in the slide area near the crown is relatively deep.

\subsubsection{Climate}

The landslide location is very close to Barabensi Bazaar (town), which is at $700 \mathrm{~m}$ above the mean sea level. The climatic condition of the area is subtropical monsoon type. The temperature variation in the area is $0^{\circ} \mathrm{C}$ to $38^{\circ} \mathrm{C}$ from winter to summer (Department of Hydrology and Metrology 2001).

\subsubsection{Field observations}

The landslide was first observed from the subsiding of a portion of a 50-m long roadway. The movement of the landslide is slow at about $1 \mathrm{~m}$ to $2 \mathrm{~m}$ per year. Joints are developed on the moving soil mass. Seepage is found at the toe of the landslide mass, interfacing with bedrock.

Soil stratification study was done using ten different test pits. The field density of the specimen was measured. A local tool similar to the standard Penetrometer was used to evaluate the in situ soil strength. Detailed engineering properties of the sliding soil mass are given in Table 5.1. The locations of the test pits are shown in Figures 5.3, 5.4 and 5.5. 
Table 5. 1 Soil parameters (NEPECON 2002)

\begin{tabular}{|l|c|c|c|c|}
\hline Sample No. & \multicolumn{2}{|l|}{ Cohesion C, } & Friction angle & \multicolumn{2}{l|}{ Dry unit weight, } & \multicolumn{2}{l|}{ Water } \\
\hline TP-1/SN2 & 0.00 & $36.5^{\circ}$ & 12.81 & 20.3 \\
\hline TP-1/SN3 & 4.0 & $14.0^{\circ}$ & 13.87 & 19.1 \\
\hline TP-1/SN4 & 4.0 & $28.0^{\circ}$ & 15.61 & 17.3 \\
\hline TP-3/SN1 & 10.0 & 32.0 & 13.85 & 18.2 \\
\hline TP-3/SN2 & 2.0 & 29.5 & 1.94 & 20.4 \\
\hline TP-3/SN3 & 2.0 & 20.0 & 15.02 & 25.2 \\
\hline TP-4/SN2 & 4.0 & 25.5 & 13.06 & 21.5 \\
\hline TP-9/SN2 & 3.0 & 29.00 & 12.30 & \\
\hline
\end{tabular}

\subsubsection{Soil index properties}

Table 5.5 in Appendix A shows the different soil layers at various depths as concealed by the test pits. Soil index properties are given in Table 5.7 in Appendix A. The soil in most of the test pits is non-plastic silty sand and gravel. On the other hand, soil in Test Pits (TP) 1/Station Number (SN) 4, TP3/SN1, TP3/SN3, TP4/SN2, TP6/SN2, and TP7/SN2 exhibit some plastic characteristics. 


\subsection{Analysis}

\subsubsection{Stability analysis from Slope/W}

Two different profiles, profile $\mathrm{A}$ and profile $\mathrm{B}$, of the Barabensi landslide are shown in Figures 5.4 and 5.5. Profile $A$ is for the steep slope with an angle of $34^{\circ}$. Profile $\mathrm{B}$ is along the gentle slope, with a slope angle of $30^{\circ}$. In this analysis, the factor of safety for these profiles is computed with and without a specified slip surface.

Profile A as shown in Figure 5.6 is analysed with the Slope/W computer software. The soil parameters are taken from the laboratory test result obtained by NEPECON (2002). The cohesion of the sliding mass ranges from $2.0 \mathrm{kPa}$ to $10.0 \mathrm{kPa}$ except TP1/SN2, which has high friction and no cohesion. The operational value of cohesion is taken as $6.0 \mathrm{kPa}$, which is an average of $2.0 \mathrm{kPa}$ and $10.0 \mathrm{kPa}$. The operational friction of the soil is taken as $30^{\circ}$. The input parameters are given in Table 5.2.

Underneath the moving soil layer is stratified bedrock, which influences the planar slip surface of failure soil mass. The slip surface is specified from the field data. Therefore, the slope stability analysis is conducted with Morgenstern and Price and Janbu's methods. 
Table 5. 2 Input parameters in Slope /W

\begin{tabular}{|l|l|}
\hline Friction angle & $30^{\circ}$ \\
\hline Cohesion & $6.0 \mathrm{kPa}$ \\
\hline Unit weight & $18.4 \mathrm{kN} / \mathrm{m}^{3}$ \\
\hline Pore pressure ratio $\left(\mathrm{r}_{\mathrm{u}}\right)$ & 0.0 \\
\hline
\end{tabular}

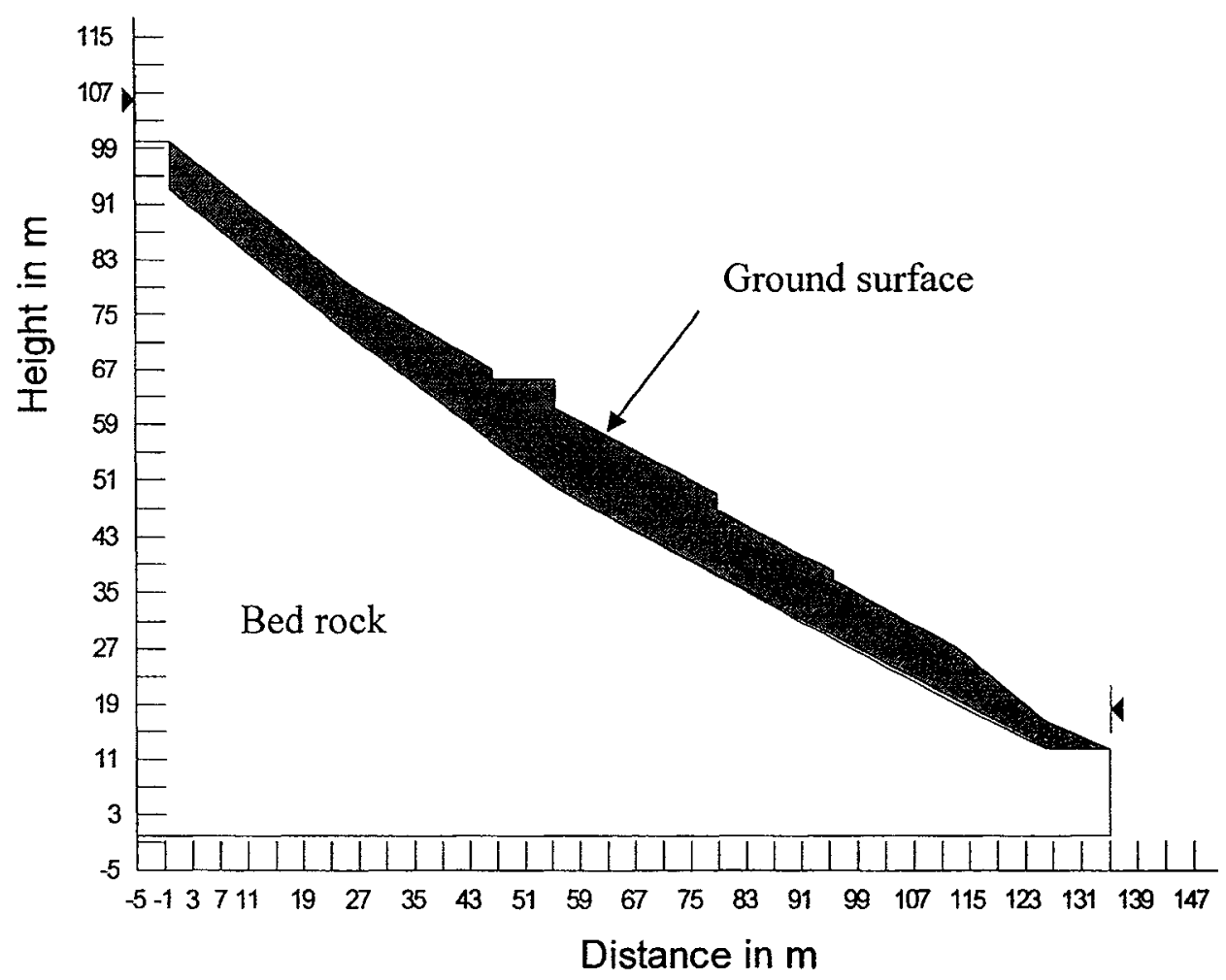

Figure 5. 6 Profile A for slope stability analysis

For zero pore pressure, the factor of safety is 1.09 using Janbu's method and 1.10 with Morgenstern and Price method. This result shows that profile $A$ is in limit 
equilibrium condition. Figure 5.7 shows the stability analysis of the slope with Morgenstern and Price method.

Stability analysis shows that slope is marginally stable with zero pore pressure and in the field; the total movement of the landslide mass has reached $1.5 \mathrm{~m}$ to $8 \mathrm{~m}$ at different parts at the time of investigation. This movement is accumulated over many seasons since it started moving. Grain size distribution and soil layer in the landslide mass are not uniform. There is a discontinuous layer of impervious clay between the bedrock and the landslide mass. Impervious bedrock and non-uniformly distributed clay layer along the failure surface permit pore pressure built-up during rainy seasons. Consequently, the normal effective stress at this clay layer will be reduced and the resulting shear strength will be lowered to approach the existing shear stress. If the rain is sufficiently heavy, the generated pore pressure leads to displacement along the clay layer. Therefore, positive pore pressure development is considered as a cause of failure.

Stability analyses have also been carried out using different pore pressure conditions. At pore pressure ratio $\left(\mathrm{r}_{\mathrm{u}}\right)$ of 0.07 , Janbu's method provides factor of safety of 0.99 , Morgenstern and Price's method of 1.0. Figure 5.7 shows the stability analysis with the Morgenstern and Price's method at $r_{u}=0.07$ for Profile A 


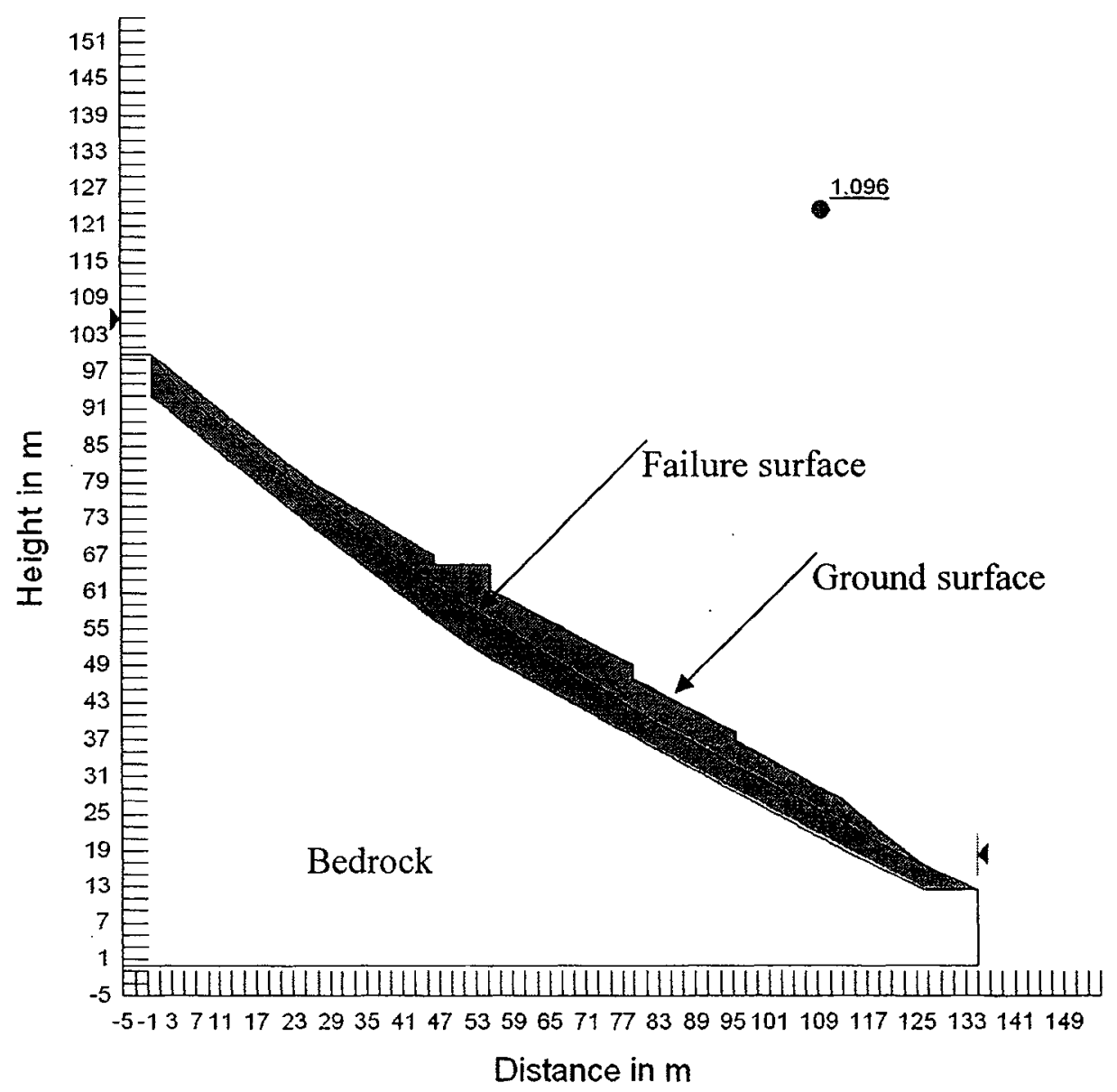

Figure 5. 7 Stability analysis of slope profile A of Barabensi landslide with Morgenstern Price Method 


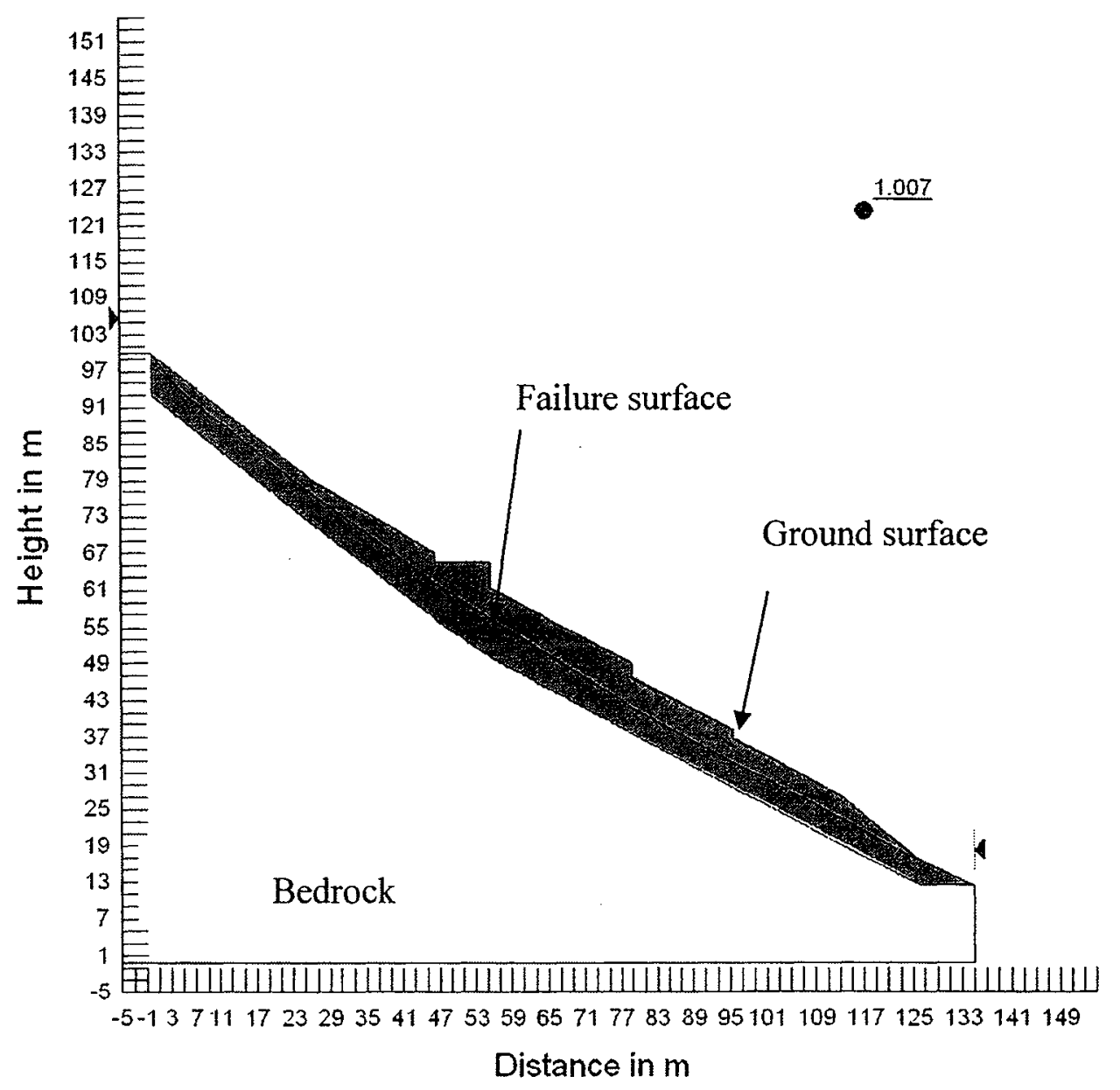

Figure 5. 8 Stability analysis of Profile A using Morgenstern Price Method $\mathrm{r}_{\mathrm{u}}=0.07$

Similar analyses have been carried out for Profile B (Figure 5.9) with the same parameters as those for Profile A except the slip surface is not specified. The slope angle for profile $\mathrm{B}$ is approximately $30^{\circ}$. The slip surface assumed in the field record is along the bedrock and colluviums interface. Therefore, in this analysis the slip surface is not specified. 
Profile B is more stable than Profile A. In Profile B, the slip surface is along the bedrock and colluvium interface but in Profile $A$ the slip surface is within colluvium. The factor of safety computed for Profile B is slightly higher than that for Profile A. The factor of safety is 1.15 using Janbu's method, and 1.18 with Morgenstern and Price method. Figure 5.10 shows the stability analysis of the slope using Morgenstern and Price method for Profile B.

Stability analyses have also been carried out for different pore pressures ratios. It is found that at the pore pressure ratio of 0.12 the factor of safety drops to about 0.98 , and 1.0 with Janbu's and Morgenstern and Price method, respectively. Figure 5.11 shows the factor of safety analysis with Morgenstern and Price method.

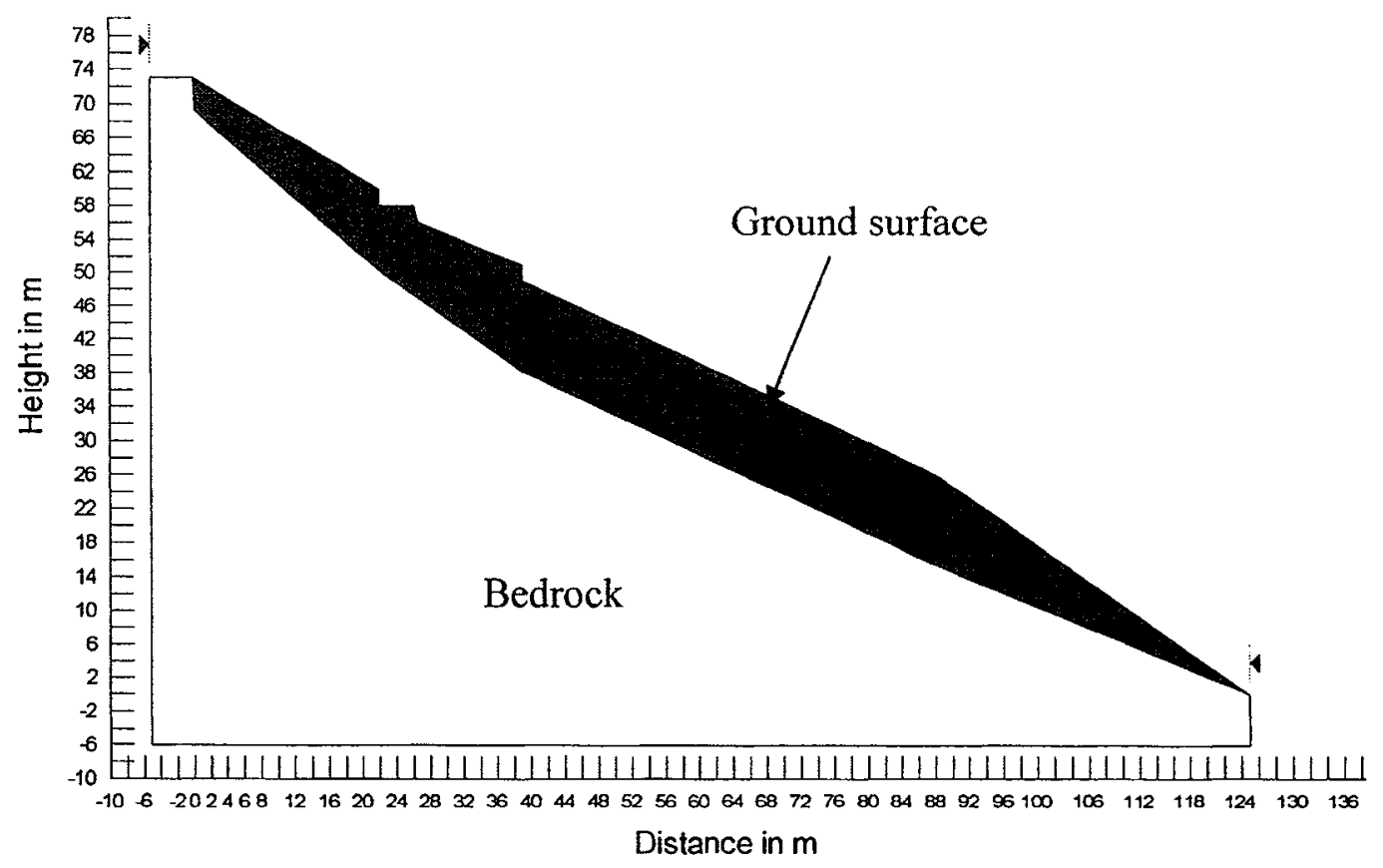

Figure 5. 9 Slope model for Profile B, Barabensi landslide 


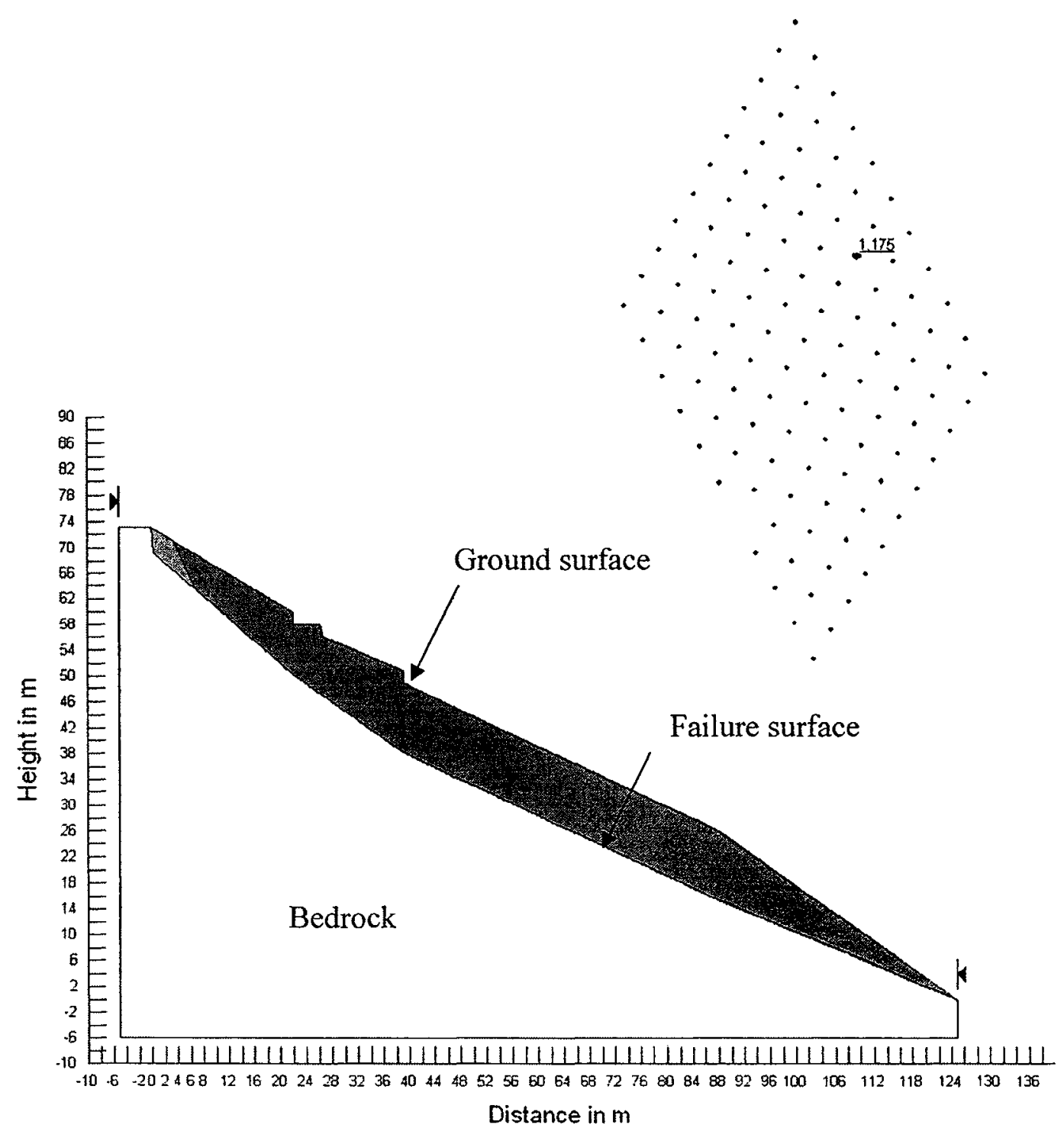

Figure 5. 10 Slope stability using Morgenstern and Price method at $\mathbf{r}_{\mathrm{u}}=0.0$ 


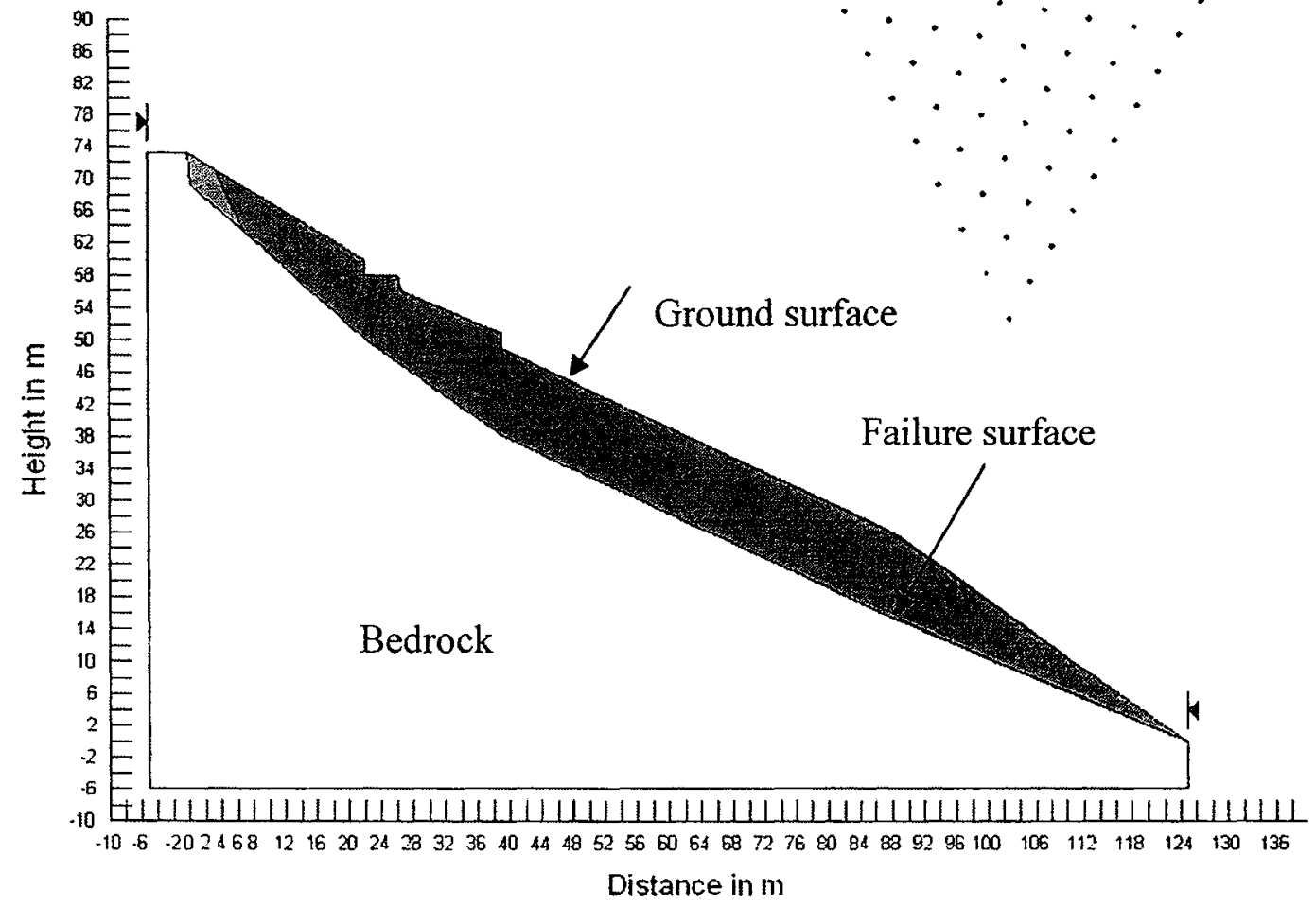

Figure 5. 11 Stability analysis for slope Profile B using Morgenstern and Price method with $\mathrm{r}_{\mathrm{u}}=0.12$ 


\subsubsection{Stability analysis using FLAC}

The modeling of FLAC computer program has been mentioned in Chapter 3. The soil strength parameters of the failed slope is analysed with FLAC in this section. The factor of safety calculated from FLAC is compared with that from SLOPE/ W.

The input parameters are given in Table 5.3. Pertinent properties are selected from NEPECON (2002), and other not measured parameters are taken from the literature for similar soils. The Mohr-Coulomb failure criterion is used in this analysis.

Table 5. 3 Input parameters in FLAC

\begin{tabular}{|l|l|}
\hline Friction & $30^{\circ}$ \\
\hline Cohesion of soil & $6 \mathrm{kPa}$ \\
\hline Cohesion of bedrock & $500 \mathrm{kPa}$ \\
\hline Bulk modulus & $67.7 \mathrm{MPa}$ \\
\hline Shear modulus & $40 \mathrm{MPa}$ \\
\hline Density of soil & $1881 \mathrm{~kg} / \mathrm{m}^{3}$ \\
\hline Density of bedrock & $2500 \mathrm{~kg} / \mathrm{m}^{3}$ \\
\hline
\end{tabular}

The boundary conditions of the model are specified as it was in the field. At the vertical boundaries on both sides of the slope soil can move freely in the vertical direction but prevented to move in the horizontal direction. There is bedrock at the bottom of the slope. Both horizontal and vertical movements are prevented at the bottom boundary of the model to represent bedrock at the bottom of the model. The boundary conditions are not significant for computation of the factor of safety. In addition, these 
boundaries are placed sufficiently far from the main slope body such that they do not impose significant effects on the movement of the failure soil mass.

The slope is modeled in a grid system of 36 by 25 as shown in Figure 5.12 . The grid numbers chosen in the model are based on software capacity and efficiency of computation. There is no significant change in the factor of safety calculation by increasing number of grids in the model.

Initially, a large tensile strength in the soil properties is applied for the stability of the model before application of gravity and other loads. The applied tensile strength is reduced to zero during analysis. The acceleration due to gravity is taken as $9.81 \mathrm{~m} / \mathrm{s}^{2}$.

Table 5. 4 Result from FLAC

\begin{tabular}{|l|l|l|}
\hline Factor of safety & Profile A & Profile B \\
\hline Without pore pressure & 0.97 & 1.12 \\
\hline With given water table & 0.95 & 0.99 \\
\hline
\end{tabular}

The factor of safety computed from FLAC is not much different from factor of safety computed from Slope/W. The factor of safety calculated using FLAC without pore pressure is 0.97 , which is less than the factor of safety of 1.10 calculated from Morgenstern and Price method and 1.09 from Janbu's method for Profile A. Applying the same watertable as in Slope/W analyses gives a factor of safety of 0.95 .

For Profile B, the factor of safety computed from FLAC is also not much different from factor of safety computed from Slope/W. The factor of safety calculated using FLAC without pore pressure is 1.12 , which is slightly less than the factor of safety of 
1.18 calculated from Morgenstern and Price method and 1.15 from Janbu's method. Applying water table same as pore pressure in Slope/W, factor of safety is 0.99 .

These analyses show that Barabensi landslide slope was marginally stable without pore pressure. Development of positive pore pressure causes failure of the slope. The remedial measure for this type of landslides is to develop sufficient drainage system so that soil can release infiltration water without any pore pressure. Monitoring of drainage clogging is also important to maintain pore pressure at zero. 


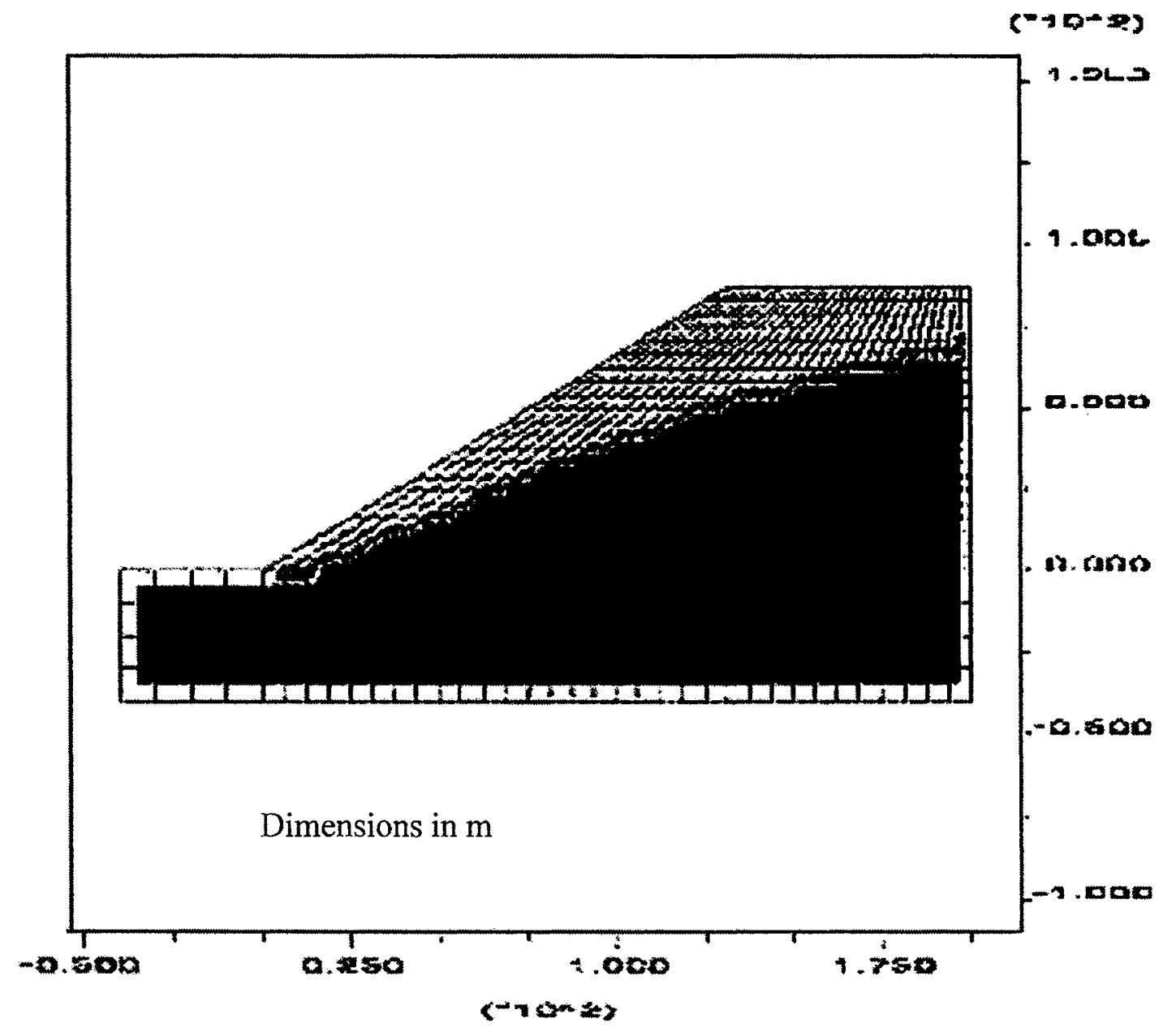

Figure 5. 12 Slope model for Profile A, Barabensi Landslide 


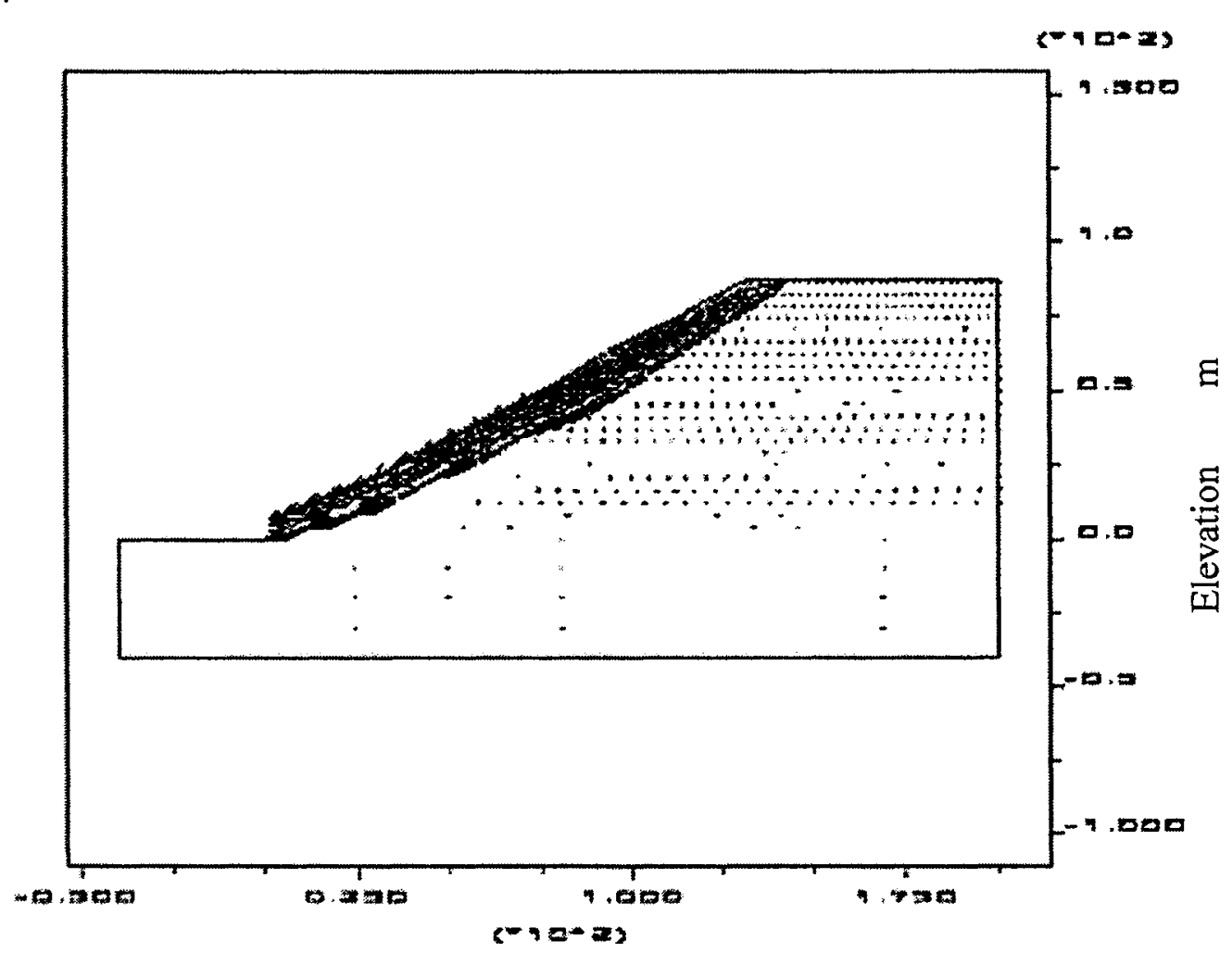

Horizontal distance $m$

Figure 5.13 Displacement at failure of Profile A, Barabensi Landslide 


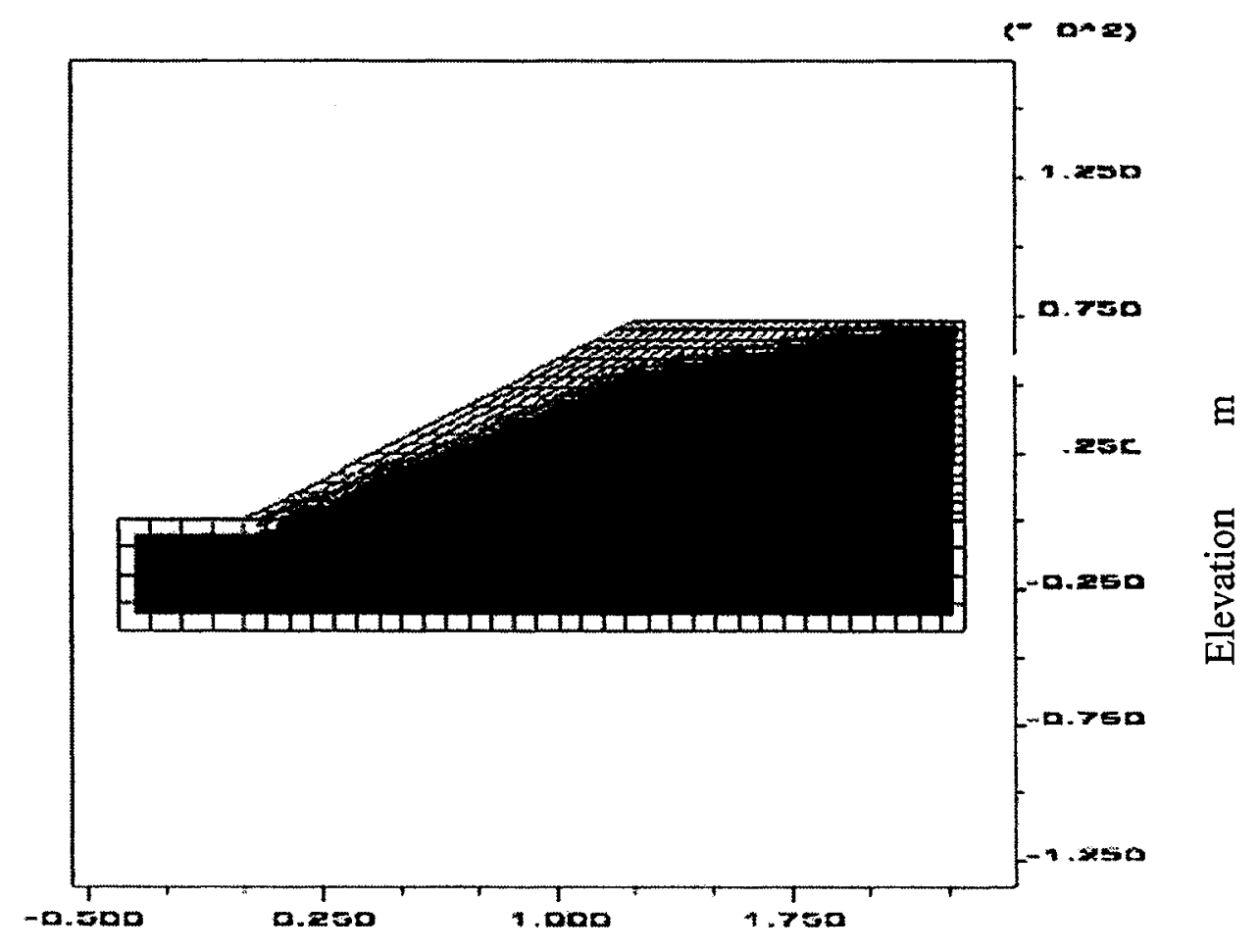

Horizontal distance $\mathrm{m}$

Figure 5. 14 Discretized slope model for Profile B of Barabensi Landslide 


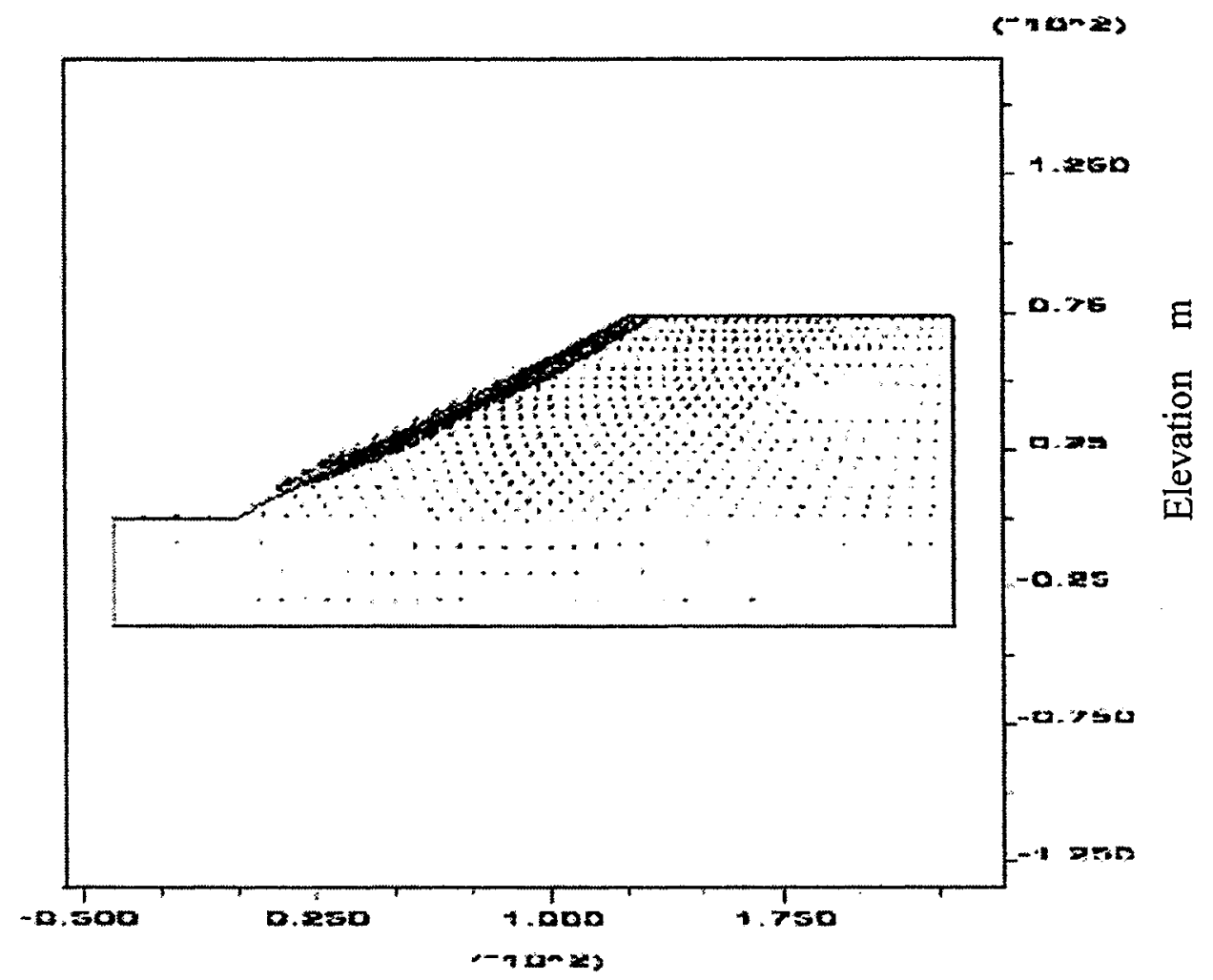

Distance $\mathrm{m}$

Figure 5. 15 Displacement at failure of Profile A, Barabensi Landslide

\subsubsection{Dynamic Analysis}

In the above section of analysis, the landslide initiation condition is known. After initiation, the failed soil mass moves down the slope. The movement of the landslide varies with the initiation condition and flow surface. Therefore, the runout distance and velocity of the soil becomes different for different landslides.

The movement of the landslide mass is studied using DAN. Barabensi landslide profile $\mathrm{A}$ and profile $\mathrm{B}$ for DAN analysis are given in Figure 5.16 and 5.17. The 
landslide mass is divided into 10 mass blocks similar to the case study in Chapter 4 (Lai Pui Street landslide) for studying the movement.

The dynamic analysis does not show significant movement of the landslide mass as compared to the size of the landslide. The movement of the slide soil mass is given in Figure 5.18 and Figure 5.19. The horizontal distance of Profile $\mathrm{A}$ is $235.0 \mathrm{~m}$ and profile $\mathrm{B}$ is $225.0 \mathrm{~m}$. The result shows that $8.0 \mathrm{~m}$ and $20.0 \mathrm{~m}$ movement at the front portion and back portion for Profile A, respectively. Similarly, moments of $8.0 \mathrm{~m}$ in the front portion and $18 \mathrm{~m}$ in the back portion in Profile B have been computed. These movements do not constitute a debris flow. 


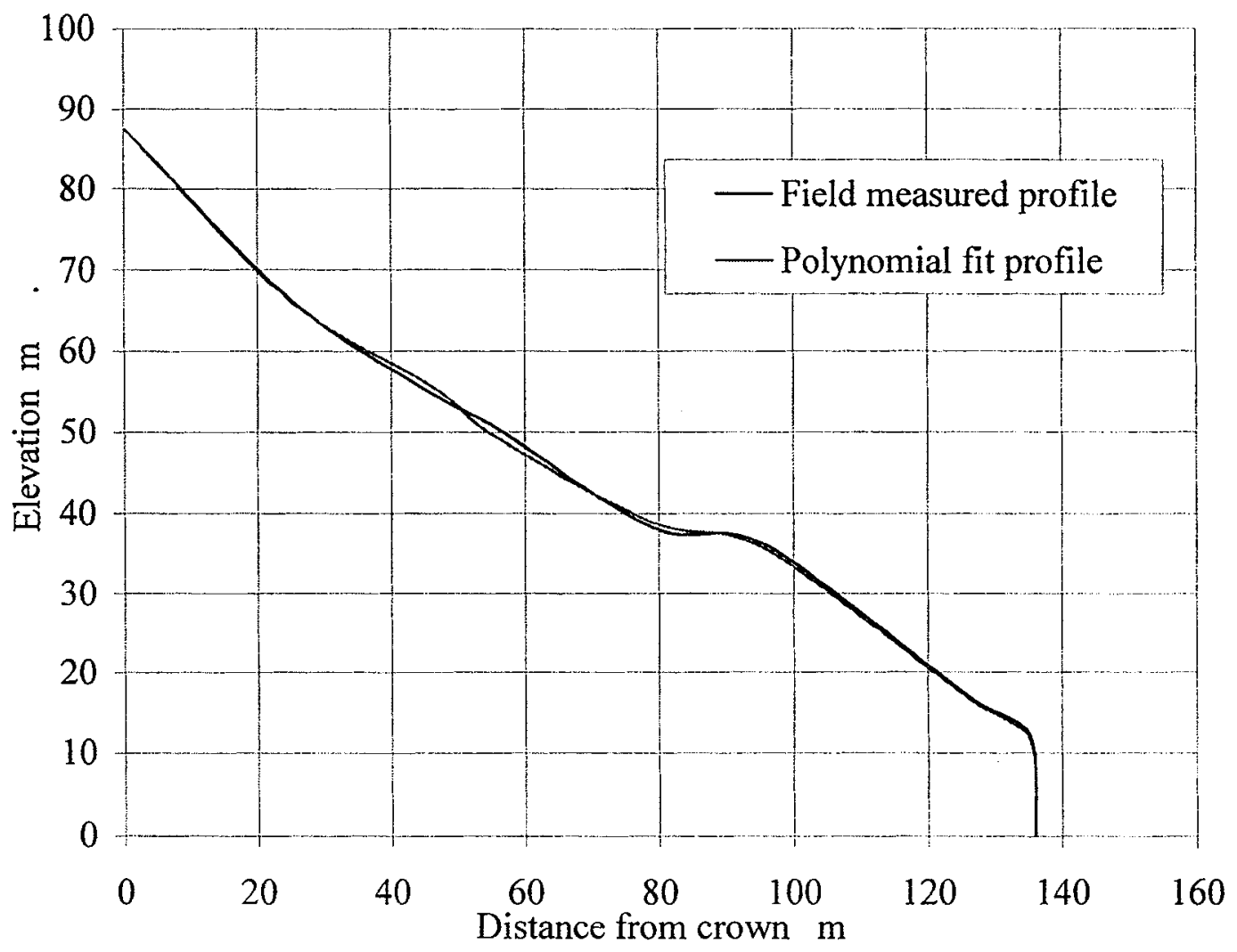

Figure 5. 16 Profile A of Barabensi landslide 


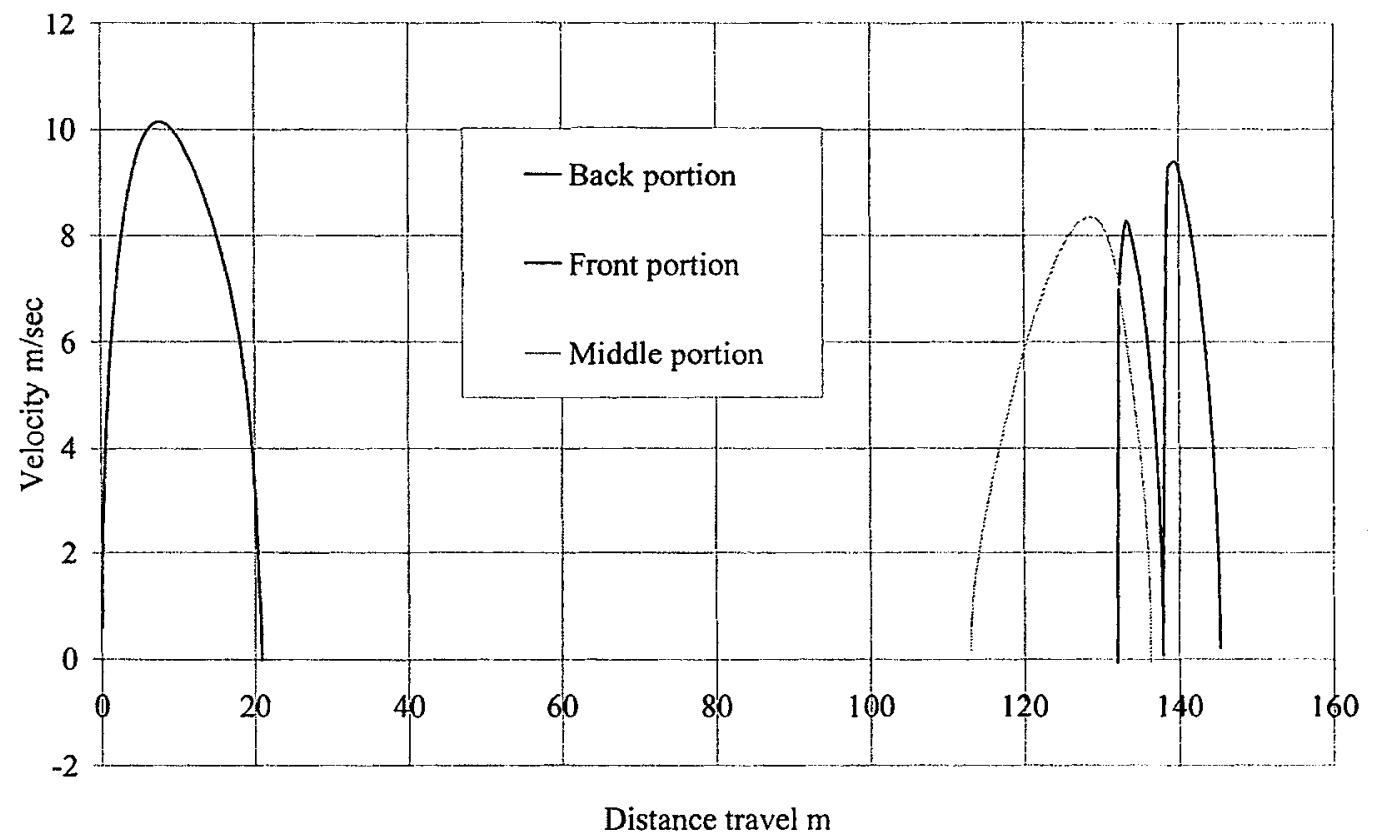

Figure 5. 17 The landslide movement of profile B Barabensi landslide 


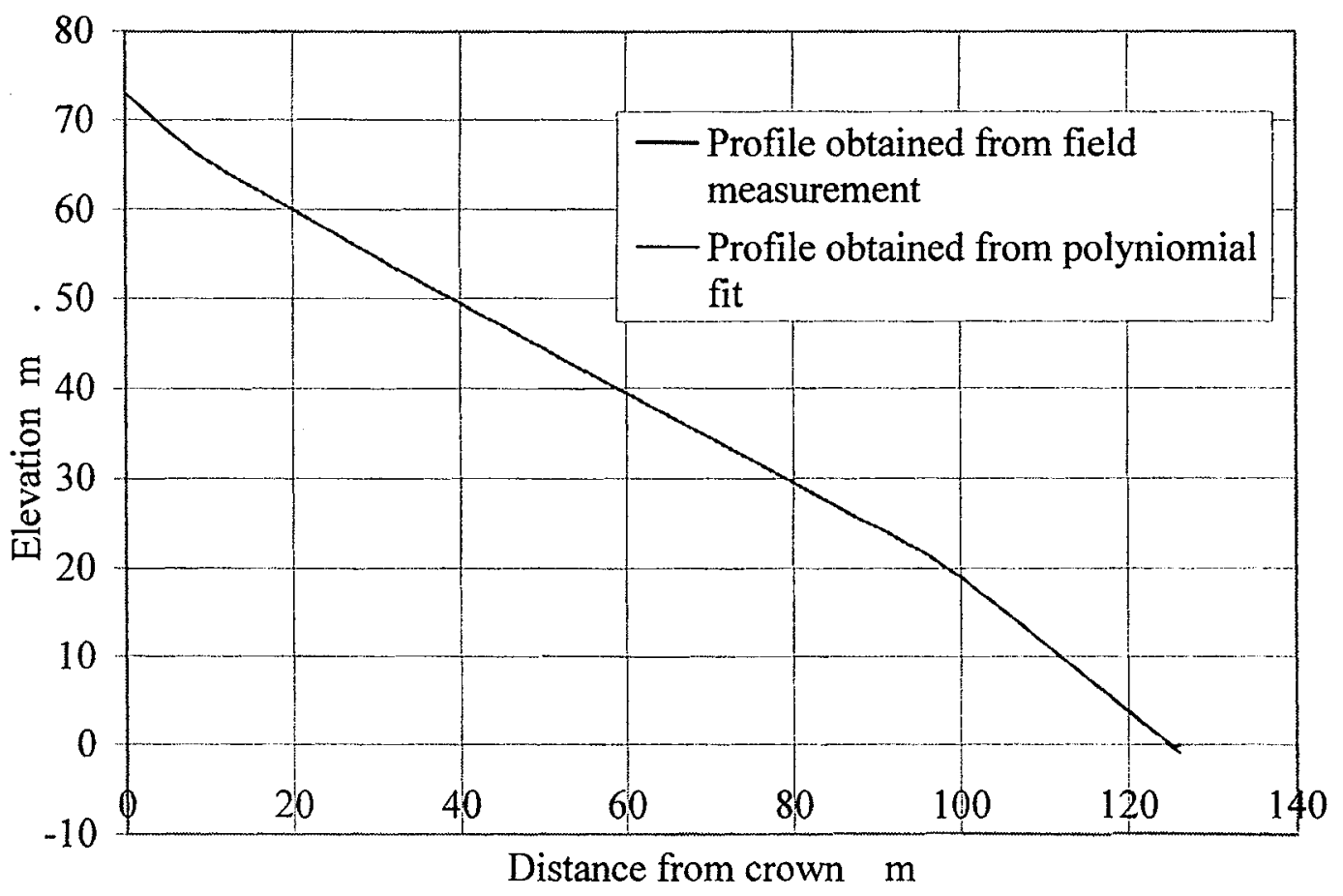

Figure 5. 18 Profile B of Barabensi landslide 


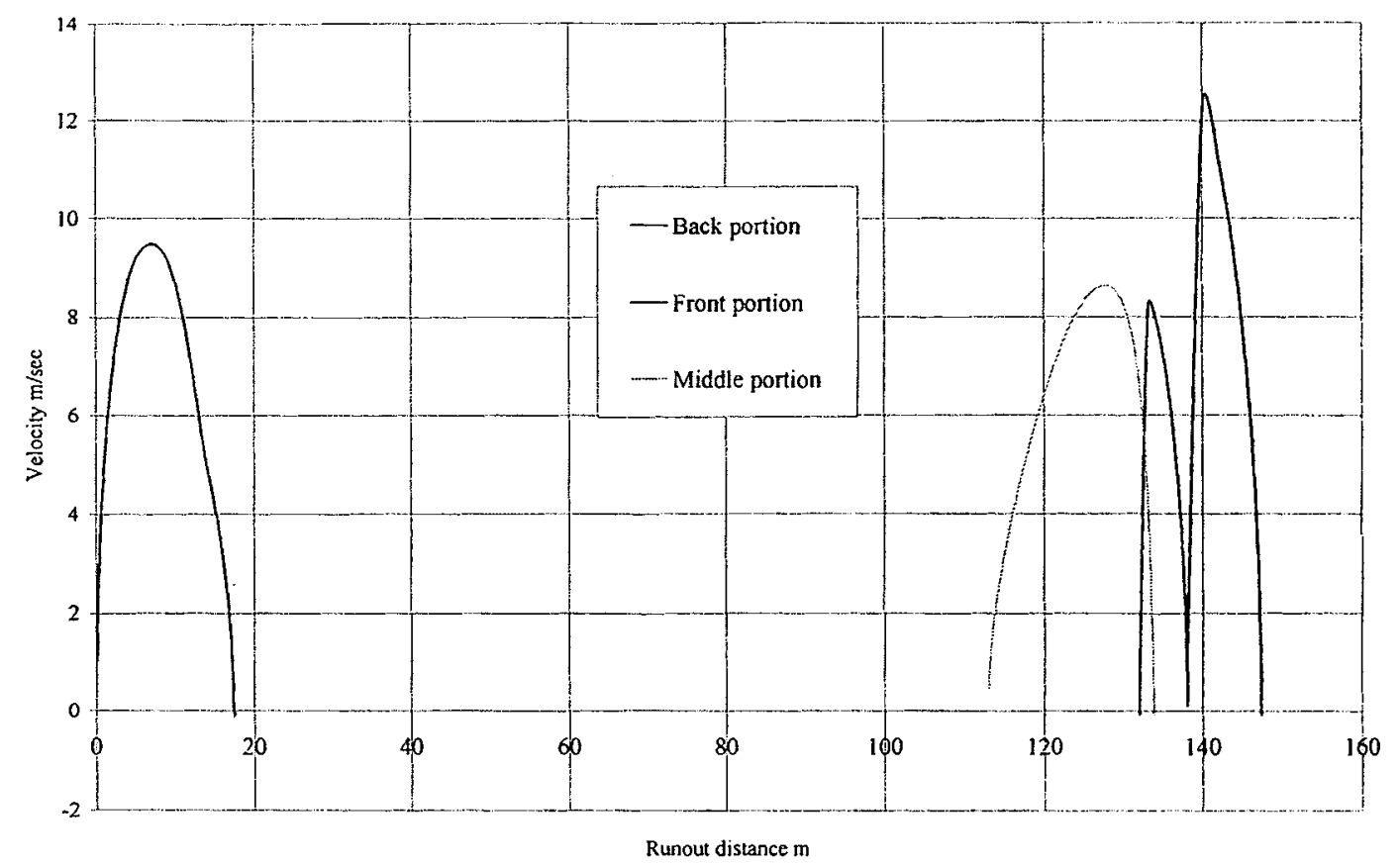

Figure 5. 19 The landslide movement of Profile B, Barabensi landslide

The movement of the soil is controlled by the existing cohesion of the soil, taken as $6 \mathrm{kPa}$. This is not destroyed during the movement of the landslide. The cohesion may develop from the contribution of cementing of soil grains and matric suction. The grain size distribution shows that there is significant amount of fines content that develops cohesion in the soil mass. The soil contains predominately colluvium, which could experience matric suction leading to development of cohesion.

Another factor preventing the soil mass changing into a debris flow is the increase of frictional resistance when the pore pressure dissipates at large deformation.

Impervious bedrock and non uniformly distributed clay layer along the failure surface enhance pore pressure development. It is observed that slope fails from pore 
pressure development but movement of soil mass is discontinuous over time and space. When the pore pressure develops in the soil mass, it starts to move. When the soil mass starts to move, cracks develop and the pore pressure dissipate and the soil movement stops.

The slope of the landslide is mild. For such a mild slope, transformation into a debris flow is unlikely for the recorded small pore pressure and energy available to transform landslide into debris flow. Slope factor is the most important among the factors considered for transformation of landslide into the debris flow. Further study on the effects of slope angle on the transformation of a landslide into a debris flow is studied in Chapter 6.

The analyses show that the relative intact cohesive strength, insignificant decrease in frictional resistance and the mild slope angle are the factors in preventing the initial landslide from transforming into a debris flow. This is an agreement with the field observation.

\subsection{Summary}

A slow moving landslide, the Barabensi landslide, is studied with the help of different computer software. Based on Slope/W and FLAC, the slope is marginally stable without pore pressure. Analyses using DAN show that the soil movement subsequent to the initial landslide is relatively small and unlikely to cause a debris flow. In the field the landslide mass is moving slowly every year in the rainy season. The movement of the slide is small as compared to the size of the landslide. 
The landslide initiation is modeled and studied with the help of Slope/W and FLAC. Using slope/W, without pore pressure, the calculated factor of safety is up to 1.18 in the mild profile and 1.08 in the steep profile of the landslide slope. Using FLAC, without pore pressure, the calculated factor of safety is 1.12 for the mild profile and 0.96 for the steep profile of the slope. Pore pressure ratios of 0.12 and 0.07 are sufficient to reduce the factor of safety to 1.0 for both steeper and the mild profile.

This landslide is also analysed using friction rheology in DAN. The model does not show that the landslide mass turning into a debris flow though the computed movement is approximately $20 \mathrm{~m}$ for the steeper slope profile and $18 \mathrm{~m}$ for the mild slope profile. This is in general agreement with the observation in the field respectively. 


\section{CHAPTER 6}

\section{PARAMETRIC STUDY}

\subsection{Introduction}

There are three main stages for a landslide transforming into a debris flow. These stages are initial slope failure, debris formation, and spreading on the flow surface (runout). The movement of soil in these three stages mainly depends on the natural terrain inclination and soil characteristics. Among the three stages, the third one - the runout distance - is the most important and the influence of natural terrain inclination and soil characteristics on it is studied in this chapter.

The major influencing factors for slope failure are friction, cohesion, pore pressure, and slope geometry. The initiation process starts when the disturbing force is greater than the resisting force, which is a function of friction, cohesion and pore pressure. For a steep slope, the failure mass above the failure surface has a small factor of safety while for a mild slope, the failure mass has a higher factor of safety.

After the initial landslide, the failure mass moves down the slope and may transform into a debris flow. As the failure mass moves down the slope the potential energy is converted into kinetic energy. A part of the kinetic energy works towards the development of grain vibration, which in turn destroys the cohesion and facilitates the movement of the failure mass. When sufficient energy is available during the movement, the failure mass will turn into a debris flow. 
Surface runoff, which depends on rainfall and infiltration into the ground, influences the transformation process as well. The more the surface runoff on the moving soil mass, the faster is the transformation. A small amount of energy may be sufficient for the transformation of a soil mass into a debris flow if a large amount of surface runoff is present.

The natural terrain inclination plays a great role in the transformation of a landslide into a debris flow. The steeper the slope, the higher is the efficiency of potential energy changing into kinetic energy during the debris movement. This kinetic energy will introduce grain vibration and degrade the strength of the moving debris. This in turn will raise the potential of the landslide change into a debris flow. Hence the steeper the slope, the greater is the potential for a landslide to transform into a debris flow.

Existing cohesion and friction in the soil mass above the failure surface play an important role in debris formation. If the cohesion and friction in the soil lying above the failure surface are small or reduced drastically, wide spread failure take place, resulting the sliding mass may be changed into a debris flow.

When a soil mass starts to move, static friction reduces to dynamic friction. As a result, the frictional strength of the soil reduces along the way of movement. Small disturbing factors such as impact on natural and man-made structures can easily dislocate soil grains and contribute to the further reduction of the frictional strength of the upper layer of the soil. The friction mobilized in the moving mass corresponds to the friction subject to the various reduction processes and is considered close to the residual value. The lower the mobilized friction angle, the higher is the potential to form a debris flow. 
Moisture contained in the sliding soil mass plays an important role in the formation of debris flow. Moisture content changes the matric suction and leads to reduction of soil strength. Therefore, moisture content is important for debris flow formation.

The length and inclination of the natural terrain is the source of the energy for the transformation of a landslide into a debris flow. The natural terrain inclination and its influence on runout distance are studied in the subsequent sections.

\subsection{General description}

The analysis of landslide runout distance, the third stage of the landslide, using different in situ soil parameters is carried out in this section. As demonstrated in the last two chapters, the friction rheology in the dynamic analysis (DAN) is appropriate for this type of analysis. Therefore, this method is used here to assess the influence of natural terrain inclination, friction, pore pressure and cohesion on runout distance.

\subsubsection{Definition of terms}

Figure 6.1 shows a sketch of the profile of the landslide and the subsequent debris flow, and the symbols used. Table 6.1 shows the different combinations of selected parameters for the study. 


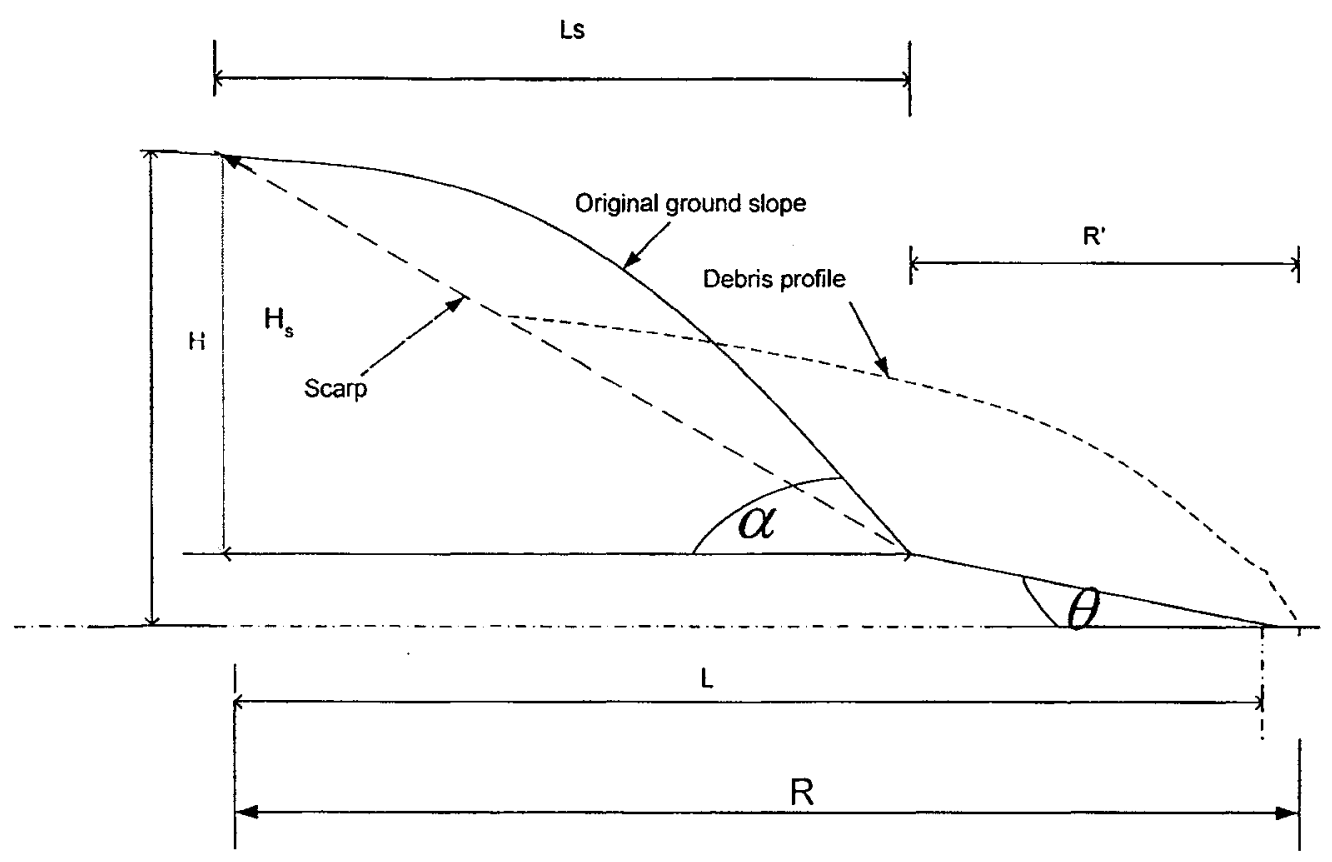

Figure 6. 1 Landslide and debris profile and symbol definition

In Figure $6.1, \mathrm{R}$ is the runout distance of the debris flow, $\mathrm{H}$ is the total height of natural terrain (including height of the initial landslide) down to the horizontal ground, $\mathrm{H}_{s}$ the height of the initial landslide, $\theta$ the natural terrain inclination, and $\alpha$ the slope of initial landslides. Furthermore, the horizontal distance from the initiation point to the meeting point of the horizontal ground and the sloping terrain is denoted by $\mathrm{L}$, and initial landslide length by Ls, $R^{\prime}$ the modified runout distance of the debris flow defined as $\mathrm{R}^{\prime}=$ $\left(L-L_{s}\right)$. Using different values for these variables along with initial friction angle $\left(\varnothing_{\mathrm{i}}\right)$, mobilized friction angle $\left(\emptyset_{\mathrm{m}}\right)$, and pore pressure $\left(\mathrm{r}_{\mathrm{u}}\right)$, we study their impacts on runout distance. 


\subsubsection{Pore pressure and Cohesion}

Pore pressure is an important factor for initiation to the runout stage of the landslide mass. Pore pressure reduces the strength of the soil. Therefore, pore pressure effect on runout distance is studied keeping other factors constant.

The other influencing factor, cohesion of the soil, gradually reduces during movement. Most landslide masses lose the cohesion when transformed into a debris flow. But this study is focused on cohesionless soil which is more susceptible to transformation into debris flow. Therefore, cohesive strength of the soil is taken as zero for the following study.

\subsubsection{Friction}

In this study the initial friction angle $\left(\varnothing_{\mathrm{i}}\right)$ is used for initiation and the mobilized friction angle $(\varnothing \mathrm{m})$ for debris flow process.

\subsubsection{Sets of parameters}

Table 6.1 shows the sets of parameters used in this parametric study.

\subsection{Results}

The results of the parameter study are presented in the following sections. 


\subsubsection{Constant height and varying slope}

At the beginning, the relation between terrain inclination and debris runout distance for constant total height is studied. The varying and constant parameters are shown in the row designated by S.N.1 in Table 6.1. The initial landslide slope angle $(\alpha)$ and the natural terrain inclination $(\theta)$ are the same and varied equally during the study. The total height of the natural terrain $(\mathrm{H})$ is taken as $150 \mathrm{~m}$ so that the horizontal distance is varied according to the selected natural terrain inclination.

Results (Figure 6.2) show that when the natural terrain inclination is flatter than $10^{\circ}$ (approximately) the landslide mass does not move. On the other hand, when the natural terrain inclination is steeper than mobilized friction angle $\left(\varnothing_{\mathrm{m}}\right) 26$ degree the landslide mass moves continuously.

The results also show that the modified runout distance increases with increasing terrain inclination up to a certain limit. After that, the modified runout distance does not increase; it starts declining. The limiting angle of the slope for the fixed height of $150 \mathrm{~m}$ is $35^{\circ}$. As the slope becomes steeper than $35^{\circ}$, the energy available from debris flow movement mostly dissipates within shorter distance. This is because the natural terrain meets the horizontal ground surface after dropping $150 \mathrm{~m}$ height.

As the terrain inclination is increased, the sloping ground meets the horizontal ground at a shorter distance that decreases the modified runout distance. Specifically in this case, the upper limit of runout distance is influenced by the geometry of the model. This result suggests beyond a certain terrain inclination $(\theta)$ followed by horizontal 
ground, the steeper the $\theta$, the shorter is the modified runout distance beyond which development can be safely constructed.

Table 6. 1 Sets of study

\begin{tabular}{|l|l|l|l|l|l|l|l|l|l|l|}
\hline $\mathrm{S}$. & $\emptyset_{\mathrm{i}}$ & $\emptyset_{\mathrm{m}}$ & $\mathrm{r}_{\mathrm{u}}$ & $\mathrm{C}$ & $\alpha$ & $\theta$ & $\mathrm{H}$ & $\mathrm{H}_{\mathrm{s}}$ & $\mathrm{L}$ & $\mathrm{L}_{\mathrm{s}}$ \\
$\mathrm{N}$. & Degree & Degree & $\mathrm{ratio}$ & $\mathrm{kP}$ & $\mathrm{degree}$ & $\mathrm{degree}$ & $\mathrm{m}$ & $\mathrm{m}$ & $\mathrm{m}$ & $\mathrm{m}$ \\
\hline 1 & 41 & 26 & 0.0 & 0.0 & varying* & varying* & 150 & 17 & varying & vary \\
\hline 2 & 41 & 26 & 0.0 & 0.0 & varying* & varying* & varying & 17 & 2000 & 20 \\
\hline 3 & Varying & Varying & 0.0 & 0.0 & 20 & 20 & 116 & 17 & 318 & 20 \\
\hline 4 & Varying & Varying & 0.0 & 0.0 & 30 & 30 & 184 & 17 & 318 & 20 \\
\hline 5 & Varying & Varying & 0.0 & 0.0 & 40 & 40 & 267 & 17 & 318 & 20 \\
\hline 6 & Varying & Varying & 0.0 & 0.0 & 50 & 50 & 379 & 17 & 318 & 20 \\
\hline 7 & 38 & 38 & varying & 4 & 30 & 30 & 184 & 17 & 318 & 20 \\
\hline 8 & 40 & 26 & varying & 4 & 41 & 41 & 276 & 17 & 318 & 20 \\
\hline 9 & 41 & 20 & 0.0 & 0.0 & 41 & Varying & varying & 17 & varying & 20 \\
\hline 10 & 41 & 26 & 0.0 & 0.0 & 41 & Varying & varying & 17 & varying & 20 \\
\hline 11 & 41 & 30 & 0.0 & 0.0 & 41 & Varying & varying & 17 & varying & 20 \\
\hline 13 & 41 & 35 & 0.0 & 0.0 & 41 & Varying & varying & 17 & varying & 20 \\
\hline
\end{tabular}

* Both values are the same and varying with equal value 


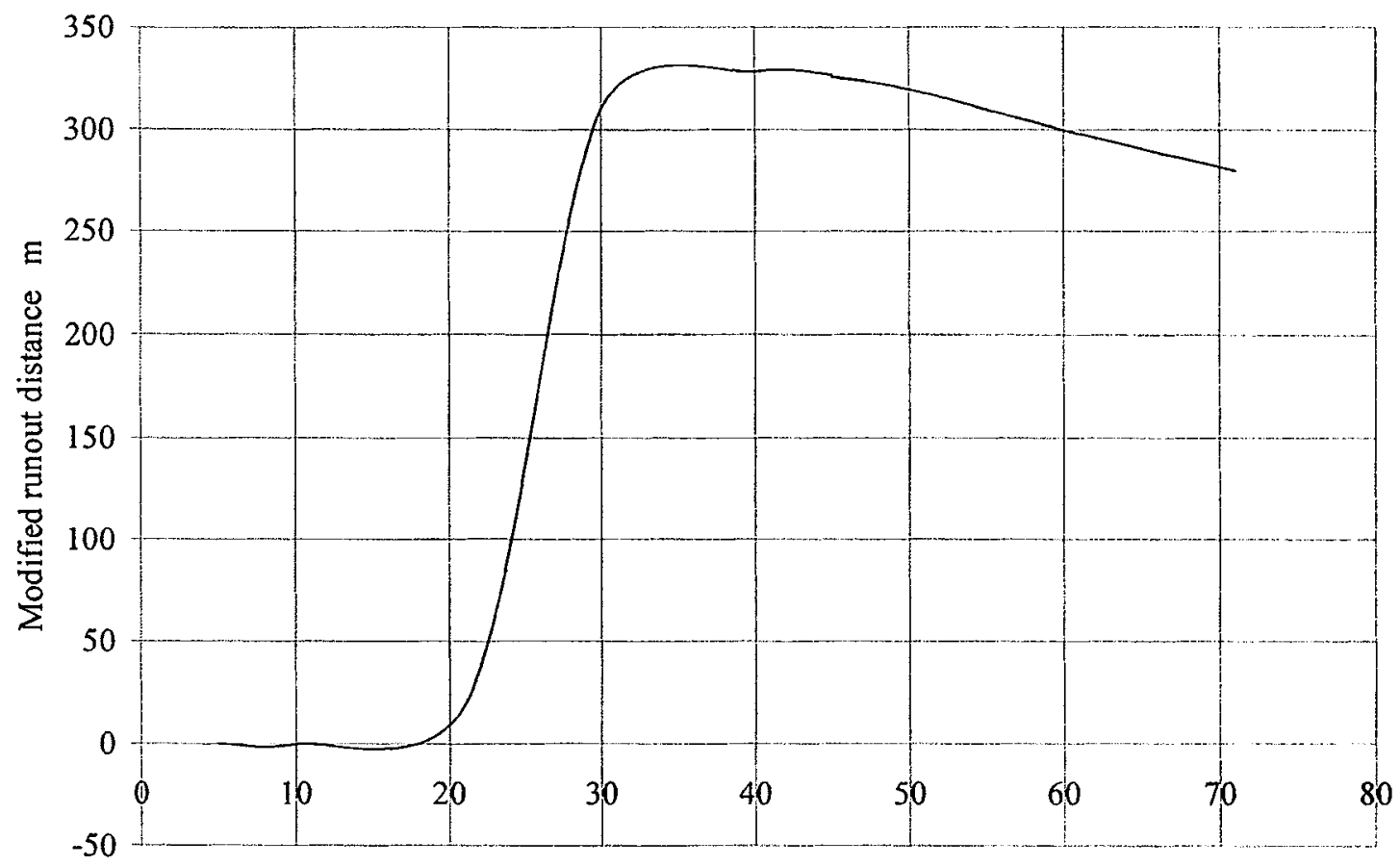

Natural terrain inclination, degree

Figure 6. 2 Modified runout distance of debris flow vs natural terrain inclination

\subsubsection{Constant horizontal distance and changing natural terrain inclination}

The movement of a landslide-induced debris flow in long slopes is studied in this section using parameters designated by Row 2 in Table 6.1. The following observations are made for different terrain inclinations at a constant horizontal distance of $2000 \mathrm{~m}$. For this case the slant path for the debris flow is long enough for the debris to move as compared to the previous case. The total height of the natural terrain is changed with the terrain inclination. The results (Figure 6.3) show that increase in terrain inclination continuously increases the modified runout distance. 


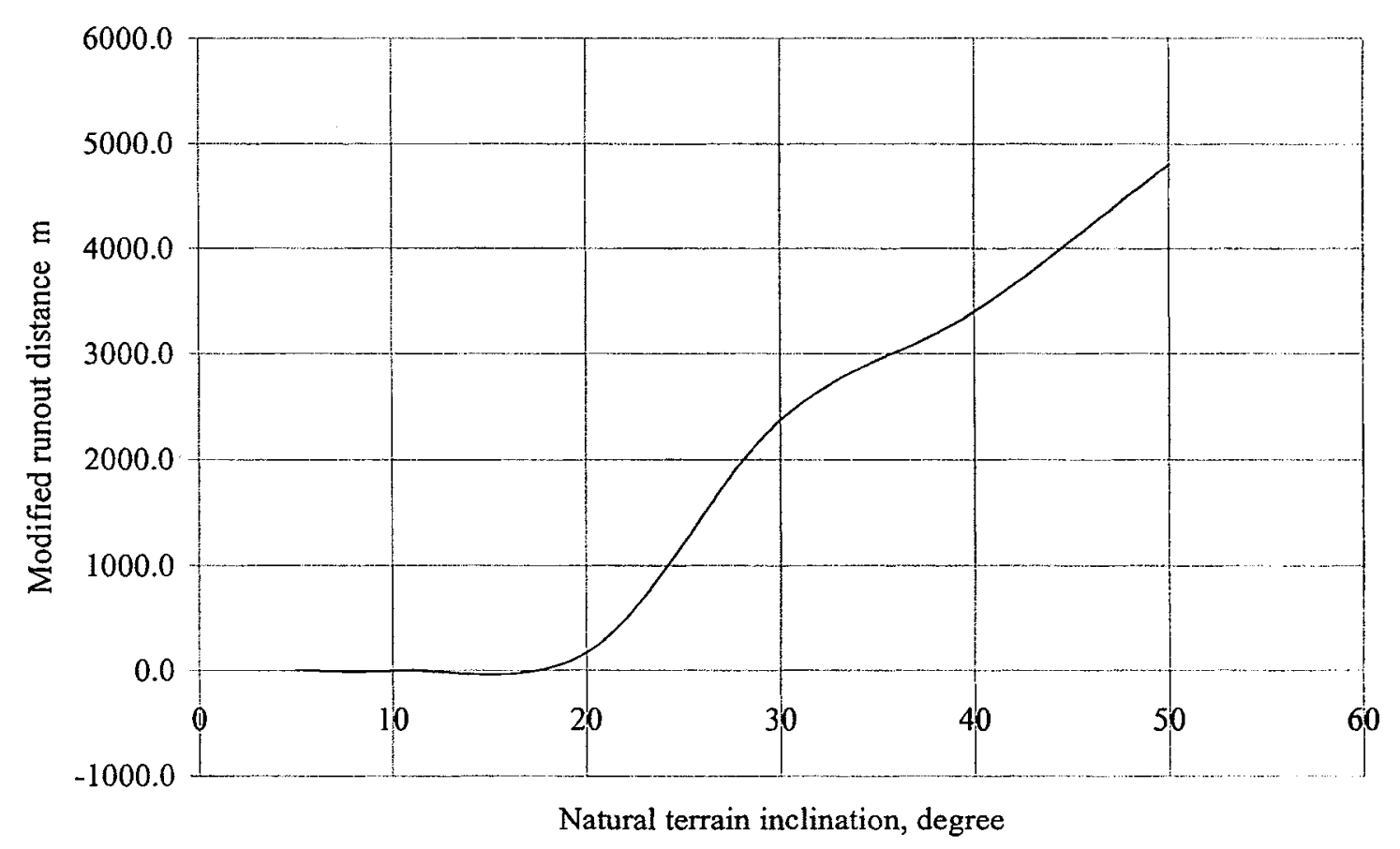

Figure 6. 3 Modified runout distance vs terrain inclination for long slope of horizontal distance of $2000 \mathrm{~m}$

\subsubsection{Friction in different terrain inclination}

Figures 6.4 shows the relation of modified runout distance and mobilized friction angle at terrain inclination ranging from $20^{\circ}$ to $50^{\circ}$. The parameters for these cases are given in Rows 3 through 6 in Table 6.1. The horizontal distance of natural terrain is taken as $318 \mathrm{~m}$. Note that the total height of natural terrain is different for these four cases as given in Table 6.1 .

Results show that at terrain inclination of $20^{\circ}$ and friction angle greater than $26^{\circ}$, the modified runout distance is limited to zero. The smaller the mobilized friction angle the larger is the modified runout distance. At 30-degree inclination, the modified runout 
distance is zero for mobilized friction angle of $40^{\circ}$ or more. For $40^{\circ}$ degree terrain inclination, the result shows that at a constant terrain inclination the modified runout distance increases with reducing mobilized friction angle. Finally, at 50 degree inclination, the runout distance is larger among the other inclinations in same mobilized friction angle.

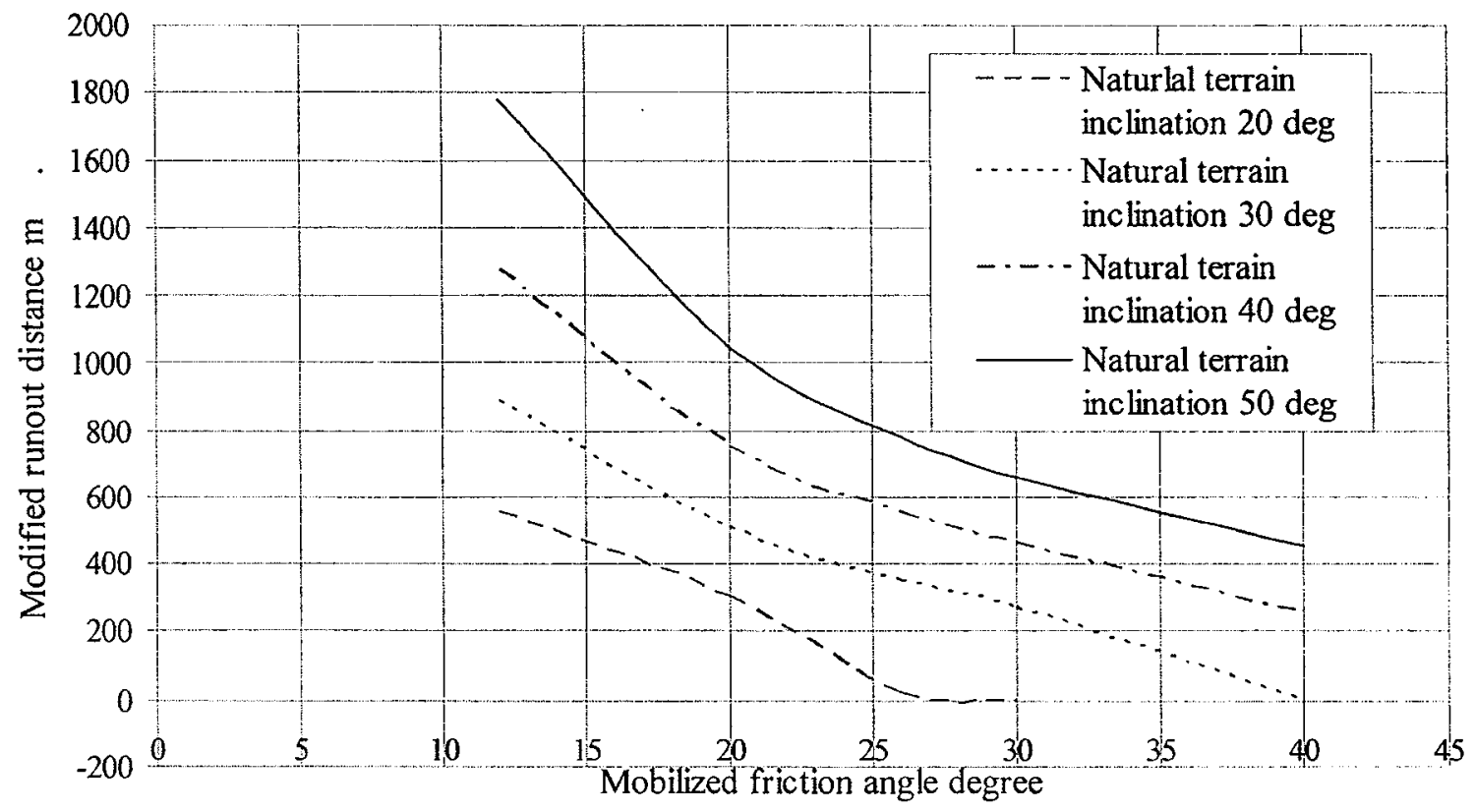

Figure 6. 4 Modified runout distance vs mobilized friction angle at terrain inclination ranging from $20^{\circ}$ to $50^{\circ}$

\subsubsection{Pore pressure}

The parameters used in the study are shown in the row designated by S.N. 7 in Table 6.1. The terrain inclination is kept at $30^{\circ}$ and the horizontal distance at $318 \mathrm{~m}$. The pore pressure ratio varies from 0.0 to 0.5 . The relationship between the modified runout 
distance and the pore pressure ratio are shown in Figure 6.5 for natural terrain inclination $30^{\circ}$. The runout distance increases with increase in pore pressure.

The response of pore pressure in steeper natural terrain inclination of $41^{\circ}$ is studied. The parameters chosen are as shown in the row designated by S.N. 8 in Table 6.1. Figure 6.6 shows the relationship between runout distance and pore pressure ratio. The higher the natural terrain inclination, the larger is the runout distance. The results also show that the effect of pore pressure is more significant for steeper slopes.

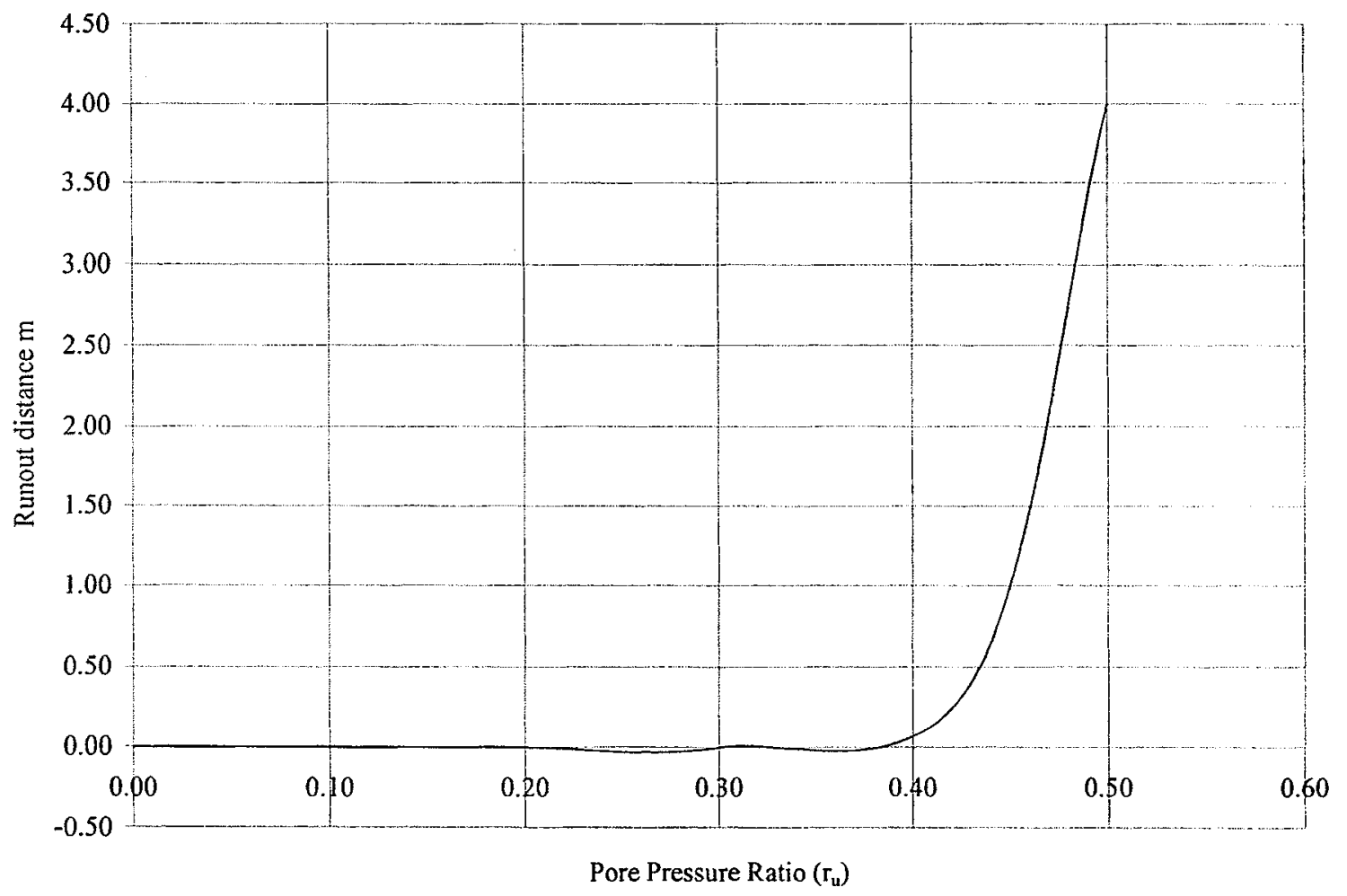

Figure 6. 5 Runout distance vs pore pressure at terrain inclination $=30^{\circ}$ 


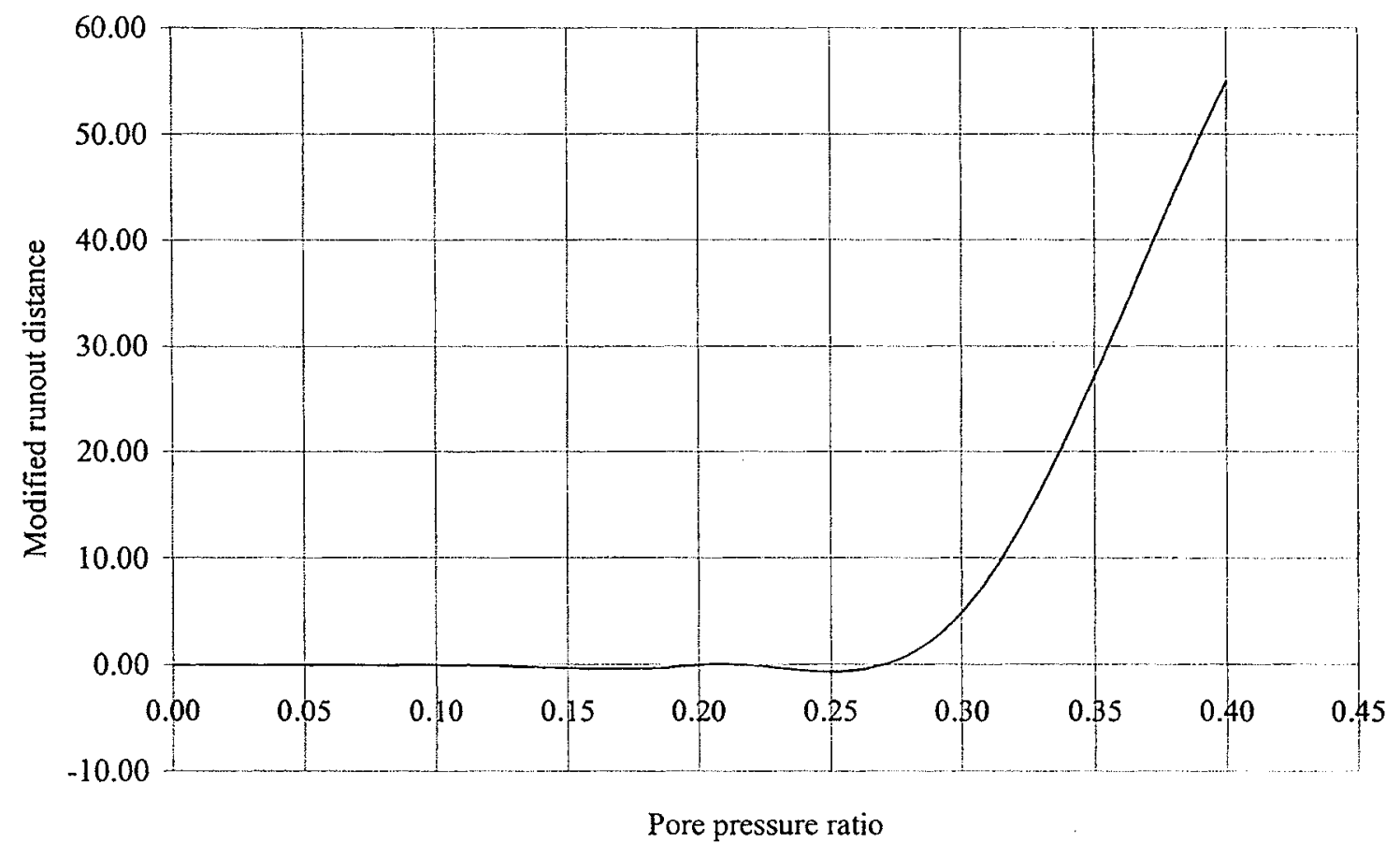

Figure 6. 6 Modified runout distance vs pore pressure ratio at terrain inclination = $41^{\circ}$

\subsubsection{Different combinations of pore pressure and cohesion}

The runout distance at different combinations of pore pressure and cohesion has been studied and the results are reported in Table 6.2.and Table 6.3. The results show that at extremely high pore pressure $\left(r_{u}=0.5\right)$, the debris mass over a significant distance moves even with some cohesion. The debris flow moves over long distances when the cohesion is destroyed and pore pressure exists in the soil mass. The results also show that for a small increase of cohesion from 1 to $2 \mathrm{kPa}$, there is a significant reduction of modified runout distance for $r_{u}=0.4$. 
Table 6. 2 Runout distance for different cohesion and pore pressure

\begin{tabular}{|c|l|l|l|l|l|}
\hline $\begin{array}{c}\text { Natural terrain } \\
\text { inclination }(\theta, \alpha) \\
(\text { degree })\end{array}$ & Cohesion & Pore pressure & $\emptyset_{\mathrm{i}}$ & $\emptyset_{\mathrm{m}}$ & $\begin{array}{l}\text { Modified } \\
\text { ratio }\end{array}$ \\
\hline 30 & 1.00 & 0.00 & 38.00 & 38.00 & 0.00 \\
30 & 1.00 & 0.10 & 38.00 & 38.00 & 0.00 \\
30 & 1.00 & 0.20 & 38.00 & 38.00 & 0.00 \\
30 & 1.00 & 0.30 & 38.00 & 30.00 & 5.00 \\
30 & 1.00 & 0.40 & 38.00 & 38.00 & 55.00 \\
30 & 2.00 & 0.40 & 38.00 & 38.00 & 4.00 \\
30 & 2.00 & 0.50 & 38.00 & 38.00 & 48.00 \\
30 & 3.00 & 0.40 & 38.00 & 38.00 & 2.00 \\
\hline
\end{tabular}

\subsubsection{Natural terrain inclination and friction angle for long slopes}

The relationship between friction angle, natural terrain inclination, and runout distance is developed. The input parameters are as shown in the rows designated by S.N. 9 to S.N. 13 in Table 6.1. The mobilized friction angle ranges from $20^{\circ}$ to $40^{\circ}$. This range is recommended for friction rheology in the DAN model. As well, this range of mobilized friction angle is mostly applicable for landslides in colluvium of mixed soils of 
silt, sand and gravel. The natural terrain inclination varies from $0^{\circ}$ to $40^{\circ}$ in the study. The pore pressure is kept at 0.0 . Other input parameters such as volume of the debris $\left(282 \mathrm{~m}^{3}\right)$, are the same as in Case Study in Chapter 4 .

Table 6. 3 Different combination of cohesion and friction for runout distance

\begin{tabular}{|l|l|l|l|l|l|}
\hline Natural terrain & Cohesion & Pore & $\emptyset_{\mathrm{i}}$ & $\emptyset_{\mathrm{m}}$ & Runout \\
inclination $(\theta, \alpha)$ & $(\mathrm{kPa})$ & pressure ratio & $($ degree $)$ & $($ degree $)$ & $(\mathrm{m})$ \\
\hline 30 & 1.00 & 0.40 & 26.00 & 26.00 & 290.00 \\
30 & 1.00 & 0.50 & 38.00 & 38.00 & 155.00 \\
\hline 41 & 0.00 & 0.00 & 42.00 & 42.00 & 0.00 \\
\hline
\end{tabular}

Figure 6.7 summarizes the relationship between runout distance, friction angle, and natural terrain inclination. The relationship shows that when friction angle is increased, the runout distance decreases for the same natural terrain inclination. If the friction angle is not changed, but the natural terrain inclination to the horizontal is increased, the runout distance increases.

Friction angle is important for the prediction of runout distance in any natural terrain. Friction angle depends on in situ moisture content, amount of surface runoff mixing with the moving soil and the type of soil. The friction angle range provided here can be used for similar types of landslide for estimating debris flow runout distance. Study of a large number of debris flow and the relationship between their runout distances and friction-angles could provide reliability of this chart. In the following 
section, the relationship obtained as shown in Figure 6.7 is compared with a large number of landslides induced in a single heavy rain storm.

\subsection{Comparison with field observation}

Approximately 800 landslides occurred in a single event in Lantau Island, Hong Kong, between November 4 to 5, 1993. Among them, Wong et al. (1996) report the details of 56 landslides. Out of these 56 landslides, 28 developed into debris flows (with modified runout distance more than the initial slant length of the landslide scarp after being detached from the source), and are used for comparison with the runout distance and natural terrain inclination chart (Figure 6.7).

The aerial views of the landslide region, taken from 6000 - $\mathrm{ft}$ height of the southern side of Lantau Island are given in Figure 6.9 and Figure 6.10. In this study, the gravitative debris flow is categorized into three types of debris mode (gravitational, hydraulic, mixed), as proposed by Wong et al. (1996). The description about different modes of gravitative debris flow is given in Chapter 2. The details of each category are given in Tables 6.4 through 6.6 .

For comparison purpose, Diagnostic report (1997) and Factual report (1996) have been used. In the reports, the landslides are numbered using prefixes $A, B, C$, which represent the study regions $\mathrm{A}, \mathrm{B}$, and $\mathrm{C}$ in Lantau Island southern terrain. The suffixes $(1,2,3)$ count the landslides from the east towards the west in the southern part of the Island. Landslide number A1A or A1B represents the number of landslides merging into a single debris flow a few moments after initiation. All the landslides were shallow up to $3 \mathrm{~m}$ in the deepest point from the ground surface, and most of the soil mass involved was 
young colluvium consisting of sand, gravel, cobble, and boulders mixed with silt. Each landslide had one or more scarps for source material. The young colluvium was overlaying on old colluvium or saprolitic soil in the area (Wong et al.1996). Landslide No B4 was a toppling failure type and other were failed on basal layer. The source length varied from 6 to $40 \mathrm{~m}$ and the width varied from 3 to $20 \mathrm{~m}$.

The runout distance of the debris flows was influenced by the size of the catchment area just above the landslide scarp and temporary drainage and permanent drainage outlets nearby the debris flow surface. These drainages provide more water that could mix with the landslide mass after traveling a few meters down the slope. The mobilized friction angle reduces as more mixing occurs. This reflects the different friction angle for different landslide mode. This consequence is accounted for the research indirectly with selecting different friction.

Rainfall of $60 \mathrm{~mm}$ to $110 \mathrm{~mm}$ was recorded in 5 -minute to 60 -minute duration, which was the maximum in a period of 20 years but not exceptionally severe (Wong 1997). Rainfall was quite severe for 6-12 hours and was recorded at $575.5 \mathrm{~mm}$ in 12 hours, which corresponds to a 900-year return period. Rainfall for a long period, longer than 7 days and a shorter period less than 2 hours, was not that severe, except for some periods in between. The highest rainfall record in the region was $954 \mathrm{~mm}$ in Tai Mo Shan on July 22, 1994. The study area experienced heavy rainfall and landslides each year. 
Table 6. 4 Debris flow with gravitational mode

\begin{tabular}{|l|l|l|l|l|l|l|}
\hline $\begin{array}{l}\text { Name of } \\
\text { Landslides }\end{array}$ & Gradient & Length(S) & Length $(\mathrm{L})$ & Height(H) $) \begin{array}{l}\text { Debris flow runout } \\
\text { Distance }\end{array}$ & $\begin{array}{l}\text { Natural terrain } \\
\text { Inclination }\end{array}$ \\
\hline A1A & 30 & 10 & 8.66 & 5.00 & 88 & 33.58 \\
A3 & 33 & 12 & 10.06 & 6.54 & 35 & 31.023 \\
A5B & 40 & 12 & 9.19 & 7.71 & 122 & 35.49 \\
A6 & 35 & 35 & 28.67 & 20.08 & 110 & 31 \\
A8 & 30 & 18 & 15.59 & 9.00 & 100 & 39 \\
A12 & 32 & 30 & 25.44 & 15.90 & 101 & 32.02 \\
A13A & 37 & 16 & 12.78 & 9.63 & 90 & 32 \\
A13B & 37 & 17 & 13.58 & 10.23 & 57 & 31.03 \\
A14 & 32 & 20 & 16.96 & 10.60 & 110 & 30.36 \\
A15 & 35 & 20 & 16.38 & 11.47 & 95 & 33 \\
B10 & 36 & 15 & 12.14 & 8.82 & 74 & 35 \\
B12 & 33 & 12 & 10.06 & 6.54 & 40 & 28.82 \\
\hline
\end{tabular}

Table 6. 5 Debris flows with hydraulic mode

\begin{tabular}{|l|l|r|l|l|l|l|}
\hline $\begin{array}{l}\text { Name of the } \\
\text { Landslide }\end{array}$ & Gradient & Length(S) & Length $(\mathrm{L})$ & Height(H) & $\begin{array}{l}\text { Debris travel } \\
\text { Length }\end{array}$ & $\begin{array}{l}\text { Natural terrain } \\
\text { Inclination }\end{array}$ \\
\hline A10B & 35 & 6 & 4.91 & 3.44 & 255 & 28.29 \\
A17 & 38 & 35 & 27.58 & 21.55 & 270 & 29.05 \\
A18A & 35 & 15 & 12.29 & 8.60 & 320 & 25.89 \\
A18B & 35 & 20 & 16.38 & 11.47 & 375 & 28.2 \\
B1A & 30 & 10 & 8.66 & 5.00 & 307 & 26.41 \\
B2A & 37 & 10 & 7.99 & 6.02 & 230 & 30.05 \\
B7M & 40 & 39 & 29.88 & 25.07 & 417 & 23.06 \\
B9 & 31 & 27 & 23.14 & 13.91 & 245 & 33.14 \\
C & 20.5 & 47 & 44.02 & 16.46 & 183 & 20.5 \\
\hline
\end{tabular}

Wong et al. (1997) suggest that the development of perched watertables leads to landslides in slope ranging from $25^{\circ}$ to $40^{\circ}$. Other factors must be involved in slides 
where the slope is below $25^{\circ}$ because just the perched watertable formation is not sufficient to disturb such mild slopes. In slopes steeper than $40^{\circ}$, soil material has more strength and the failure mechanism is different. Most of the landslides in the Island are in the slopes of $30^{\circ}$ to $40^{\circ}$.

Table 6. 6 Debris flows with mixed mode

\begin{tabular}{|c|l|l|l|l|l|l|}
\hline Name of the & Gradient & Length(S) & Length $(\mathrm{L})$ & Height(H) & Debris travel & Natural terrain \\
Landslide & & & & & Length & Inclination \\
\hline A1B & 35 & 20 & 16.38 & 11.47 & 176 & 31.3 \\
A2 & 34 & 12 & 9.95 & 6.71 & 142 & 30.33 \\
B1B & 40 & 17 & 13.02 & 10.93 & 94 & 35.9 \\
B4 & 7 & 9 & 7.19 & 5.42 & 244 & 35.86 \\
B11 & 5 & 11 & 9.01 & 6.31 & 171 & 37.29 \\
B7A & 38 & 10 & 7.88 & 6.16 & 110 & 30.8 \\
\hline
\end{tabular}

In this study, only the landslides with significant debris flow runout distance are considered. Therefore, 28 landslides are selected in the study.

The runout distance and natural terrain inclination of landslides listed in the Table 6.4, 6.5 and 6.6 are plotted in the Figure 6.7 and shown in Figure 6.8. Mobilized friction angle of debris flow is suggested $20^{\circ}$ to $40^{\circ}$ in the region, which is also in agreement with landslides in Lantau region. The initial landslide height $\left(\mathrm{H}_{\mathrm{s}}\right)$ is taken to be $17 \mathrm{~m}$ and 
initial landslide terrain inclination to be $41^{\circ}$. These selections are also based on the majority of the landslides that changed into debris flow.

\subsubsection{Comparison chart}

Figure 6.8 shows that there is a clear demarcation between different types of debris mode according to their characteristics. The friction of debris flows in gravitational mode are found to fall within the friction angle range of $35^{\circ}$ to $40^{\circ}$, hydraulic mode of $20^{\circ}$ to $35^{\circ}$, mixed mode of $34^{\circ}$ to $38^{\circ}$. Hydraulic mode of debris flow exhibits smaller friction angle, compared to the mixed and gravitational modes. Hydraulic mode is influenced with more surface runoff, which leads to lower mobilized friction than that in the gravitational mode. This study reflects the gradual decrease of friction in the debris from gravitational to the hydraulic mode type of debris flow.

The movement of gravitative debris flow is related to the debris characteristics. When the mobilized friction angle of the debris reduces, the debris flow mode changes from gravitational to hydraulic. The mixed mode of the gravitative debris flow is more complex and is probably developed from influence of partial mixing of surface water. When the condition is not clear whether the gravitational mode changes into a hydraulic mode it is safe to consider it a mixed mode.

\subsubsection{Discussion}

The foregoing analyses show that the overall majority (27 out of 28 ) of the landslides that changed into debris flow in the Lantau Island landslide incident are characterized by a mobilized friction angle higher than $26^{\circ}$. Therefore, analyses using a 
mobilized friction angle of $26^{\circ}$ give an upper bound or maximum probable runout distance of any mode of the gravitative debris flow. This upper bound provides a simple and conservative way to estimate the runout distance within which destruction will occur.

Before closing discussion of results and those of Wong et al, I would like to provide some comments on the travel angle, the angle of inclination of a line drawn from the crown to the front of the debris. Wong et al. (1997) suggest that the observed relation between the debris flow travel angle and the runout distances could be applicable for predicting runout distance in similar conditions. However, this may not be the case in all circumstances as there are various factors influencing the travel angle, such as the amount of water mixing in the moving mass, length of natural terrain. In addition, it is difficult to estimate the length of natural terrain with travel angle.

For estimating of the runout distance for debris flows in materials similar to those in the Lantau Island incident, it is more reliable to use the mobilized friction angle and natural terrain inclination as demonstrated in this Chapter. 


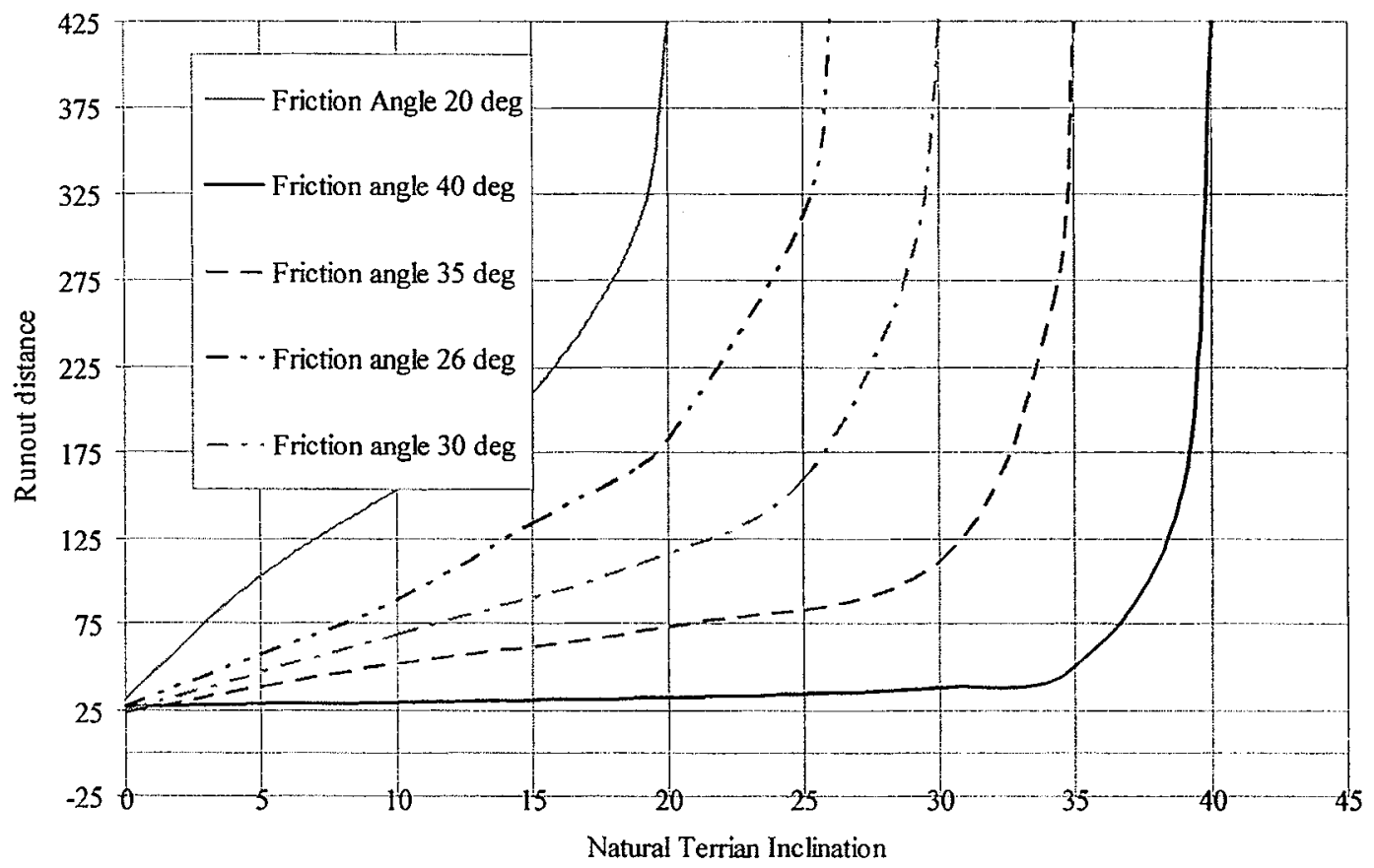

Figure 6. 7 Runout distance vs natural terrain inclination at different mobilized friction angles 


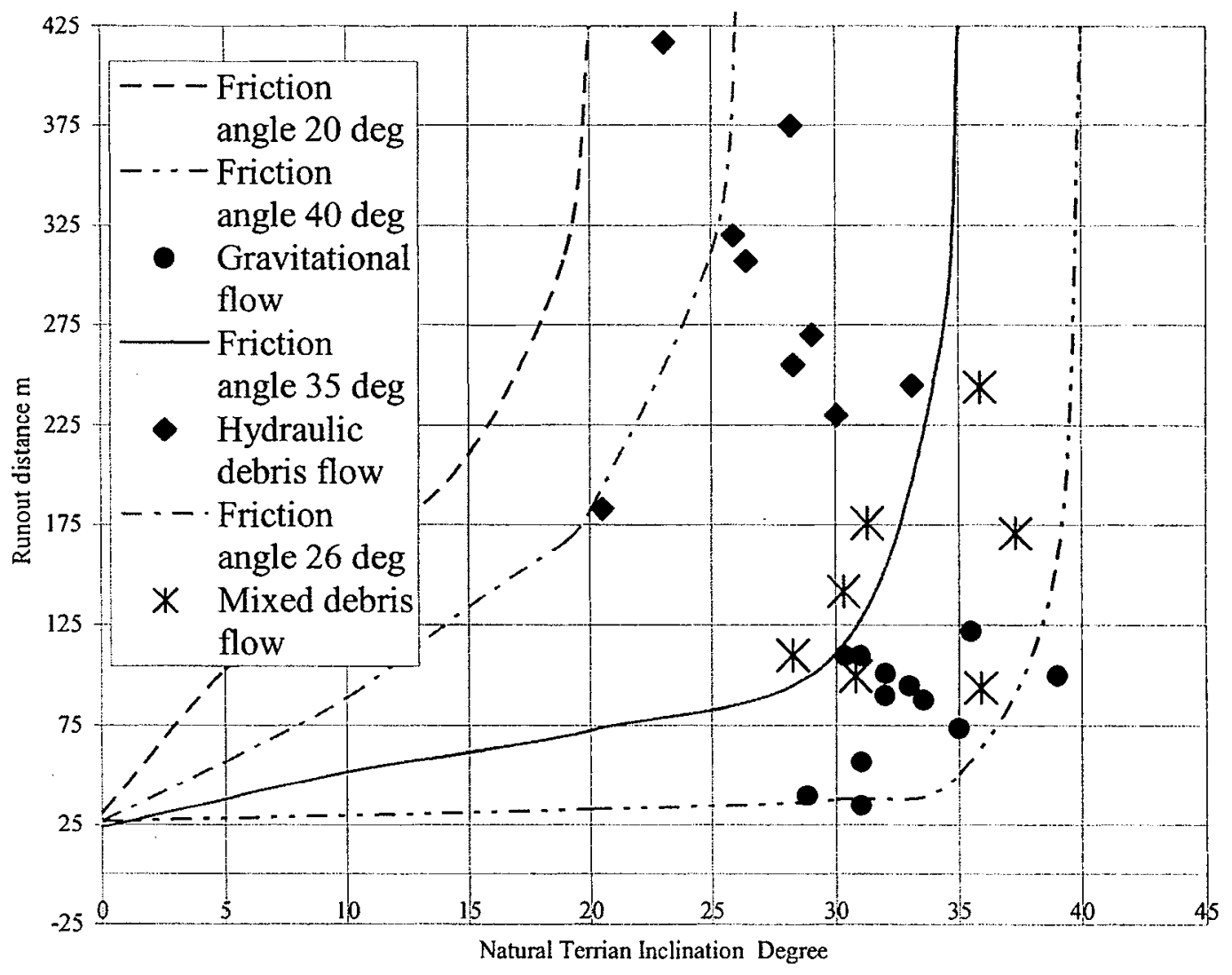

Figure 6. 8 Runout distance comparison of observed and estimated runout distance of the November 1993 debris flow on Lantau Island 


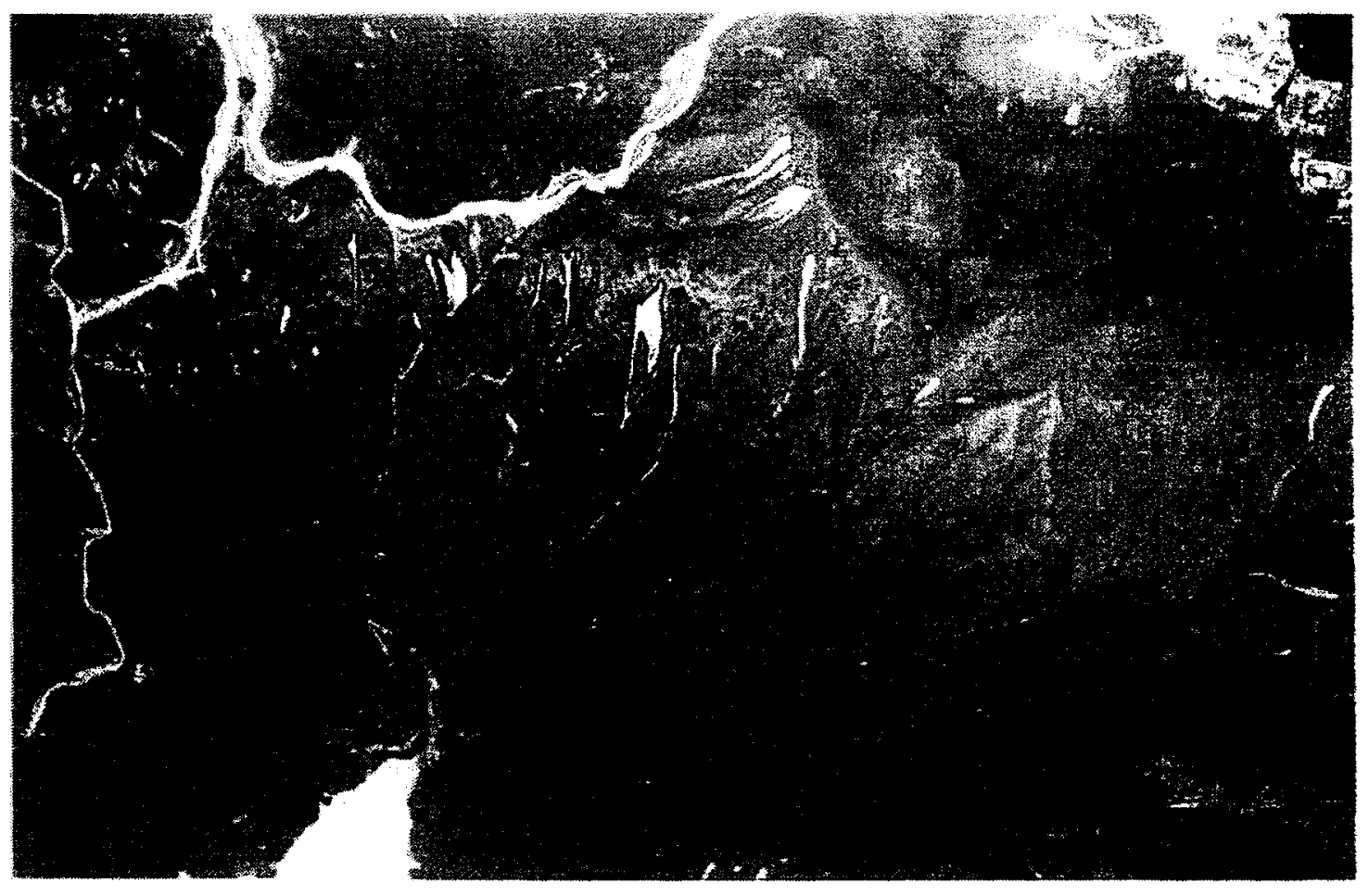

Figure 6. 9 Aerial photograph of landslides in Lantau Island area B

(Wong et al. 1996) 


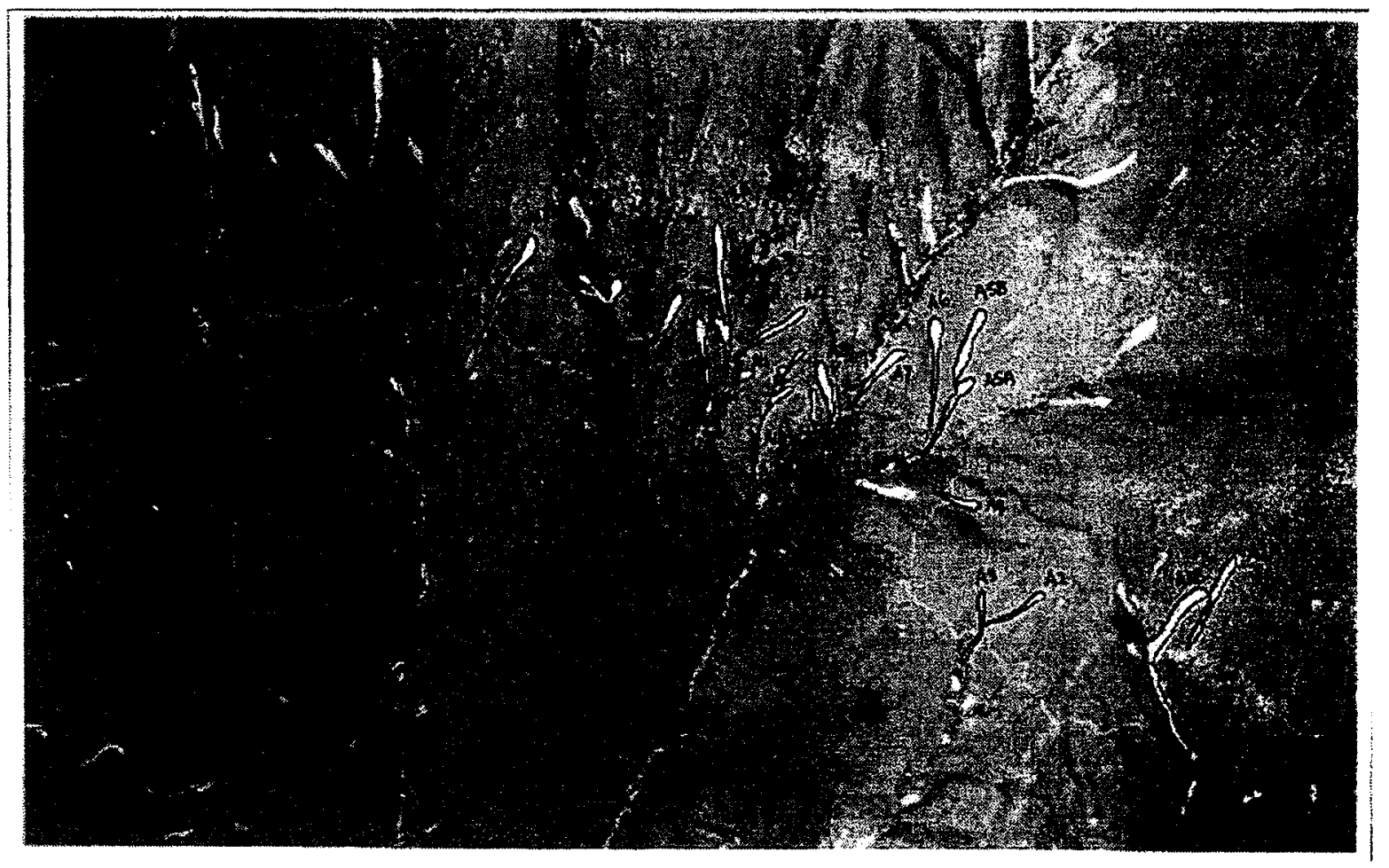

Figure 6. 10 Aerial photograph of landslides in Lantau Island area A

(Wong et al. 1996) 


\subsection{Summary}

This chapter presents a parametric study involving runout distance of landslideinduced gravitative debris flows based on the friction rheology model in DAN. The parametric study is conducted to study runout distance of debris flow as a function of various parameters. A chart of runout distance, soil characteristics, and natural terrain inclination is developed and compared with field data.

The individual effects of various parameters, such as friction angle, natural terrain inclination, cohesion and pore pressure on runout distance, have been considered. The study showed that the runout distance decreases with the increase in friction angle, despite increase in natural terrain inclination. When the natural terrain inclination approaches to the mobilized friction angle of the flowing debris, the runout distance increases vary rapidly. A chart of runout distance, friction angle, and natural terrain inclination is developed to show that for friction angle of $40^{\circ}$, the slide mass shows no movement but for a friction angle of $20^{\circ}$, the debris flow moves continuously even on a natural terrain inclination of $20^{\circ}$.

The chart obtained from the numerical model is compared with the debris flow factual records from 28 landslides in Lantau Island, Hong Kong, where in a single event, approximately 800 landslides occurred. The comparison of the results of parametric study with factual data shows that this model could be used to estimate runout distance of debris flow. The demarcation between different types of debris movement and their characteristics is drawn. The runout distances for three types of debris mode, i.e. 
gravitational mode, hydraulic mode and mixed mode, are compared. The hydraulic mode of debris flow is found to result in the longest runout distance compared to the gravitational or mixed mode. The debris in the gravitational mode is found to fall within the friction angle range of $35^{\circ}$ to $40^{\circ}$, hydraulic mode $20^{\circ}$ to $35^{\circ}$ and mixed mode $34^{\circ}$ to $38^{\circ}$

Study shows that the landslides, soil mass has mobilized friction angle greater than $26^{\circ}$. Based on this study, it is found that the runout distance in materials similar to those in the Lantau Island landslides can be estimate in a simple and conservative way by using mobilized friction angle of $26^{\circ}$ in connection with the natural terrain inclination of the slope.

The limitation of the chart developed in this thesis is that it should be used on materials similar to those of the Lantau Island landslide. 


\section{CHAPTER 7}

\section{SUMMARY, CONCLUSIONS AND RECOMMENDATIONS}

\subsection{Summary}

In this thesis, the landside initiation and the runout distance of debris flow are studied. Two different landside case histories are analyzed and a parametric study of influential factors for runout distance is conducted. A chart of influence of natural terrain inclination and debris friction angle on runout distance is developed. The chart is compared to 28 landslides in Lantau Island, Hong Kong.

The first case record involved different stages of a fast moving landslide at Lei Pue Street, Hong Kong. This landslide mass changed into a debris flow in a matter of seconds. Analyses using Slope/W and FLAC were conducted to investigate the initial failure condition of the landslide. The results show that the friction angle is $41^{\circ}$ and pore pressure ratio 0.04 , and zero cohesion at failure.

The DAN numerical model (Hungr 1995) was used to simulate the debris flow movement. In the simulation, the initial soil strength parameters were used within the source region and the mobilized friction angle was applied beyond the source region. The mobilized friction angle was taken as $26^{\circ}$, obtained from laboratory study on debris sample deposited at the site. The runout distance of the debris flow estimated with the friction rheology in DAN was $235 \mathrm{~m}$. This is in agreement with the field observation. The Voellmy rheology in the DAN, however, produced a runout distance of $130 \mathrm{~m}$, much 
shorter than the measured value in the field. The friction rheology was, therefore, considered as more appropriate for the simulation of debris flow movement in this case.

The FLO-2D model (O'Brien, 2003) was used for the simulation of debris flow inundation in the flow surface. The parameters proposed by Kang and Zang (1980) for similar conditions were used for the simulation. The flow velocity using the FLO-2D simulation was found to be smaller than the velocity obtained from DAN. The debris flow depth obtained from FLO-2D was similar to the flow depth observed in the field, for the lower portion of the debris flow surface. The debris flow simulation shows that there was no final deposition point within the debris flow surface. In other words, the runout distance is way beyond the observed value. Therefore, FLO-2D is not used further in this research.

The second case history involved the slow moving Barabensi Landslide in Nepal. The initial failure condition was obtained using Slope/W and FLAC. The simulation showed that friction angle of $30^{\circ}$, pore pressure ratio of 0.07 , and cohesion of $6 \mathrm{kPa}$ were operational at failure. The results show that the slope failed following the soil mass experiencing a pore pressure ratio of 0.07 . Because of the mild slope, the failure mass only moved a short distance.

There was a thin discontinuous clay layer in the failure surface, which experienced seepage and positive pore pressure in every rainy season. Thus, every year a small movement was developed in the soil mass.

The small movement of the landslide mass may be caused by the generated pore pressure quickly dissipated upon any movement. In every rainy season, the pore pressure increases, lowering the soil strength and resulting in soil mass movement. Due to 
differential deformation, the soil mass breaks up and develops cracks, allowing the pore pressure to dissipate. The soil hence regains its shear strength. The differential deformation was displayed by the presence of horizontal and vertical cracks in the failure soil mass.

Based on experience from the previous case study the friction rheology of DAN has been used to analyze the Barabensi landslide. The results from this rheological model in DAN showed relatively small movement in the soil, which is in agreement with the field data.

The case record study shows that cohesion being intact is the most important factor for also reducing the chance of debris flow formation from a failure soil mass.

In the parametric study, the friction rheologic model of DAN is used to study individual effects of various parameters, such as friction angle, and natural terrain inclination on runout distance. The values of some parameters are taken from the case studies. A number of series of analyses have been conducted, each with one parameter being varied while the other parameters being kept constant. Finally, the study is focused on cohesionless soils that are commonly encountered in debris flows.

A chart of runout distance, friction angle, and natural terrain inclination was developed from the parametric study. The chart obtained from the numerical model was compared with the debris flows in Lantau Island, Hong Kong, where in a single event, approximately 800 landslides occurred on November 4 and 5, 1993. Some of these landslides were transformed into debris flows. 


\subsection{Conclusions}

Based on the foregoing study, the following conclusions can be drawn:

1 The Lei Pui Street landslide turns into a debris flow mainly because of the steep natural terrain and the soil being cohesionless. This allows the initial failure to move down the slope with significant kinetic energy that reduces the initial friction angle to the lower mobilized value. This causes the landslide to transform into a debris flow.

2 The Barabensi landslide occurs in the mild slope and in a cohesive frictional soil. The cohesion was not significantly reduced during the movement, hence preventing the landslide from changing into a debris flow.

3 Based on comparison of computed and observed runout distance, the friction rheology model in DAN is found to be more appropriate than the other model in DAN and the FLO-2D method.

$4 \quad$ The parametric study shows the following:

a. The runout distance of a debris flow is a function of pore pressure, cohesion, mobilized friction and natural terrain inclination.

b. When the mobilized friction angle approaches the natural terrain inclination the runout distance will be very large. 
c. The results of the parametric studies were summarized in a chart to develop the relationship between runout distance, mobilized friction angle and natural terrain inclination.

5 The results of the field observation among the 28 landslides induced debris flow caused by the 1993 Lantau Island incident are plotted in the chart. It is found that a curve corresponding to the mobilized friction angle of $26^{\circ}$ provides an upper bound estimate of the runout distance from all the different modes of the debris flows. While this curve gives reasonable runout distance for the hydraulic mode of debris flow, it also gives conservative runout distance for the gravitational and mixed modes of the debris flows. Hence, the upper bound curve provides a practical, simple and safe solution for estimating runout distance of debris flow of nature similar to the 1993 Lantau Island landslides.

\subsection{Recommendations}

The initiation of landslide can be predicted using Slope/W and FLAC software. Slope/W provides stability estimated using the limit equilibrium method, while FLAC provides additional information in terms of deformation. The runout distance of the debris flow can be better estimated with the friction rheology in DAN. The flow inundation (maximum velocity and depth of the flow in any specific point) on the flood plain can be studied using FLO-2D. 
The relationship between rainfall intensity, catchment areas immediately above the landslide area and the catchment area of the natural drainage, for predicting debris flow occurrence, is a topic for future research.

Two possibilities for prediction of debris flow from landslide are recommended for further study.

- Energy approach:

The energy required for a soil to liquefy can be studied in the laboratory using cyclic triaxial or other dynamic test devices. Similarly, energy required for an initial landslide turning into a debris flow can be estimated by some method yet to be developed. By comparison of the energy established in the laboratory and the energy required in field for debris flow formation, one can estimate the likelihood of a landslide transforming into a debris flow.

- Empirical approach:

Using in situ soil tests (SPT or CPT) in landslide prone areas and correlating the test results with runout distance and other parameters of the debris flow, an empirical approach may be established for assessing debris flow formation and runout distance. 


\section{REFERENCES}

Armanini, A., and Fraccarllo, L. (1997) Critical conditions for debris flow, Cheng-Lung Chen (eds) debris flow hazards mitigation mechanics prediction and assessment pp 434443, New York, ASCE.

Akan, A. O. and Yen, B.C. (1981) Diffusive-wave flood routing in channel networks, Journal of Hydraulics, ASCE, 107(6)719-732.

Anderson, S. A. and Sitar, N. (1995) Analysis of rainfall-induced debris flows. J. Geotech. Eng. 121:544-52.

Atkinson, J. H. (1981) Foundations and Slopes, McGraw-Hill Book Company (UK) Limited ISBN 0-07-084118-7.

Ayotte, D., Evans, N., and Hungr, O. (1999) Runout analysis of debris flows and avalanches in Hong Kong. Proceeding of Symposium on Slope Stability and Landslides, organized by the Vancouver Geotechnical Society, Vancouver, B.C., Canada, May 1999, pp 39-46.

Bagnold, R. E. (1954) Experiment on a gravity free dispersion of large solid sphere in a Newtonian fluid shear, Proc. Royal Society of London 225 A.

Bertocci, R., Canuti, P., Casagli, G. C. A., Vannocci, P. (1995) Landslides on clay and shale hill slopes in Tuscany, Italy, Geological Society of America, Reviews in Engineering Geology, Volume X pp107-118.

Bishop, A. W. (1967) Progressive failure - with special reference to the mechanism causing it, Proceedings of the Geotechnical Conference on Shear Strength Properties of Natural Soils and Rocks. Oslo. 2: 142-150.

Bjerrum, L. Jorstad, F.A. (1968) stability of rock slopes in Norway, Norwegian Geotechnical Institute, Publication No. 79.

Blackwelder, E. (1928) Mudflow as a geological agent in semi-arid mountains, Geological Society of America, Bulletin, 39, 465-484.

Brand, E.W. (1981) Some thoughts on rain-induced slope failures, In Proceedings of the 10th International Conference on Soil Mechanics and Foundation Engineering, Stockholm, 15-19 June 1981, A.A. Balkema, Rotterdam, The Netherlands. Vol. 1.pp. 373-376.

Bromhead, E. N. (1986) the Stability of Slopes Surrey University Press, Chapman, and Hall, New York. 
Buma, J. and Van Asch T. (1996) Soil (debris) spreading, Dikau R, Brunsden D, Schrott L, Ibsen M-L (eds) Landslide recognition: identification, movement and causes. Wiley, Chichester, pp 137-148.

Campbell, R. H. (1975) Soil slips, debris flows and rainstorms in the Santa Monica Mountains and vicinity, southern California, U.S.G.S. Prof. Paper, 851, 51 pp.

Cannon, S.H. and Ellen, S.D. (1988) Rainfall that resulted in abundant debris-flow activity during the storm, In: Ellen S.D., Wieczorek G.F. , Eds., "Landslides, floods, and marine effects of the storm of January 3-5, 1982, in the San Francisco Bay area", U.S.G.S. Prof. Paper, 1434, 27-34

Chen, H., and Lee, C.F. (2002) Runout Analysis of Slurry flow with Bingham Model, Journal of Geotechnical and Geo-environmental Engineering Vol 128 No 12 ASCE, ISSN 1090-0241/2002/12-1032-1042.

Chau, K.T., Chan, C.P.L., Luk, S.T., and Wai, W.H.,(2000) Shape of deposition fan and runout distance of debris flow: effect of granular and water contents, Wieczorek and Naeser (eds) 2000 Balkema, Rotterdam, ISBN 90 149X.

Chen, H., and Le, C.F. (2000) Numerical simulation of debris flows, Canadian Geotechnical Journal 37 14-160.

Chowdhury, R. N. (1978) Slope Analysis, Elsevier Scientific Publishing Company, Amsterdam.

Chuang, M. H., Hsu, M. H., Chang, T., J. and Lin, M. L. (2000)An analysis of debris flow transport in tributaries of Chen-Yo-Lan Creek Wieczorek and Naeser(eds) Debris flow Hazards Mitigation: Mechanics, Prediction, and Assessment, Balkema, Rotterdam, ISBN $905809149 \mathrm{X}$.

Collin, A. (1846) landslides in Clays, translated by Schriever, W. R., Carriere, R. F. 1., Skampton, A.W., University of Toronto Press (1956).

Crawford, C.S., and Eden, W. J. (1967) Stability of natural slopes in sensitive clay. Journal of Soil Mechanics and Foundation Engineering, American Society of Civil Engineers, SM4: 419-436.

Cruden, D. and Varnes, D. (1996) Landslide Types and Processes in Landslides: Investigation and Mitigation. ed. Turner, A. and Schuster, R. Transportation Research Board, National Research Council; 247. p. 36-75.

Das, B.M. (1998) Principle of Geotechnical Engineering Fourth Edition, PWS Publishing Company, 20 Park Plaza, Boston, MA 02116. 
Dawson, E.M., Roth, W.H., and Drescher, A. (1999) Slope stability analysis by strength reduction, Geotechnique $49(6), 835-840$.

Dieter, R. and Daniel, A. (2000) Flow resistance of natural and experimental debris flow in torrent channels Debris flow hazard Wieczorek and Naeser(eds) Debris flow Hazards Mitigation: Mechanics, Prediction, and Assessment, Balkema, Rotterdam, ISBN 905809 $149 \mathrm{X}$.

Egashira, S., K. Ashida, H., Yajima, and Takahama, J. (1989) Constitutive equation of debris flow, Annual of the Disaster Prevention Research Institute, Kyoto University, No 32B-2, 487-501.

Egashira, S., Honda, N., Itoh, T. (2000) Experimental study on bed material entrainment into debris flow, Wieczorek and Naeser (eds) Debris flow Hazards Mitigation: Mechanics, Prediction, and Assessment, Balkema, Rotterdam, ISBN 905809149 X

Evans, S. G. (2000) Catastrophic Landslide in Canada. http://www.cseg.ca/conference/2000/1072.pdf

Eckersley, J. D. (1990) Instrumented laboratory flowslides, Geotechnique, 40(3), 489-502.

Ellen, S. D. and Fleming R. W. (1987) Mobilization of debris flows from soil slips, San Francisco Bay region, California. See Costa \& Wieczorek 1987, pp. 31-40

Ferguson, H.E. (1974) Geological observations and geotechnical effects of valley stress relief in Allegheny Plateau, preprint of paper presented to ASCE National Meeting on Water Resources Engineering, Los Angeles, California, $31 \mathrm{pp}$

FLAC Manual (2002) Itasca Consulting Group Inc. User's Guide, theory and Back ground, Fast Lagrangian Analysis of Continua, Minneapolis, Minnesota 55415 USA

Fletcher, L., Hungr, O., Evans, S.G. (2002) Contrasting failure behavior of two large landslides in clay and silt, NRC Research Press.

FLO-2D User's manual (2003) Version 2003.06, FO-2D Software Inc. P. O. Box 66 Nutrioso, Arizona 85932.

Fredlund, D.G., and Krahn, J. (1977) Comparision of slope stability methods of analysis, Canadian Geotechnical Journal Vol 141977 pp429-439.

Fredlund, D. G., and Rahardjo, H. (1993) soil mechanics for unsaturated soils, Wiley, New York.

Goodman, R. E., and Seed, H. B. (1965) Displacement of slopes in cohesionless materials, Soil Mechanics and Bituminous Materials Research Laboratory. 
Hashimoto, H. (1997) A comparision between gravity flows of dry sand and sand-water mixtures, Recent Development on Debris Flows, Springer, A. Armanini and $M$. Michiue(eds), NY, NY.

Henderson, F. M. (1966) Open Channel Flow MacMillan Publishing Co., Inc.,NY,NY.

Hirano, M. (2000) Prediction of Debris Flow for Warning and Evacuation, Recent development on debris flows, Lecture Notes in Earth Sciences volume 64, Aronne Armanini (eds) ISBN:354062466X.

Holzer, T. Youd, T. L, Hanks, T. C. (1989) Dynamics of liquefaction during the 1987 Superstition Hills, California, earthquake. Science 244:56-59

Hutchinson, J. N. (1988) General report: morphological and geotechnical parameters of landslides in relation to geology and hydrogeology. In: Bonnard $\mathrm{Ch}$ (ed) Landslides. Proc 5th Int Symp on Landslides. AA Balkema, Rotterdam, pp 3-35

Hungr, O., Evans, S.G. (1985) An example of a peat flow near Prince Rupert, British Columbia, Canadian Geotechnical Journal Vol 22 pp 246-249.

Hungr, O. (1995) A model for the runout analysis of rapid flow slides, debris flows, and avalanches, Canadian Geotechnical journal, Vol. 32, pp610-623.

Hungr, O., Sun, H. W., and Ho, K. K. S. (1999) Mobility of selected landslides in Hong Kong- pilot back-analysis using a numerical model, proceeding of the HKIE Geotechnical Division Seminar on Geotechnical Risk Management, May 1999, Hong Kong Institute of Engineers, pp169-175.

Hungr, O., Evans, S.G. Bovis, M. J., Hutchinson, J.N., (2001) A review of the classification of Landslide of the flow type, Environmental and Engineering Geoscience, Vol VII No. 3 pp221-238.

IAEG Commission on Landslides (1990) Suggested Nomenclature for Landslides, Bulletin of the international Association of Engineering Geology No 41 Paris 1990.

Itoh, T., Egashira, S. Miyamoto, K. (2000) Influence of inter-particle friction angle on debris flows, Wieczorek and Naeser(eds) Debris flow Hazards Mitigation: Mechanics, Prediction, and Assessment, Balkema, Rotterdam, ISBN 905809149 X.

Itoh, T., Egashira, S., Miyamoto, K. (2000) Debris flow Hazard Mitigation: Mechanics, Prediction, and Assessment, Wieczorek and NAESER (eds) 2000 Balkema, Rotterdam, ISBN 90 149X.

Iverson, R.M., (1997) the physics of debris flow, Reviews of Geophysics, Vol. 35(3) pp245-296. 
Iverson, R. M., and LaHusen, R. G. (1989) Dynamic pore-pressure fluctuations in rapidly shearing granular materials: Science, 246:796-799.

Iverson, R. M. (1990) Groundwater flow fields in infinite slopes, Geotechnique, 40, 139$143,1990$.

Iverson, R. M., Reid, M. E., La Husen, R. G. (1997) Debris flow mobilization from landslides, Annual Review Earth Planet Science Volume 25 pp85-138.

Johnson, A. M. (1970) Physical Processes in Geology.San Francisco, Freeman, Cooper. $577 \mathrm{pp}$.

Johnson, A. M., and Rodine, J. R. (1984) Debris Flow, Brundsden, D., and Prior, D.B., eds., Slope Instability, John Wiley \& Sons. p. 257-361.

Johnson, K. A. and Sitar, N. (1990) Hydrologic conditions leading to debris flow initiation. Canadian Geotechnical. J. 27:789-801

Julien, P.Y., O' Brien, J. S. (2000) Recent development on debris flows, Lecture Notes in Earth Sciences volume 64, Aronne Armanini (eds) ISBN:354062466X.

Julien, P. Y. (1995) Erosion and Sedimentation, Cambridge University press, New Yorl, N.Y.

Julien P.Y. and Lan Y. Q. (1991) On the rheology of hyperconcentrations, Journal of Hydraulics Engineering ASCE, 117(3), 346-353.

Kang, Z.C., Law, K.T., Lee, C. F. (2003) Movement Pattem of Debris flow SPISODE, Beijing, China.

Kang, Z. \& Zhang, S. (1980) A preliminary analysis of the characteristics of debris flow, Proceedings of the International Symposium on River Sedimentation, Chinese Society for Hydraulic Engineering: Beijing 225-226.

Kang, Z. Wang, S.J., Lee, C.F. , Law K.T. (2000) A study of debris flow Hazard Prevention, Institute of Mountain disasters and Environment Chinese Academy of Science, Department of Civil Engineering the University of Hong Kong, The Jockey Club research and Information Centre for Landslip Prevention and Land Development.

Klubertanz, G., Laloui, L., and Vulliet, L. (2000) Parameters governing debris-flow initiation, Wieczorek and Naeser (eds) Debris flow Hazards Mitigation: Mechanics, Prediction, and Assessment, Balkema, Rotterdam, ISBN 905809149 X. 
Komatina, D., (2000) Experimental analysis of unsteady solid-liquid mixture flows Wieczorek, and Naeser (eds) Debris flow Hazards Mitigation: Mechanics, Prediction, and Assessment, Balkema, Rotterdam, ISBN 905809149 X.

Lam, C.C. and Leung, Y. K. (1994) Extreme rainfall statistics and design rainstorm profiles at selected locations in Hong Kong, Royal observatory 134A Nathan Road Kowloon, Hong Kong.

Lara, F. Hungr, O., Evans S.G. (2002) Contrasting failure behavior of two large landslides in clay and silt Canadian Geotech. J. 39 pp 46-62

Lau, K.C. and Woods, N. W. (1997) Review of methods for predicting the travel distance of debris from landslides on natural terrain, Technical note No TN7/97, Geotechnical Engineering Office, Hong Kong.

Li, A. G., Yue, Z. Q., Tham, L.G., Lee, C. F. Law, K. T. (2004) Field monitored variation of soil moisture and matric suction in a saprolite slope, Canadian Geotechnical Journal.

Li, K.S., Kay, J.N., Ho, K. K. S. (1998) Slope engineering in Hong Kong, Proceeding of the annual seminar on slope engineering in Hong Kong, A. A. Balkema, Rotterdam, Brookfield.

Matheson, D. S. (1972) Geotechnical implication of Valley Rebound, Ph. D. Thesis, University of Alberta, Edmonton, Canada.

Maunsell geotechnical Services Ltd (2002), Detailed Study of the 1 September 2001 debris flow on the Natural Hillside above Lei Pui Street, Landslide Investigation division, Geotechnical Engineering Division, Special Administration Region, Hong Kong.

McLellan, P.J., and Kaiser, P.K. (1984), Application of a two parameters model to avalanches in the Mackenzi Mountains, Proceedings, $4^{\text {th }}$ International Symposium on Landslides, Toronto, Vol 1 pp 135-140.

Nepal Engineering Consultancy Services Centre Ltd. (2002) Geotechnical Investigation of Km 53 Landslide at Arniko Highway, Department of Roads, His Majesty's Government of Nepal.

Nepal Engineering Consultancy Services Centre Ltd. (2002) Geotechnical Investigation of Dolalghat Rockslide, Department of Roads, His Majesty's Government of Nepal. Nepal Engineering Consultancy Services Centre Ltd. (2002) Geotechnical and Bio-Engineering Investigation of $\mathrm{Km}$ 84-85 Landslide of Arniko Highway, Department of Roads, His Majesty's Government of Nepal.

Nepal Red-Cross Society (NRCS), (2003) Disaster Management http:// www.nrcs.org/refugee.html. 
O'Brien, J. S. (1986) Physical process rheology and modeling of mudflows Doctoral dissertation, Colorado State Univerity, Fort Collins, Colorado.

O'Brien, J. S., and Julien, P. Y. (1988), Laboratory analysis of mudflow properties, ASCE, Journal of Hydraulic Engineering, 114(8): 877-887.

O'Brien, J. S. and Julien, P.Y. (1985) Physical processes of hyperconcentrated sediment flows, Proc. Of the ASCE Speciality Conf. On the Delineation of Landslides, Floods, and Debris Flow Hazard in Utah, Utah Water Research Laboratory, Series UWRL/G-85/03, 260-279.

O' Brien J. S. and Julien, P.Y. (1987), Discussion on Mountain torrent erosion, By K. Ashida in Sediment Transport in Gravel-Bed Rivers, John Wiley and Sons, 537-539.

O' Brien, J. S., Julien, P. Y. and Fullerton, W. T. (1993) Two dimensional water flood and mudflow simulation, J. of Hydraulic Engineering, ASCE, 119(2)244-259.

Pain, C.F. (1972) Characteristics and geomorphic effects of earthquake-initiated landslides in the Adelbert Range, Papua New Guinea, Engineering. Geol., 1972, 6(4), pp. 261-264.

Paula, L. G. and Elliot C. S. (2001) USGS National Mitigation Strategy to Reduce Losses from Landslide Hazards http://www.geotimes.org/mar01/usgs_landslides.html.

Pierson, T.C., Janda, R., Thouret J.C. \& Borrero C.A. (1990) - Perturbation and melting of snow and ice by the 13, November 1985 eruption of Nevado del Ruiz, Colombia, and consequent mobilization, flow and deposition of lahars, J. Volcanol. Geotherm. Res., 41, 17-66.

Reid, M.E., LaHunsen, R.G., Iverson, R.M. (1997) Debris-flow initiation experiments using diverse hydrologic triggers, Cheng-lung Chen Ed., "Debris-Flow Hazard: Mechanics, Prediction, and Assessment", Proc. 1st int. conf., ASCE, S.Francisco, 1-11

Rodine, J.D. (1974) Analysis of the mobilization of debris flows, Final Report to U.S. Army Research Office, Grant no. DA-ARO-D-31-124- 71-G158, pp.226.

Rodine, J.D. and Johnson, A.M. (1976) the ability of debris, heavily freighted with coarse clastic materials, to flow on gentle slopes, Sedimentology, v.23, 213-234.

Sladen, J. A., Hollander, R. D. and Krahn, J. (1985) the liquefaction of sands, a collapse surface approach. Canadian Geotechnical Journal, 22:564-578.

Salm, B., Burkard, A. and Gubler H. (1990) Berechnung von Fliesslawinen, eine Anleitung für Praktiker mit Beispielen. Mitteilungen des Eidgenössischen Institutes für Schnee und Lawinenforschung, No. 47, Davos, Switzerland. 
Sassa, K. (1985) the mechanism of debris flows. Proceedings of XI International Conference on Soil Mechanics and Foundation Engineering, San Francisco, 3, pp. 11731176.

Schuster, R. L. (2000) Outburst debris-flows from failure of natural dams Wieczorek and Naeser(eds) Debris flow Hazards Mitigation: Mechanics, Prediction, and Assessment, Balkema, Rotterdam, ISBN 905809149 X.

Sidle, R. C. and Swanston, D. N. (1982) Analysis of a small debris slide in coastal Alaska, Can. Geotech. J., 19, $167-1741982$

Skempton, A. M. and Hutchinson, J. N. (1969) Stability of natural slopes embankment foundations, Proc. $7^{\text {th }}$ International Conference on Soil Mechanics and Foundation Engineering, State-of- the-Art Volume, Mexico City, pp 91.

Suwa, H., Yamakoshi, T. and Sato, K. (2000) Relation between debris flow discharge and ground vibration, debris flow hazard Wieczorek and Naeser(eds) Debris flow Hazards Mitigation: Mechanics, Prediction, and Assessment, Balkema, Rotterdam, ISBN 905809 $149 \mathrm{X}$.

Sun, H. W. (1998) Review of Fill Slope failures in Hong Kong, Geotechnical engineering Office (GEO), Civil Engineering Department, Government of the Hong Kong Special Administrative Region.

Takahashi, T. (1978) Mechanical characteristics of debris flow, J. Hydraul. Div. American Society of Civil Engineering, 104, 1153-1169, 1978.

Takahashi, T. (1979) Debris flow on prismatic open channel flow, J. of the Hydraulic Div., ASCE, 106(3), 381-396.

Takahashi, T., and Yoshida, H. (1979) Study on the deposition of debris flows. Part I deposition due to abrupt change of bed slope. Annals of the Disaster Prevention Research Institute, Kyoto University, Kyoto, Japan, 22 B-2.

Takahashi, T. and Nakagawa, H. (1989), Debris flow hazard zone mapping, Proc. Of the Japan-China (Taipai) Joint seminar on Natural Hazard Mitigation Kyoto, Japan, 363-372.

Takahashi, T., Nakagawa, H., Satofuka, Y. (2000) Newtonian fluid model for viscous debris flow, Wieczorek and Naeser (eds) Debris flow Hazards Mitigation: Mechanics, Prediction, and Assessment, Balkema, Rotterdam, ISBN 905809149 X.

Takahashi, T., Satofuka, Y., Chishire, K. (2000) Dynamics of Debris flows in the inertial regime Newtonian fluid model for viscous debris flow, Wieczorek and Naeser(eds) Debris flow Hazards Mitigation: Mechanics, Prediction, and Assessment, Balkema, Rotterdam, ISBN 905809149 X. 
Terzaghi, K. and Peck, R. B. (1948) Soil Mechanics in Engineering Practice, Wiley, New York.

Terzaghi K. Peck, R.B., Mesri, G. (1995) Soil Mechanics in Engineering Practice Third Edition John wiley \& Sons, Inc. New York.

Uddin, M. K. (2000) Salient Causes of debris flows in clays soils Wieczorek and Naeser(eds) Debris flow Hazards Mitigation: Mechanics, Prediction, and Assessment, Balkema, Rotterdam, ISBN 905809149 X.

User's Manual (2003) GEO DAN, Geotechnical Engineering Division, Special Administration Region, Hong Kong.

User's manual Geo-Slope (2002) GEO-SLOPE International, Ltd.

Travel information network, Nepal (TIN) (2004)

$\mathrm{http} / / \mathrm{www} . v i s i t n e p a l . c o m / t r a v e l e r s$ guide/where_is_nepal.htm

Varnes, D.J. (1978) Slope Movement types and processes, in Schuster, R.L. and R.J. Krizek (ed.), Landslides Analysis and Control: National Academy of Sciences Transportation Research Board Special Report No. 176, p. 12-33.

Voellmy, A. (1955) Uber die Zerstorungskraft von Lawinen Schweizerische Bauzeitung, Jahrg 73. Heft 12, 159 - 162, 15, 212 - 217, 17, 246 - 249, 19, 280-285.

Wieczorek, G. F., Larsen, M.C., Eaton, L. S., Morgan, B. A. and Blair, J. L. (2001) United States Geological Survey open file report 01, $0144 \mathrm{http} / /$ pubs.usgs.gov/of/2001/ofr-01$0144 /$.

Wong, H. N. Chen, Y. M. and Lam, K. C. (1996) Factual Report on the November 1993 Natural Terrain Landslides in three study areas on Lantau Island, Geotechnical Engineering Office, Civil Engineering Department, Hong Kong.

Wong, H. N., Lam, K. C and Ho, K. K. S. (1997) Diagnostic report on November 1993 Natural Terrain Landslides on Lantau Island, GEO special report number 6/97.

Woolhiser, D. A. (1975) Simulation of Unsteady Overland Flow, Unsteady Flow In Open Channels, K. Mahmood and V. Yevjevich, ed., Water Resources Publications, Colorado State University, Fort Collins, CO.

Youd, T. L. (1973) Liquefaction, flow and associated ground failure Geological Survey Circular 688, United States Department of the Interior, U. S. Geological survey, Washington, D.C.2044. 
Youd, T. L. (1993) Liquefaction-Induced Damage to Bridges, Transportation Research Record No. 14311, National Research Council, National Academy Press, Washington, D.C., 35-41.

Zhang, J., Xiong, G. (1997) Mechanical characteristics of debris flow deposits, ChengLung Chen(eds)debris flow hazards mitigation mechanics prediction and assessment pp 473-381, New York, ASCE. 


\section{APPENDIX}

Table Al Summary of soil testing in Barabensi landslide area

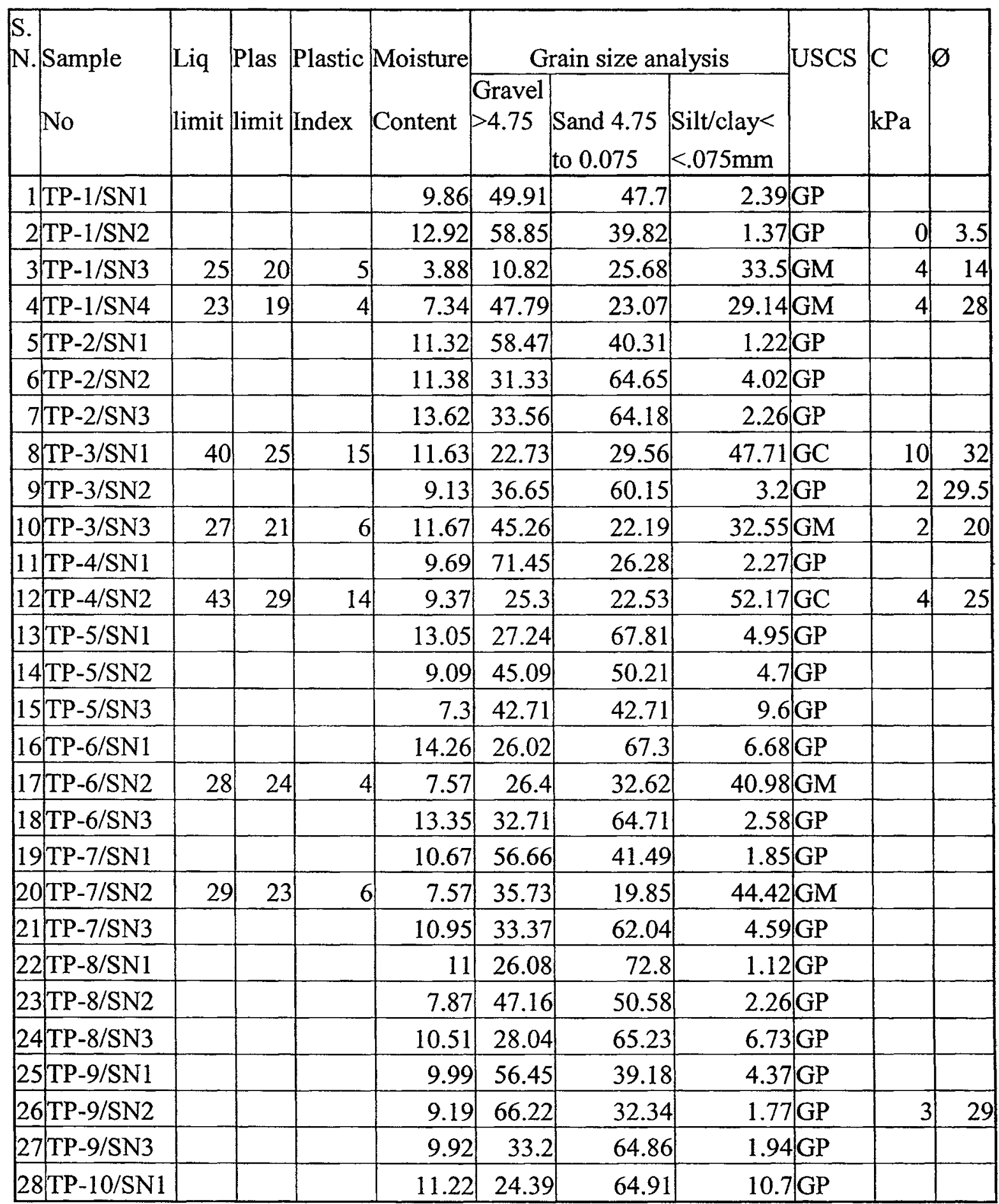


Table A2 Rainfall in Barabensi landslide area

\begin{tabular}{|c|c|c|c|c|}
\hline \multicolumn{5}{|c|}{ Rain fall in Barabensi Nepal } \\
\hline \multicolumn{4}{|c|}{ Latitude: $2747 \mathrm{~N}$} & \multirow{3}{*}{$\begin{array}{l}\text { Longitude: } 8554^{\prime} \mathrm{E} \\
24 \text { hrs Rainfall } \\
\text { Intensity, mm }\end{array}$} \\
\hline \multirow{2}{*}{ Year } & \multirow{2}{*}{ Annual rain fall mm } & \multicolumn{2}{|c|}{$\begin{array}{l}\text { Maximum } \\
\text { Monthly } \\
\text { Rainfall, }\end{array}$} & \\
\hline & & Month & $\mathrm{mm}$ & \\
\hline 1968 & 2639.6 & Jul & 755.60 & \\
\hline 1969 & 2619.3 & Jul & 700.60 & \\
\hline 1970 & 3103.8 & Jul & 1054.90 & \\
\hline 1971 & 3006.3 & Aug & 765.80 & \\
\hline 1972 & 2185.3 & Jul & 693.00 & \\
\hline 1973 & 3739.3 & Aug & 880.90 & \\
\hline 1974 & 3047.1 & Aug & 913.40 & \\
\hline 1975 & 2008.2 & Jun & 634.00 & \\
\hline 1976 & 3125.1 & Aug & 870.90 & \\
\hline 1977 & 3329.4 & Jul & 1129.00 & \\
\hline 1978 & 1544.7 & Jul & 574.00 & \\
\hline 1979 & 2430.3 & Jul & 990.60 & \\
\hline 1980 & 3351.4 & Jul & 1165.80 & \\
\hline 1981 & 2335.4 & Aug & 794.50 & \\
\hline 1982 & 2765 & Jul & 768.90 & \\
\hline 1983 & 3088.6 & Aug & 1077.00 & \\
\hline 1984 & 572 & Aug & 122.80 & \\
\hline 1985 & 3355.6 & Sept & 819.10 & \\
\hline 1986 & 2799.9 & Sept & 630.60 & \\
\hline 1987 & 2807.6 & Jul & 975.30 & $400 \mathrm{~mm}$ \\
\hline 1988 & 4845.6 & Jul & 1362.30 & \\
\hline 1989 & 3788.5 & Jul & 1221.40 & \\
\hline 1990 & 1834.2 & Jul & 654.70 & \\
\hline 1991 & 2729.2 & Jul & 690.90 & \\
\hline 1992 & 2233.5 & Aug & 710.30 & \\
\hline 1993 & 3012.4 & Aug & 842.00 & \\
\hline 1994 & 2454.5 & Jul & 683.40 & \\
\hline 1995 & 3053 & Aug & 853.20 & \\
\hline 1996 & 3320.6 & Aug & 948.70 & \\
\hline 1997 & 1831.5 & Aug & 825.40 & \\
\hline \begin{tabular}{|l|} 
Max in \\
1988
\end{tabular} & & Jul & 1362.30 & \\
\hline $\begin{array}{l}\text { Minimu } \\
\mathrm{m} \text { in } \\
1984 \\
\end{array}$ & & Aug & 122.80 & \\
\hline
\end{tabular}


Table A3 Soil index properties in Barabensi landslide area

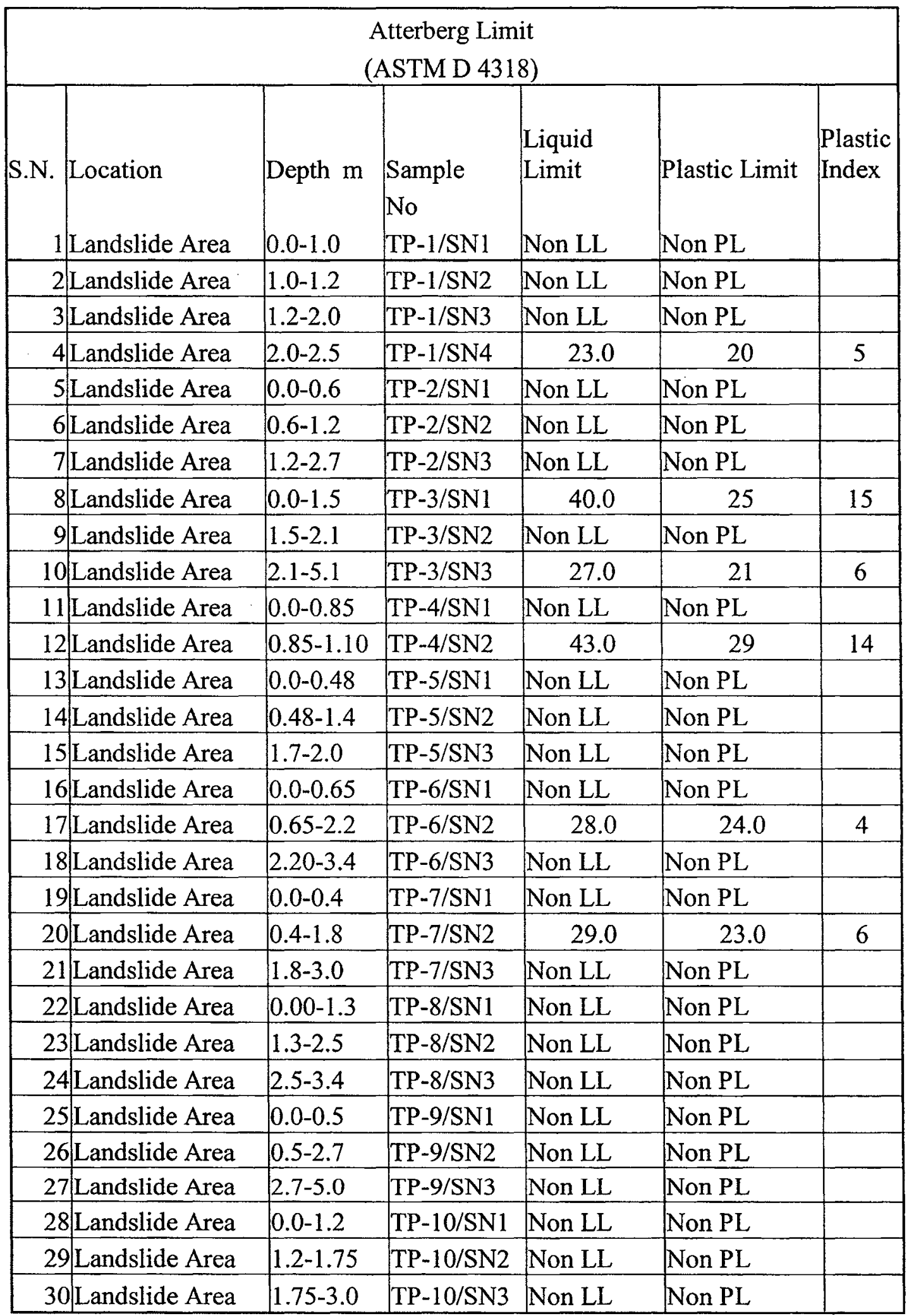

